\title{
An in vitro - in vivo integrated approach for hazard and risk assessment of silver nanoparticles for soil organisms
}

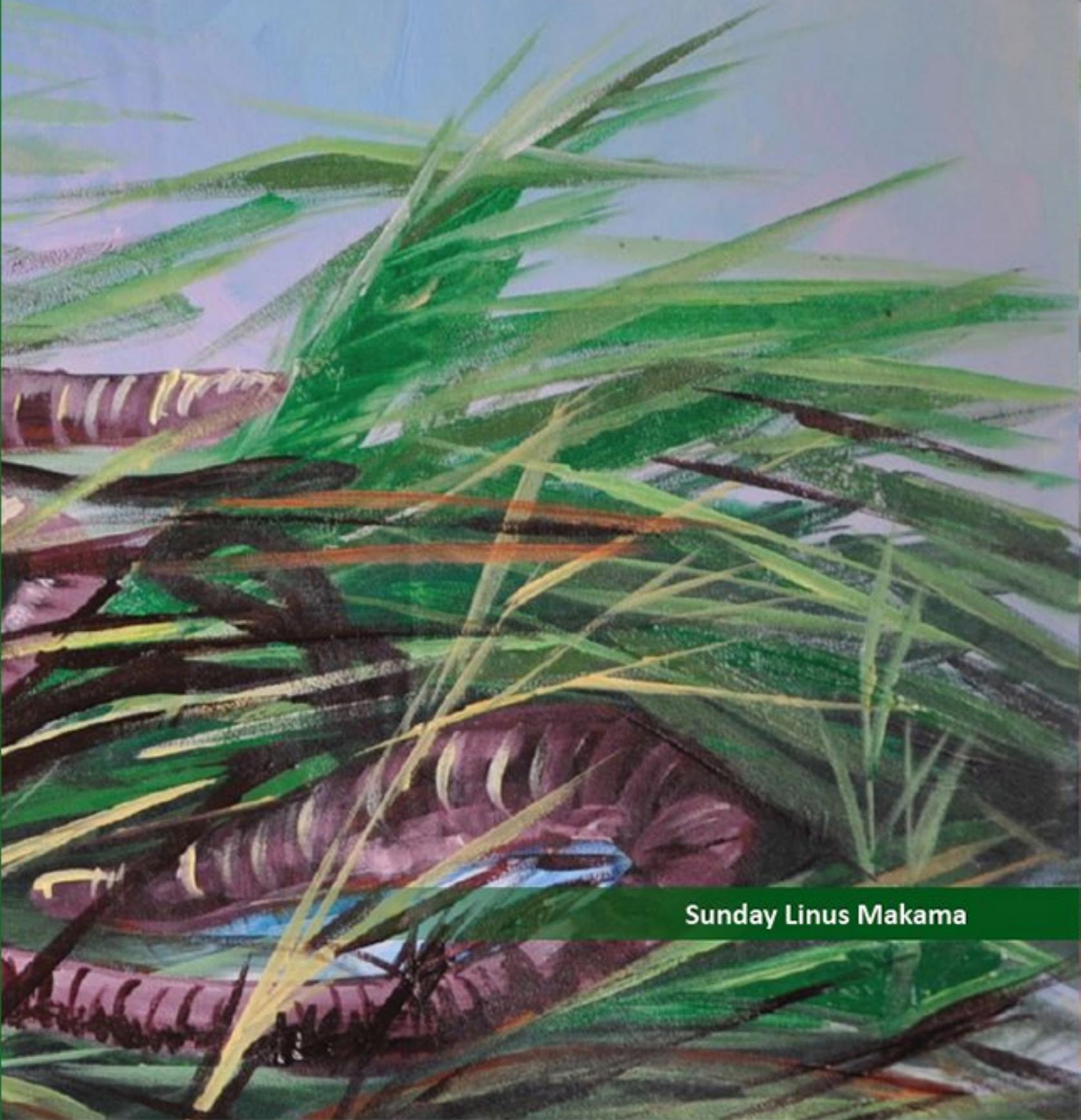




\section{An in vitro - in vivo integrated approach for hazard and risk assessment of silver nanoparticles for soil organisms}

Sunday Linus Makama 


\section{Thesis committee}

\section{Promotor}

Prof. Dr I.M.C.M. Rietjens

Professor of Toxicology

Wageningen University

\section{Co-promotor}

Dr N.W. van den Brink

Associate professor, Sub-department of Toxicology

Wageningen University

\section{Other members}

Prof. Dr H.H.M. Rijnaarts, Wageningen University

Prof. Dr A.P. van Wezel, Utrecht University, The Netherlands

Prof. Dr W.J.G.M. Peijnenburg, RIVM - National Institute for Public Health and the Environment, Bilthoven and Leiden University, The Netherlands

Dr J.H. Faber, Alterra, Wageningen UR

This research was conducted under the auspices of the Graduate School for SocioEconomic and Natural Sciences of the Environment (SENSE) 


\title{
An in vitro - in vivo integrated approach for hazard and risk assessment of silver nanoparticles for soil organisms
}

\author{
Sunday Linus Makama
}

Thesis

submitted in fulfilment of the requirements for the degree of doctor

at Wageningen University

by the authority of the Rector Magnificus

Prof. Dr A.P.J. Mol,

in the presence of the

Thesis Committee appointed by the Academic Board

to be defended in public

on Thursday 15th of September 2016

at 11 a.m. in the Aula. 
Sunday Linus Makama

An in vitro - in vivo integrated approach for hazard and risk assessment of silver nanoparticles for soil organisms,

190 pages.

PhD thesis, Wageningen University, Wageningen, NL (2016)

With references, with summary in English

ISBN: 978-94-6257-843-2

DOI: $10.18174 / 384962$ 
Looking around us we realize that nanoparticle is not an invention. It is a marvellous discovery.

Victor Puntes (2013) 



\section{Contents}

Chapter $1 \quad$ General Introduction

Chapter 2 Cellular interactions of different forms of silver nanoparticles with mouse monocyte macrophages RAW 264.7 cells

Chapter 3 A novel method for the quantification, characterisation and speciation of silver nanoparticles in earthworms exposed in soil

Chapter 4 Properties of silver nanoparticles influencing their toxicity to the earthworm Lumbricus rubellus following exposure in soil

Chapter 5 Transcriptome analysis reveals the importance of surface coating in driving effects of silver nanoparticles on the earthworm Lumbricus rubellus

Chapter 6 General discussion, future perspectives and conclusions

About the Author

List of publications

Conferences and proceedings

Overview of completed training activities

SENSE Certificate 



\section{Chapter 1}

General Introduction 



\section{General Introduction and Aim}

\section{Nanotechnology}

Miniaturizing particles to their nanometre size ranges $(1-100 \mathrm{~nm})$ results in new materials called nanoparticles (NPS), usually having new physical and chemical properties different from those of their bulk counterparts. NPs are generally regarded as products of nanotechnology and play a prominent role in the exciting advancements in nanotechnology. NPs also occur naturally and already existed before the emergence of nanotechnology, originating in nature from biogenic, geogenic or cosmogenic sources [1]. Anthropogenic activities like combustion of fuels (wood, oil) have also resulted in the unintentional release of NPs in the environment. With the advent of nanotechnology, engineered NPS or manufactured nanomaterials were intentionally developed or engineered to exploit their nano-derived properties. It has become evident that nanotechnology is considerably improving many technology and industry sectors [2, 3]. The small particle size and increased surface area of these materials result in new behaviours and biological effects that can be markedly alien from that of conventional bulk elements or chemicals [4]. At the nano range, matter is governed more by quantum mechanics laws than by those of classical physics. The novel properties of NPs include increased specific surface area and chemistry, enhanced catalytic potentials, increased conductivity, high tensile strength and light weight, antimicrobial activities, etc. [5-11]. These specific properties have been applied in many industrial sectors including textiles, electronics and medical devices, food and transport systems [12, 13]. Additionally, these desired "novel" properties and functions can be enhanced by stabilization and/or functionalization of the NPs using biocompatible molecules for coating their surfaces. Essentially, the type of surface coating and process used in stabilizing NPs during synthesis have great impact on their surface chemistry (charge), solubility and/or hydrophobicity [14-17]. Size-specific properties may in turn influence their behaviour and environmental fate, as well as their effects on organisms [18-21].

\section{Potential hazards of NPs in the environment and the role of physico-chemical characteristics of NPs}

While recognizing their benefits, public and regulatory concerns regarding the potential of NPs to pose hazards to health and the environment have continued to increase over the years. With even more applications of NPs being discovered and an increase in the production and use of nano-based consumer products, the potential for environmental release of NPs is likely. Environmental release of NPs could result from industrial wastes 
or by-products formed during manufacture, release during use or in the waste phase of nano-based products in sewage or waste water, resulting in potential uptake of NPs by organisms and harmful impacts on the ecosystem [2, 22-25]. NPs have been detected in various important members of different ecosystems including daphnids [26], fish, snails [27], mice [28], earthworms [21, 29-31], amphipods [32], isopod crustacean [33], tellinid clams [34], etc. One important group of NPs that has attracted the attention of researchers and regulators are silver NPs (AgNPs). Currently, AgNPs constitute the most frequently applied nanomaterial used in products on the European market [3], generally attributed to the well demonstrated antimicrobial properties of silver [35-38]. Also, the chemical properties of Ag provide distinct physical and chemical characteristics to AgNPs including dissolution and re-reduction, sulfidation, and chlorination, making AgNPs highly dynamic species in the environment [39]. Increase in the manufacture and use of AgNPs suggests an increased likelihood of release into the environment where these NPs could have deleterious impact on health and the environment, informing the choice of AgNPs as model NPs for this research.

The need to understand the fate of NPs and the potential hazards and risks they may pose to the environment is critical for environmental risk assessment (ERA) and policy decisions. Data on the occurrence, transport, transformation, distribution, fate, effects, and toxicity of AgNPs in the environment are needed for a proper evaluation of the environmental safety of NPs [39]. While progress continues to be made in this regard, knowledge gaps do exist in the areas of characterization and determination of the environmental fate and biological effects or hazards associated with AgNPs. The majority of the data on the ecotoxicological effects of AgNP exposure is often obtained from studies using aquatic models, with information on terrestrial nanoecotoxicology relatively lacking. It is essential therefore, to investigate the effects of intrinsic physicochemical properties of NPs including particle size, functionalization/coating, zetapotential/surface charge, hydrophobicity, hydrodynamic diameter, etc. on the hazards and risks they may pose to especially terrestrial organisms. Furthermore, extrinsic environmental matrix properties $(\mathrm{pH}$, organic matter and clay contents, pore water ionic strength, ageing, etc.) may drive or influence the bioavailability and bioaccumulation of NPs in model environmental organisms [40], thereby influencing their ultimate effects.

In an earlier study on Lymnaea stagnalis, exposure route and capping agent were reported to influence $\mathrm{Ag}$ bioaccumulation dynamics of ions as well as NPs [41]. Snails efficiently accumulated Ag from both citrate- and humic acid-coated AgNPs (cit-AgNPs and HA-AgNPs, respectively) after either aqueous or dietary exposure. There was greater waterborne accumulation of Ag from HA-AgNPs compared to that from cit-AgNPs. When exposure was via food, the rate constant of loss of HA-AgNPs was similar as in the waterborne exposure, but cit-AgNPs were retained with no detectable loss [41]. Shoults- 
Wilson et al. [21] on the other hand, reported that neither polyvinylpyrrolidone (hydrophilic) nor oleic acid (amphiphilic) surface coatings had an effect on bioaccumulation of $\mathrm{Ag}$ in earthworms (Eisenia fetida) exposed to AgNPs. Absence of accumulation was reported in a study in which Lumbricus terrestris was exposed via soil and water to titanium oxide nanocomposites coated with consecutive layers of $\mathrm{Al}(\mathrm{OH})_{3}$ and polydimethyl siloxane (PDMS) [42]. In biomedical research, polymeric NPs clearance and biodistribution were reported to be affected by particle properties such as composition, size, core properties, surface modifications (pegylation and surface charge), and targeting ligand functionalization [43].

From literature, the surface charge, hydrophobicity and hydrodynamic diameter of NPs were identified as important properties of NPs that may influence their uptake in earthworm [24, 44]. Surface charge is important in predicting the long term dispersive stability of NPs, partly achieved through electrostatic repulsion forces [45]. Therefore, the nature and magnitude of the surface charge affect the formation of agglomerates or flocculation [46]. Surface charge also influences the adsorption of ions and biomolecules to the NPs, which may change how cells "see" and react to these particles during exposure [47]. Hydrophobicity can affect the dissolution of NPs [48], which in turn will invariably influence bioaccumulation depending on whether the ionic or particulate form is accumulated more. An increase in the hydrophobicity of the NP surface may also lead to a decrease in its dispersibility in aqueous solutions [49]. This decrease in dispersibility may however enhance NPs interaction with organic matter and thus decrease the potential for accumulation by organisms. By functionalizing the surface of NPs to achieve increased hydrophobicity while retaining high dispersibility in aqueous solutions, NPs are able to cross hydrophobic barriers and their potential for wide applications is enhanced [49]. The size of NPs has also been reported to be important in the assimilation or translocation of NPs across biologic membranes. Shoults-Wilson et al. [30] reported that in a few cases, AgNPs with larger (hydrodynamic) sizes (30 - $50 \mathrm{~nm}$ ) significantly accumulated more in Eisenia fetida tissues than smaller particles $(10 \mathrm{~nm})$ at similar exposure concentrations. In an in vitro study with PEGylated NPs, it was similarly observed that particles greater than $100 \mathrm{~nm}$ in size were significantly internalized more than the $40 \mathrm{~nm}$ ones [50]. The varying and sometimes conflicting scientific data in literature only add to the challenges confronting authorities regarding the regulation of NPs in the environment. 


\section{Challenges for regulation of nanomaterials}

Nano-products are products which contain (or claim to contain) nanomaterials. This term however, is ambiguous since the term 'nano-product' may have several meanings. For instance, it could mean a product having nano-sized pores, thin nanometre coatings, or that NPs have actually been added to the product. Often, neither consumers nor regulatory authorities know exactly what the composition of the product is. Usually, it is also not clear whether the product contains nanomaterials and if so, in which form and concentration [51]. To assess possible environmental or health risks of nanomaterials, such knowledge is essential and will enhance regulatory policies by determining products requiring mandatory labelling for example [52]. A generally acceptable definition of the terms nanomaterial, NP, and other NP-related terms is important in order to take such measures. Such general definitions are required to be science-based and comprehensive. For regulatory measures that concern individual sectors, these definitions are also required to be unambiguous, flexible, easy and practical to handle. This is however not the case in various industry and research sectors, and definitions pertaining to nanomaterials and NPs are usually not very clear. For the purpose of regulating the development and use of new engineered nanomaterials, the European Commission has adopted a definition of a nanomaterial as "a natural, incidental or manufactured material containing particles, in an unbound state or as an aggregate or as an agglomerate and where, for $50 \%$ or more of the particles in the number size distribution, one or more external dimensions is in the size range $1 \mathrm{~nm}-100 \mathrm{~nm}$ " [53]. However, even this definition is still under debate.

Many of the regulatory challenges are related to the physico-chemical properties of the nanomaterials which influence their fate and effects upon release into the environment, as already indicated above. Different NPs have different physical and chemical properties, and it is essential to recognise that the increasing numbers and forms of NPs entering the market certainly complicate the ERA further. For instance, there is no scientific evidence that the lower or upper limit values for the size (i.e. $1-100 \mathrm{~nm}$ ) are appropriate, and the stipulated size range might actually be too limiting for the classification of nanomaterials. On the other hand, the use of distinct values for the size range is important for legislation where precise data are necessary. Also, by using particle size range, the EU definition is likewise limited to materials consisting of particles. This implies that other non-particulate materials (proteins or micelles) and nanostructured materials (solid products, parts or components) with an internal or surface structure in the range between $1 \mathrm{~nm}$ and $100 \mathrm{~nm}$ in only one or two dimensions such as computer chips, are excluded [51]. Other non-governmental stakeholders involved with nanotechnology from agencies addressing environment, health and consumer protection favour a larger size range from 0.3 to $300 \mathrm{~nm}$ for the purpose of 
defining nanomaterials [51]. This wider NP size range is based on research evidence which shows that some NPs of up to several hundred nanometer sizes, share many of the novel properties of nanomaterials that are of sizes less than $100 \mathrm{~nm}$.

It is important to note that the definition of nanomaterial as adopted by the EU Commission, concerns exclusively the defining aspects of materials (which may be hazardous or not) within a specific size range. Therefore, the Commission was careful to stress that there is no consistent causal link between NP size alone and hazards. In fact, the Scientific Committee on Emerging and Newly Identified Health Risks (SCENIHR) has clearly expressed that: "...'nanomaterial' is a categorisation of a material by the size of its constituent parts. It neither implies a specific risk nor does it necessarily mean that this material actually has new hazard properties compared to its constituent parts" [54]. Other types of nanostructured materials such as nano-porous or nano-composite materials were also not included, because evidence to guide what materials should be included is currently insufficient. Other challenging issues for regulation relate to NP size distributions, existence of agglomerates and/or aggregates, and the $50 \%$ threshold for nanomaterial definition given above. These components of the definition are important as NP agglomerates or aggregates, for example, may exhibit the same properties as the unbound NP, and are also capable of releasing particles during the life cycle of the nanoproduct. For the purpose of this thesis, the term NPs will be generally applied to mean a particle with all three external dimensions at the nanoscale, between $1-100 \mathrm{~nm}$ [55].

In recent times, our understanding of the fate and effect of various NPs has improved based on investigations utilizing both in vivo and in vitro models $[56,57]$. In addition to the exposure matrix-associated factors, the importance of physico-chemical properties including size and size dispersion (both mono- and polydispersity), shape, zeta potential, and agglomeration and dissolution rates, etc. in influencing the fate and toxicity of NPs has been highlighted [24]. However, available information in literature regarding the role of these physico-chemical properties in influencing NP hazards has varied widely, and is often inconsistent $[57,58]$. For example, while some studies have reported different physico-chemical properties of NPs in influencing their effects including size [59] and charge [60], others did not [61]. Also, the debate on the involvement of particulate and or ionic forms of $\mathrm{Ag}$ in the toxicity of AgNPs has remained. Nevertheless, with the development of techniques that can characterize NPs in biological matrices [58, 62, 63], it has become more evident that both particulate and ionic Ag are involved.

Considering the increasing numbers of nano-based products entering the global market annually and the necessary regulatory requirements for assessing the health and environmental risks of the engineered NPs in these products, studies elucidating the synthesis, fate and hazards of NPs are essential and are increasing [24, 31, 57, 58, 64- 
67]. However, as already mentioned, information on the effects of NP properties on their uptake and toxicity especially for soil organisms is limited. In order to address this, the current study was conducted on the red earthworm Lumbricus rubellus, as a model soil species.

\section{Aim of the thesis study}

From the different physico-chemical properties of NPs that are considered important in influencing their fate and toxicity as reported in literature, two were selected and investigated in the studies described in the current thesis. These were size and surface coating (charge) of NPs, both considered to be more important than the other NP properties $[24,44,68]$. For practical reasons, it was not feasible to integrate more NPproperties within the lifespan of the project. The aim of this thesis was to investigate the influence of size and surface coating (charge) on the uptake and ultimate toxicity of AgNPs to L. rubellus. To this end, an in vitro - in vivo integrated approach was applied, looking at effects of size and surface coating on genetic (molecular), cellular, and individual levels. A better understanding of the factors that influence uptake and toxicity in soil organisms is essential for adequate risk assessment of AgNPs in the environment. The identification of the intrinsic properties that drive the uptake and toxicity will provide more insight in the basic processes underlying the toxicokinetics and toxicodynamics of AgNPs in soil organisms. This project provides additional data on the interactions of AgNPs with in vitro cell and in vivo terrestrial organism models, with studies using the latter models being relatively few at present. In the section below, additional details on the choice of AgNPs as model NP, and the toxicity test models used in the studies presented in the current thesis, are briefly highlighted.

\section{Silver nanoparticle}

Silver is a precious and rare metal that has a white lustre appearance, with a long history of use as currency and jewellery, as well as for making kitchen utensils and in photography [57]. Due to its high biocidal property against pathogenic bacteria, fungi and even some viruses [69], Ag has been used for many years in medical practice for wound treatment [70]. One of the earliest scientifically documented medical uses of silver was in 1884 by the German obstetrician Crede who introduced 1\% silver nitrate $\left(\mathrm{AgNO}_{3}\right)$ as an eye solution for the prevention of gonococcal ophthalmia neonatorum [71]. The use of Ag has persisted over time and it is still being used in medical practice [72], even though its use is limited due to inadequate local retention and severe 
cytotoxic effects $[73,74]$. In recent times, advancements in nanotechnology have made it possible to produce $\mathrm{Ag}$ at the nanoscale, further extending its application in various consumer products. As a result, AgNPs are used extensively in consumer products and therefore, have a high potential for release into the environment where they may cause harmful impacts. Current background levels of Ag in the environment are generally low $[75,76]$, which facilitated the current studies because control for background levels of $\mathrm{Ag}$ was not necessary for the quantification and characterisation of the uptake and effects of AgNPs in biological tissues of our model soil organism.

In order to appropriately conduct an adequate ERA of NPs, quantification and characterisation of the NPs in different environmental and biological matrices is essential. Several methods for assessing AgNPs are available, and have been validated and reported in literature. These include detection tools like inductively coupled plasma mass spectrometry (ICP-MS), single particle (sp) ICP-MS, transmission/scanning electron microscopy (TEM/SEM) coupled with energy-dispersive X-ray (EDX), UV-Visible spectroscopy (UV-Vis), confocal laser scanning microscopy (CLSM), dynamic light scattering (DLS), and particle size separation techniques like asymmetric flow field flow fractionation (AF4) and other hyphenated techniques [77, 78]. Most of these techniques are highly appropriate for the detection of AgNPs and were available for the current thesis, further supporting the choice for AgNPs as model NP to be studied. For instance, a combination of several of the techniques mentioned above was used in the studies described in Chapters $2-5$ of the present thesis, and their versatility and draw-backs are discussed in these chapters. In Chapter 6, additional perspectives on the current and future applications of some of the techniques available are also discussed. One of the challenges with quantifying and characterising NPs for ERA comes from the difficulties associated with assessing NPs in complex tissue or soil matrices, as was the case in the in vivo study in Chapter 4. Techniques to extract the NPs from these complex matrices with minimal impact on their properties are therefore crucial, and in chapter 3 such a method was developed. The physical and chemical properties of NPs determine their interactions with these matrices, and for AgNPs (and most NPs) available data in literature indicate size and surface coating (charge) of the NPs to be important $[24,68,79]$.

Size and surface coating (charge) as focal NP-properties

The size of NPs plays a critical role in their fate and behaviour in the environment. The smaller the NP size, the larger the specific surface area and thus the potential for interaction with exposure media. Thus in many studies, smaller sized NPs (10-20 nm) were found to be more toxic than larger ones (30 - $100 \mathrm{~nm}$ ), often also attributable to their being easily taken up due to their smaller size $[24,68,80]$. Equally important in the hazard assessment of NPs is their surface coating, often used to decrease NP 
agglomeration [81] and dissolution [61], as well as to modify their biological activities $[59,60]$. Over the last two decades, researchers have attempted to elucidate the fate and effect of various NPs using both in vivo and in vitro models $[31,56,57,82]$. The importance of physico-chemical properties of NPs in influencing their fate and toxicity has increasingly been investigated, but reports in available literature have not been consistent. Important physico-chemical properties in this regard include size and NPs dispersion (both mono- and polydispersity), shape, zeta potential, and agglomeration and dissolution rates [24]. While some studies have reported effects of size [59] or charge [60], others fail to detect these [61].

Additional perspectives on the influence of physico-chemical properties of AgNPs on their interactions in both in vivo and in vitro models, have been reviewed earlier $[24,68]$. From the reviews cited and examples mentioned above, one can identify the challenge associated with the regulation of AgNPs and other nanoparticles in general. This is especially so, given the limited data base and the limitations of generating in vivo data for all different forms and types of NPs. This informed our choice to systematically synthesise AgNPs that differed at the most important properties of interest: size and surface coating (charge). Methods for the synthesis of AgNPs are also quite well developed, and can be kinetically controlled to achieve various sizes [14] as was done in the current thesis. Soil-related factors like organic matter and clay contents, pore water ionic strength, presence of other metals, etc. are also important factors [30] to consider in assessing hazards of NPs. In the current thesis however, a single natural soil type was used to investigate the main research questions which focuses only on the properties of the AgNPs. The AgNPs used in the current thesis were systematically synthesised to differ at the target properties of interest. In addition, a PVP-coated AgNP was commercially obtained and also used in the studies described in Chapters 2 and 3. In summary, AgNPs were investigated because compared to other NPs: 1) they are used relatively heavily; 2) they are relatively easy to detect in soil and organisms without having to control for background levels, and; 3) they can be synthesised to deliver systematically altered properties.

\section{Selection of earthworm as the model organism}

The release of NPs into the environment due to increasing production and use of nanobased products has potentially increased, and soil is considered a sink for environmental contaminants [83]. Exposure routes to soil could be from point or diffuse sources, and the NPs involved may be in various forms e.g. as primary particles, agglomerates, aggregates, embedded in a matrix or coated with different molecules and substances 
[84]. Direct exposure pathways to soil may occur as a result of accidental release, agricultural practices involving the use of nanomaterials as pesticides or fertilizers, and for contaminated soil remediation purposes [40 and references cited therein]. Another source of soil contamination is via the application of sludge from waste water treatment plants (WWTP) for the purpose of land amendment, since sludge has a high NP retention capacity in excess of $90 \%$ for Ag [40]. Several processes in the soil likely result in the resuspension of nanomaterial aggregates from the sludge matrix into soil pore water. These include bacterial breakup and biological decomposition of the organic material in the sludge, hydrodynamic shear (e.g., during a rain event), a sudden drop in ionic strength, a redox change dissolving iron oxides that cement colloids together, or adsorption of dissolved organic macromolecules [40 and the references therein]. Organisms dwelling in the soil are therefore expected to be exposed to NPs, leading to potentially deleterious effects. Investigating the impacts of NP exposure on soil organisms is therefore critical for ERA especially as information on toxicity, though increasing, is still relatively limited for soil organisms compared to studies on aquatic species.

Earthworms are one of the most commonly used key indicators for ecotoxicological investigations of chemical hazards to soil organisms. As such, knowledge and expertise about handling these invertebrates are increasing, and standardised guidelines for testing have been developed (OECD 222) [85]. Also, potential exposure of earthworms can result via both epidermis and orally $[30,86]$, since they are in contact with both soil and the soil pore water. Responses by earthworms to toxicants are also easily detectable at various levels of biological organisation [87-90]. Eisenia fetida and E. andrei are most commonly used due to their rapid life cycle and ease of culturing in the laboratory. In the in vivo studies described in this thesis, the red earthworm L. rubellus was used as an ecologically more relevant species. It is a very common upper soil-dwelling detrivore in most parts of Europe. Being an abundant species in the soil, L. rubellus could serve as an indicator for the risks of soil contaminants. It has commonly been used in ecotoxicological studies on NPs $[82,90]$ and other contaminants like zinc, lead and polycyclic hydrocarbons [91]. Because of its larger body mass compared to E. fetida, it was also a more practical choice to obtain sufficient sample for quantification and characterisation of $\mathrm{Ag}$ in the tissues since uptake of $\mathrm{Ag}$ is generally low.

\section{In vitro - in vivo approach}

In vitro models have generally proven to present potential for high throughput and screening of hazards to chemicals. From an ethical perspective, they are more desirable 
than in vivo animal tests and thus commonly used. Using in vitro models in risk assessment of chemicals facilitates the setting of priorities for in vivo testing, thereby reducing the number of animals required [92]. Also, the potential for read-across and extrapolation of in vitro toxicity information to in vivo situations, makes the use of in vitro models an interesting prospect. By first investigating with in vitro models, insights in the toxicity and possible mode of action of NPs are obtained. Such information could be used in a weight of evidence approach [93], furthering our understanding of observations made under in vivo situations, as well as defining priorities for in vivo testing and facilitating read-across. It must be noted however, that there are challenges involved with such extrapolations and currently, a comprehensive risk assessment cannot entirely be based upon in vitro data. Nevertheless, the opportunity for developing alternative in vitro models are worth exploring, and where validated can improve hazard assessments of NPs.

In this study, we investigated the effects of size and surface coating (charge) of AgNPs in driving their interactions at the cellular level, using an in vitro mammalian cell line model: the mouse monocyte macrophage (RAW 264.7). Macrophages provide the first line of defence in an organism, and their role in initiating inflammatory and oxidative stress responses were investigated. Earthworms have macrophage immune cells called coelomocytes, and their viability has previously been shown to be affected by exposure to AgNPs [31]. End-points of toxicity that were assessed in the current thesis include cell viability, intracellular ROS production, reduction in ATP cellular levels, alterations in the integrity of the mitochondrial permeability transition pore opening, and induction of TNF- $\alpha$ [94-99]. At the individual level, in vivo responses to AgNP exposures may confirm mechanistic insights derived from in vitro studies, and toxicity end-points commonly studied are survival, growth rate and reproduction (cocoon production). Compared to growth and reproduction, survival is generally a less sensitive end-point and may be limited in relevance from an ecological point of view [100]. In the current thesis, these in vivo toxicity end-points, including hatchability, were assessed in a 28-day sub-chronic reproduction test, and the results obtained are presented in Chapter 4.

\section{Overview of the chapters:}

A systematic approach was applied, covering cellular (in vitro) and individual (in vivo) levels of biological organisation, in combination with observations at the molecular (gene expression) level to corroborate the in vitro and in vivo results. Exposures were carried out using synthesized AgNPs that systematically differed in size and surface coating (charge). The outcomes of the studies in this thesis provided insights into how 
AgNP properties determine their fate and effects at the molecular, cellular, and individual levels.

Chapter 1 (the present chapter) introduced the subject of nanotechnology and NPs, and gives general background information about the need and challenges of regulating nanobased products. The aim of this thesis was highlighted, which was to investigate the influence of size and surface coating (charge) on the uptake and ultimate toxicity of AgNPs to L. rubellus.

In Chapter 2, cellular interactions of AgNPs were assessed in an in vitro mammalian cell line model: the mouse monocyte macrophage (RAW 264.7) cell line. Since macrophages are involved in providing the first physiological line of defence in an organism, the role of AgNP properties in initiating inflammatory (TNF- $\alpha$ ) and oxidative stress responses in these macrophages were investigated. This cell line was selected with the assumption that these macrophages can be used as a model for coelomocytes (leucocytes of earthworms) similar to van der Ploeg et al. [82]. The outcome of this study provided insight into how AgNP properties determined their fate and effects at the cellular level, thus possibly shedding light on what the outcome could be for higher organisms [40, 101].

Investigating the impact of AgNP exposure on living organisms, means having to deal with complex biological matrices. This requires methodologies that can extract NPs from such matrices, enabling post-exposure characterization of NPs. Currently applied methods do not retain the properties of the NPs after extraction. Chapter 3 presents a novel approach with which AgNPs can be characterised and quantified in tissues from in vivo exposed earthworms. To assess the uptake of NPs in earthworm tissues no specific method for the extraction of NPs from the tissues of earthworms was available. The method for eluting NPs from earthworm tissue described in this chapter uses enzymatic procedures based on methods described previously [102-104]. The method also incorporated detection of subcellular compartmentalisation of the NPs in the earthworm, further elucidating their bioavailability [105]. Subcellular fractionation of tissues was conducted to investigate likely association of AgNPs with the cellular fraction containing metallothionein (MT) of the red earthworm (Lumbricus rubellus). To our knowledge, this was the first attempt to perform such characterisation and quantification in an in vivo exposed soil invertebrate species.

In Chapter 4, we extended our evaluation of the influence of the properties of AgNPs on their biological effects to the organismal level, assessing NP effects on survival, growth and reproduction of a model soil organism L. rubellus in a 28-day sub chronic exposure study. Exposures were carried out in soil, and $\mathrm{AgNO}_{3}$ exposures were included to control 
for effects of ionic $\mathrm{Ag}^{+}$. The responses that will be elicited in the in vivo study, may inform on the hazards of AgNPs on the population dynamic parameters of the model soil organism and may validate our in vitro observations.

To further elucidate likely mechanistic pathways of toxicity, a toxicogenomic study was carried out in Chapter 5 where earthworms were exposed to AgNPs for 72 hours. Using the same synthesized AgNPs as were used in Chapter 4, we tested whether AgNPs size or surface coating (charge) had any effect on the gene expression profile of $L$. rubellus in order to corroborate the in vitro and in vivo results of Chapters 2 and 4 . Here, we extended on the approach described by Poynton et al. [87] and included the three different coating types on AgNPs of three specific core sizes. RNA sequencing (RNAseq) techniques were used to assess the gene expression profiles occurring in the earthworms exposed to the different forms of AgNPs. The toxicogenomic study provided insight into the gene expression profile of the model soil organism L. rubellus as a result of AgNP exposure under environmentally relevant conditions, and how AgNP properties may influence this. Subtle (mild) effects, not easily detectable by other toxicological endpoints investigated in chapters 2 and 3, may be identified based on gene ontology.

In Chapter 6, the overall findings of this research along with its applications and implications were discussed with focus on both current and future perspectives thus placing it within the wider context of nano-research and development. This was followed by a summary in Chapter 7 and appendices. 


\section{References}

[1] Cavalle JS, Puntes V. Nanoparticles before nanotechnology. nanowikiinfo. 2013, 3.

[2] Wijnhoven SWP, Oomen AG, Sips AJAM, Bourgeois FC, te Dorsthorst JPM, Kooi MW, et al. Development of an inventory for consumer products containing nanomaterials Final Report. RIVM Report. 2010, (070307/2010/580587/SER/D3), 1-103.

[3] Vance ME, Kuiken T, Vejerano EP, McGinnis SP, Hochella MF, Jr., Rejeski D, et al. Nanotechnology in the real world: Redeveloping the nanomaterial consumer products inventory. Beilstein journal of nanotechnology. 2015, 6, 1769-80. doi10.3762/bjnano.6.181

[4] Borm PJ, Robbins D, Haubold S, Kuhlbusch T, Fissan H, Donaldson K, et al. The potential risks of nanomaterials: a review carried out for ECETOC. Part Fibre Toxicol. 2006, 3, 11. doi10.1186/17438977-3-11

[5] Rai M, Yadav A, Gade A. Silver nanoparticles as a new generation of antimicrobials. Biotechnol Adv. 2009, 27(1), 76-83. doihttp://dx.doi.org/10.1016/j.biotechadv.2008.09.002

[6] Windler L, Height M, Nowack B. Comparative evaluation of antimicrobials for textile applications. Environ Int. 2013, 53, 62-73. doi10.1016/j.envint.2012.12.010

[7] Shirkavand S, Moslehifard E. Effect of $\mathrm{TiO}(2)$ Nanoparticles on Tensile Strength of Dental Acrylic Resins. Journal of Dental Research, Dental Clinics, Dental Prospects. 2014, 8(4), 197-203. doi10.5681/joddd.2014.036

[8] Jain PK, Huang X, El-Sayed IH, El-Sayed MA. Review of Some Interesting Surface Plasmon Resonanceenhanced Properties of Noble Metal Nanoparticles and Their Applications to Biosystems. Plasmonics. 2007, 2(3), 107-18. doi10.1007/s11468-007-9031-1

[9] Oliver-Meseguer J, Cabrero-Antonino JR, Domínguez I, Leyva-Pérez A, Corma A. Small Gold Clusters Formed in Solution Give Reaction Turnover Numbers of 107 at Room Temperature. Science. 2012, 338(6113), 1452-5. doi10.1126/science.1227813

[10] Jeong YS, Park J-B, Jung H-G, Kim J, Luo X, Lu J, et al. Study on the Catalytic Activity of Noble Metal Nanoparticles on Reduced Graphene Oxide for Oxygen Evolution Reactions in Lithium-Air Batteries. Nano Lett. 2015, 15(7), 4261-8. doi10.1021/nl504425h

[11] Li Q, Mahmood N, Zhu J, Hou Y, Sun S. Graphene and its composites with nanoparticles for electrochemical energy applications. Nano Today. 2014, 9(5), 668-83. doihttp://dx.doi.org/10.1016/j.nantod.2014.09.002

[12] Ahamed M, Alsalhi MS, Siddiqui MK. Silver nanoparticle applications and human health. Clin Chim Acta. 2010, 411(23-24), 1841-8. doi10.1016/j.cca.2010.08.016

[13] Haider A, Kang IK. Preparation of Silver Nanoparticles and Their Industrial and Biomedical Applications: A Comprehensive Review. Advances in Materials Science and Engineering. 2015, 2015, 16. doi10.1155/2015/165257

[14] Bastús NG, Merkoçi F, Piella J, Puntes V. Synthesis of Highly Monodisperse Citrate-Stabilized Silver Nanoparticles of up to 200 nm: Kinetic Control and Catalytic Properties. Chem Mater. 2014, 26(9), 2836-46. doi10.1021/cm500316k

[15] Evanoff DD, Jr., Chumanov G. Synthesis and optical properties of silver nanoparticles and arrays. Chemphyschem. 2005, 6(7), 1221-31. doi10.1002/cphc.200500113

[16] Shenashen MA, El-Safty SA, Elshehy EA. Synthesis, Morphological Control, and Properties of Silver Nanoparticles in Potential Applications. Particle \& Particle Systems Characterization. 2014, 31(3), 293316. doi10.1002/ppsc.201300181

[17] Abou El-Nour KMM, Eftaiha Aa, Al-Warthan A, Ammar RAA. Synthesis and applications of silver nanoparticles. Arabian Journal of Chemistry. 2010, 3(3), 135-40. doi10.1016/j.arabjc.2010.04.008

[18] Chanana M, Liz-Marzán Luis M. in Nanophotonics 2012, pp. 199.

[19] Kreuter J. Influence of the surface properties on nanoparticle-mediated transport of drugs to the brain. Journal of nanoscience and nanotechnology. 2004, 4(5), 484-8. doi10.1166/jnn.2003.077

[20] Roohani-Esfahani SI, Nouri-Khorasani S, Lu Z, Appleyard R, Zreiqat H. The influence hydroxyapatite nanoparticle shape and size on the properties of biphasic calcium phosphate scaffolds coated with hydroxyapatite-PCL composites. Biomaterials. 2010, 31(21), 5498-509. doi10.1016/j.biomaterials.2010.03.058

[21] Shoults-Wilson WA, Reinsch BC, Tsyusko OV, Bertsch PM, Lowry GV, Unrine JM. Effect of silver nanoparticle surface coating on bioaccumulation and reproductive toxicity in earthworms (Eisenia fetida). Nanotoxicology. 2011, 5(3), 432-44. doi10.3109/17435390.2010.537382 
[22] Benn T, Cavanagh B, Hristovski K, Posner JD, Westerhoff P. The Release of Nanosilver from Consumer Products Used in the Home. J Environ Qual. 2010, 39(6), 1875-82. doi10.2134/jeq2009.0363

[23] Geranio L, Heuberger M, Nowack B. The behavior of silver nanotextiles during washing. Environ Sci Technol. 2009, 43(21), 8113-8. doi10.1021/es9018332

[24] Reidy B, Haase A, Luch A, Dawson K, Lynch I. Mechanisms of Silver Nanoparticle Release, Transformation and Toxicity: A Critical Review of Current Knowledge and Recommendations for Future Studies and Applications. Materials. 2013, 6(6), 2295-350. doi10.3390/ma6062295

[25] Wijnhoven SWP, Peijnenburg WJGM, Herberts CA, Hagens WI, Oomen AG, Heugens EHW, et al. Nanosilver - a review of available data and knowledge gaps in human and environmental risk assessment. Nanotoxicology. 2009, 3(2), 109-38. doi10.1080/17435390902725914

[26] Hu J, Wang D, Wang J, Wang J. Bioaccumulation of Fe2O3(magnetic) nanoparticles in Ceriodaphnia dubia. Environ Pollut. 2012, 162, 216-22. doi10.1016/j.envpol.2011.11.016

[27] Zhang P, He X, Ma Y, Lu K, Zhao Y, Zhang Z. Distribution and bioavailability of ceria nanoparticles in an aquatic ecosystem model. Chemosphere. 2012, 89(5), 530-5. doi10.1016/j.chemosphere.2012.05.044

[28] Lasagna-Reeves C, Gonzalez-Romero D, Barria MA, Olmedo I, Clos A, Sadagopa Ramanujam VM, et al. Bioaccumulation and toxicity of gold nanoparticles after repeated administration in mice. Biochem Biophys Res Commun. 2010, 393(4), 649-55. doi10.1016/j.bbrc.2010.02.046

[29] Cong Y, Banta GT, Selck H, Berhanu D, Valsami-Jones E, Forbes VE. Toxicity and bioaccumulation of sediment-associated silver nanoparticles in the estuarine polychaete, Nereis (Hediste) diversicolor. Aquat Toxicol. 2014, 156, 106-15. doi10.1016/j.aquatox.2014.08.001

[30] Shoults-Wilson WA, Reinsch BC, Tsyusko OV, Bertsch PM, Lowry GV, Unrine JM. Role of Particle Size and Soil Type in Toxicity of Silver Nanoparticles to Earthworms. Soil Sci Soc Am J. 2011, 75(2), 365. doi10.2136/sssaj2010.0127nps

[31] van der Ploeg MJ, Handy RD, Waalewijn-Kool PL, van den Berg JH, Herrera Rivera ZE, Bovenschen J, et al. Effects of silver nanoparticles (NM-300K) on Lumbricus rubellus earthworms and particle characterization in relevant test matrices including soil. Environ Toxicol Chem. 2014, 33(4), 743-52. doi10.1002/etc. 2487

[32] Jackson BP, Bugge D, Ranville JF, Chen CY. Bioavailability, toxicity, and bioaccumulation of quantum dot nanoparticles to the amphipod Leptocheirus plumulosus. Environ Sci Technol. 2012, 46(10), 55506. doi10.1021/es202864r

[33] Novak S, Drobne D, Valant J, Pelicon P. Internalization of Consumed TiO2 Nanoparticles by a Model Invertebrate Organism. Journal of Nanomaterials. 2012, 2012, 8. doiArtn 658752. Doi $10.1155 / 2012 / 658752$

[34] Pan JF, Buffet PE, Poirier L, Amiard-Triquet C, Gilliland D, Joubert Y, et al. Size dependent bioaccumulation and ecotoxicity of gold nanoparticles in an endobenthic invertebrate: the Tellinid clam Scrobicularia plana. Environ Pollut. 2012, 168, 37-43. doi10.1016/j.envpol.2012.03.051

[35] Franci G, Falanga A, Galdiero S, Palomba L, Rai M, Morelli G, et al. Silver nanoparticles as potential antibacterial agents. Molecules (Basel, Switzerland). 2015, 20(5), 8856-74. doi10.3390/molecules20058856

[36] Hwang IS, Hwang JH, Choi H, Kim KJ, Lee DG. Synergistic effects between silver nanoparticles and antibiotics and the mechanisms involved. J Med Microbiol. 2012, 61(Pt 12), 1719-26. doi10.1099/jmm.0.047100-0

[37] Sondi I, Salopek-Sondi B. Silver nanoparticles as antimicrobial agent: a case study on E. coli as a model for Gram-negative bacteria. J Colloid Interface Sci. 2004, 275(1), 177-82. doi10.1016/j.jcis.2004.02.012

[38] Lara HH, Ayala-Nunez NV, Ixtepan-Turrent L, Rodriguez-Padilla C. Mode of antiviral action of silver nanoparticles against HIV-1. Journal of nanobiotechnology. 2010, 8, 1. doi10.1186/1477-3155-8-1

[39] Liu J, Jiang G. Silver nanoparticles in the environment. 2015. doi10.1007/978-3-662-46070-2

[40] Cornelis G, Hund-Rinke K, Kuhlbusch T, van den Brink N, Nickel C. Fate and Bioavailability of Engineered Nanoparticles in Soils: A Review. Crit Rev Environ Sci Technol. 2014, 44(24), $2720-64$. doi10.1080/10643389.2013.829767

[41] Croteau MN, Misra SK, Luoma SN, Valsami-Jones E. Silver bioaccumulation dynamics in a freshwater invertebrate after aqueous and dietary exposures to nanosized and ionic Ag. Environ Sci Technol. 2011, 45(15), 6600-7. doi10.1021/es200880c

[42] Lapied E, Nahmani JY, Moudilou E, Chaurand P, Labille J, Rose J, et al. Ecotoxicological effects of an aged TiO 2 nanocomposite measured as apoptosis in the anecic earthworm Lumbricus terrestris after 
exposure through water, food and soil. Environ Int. 2011, 37(6), 1105-10. doi10.1016/j.envint.2011.01.009

[43] Alexis F, Pridgen E, Molnar LK, Farokhzad OC. Factors affecting the clearance and biodistribution of polymeric nanoparticles. Mol Pharm. 2008, 5(4), 505-15. doi10.1021/mp800051m

[44] Shin S, Song I, Um S. Role of Physicochemical Properties in Nanoparticle Toxicity. Nanomaterials. 2015, 5(3), 1351-65. doi10.3390/nano5031351

[45] French RA, Jacobson AR, Kim B, Isley SL, Penn RL, Baveye PC. Influence of ionic strength, pH, and cation valence on aggregation kinetics of titanium dioxide nanoparticles. Environ Sci Technol. 2009, 43(5), 1354-9.

[46] Ayala V, Herrera AP, Latorre-Esteves M, Torres-Lugo M, Rinaldi C. Effect of surface charge on the colloidal stability and in vitro uptake of carboxymethyl dextran-coated iron oxide nanoparticles. Journal of nanoparticle research : an interdisciplinary forum for nanoscale science and technology. 2013, 15(8), 1874. doi10.1007/s11051-013-1874-0

[47] Powers KW, Brown SC, Krishna VB, Wasdo SC, Moudgil BM, Roberts SM. Research Strategies for Safety Evaluation of Nanomaterials. Part VI. Characterization of Nanoscale Particles for Toxicological Evaluation. Toxicol Sci. 2006, 90(2), 296-303. doi10.1093/toxsci/kfj099

[48] Li Y, Chen X, Gu N. Computational Investigation of Interaction between Nanoparticles and Membranes: Hydrophobic/Hydrophilic Effect. The Journal of Physical Chemistry B. 2008, 112(51), 16647-53. doi10.1021/jp8051906

[49] Sekiguchi S, Niikura K, Matsuo Y, ljiro K. Hydrophilic Gold Nanoparticles Adaptable for Hydrophobic Solvents. Langmuir. 2012, 28(13), 5503-7. doi10.1021/la300299x

[50] Yu SS, Lau CM, Thomas SN, Jerome WG, Maron DJ, Dickerson JH, et al. Size- and charge-dependent non-specific uptake of PEGylated nanoparticles by macrophages. International journal of nanomedicine. 2012, 7, 799-813. doi10.2147/ijn.s28531

[51] Greßler S, Gazsó A. Definition of the term “nanomaterial” Nanotrust dossiers. 2013, 6. doi10.1553/itant-039en

[52] Eisenberger I, Greßler S, Nentwich M. On voluntary and obligatory nano-labelling. Nanotrust dossiers. 2012, 031. doi10.1553/ita-nt-031en

[53] EU Commission Recommendation of 18 October 2011 on the definition of nanomaterial (1). Official Journal of the European Union. 2011, 2011/696/EU, L275/38. doi10.3000/19770677.L_2011.275.eng

[54] SCENIHR. (Scientific Committee on Emerging and Newly Identified Health Risks), Opinion on the scientific basis for the definition of the term "nanomaterial" 2010, 46.

[55] (NIOSH) NIfOSaH. National Institute for Occupational Safety and Health (NIOSH) Approaches to Safe Nanotechnology: Managing the Health and Safety Concerns Associated with Engineered Nanomaterials (March 2009). DHHS (NIOSH). 2009, Publication No. 2009-125.

[56] Foldbjerg R, Irving ES, Hayashi Y, Sutherland DS, Thorsen K, Autrup H, et al. Global gene expression profiling of human lung epithelial cells after exposure to nanosilver. Toxicol Sci. 2012, 130(1), 145-57. doi10.1093/toxsci/kfs225

[57] Yu SJ, Yin YG, Liu JF. Silver nanoparticles in the environment. Environ Sci Process Impacts. 2013, 15(1), 78-92. doi10.1039/C2EM30595J

[58] Makama S, Peters R, Undas A, van den Brink NW. A novel method for the quantification, characterisation and speciation of silver nanoparticles in earthworms exposed in soil. Environmental Chemistry. 2015, 12(6), 643. doi10.1071/en15006

[59] Powers CM, Badireddy AR, Ryde IT, Seidler FJ, Slotkin TA. Silver nanoparticles compromise neurodevelopment in PC12 cells: critical contributions of silver ion, particle size, coating, and composition. Environ Health Perspect. 2011, 119(1), 37-44. doi10.1289/ehp.1002337

[60] Suresh AK, Pelletier DA, Wang W, Morrell-Falvey JL, Gu B, Doktycz MJ. Cytotoxicity induced by engineered silver nanocrystallites is dependent on surface coatings and cell types. Langmuir. 2012, 28(5), 2727-35. doi10.1021/la2042058

[61] Yang X, Gondikas AP, Marinakos SM, Auffan M, Liu J, Hsu-Kim H, et al. Mechanism of silver nanoparticle toxicity is dependent on dissolved silver and surface coating in Caenorhabditis elegans. Environ Sci Technol. 2012, 46(2), 1119-27. doi10.1021/es202417t

[62] Peters RJ, Rivera ZH, van Bemmel G, Marvin HJ, Weigel S, Bouwmeester H. Development and validation of single particle ICP-MS for sizing and quantitative determination of nano-silver in chicken meat. Anal Bioanal Chem. 2014, 406(16), 3875-85. doi10.1007/s00216-013-7571-0 
[63] van der Zande M, Vandebriel RJ, Van Doren E, Kramer E, Herrera Rivera Z, Serrano-Rojero CS, et al. Distribution, elimination, and toxicity of silver nanoparticles and silver ions in rats after 28-day oral exposure. ACS nano. 2012, 6(8), 7427-42. doi10.1021/nn302649p

[64] Izak-Nau E, Huk A, Reidy B, Uggerud H, Vadset M, Eiden S, et al. Impact of storage conditions and storage time on silver nanoparticles' physicochemical properties and implications for their biological effects. RSC Advances. 2015, 5(102), 84172-85. doi10.1039/c5ra10187e

[65] Sharma VK, Filip J, Zboril R, Varma RS. Natural inorganic nanoparticles - formation, fate, and toxicity in the environment. Chem Soc Rev. 2015, 44(23), 8410-23. doi10.1039/c5cs00236b

[66] Topuz E, van Gestel CA. Toxicokinetics and toxicodynamics of differently coated silver nanoparticles and silver nitrate in Enchytraeus crypticus upon aqueous exposure in an inert sand medium. Environ Toxicol Chem. 2015, 34(12), 2816-23. doi10.1002/etc.3123

[67] Baalousha M, Cornelis G, Kuhlbusch TAJ, Lynch I, Nickel C, Peijnenburg W, et al. Modeling nanomaterial fate and uptake in the environment: current knowledge and future trends. Environmental Science: Nano. 2016. doi10.1039/c5en00207a

[68] Johnston HJ, Hutchison G, Christensen FM, Peters S, Hankin S, Stone V. A review of the in vivo and in vitro toxicity of silver and gold particulates: particle attributes and biological mechanisms responsible for the observed toxicity. Crit Rev Toxicol. 2010, 40(4), 328-46. doi10.3109/10408440903453074

[69] Morones-Ramirez JR, Winkler JA, Spina CS, Collins JJ. Silver Enhances Antibiotic Activity Against GramNegative Bacteria. Sci Trans/ Med. 2013, 5(190), 190ra81-ra81. doi10.1126/scitranslmed.3006276

[70] EPA. EPA document 2012 Nanomaterial Case Study: Nanoscale Silver in Disinfectant Spray. EPA/600/R-10/081F 423. 2012.

[71] Russell AD, Hugo WB. in Prog Med Chem Eds. Ellis GP, Luscombe DK)1994, pp. 351-70 (Elsevier).

[72] Atiyeh BS, Costagliola M, Hayek SN, Dibo SA. Effect of silver on burn wound infection control and healing: Review of the literature. Burns. 2007, 33(2), 139-48. doi10.1016/j.burns.2006.06.010

[73] Van de Voorde K, Nijsten T, Schelfhout K, Moorkens G, Lambert J. LONG TERM USE OF SILVER CONTAINING NOSE-DROPS RESULTING IN SYSTEMIC ARGYRIA. Acta Clin Belg. 2005, 60(1), 33-5. doi10.1179/acb.2005.008

[74] Vik H, Andersen KJ, Julshamn K, Todnem K. Neuropathy caused by silver absorption from arthroplasty cement. Lancet. 1985, 1(8433), 872.

[75] Mueller NC, Nowack B. Exposure modeling of engineered nanoparticles in the environment. Environ Sci Technol. 2008, 42(12), 4447-53. doi10.1021/es7029637

[76] Gottschalk F, Sun T, Nowack B. Environmental concentrations of engineered nanomaterials: review of modeling and analytical studies. Environ Pollut. 2013, 181, 287-300. doi10.1016/j.envpol.2013.06.003

[77] Peters RJ, van Bemmel G, Herrera-Rivera Z, Helsper HP, Marvin HJ, Weigel S, et al. Characterization of titanium dioxide nanoparticles in food products: analytical methods to define nanoparticles. J Agric Food Chem. 2014, 62(27), 6285-93. doi10.1021/jf5011885

[78] Sarker SD, Nahar L. Hyphenated techniques and their applications in natural products analysis. Methods Mol Biol. 2012, 864, 301-40. doi10.1007/978-1-61779-624-1_12

[79] Coutris C, Hertel-Aas T, Lapied E, Joner EJ, Oughton DH. Bioavailability of cobalt and silver nanoparticles to the earthworm Eisenia fetida. Nanotoxicology. 2012, 6(2), 186-95. doi10.3109/17435390.2011.569094

[80] Choi O, Hu Z. Size dependent and reactive oxygen species related nanosilver toxicity to nitrifying bacteria. Environ Sci Technol. 2008, 42(12), 4583-8. doi10.1021/es703238h

[81] Chappell MA, Miller LF, George AJ, Pettway BA, Price CL, Porter BE, et al. Simultaneous dispersiondissolution behavior of concentrated silver nanoparticle suspensions in the presence of model organic solutes. Chemosphere. 2011, 84(8), 1108-16. doi10.1016/j.chemosphere.2011.04.040

[82] van der Ploeg MJ, van den Berg JH, Bhattacharjee S, de Haan LH, Ershov DS, Fokkink RG, et al. In vitro nanoparticle toxicity to rat alveolar cells and coelomocytes from the earthworm Lumbricus rubellus. Nanotoxicology. 2014, 8(1), 28-37. doi10.3109/17435390.2012.744857

[83] Aqeel M, Jamil M, Yusoff I. Soil Contamination, Risk Assessment and Remediation. 2014. doi10.5772/57287

[84] Nowack B, Bucheli TD. Occurrence, behavior and effects of nanoparticles in the environment. Environ Pollut. 2007, 150(1), 5-22. doi10.1016/j.envpol.2007.06.006

[85] OECD. Test No. 222: Earthworm Reproduction Test (Eisenia fetida/Eisenia andrei) (OECD Publishing). 
[86] Diez-Ortiz M, Lahive E, Kille P, Powell K, Morgan AJ, Jurkschat K, et al. Uptake routes and toxicokinetics of silver nanoparticles and silver ions in the earthworm Lumbricus rubellus. Environ Toxicol Chem. 2015, 34(10), 2263-70. doi10.1002/etc.3036

[87] Poynton HC, Lazorchak JM, Impellitteri CA, Blalock BJ, Rogers K, Allen HJ, et al. Toxicogenomic responses of nanotoxicity in Daphnia magna exposed to silver nitrate and coated silver nanoparticles. Environmental Science and Technology. 2012, 46(11), 6288-96. doi10.1021/es3001618

[88] Poynton HC, Lazorchak JM, Impellitteri CA, Smith ME, Rogers K, Patra M, et al. Differential Gene Expression in Daphnia magna Suggests Distinct Modes of Action and Bioavailability for $\mathrm{ZnO}$ Nanoparticles and Zn lons. Environ Sci Technol. 2011, 45(2), 762-8. doi10.1021/es102501z

[89] van der Ploeg MJC, Baveco JM, van der Hout A, Bakker R, Rietjens IMCM, van den Brink NW. Effects of C60 nanoparticle exposure on earthworms (Lumbricus rubellus) and implications for population dynamics. Environ Pollut. 2011, 159(1), 198-203. doihttp://dx.doi.org/10.1016/j.envpol.2010.09.003

[90] Van Der Ploeg MJ, Handy RD, Heckmann LH, Van Der Hout A, Van Den Brink NW. C60 exposure induced tissue damage and gene expression alterations in the earthworm Lumbricus rubellus. Nanotoxicology. 2013, 7(4), 432-40. doi10.3109/17435390.2012.668569

[91] Lionetto MG, Calisi A, Schettino T. Earthworm Biomarkers as Tools for Soil Pollution Assessment. Soil Health and Land Use Management, Dr Maria C Hernandez Soriano (Ed). 2012.

[92] Braakhuis HM, Kloet SK, Kezic S, Kuper F, Park MV, Bellmann S, et al. Progress and future of in vitro models to study translocation of nanoparticles. Arch Toxicol. 2015, 89(9), 1469-95. doi10.1007/s00204-015-1518-5

[93] Connolly M, Fernandez-Cruz ML, Quesada-Garcia A, Alte L, Segner H, Navas JM. Comparative Cytotoxicity Study of Silver Nanoparticles (AgNPs) in a Variety of Rainbow Trout Cell Lines (RTL-W1, RTH-149, RTG-2) and Primary Hepatocytes. Int J Environ Res Public Health. 2015, 12(5), 5386-405. doi10.3390/ijerph120505386

[94] Kloet SK, Walczak AP, Louisse J, van den Berg HHJ, Bouwmeester H, Tromp P, et al. Translocation of positively and negatively charged polystyrene nanoparticles in an in vitro placental model. Toxicol In Vitro. 2015, 29(7), 1701-10. doihttp://dx.doi.org/10.1016/j.tiv.2015.07.003

[95] Carlson C, Hussain SM, Schrand AM, Braydich-Stolle LK, Hess KL, Jones RL, et al. Unique cellular interaction of silver nanoparticles: size-dependent generation of reactive oxygen species. J Phys Chem B. 2008, 112(43), 13608-19. doi10.1021/jp712087m

[96] Aranda A, Sequedo L, Tolosa L, Quintas G, Burello E, Castell JV, et al. Dichloro-dihydro-fluorescein diacetate (DCFH-DA) assay: a quantitative method for oxidative stress assessment of nanoparticletreated cells. Toxicol In Vitro. 2013, 27(2), 954-63. doi10.1016/j.tiv.2013.01.016

[97] AshaRani PV, Low Kah Mun G, Hande MP, Valiyaveettil S. Cytotoxicity and genotoxicity of silver nanoparticles in human cells. ACS nano. 2009, 3(2), 279-90. doi10.1021/nn800596w

[98] Lemasters JJ, Nieminen A-L, Qian T, Trost LC, Elmore SP, Nishimura Y, et al. The mitochondrial permeability transition in cell death: a common mechanism in necrosis, apoptosis and autophagy. Biochim Biophys Acta. 1998, 1366(1-2), 177-96. doi10.1016/S0005-2728(98)00112-1

[99] Yen HJ, Hsu SH, Tsai CL. Cytotoxicity and immunological response of gold and silver nanoparticles of different sizes. Small. 2009, 5(13), 1553-61. doi10.1002/smll.200900126

[100] van Gestel CAM. Soil ecotoxicology: state of the art and future directions. ZooKeys. 2012, (176), 27596. doi10.3897/zookeys.176.2275

[101] Landsiedel R, Fabian E, Ma-Hock L, van Ravenzwaay B, Wohlleben W, Wiench K, et al. Toxico/biokinetics of nanomaterials. Arch Toxicol. 2012, 86(7), 1021-60. doi10.1007/s00204-012-0858-7

[102] Garcia-Alonso J, Khan FR, Misra SK, Turmaine M, Smith BD, Rainbow PS, et al. Cellular internalization of silver nanoparticles in gut epithelia of the estuarine polychaete Nereis diversicolor. Environ Sci Technol. 2011, 45(10), 4630-6. doi10.1021/es2005122

[103] Jones RP, Bednar AJ, Inouye LS. Subcellular compartmentalization of lead in the earthworm, Eisenia fetida: Relationship to survival and reproduction. Ecotoxicol Environ Saf. 2009, 72(4), 1045-52. doihttp://dx.doi.org/10.1016/j.ecoenv.2008.12.011

[104] Wallace WG, Lee BG, Luoma SN. Subcellular compartmentalization of Cd and Zn in two bivalves. I. Significance of metal-sensitive fractions (MSF) and biologically detoxified metal (BDM). 2003, 249, 183-97.

[105] Vijver MG, van Gestel CAM, van Straalen NM, Lanno RP, Peijnenburg WJGM. Biological Significance of Metals Partitioned to Subcellular Fractions within Earthworms (Aporrectodea Caliginosa). Environ Toxicol Chem. 2006, 25(3), 807. doi10.1897/05-128r.1 



\section{Chapter 2}

Cellular interactions of different forms silver nanoparticles with mouse monocyte macrophages RAW 264.7 cells

\section{Based on:}

Cellular interactions of silver nanoparticles with systematic variation in size and surface coating with macrophage RAW 264.7 cells

Sunday Makama, Samantha K. Kloet, Jordi Piella, Johannes H.J. van den Berg, Norbert C. A. de Ruijter, Victor F. Puntes, Ivonne MCM Rietjens, Nico W. van den Brink

Submitted for publication 


\section{Abstract}

Increasing use of engineered nanoparticles has led to an increased likelihood of environmental release, raising environmental and health hazard concerns. The volume of silver nanoparticles (AgNPs)-based products entering the market is relatively high, making the risk assessment of AgNPs a priority. Therefore, elucidating the factors that drive AgNPs' potential to pose environmental risks is urgent. Small and medium sized (20 and $50 \mathrm{~nm}$ ) AgNPs with different surface coating/charges (chitosan/positive AgNP_Chit; bovine serum albumin/negative AgNP_BSA, and; polyvinylpyrrolidone/neutral AgNP_PVP) were synthesized and characterized. Macrophage cells (RAW 264.7) were exposed to these AgNPs at $0-200 \mu \mathrm{g} / \mathrm{ml}$ (nominal concentrations), and uptake dynamics, cell viability, inductions of tumour necrosis factor (TNF)- $\alpha$ and reactive oxygen species (ROS) were assessed. Decreased cell viability was observed for all AgNPs tested, while tests targeting specific mechanisms of action indicated the highest induction of (TNF- $\alpha$ ) in cells exposed to both sizes of the negatively charged AgNP_BSA (80x higher than control). Significant ROS induction was only observed with the $20 \mathrm{~nm}$ positively charged AgNP_Chit. Generally, adverse effects from exposure to the tested AgNPs resulting in reduced overall viability were similar irrespective of AgNP types or sizes. On adenosine triphosphate production and specific mechanisms of toxicity (TNF- $\alpha$ and ROS) however, we find that the AgNPs differ significantly. Also, the negatively charged AgNP_BSA were the most potent in inducing cellular effects. The present study provides further evidence of the influence of physico-chemical properties of nanoparticles in driving toxicity in an in vitro model.

\section{Keywords}

Immunocytotoxicity, nanoparticle properties, oxidative stress, surface coating, TNF- $\alpha$ 


\section{Introduction}

Nanotechnology can be considered as one of the fastest growing technologies which has revolutionized the industrial sector [1-3], bringing about possibilities only imagined a few decades ago. This has led to increased production and applications of engineered nanoparticles (NPs) for consumer products, affecting virtually all industrial sectors $[4,5]$. Presently, NPs continue to find applications in the design and manufacture of household products, electronics and medical devices, food and transport systems, to mention a few $[6,7]$. Consequently, the increase in production and use of NPs will likely result in an increased release into the environment as industrial waste (or by-product), sewage and/or waste water [5, 8-10]. Such environmental release could potentially have harmful impacts.

Currently, silver nanoparticles (AgNPs) represent the nanomaterial most frequently used in products on the market $[4,11]$, owing to their well demonstrated antimicrobial activity [12-17]. At the nanoscale $(1-100 \mathrm{~nm})$, the small size and increased surface area of AgNPs result in novel physico-chemical properties. These can be enhanced by stabilization and/or functionalization using biocompatible conjugates. Essentially, the type of surface coating and process used in stabilizing engineered NPs during synthesis determines their surface charges, solubility and/or hydrophobicity [18-21]. This in turn, influences the behaviour and environmental fate of NPs, as well as their effects on organisms [22-25].

Over the last two decades, researchers have attempted to elucidate the fate and effect of various NPs using both in vivo and in vitro models [26-29]. The importance of physicochemical properties of NPs in influencing their fate and toxicity has increasingly been investigated, but reports in available literature have not been consistent. Important physico-chemical properties in this regard include size and NPs dispersion (both monoand polydispersity), shape, zeta potential, and agglomeration and dissolution rates [10]. While some studies have reported effects of size [30] or charge [31], others fail to detect these [32]. Additional perspectives on the influence of physico-chemical properties of AgNPs on their interactions in both in vivo and in vitro models, has been reviewed earlier $[10,33]$. From the reviews cited and examples mentioned above, one can identify the challenge associated with the regulation of AgNPs and other nanoparticles in general. This is especially so, given the limited data base and the limitations of generating in vivo data for all different forms and types of NPs.

A better understanding of the properties that influence the fate and effects of AgNPs in organisms will facilitate appropriate risk assessment, which in turn will assist the regulation of nanomaterials. In the $\mathrm{EU}$ and the US, chemical regulations require an 
assessment of the health and environmental risks of NPs. Considering the increasing numbers of NPs with differing physico-chemical properties entering the market annually, it is urgent for research to continue to seek approaches that will be effective and efficient at addressing these needs. In vitro models have generally proven to present high throughput and to be from an ethical perspective, more desirable and thus continually exploited. Using in vitro models in risk assessments of chemicals facilitates the setting of priorities for in vivo testing, thereby reducing the number of animals required [34]. Also, an interesting prospect for using in vitro models is the potential for read-across and extrapolating in vitro toxicity information to in vivo situations. Although this presents its own unique challenges and a comprehensive risk assessment may not be entirely based upon in vitro data, the opportunities for alternative in vitro methods available are worth exploring. By first investigating with in vitro models, insights in the toxicity and possible mode of action of NPs are obtained. Such information could be used in a weight of evidence approach [35], furthering our understanding of observations made under in vivo situations, as well as defining priorities for in vivo testing and facilitating read-across.

In this study, we systematically investigated the physico-chemical properties of AgNPs influencing their interactions at cellular level, using an in vitro mammalian cell line model: the mouse monocyte macrophage (RAW 264.7). Macrophages provide the first line of defence in an organism, and their role in initiating inflammatory (TNF- $\alpha$ ) and oxidative stress responses were investigated. Exposures were carried out using synthesized AgNPs that differed in size and surface chemistry (charge), two important properties influencing NPs uptake and effects [10]. The outcome of this study will provide an initial insight into how AgNP properties determine their fate and effects at cellular level, thus indirectly shedding light on what the outcome may likely be in intact organisms [36, 37].

\section{Materials and methods}

\section{Experimental design}

The mouse monocyte macrophage cell line (RAW 264.7) was used as the in vitro model, and cells were treated with AgNPs. Experiments were conducted in three independent exposures for each type of $\operatorname{AgNP}(n=3)$ and the data generated were processed with Microsoft Excel. Where appropriate, the data were subjected to one-way analysis of variance (ANOVA) with the aid of GraphPad Prism 5.04 for Windows (GraphPad Software, San Diego California USA, www.graphpad.com"), and logistic regression was 
done using GenStat 17th ed. (17.1.0.14713; VSN International, Hemel Hempstead, UK, GenStat.co.uk). A $p$ value of $<0.05$ is considered to be significant.

\section{Reagents and Instruments}

All chemicals used were analytical grade. Unless where stated otherwise, all chemicals, enzymes and reagents were purchased from Sigma-Aldrich (Zwijndrecht, The Netherlands). Apart from one commercially obtained AgNP, all other AgNPs were synthesized at the Catalunya Institute of Nanoscience and Nanotechnology (ICN2), Barcelona, Spain by methods for which details are provided below. End-point measurements were carried out using SpectraMax M2 Microplate Reader (Molecular Devices LLC, Sunnyvale, CA USA) for fluorescence and absorbance, or Luminoskan Ascent (Thermo Scientific, 5300172, MA USA) for luminescence.

\section{Synthesis of AgNPs}

Colloidal, dispersed AgNPs of two different sizes (20 and $50 \mathrm{~nm}$ ) were prepared separately, following a kinetically controlled seeded-growth method previously reported [18] with slight modifications. The approach is based on the reduction of silver nitrate $\left(\mathrm{AgNO}_{3}\right)$ in the presence of two competing reducing agents, tannic acid (TA) and trisodium citrate hexahydrate (SC) at $100^{\circ} \mathrm{C}$. Six different AgNPs were synthesized by surface-coating both sizes with bovine serum albumin (BSA), chitosan (Chit) or polyvinylpyrrolidone (PVP) to generate negative AgNP_BSA, positive AgNP_Chit and neutral AgNP_PVP, respectively. Details of this procedure are elaborated upon in the electronic supplementary material (ESM_01.pdf).

An aqueous suspension of a negatively charged $50 \mathrm{~nm}$ PVP-coated AgNP (AgNP_NC) was obtained from NanoComposix ${ }^{\circledR}$ (San Diego, USA) and included in this study for comparison with the synthesized AgNPs. Based on the manufacturer's information, the AgNP_NC is reported to have mean core- and hydrodynamic diameters of $54.8 \pm 10 \mathrm{~nm}$ and $72 \pm 14.4 \mathrm{~nm}$ respectively. The stock suspension of the pristine AgNP has a mass concentration of $5.0 \mathrm{mg} \mathrm{Ag} / \mathrm{ml}$, and a particle number concentration of $5.2 \times 10^{12}$ particles/ml. The surface area was $9.8 \mathrm{~m}^{2} / \mathrm{g}$ while surface charge (zeta-potential) was $37.8 \mathrm{mV}$. The DLS and zeta potential in both milliQ and DMEM were confirmed in our laboratory, and details have been presented earlier [38].

\section{AgNP Characterization}

Prior to exposure experiments, pristine AgNPs were dispersed in Dulbecco's modified Eagle's medium, DMEM (Invitrogen Breda, The Netherlands), as well as milliQ water and characterized by transmission electron microscopy (TEM), UV-Vis spectroscopy, dynamic 
light scattering (DLS), and zeta-potential measurements ( $\zeta$-potential). A combination of different techniques was used to characterize the AgNPs and to monitor their proper coating and stability in the different media. Details of these are further elaborated on in the electronic supplementary material (ESM_01.pdf).

\section{NPs dispersions}

AgNPs stock dispersions were prepared by first suspending the respective powders in milliQ water except for AgNP_Chit, where 50 mM acetic acid (Merck, Darmstadt, GER) was used instead. AgNP_Chit suspensions were initially prepared in $50 \mathrm{mM}$ acetic acid in order to prevent agglomeration while ensuring monodispersity [39, 40]. Where used, the final acetic acid concentration in the medium at which the cells were exposed to was $4 \mathrm{mM}(0.02 \%)$, and determined to be non-cytotoxic (data not shown). For all AgNPs, the stock dispersions were prepared at $2.5 \mathrm{mg} \mathrm{Ag} / \mathrm{ml}$ and sonicated in a Sonorex RK100 (Berlin, Germany) water-bath over ice for $15 \mathrm{~min}$. Further dilutions to the desired exposure concentration ranges $(0.1,1,5,10,20,50,100$, and $200 \mu \mathrm{g} \mathrm{Ag} / \mathrm{ml}$ ) were made in DMEM fortified with heat inactivated foetal calf serum (FCS) at $10 \%$.

\section{AgNP exposure and Uptake dynamics}

A mouse monocyte macrophage cell line, RAW 264.7 (ATCC ${ }^{\circ}$ TIB-71 ${ }^{\text {TM }}$; Manassas, VA USA) was used in this study at passages 16-22. Cells were cultured in DMEM, enriched with FCS at $10 \%(v / v)$. Sub-culturing and passaging of cells was done every $3-4$ days when reaching $80 \%$ confluency by trypsinisation after rinsing with phosphate buffered saline, PBS. Before exposure to AgNPs, cells were grown for $24 \mathrm{hrs}$ in 96 -well plates at a seeding density of $10^{5}$ cells/well for all assays, and incubated at $37^{\circ} \mathrm{C}$ in humidified air (plus $5 \%$ $\mathrm{CO}_{2}$ ) to attain above $80 \%$ adherent confluency. After this initial $24 \mathrm{hrs}$ of stabilization and growth, AgNPs exposures for all assays with the exception of the Dichlorofluoroscein (DCF) assay for ROS production, were conducted over a $24 \mathrm{~h}$ duration. For the ROS production assay, exposure to AgNPs was for $6 \mathrm{~h}$, based on an adaptation of a similar method described earlier [41]. Unless stated otherwise, general incubation conditions were as described above.

AgNPs were imaged by means of confocal microscopy to follow cellular uptake, localization and accumulation behaviour of the different AgNPs over time. Due to limited capacity, this was performed for the $50 \mathrm{~nm}$ size class only, assuming that this size is generally taken up less rapidly in comparison to $20 \mathrm{~nm}[42,43]$. Details on methodology and complete results are provided in the supplementary material. 


\section{Effect assessment:}

Cytotoxicity assays were performed to evaluate the viability of the macrophages after exposure to the different AgNPs. 3-(4,5-dimethylthiazol-2-yl)-2,5-diphenyltetrazolium bromide (MTT) assay [44]; ATP content was determined using a bioluminescent somatic cell assay kit (Sigma-Aldrich , St Louis, MO, USA), and; mitochondrial permeability transition-pore (MTP) assays were performed using a commercial kit from Molecular Probes (Leiden, NL). The production of ROS as well as the induction of TNF- $\alpha$ were also assessed to elucidate specific modes of action involved. A 2',7'dichlorodihydrofluorescein diacetate $\left(\mathrm{H}_{2} \mathrm{DCF}-\mathrm{DA}\right)$ dye from Molecular probes (Carlsbad, CA, USA) was used for ROS, while TNF- $\alpha$ induction was assessed by a solid phase sandwich Enzyme-Linked Immuno-Sorbent Assay (ELISA) using a Mouse TNF- $\alpha$ ELISA kit (Invitrogen $^{\mathrm{TM}}$, Paisley, UK). Protocols for these assessments were based on the manufacturers' instructions with few modifications, and details are provided in the electronic supplementary material (ESM_01.pdf).

\section{Controls}

Macrophage cells exposed to DMEM, containing equal proportions of milliQ $\mathrm{H}_{2} \mathrm{O}$, but no nanoparticles served as blanks. For exposures with AgNP_Chit group, $0.02 \%$ acetic acid (4 mM final exposure concentration) was used. Positive controls were prepared in exposure medium without nanoparticles and included for each assay. All controls were incubated according to the respective protocols and results can be found in the supplementary Fig. S2.1. To check the likelihood of particle interference with spectroscopic measurements, different AgNP concentrations were included (in the absence of cells) and measured for all assays. Readings confirmed no interference of the particles with the fluorescence, absorbance or luminescence readings, and all controls were as expected (Supplementary Fig. S2.1).

\section{Results}

\section{AgNPs Characterization}

Fig. 2.1a - c presents representative TEM images and UV-Vis spectra of $50 \mathrm{~nm}$ AgNPs characterization, while information on the $20 \mathrm{~nm}$ size group is provided in supplementary Table 2.1 and Fig. S2.1. TEM images below (Fig. 2.1a - c) indicate visually that the primary particle sizes targeted by the synthesis were achieved and that for all coatings, the morphology of the particles were preserved after coating and lyophilisation processes. Average particle sizes obtained by analysis of over 250 nanoparticles by TEM 
were $51.1 \pm$ 5.7, $51.9 \pm 6.4$ and $51.0 \pm 6.1$ for AgNP_BSA, AgNP_Chit and AgNP_PVP 50 $\mathrm{nm}$ size group, respectively (Fig. $2.1 \mathrm{a}-\mathrm{c}$ ). For the $20 \mathrm{~nm}$ group, these values were respectively $19.5 \pm 5.4,18.2 \pm 5.1$ and $23.8 \pm 4.6 \mathrm{~nm}$.

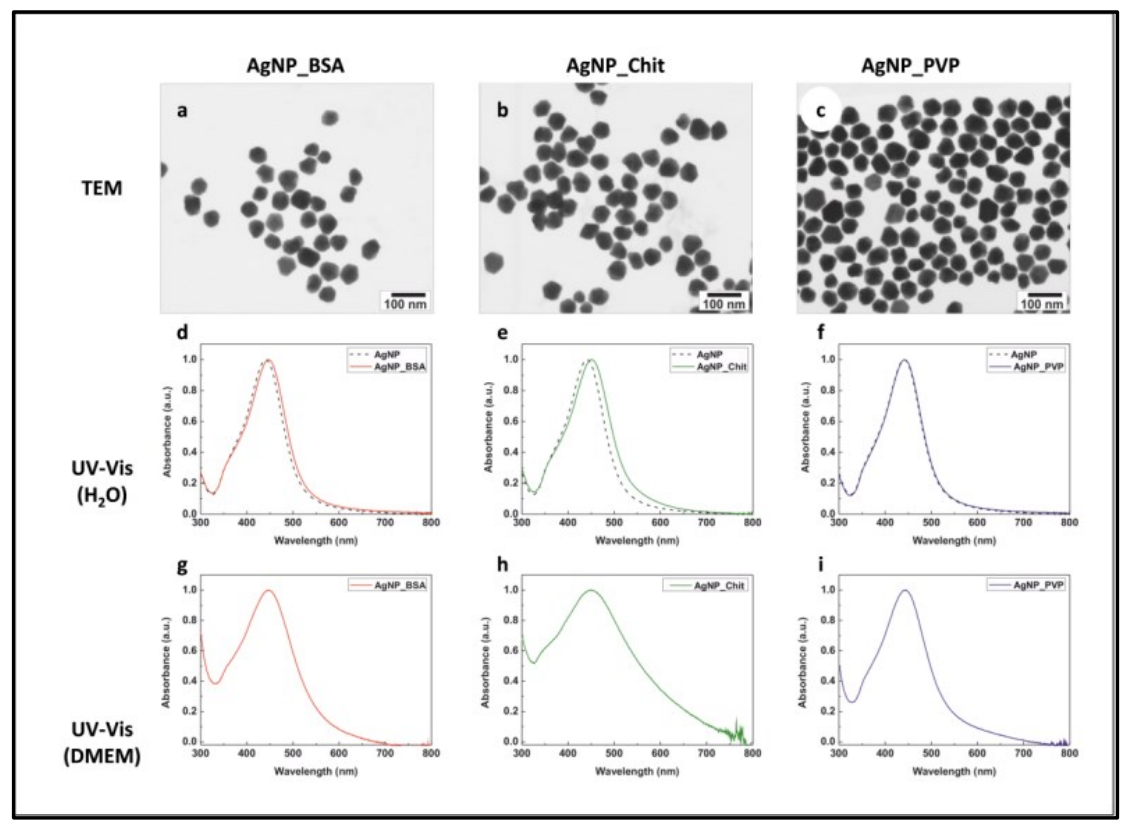

Fig. 2.1 Representative AgNPs characterization results for 50nm size group. TEM images $(\mathrm{a}-\mathrm{c})$ of re-suspended AgNPs showing quasi-spherical particles within the expected size ranges, with overall average diameter of 51.3 $\pm 6.1 \mathrm{~nm}$. UV-Vis also shows SPR peaks within the expected wavelength range $300-600 \mathrm{~nm}$ both in milliQ water and in cell culture medium ( $d-f$ and $g-i$, respectively). The UV-Vis SPR curves of coated and noncoated AgNPs nicely overlaps $(d-f)$, with the post-coating SPR curves exhibiting a red-shift indicative of the effect of AgNPs coating. DMEM: Dulbecco's modified Eagle's medium.

The UV-Vis spectre of pre-coated AgNPs showed SPR peaks centred at $405 \mathrm{~nm}$ (Supplementary Fig. S2.2d-f) for the $20 \mathrm{~nm}$ size group, and $441 \mathrm{~nm}$ (Fig. 2.1d-f dashed line) for the $50 \mathrm{~nm}$ sizes. Also, the hydrodynamic sizes for $20 \mathrm{~nm}$ and $50 \mathrm{~nm}$ AgNPs were $36 \mathrm{~nm}$ and $55 \mathrm{~nm}$, respectively. Coating the AgNPs with BSA, PVP and Chitosan led to a slight red-shift in the positions of the SPR peaks, indicating an affinity of these molecules for the silver surfaces and their spontaneous association. The SPR peaks shifted 6-8 nm in the case of AgNP_BSA, 2-3 nm for the AgNPs-PVP and 9-10 nm for the AgNPs-Chit.

DLS measurements in milliQ water and DMEM showed larger particles sizes (Supplementary Table 2.1) than those obtained from TEM. The hydrodynamic sizes for $20 \mathrm{~nm} / 50 \mathrm{~nm}$ NPs were $41.5 \pm 1.3 / 69.9 \pm 3.2$ and $46.8 \pm 0.1 / 71.3 \pm 2.0$ for AgNP_BSA and AgNP_PVP respectively. In accordance with these results, the hydrodynamic sizes of the AgNPs after their surfaces were coated also increased by 10-12 nm for the AgNPs_BSA, 
15-20 nm for the AgNPs_PVP and 50-100 nm for AgNP_Chit. AgNP_Chit formed agglomerates during re-suspension, overestimating the average diameter to be around $240 \mathrm{~nm}$ for both sizes. Fig. 2.2 shows the particle size distribution of AgNPs as determined by TEM. The frequency curves shifts from left to right with increasing particle sizes. The surface charges of the $20 \mathrm{~nm}$ AgNPs measured in water (and DMEM) showed $\zeta$-potentials (meV) of $-37.0 \pm 2.0(-23.0 \pm 2.0),+7.0 \pm 1.0(-21.3 \pm 1.4)$ and -22.0 $\pm 2.0(-19.3 \pm 0.7)$ for AgNP_BSA, AgNP_Chit and AgNP_PVP, respectively. The surface charges for the $20 \mathrm{~nm}$ particles were similar to their $50 \mathrm{~nm}$ counterparts (see supplementary material Table 2.1). After coating, the $\zeta$-potential measured indicated changes in the surface charges from -40 to $-50 \mathrm{meV}$ corresponding to citrate ions on the surface of the pre-coated intermediate product of AgNP synthesis, to between -29 and $-37 \mathrm{meV}$ (AgNP_BSA), -16 and $-22 \mathrm{meV}$ (AgNP_PVP) and +7 to +8 meV (AgNP_Chit). The $\zeta$-potential values in DMEM were all negative, although the negatively charged AgNP_BSA had a slightly more negative potential in all measurements.

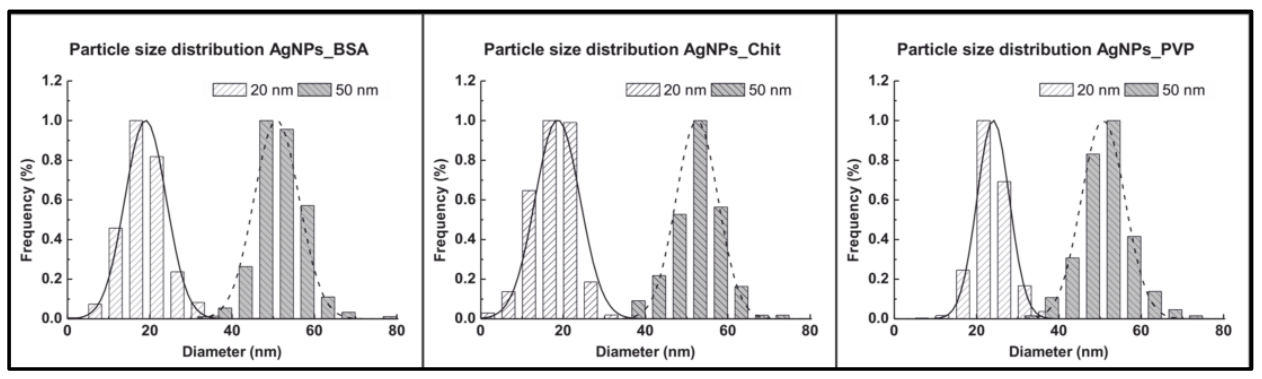

Fig. 2.2 Particle size distribution of AgNP_BSA (a), AgNP_Chit (b) \& AgNP_PVP (c) showing frequency counts as determined by transmission electron microscopy (TEM). The frequency curves shifts from left to right with increasing particle sizes: $20 \mathrm{~nm}$ (solid lines); $50 \mathrm{~nm}$ (broken lines).

\section{Effect assessments}

MTT Assay

There was a concentration-dependent decrease in mitochondrial function assessed by the MTT viability assay, with smaller AgNPs $(20 \mathrm{~nm})$ presenting lower $\mathrm{EC}_{50}$ values compared to their larger (50 nm) counterparts (Fig. 2.3a - d; Table 2.1). Exposure of the cells to the AgNP_BSA results in a statistically significant decrease in MTT, already at low exposure concentration of $10 \mu \mathrm{g} / \mathrm{ml}$ for the $20 \mathrm{~nm}$ AgNPs. Further statistical analyses however, did not present any significant difference between the $E_{50}$ values obtained for the different sizes ( $20 \mathrm{~nm}$ vs $50 \mathrm{~nm}$ ) nor types (surface-coating/charge) of AgNPs. Except for AgNP_Chit $50 \mathrm{~nm}$ for which the $E_{50}$ value exceeded the highest exposure concentration (Table 2.1). 
Table 2.1. Table of $\mathrm{EC}_{50} \mathrm{~S}(\mu \mathrm{g} / \mathrm{ml})$ for assays, representing the effective concentration of AgNPs required to produce the effect (increase/decrease) by $50 \%$. nc, not converged.

\begin{tabular}{lrrrrrrrrrr}
\hline & \multicolumn{3}{c}{ AgNP_BSA } & \multicolumn{3}{c}{ AgNP_Chit } & \multicolumn{3}{c}{ AgNP_PVP } & AgNP_NC \\
\cline { 2 - 11 } Assay & 20nm & 50nm & $P$-value & 20nm & 50nm & $P$-value & 20nm & 50nm & $P$-value & 50nm \\
\hline MTT & 11.7 & 58.9 & 0.224 & 10.3 & 125.9 & 0.553 & 14.8 & 37.6 & 0.438 & 40.7 \\
ATP & 28.4 & 114.7 & 0.005 & 93.0 & $>200$ & 0.006 & 66.8 & 104.2 & 0.333 & 182.0 \\
MTP & 23.3 & 114.3 & 0.197 & 14.5 & 24.3 & 0.112 & 56.3 & 109.2 & 0.301 & 137.3 \\
ROS & 77.6 & 31.6 & 0.073 & $>200$ & $>200$ & $<0.001$ & 80.2 & $>200$ & 0.588 & 89.5 \\
TNF- $\alpha$ & 1.1 & 5.0 & 0.156 & 49.9 & 15.1 & 0.002 & $\mathrm{nc}$ & 14.2 & 0.038 & 93.6 \\
\hline
\end{tabular}

Significance when $p<0.05 ; n c$, not converged

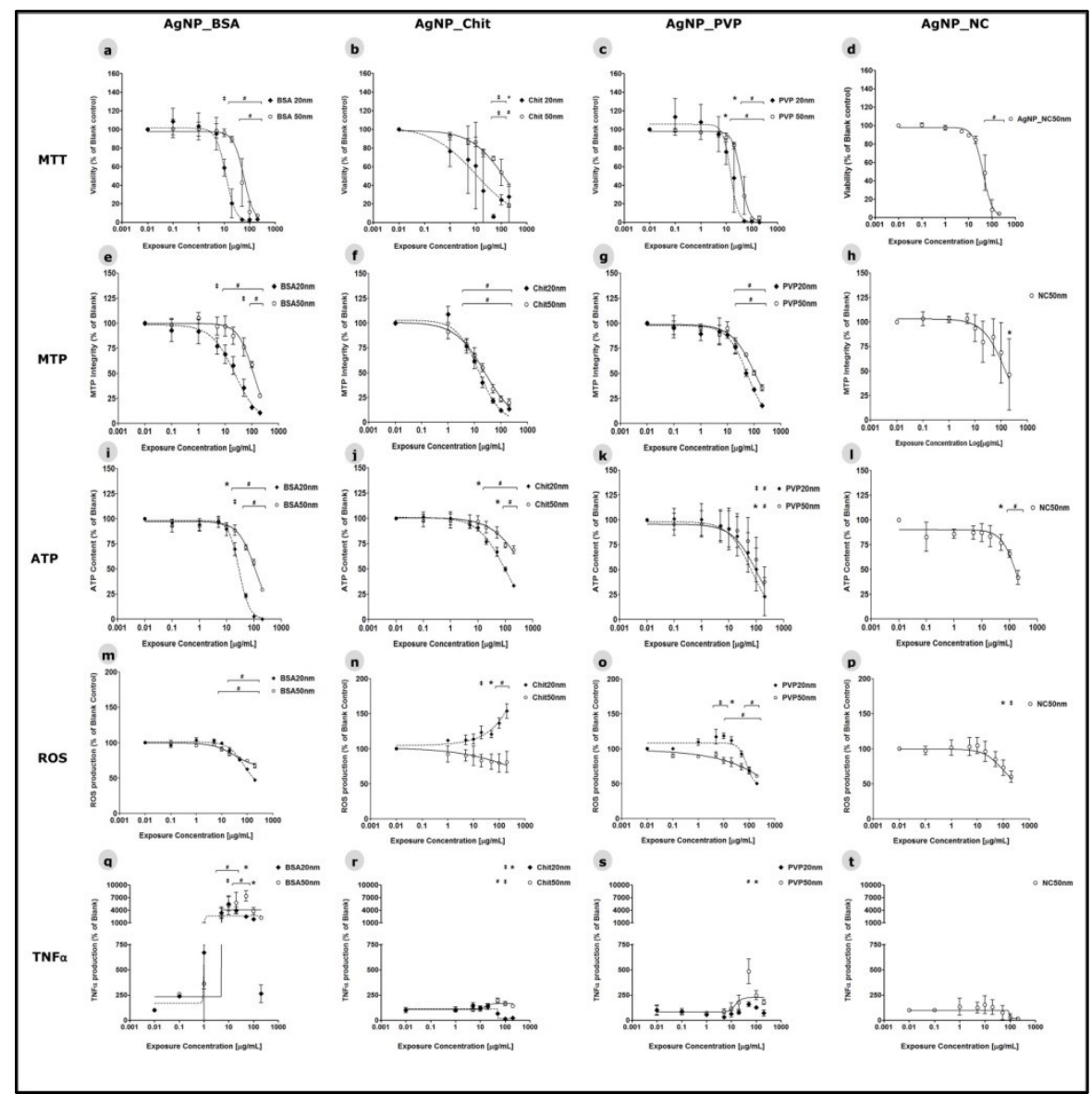

Fig. 2.3 Cytotoxicity of 20 and $50 \mathrm{~nm}$ NPs (AgNP_BSA, AgNP_Chit, AgNP_PVP) and $50 \mathrm{~nm}$ AgNP_NC to mouse monocyte macrophage cells (RAW 264.7 cell line) assessed by MTT $(a-d)$, MTP $(e-h)$ and ATP $(i-l)$ assays; and by assays for reactive oxygen species (ROS) production $(m-p)$ and TNF- $\alpha$ production $(q-t)$. Results are expressed as percentages (mean \pm standard deviation, $n=3$ ) relative to the blank, set at $100 \%$. Dotted lines and filled diamond $\quad(20 \mathrm{~nm})$; solid lines and empty circle "O" $\mathrm{O}^{\prime}(50 \mathrm{~nm})$. Statistical significance compared to control is indicated by * $(p \leq 0.05) ; \neq(p \leq 0.01) ; \#(p \leq 0.001)$. Cytotoxicity (MTT, ATP and MTP assays) showed a similar pattern for all tested AgNPs, with viability decreasing with increasing exposure concentrations and minimal differences between NPs of different sizes. On mechanisms of action (ROS production and TNF- $\alpha$ induction) however, there were effects of NP type and size (ROS production, 3n), while surface coating of AgNPs with BSA 
Results indicated a significant opening of the MTP with increasing AgNP exposure concentration. A slight right-shift of the AgNPs $50 \mathrm{~nm}$ curves was observed, indicating a lesser potency in induction of opening of the MTP by the larger nanoparticles compared to the $20 \mathrm{~nm}$ AgNPs on a mass basis (Fig. 2.3e - h). This difference however was not statistically significant, and $\mathrm{EC}_{50} \mathrm{~s}$ for 20 and $50 \mathrm{~nm}$ sizes were within 1-fold difference for chitosan- and PVP-coated nanoparticles (Table 2.1). The EC 50 for the $50 \mathrm{~nm} \mathrm{AgNP \_ BSA}$ exceeded the highest exposure concentration of $200 \mu \mathrm{g} / \mathrm{ml}$.

Adenosine Triphosphate (ATP) Assay

With increasing exposure concentration, the amount of ATP measured in the cells decreased in a concentration dependent manner, suggesting a loss in viability since ATP is rapidly degraded or lost from the cells as they die [45]. For AgNP_Chit and AgNP_BSA, there was a significant effect of size in addition to exposure concentration, with $p$ values of 0.006 and 0.005 respectively when comparing the $\mathrm{EC}_{50} \mathrm{~S}$ for the respective 20 and 50 $\mathrm{nm}$ particles. There was no effect of size for the AgNP_PVP. Similar to the $50 \mathrm{~nm}$ AgNP_PVP, AgNP_NC (also 50nm, PVP-coated, but negatively charged), ATP was significantly depleted at the highest exposure concentrations, and $\mathrm{EC}_{50}$ values for both types of AgNPs exceeded the highest concentration of exposure (Fig. 2.3i-l; Table 2.1).

Intracellular Reactive Oxygen Species (ROS) generation; $\mathrm{H}_{2}$ DCF-DA Assay

AgNP_Chit $20 \mathrm{~nm}$ were the only nanoparticles observed to increase ROS after $6 \mathrm{~h}$ exposure (Fig. $2.3 \mathrm{~m}$ - p). For these NPs, a 1.5x increase in ROS was observed at the highest exposure concentration (Fig. 2.3n). The "uncharged" AgNP_PVP $20 \mathrm{~nm}$, also showed an initial increase in ROS until $10 \mu \mathrm{g} / \mathrm{ml}$ beyond which the curve plunged downwards. For the 50nm nanoparticles, no increase in ROS was observed for any type of AgNPs tested (Fig. $2.3 \mathrm{~m}-\mathrm{p}$ ). Estimates of the $\mathrm{EC}_{50}$ s indicated lower values for the 20 $\mathrm{nm}$ size AgNPs, and only the AgNP_Chit showed significant differences between the two sizes tested (Fig. 2.3n). Comparing the different $20 \mathrm{~nm} \mathrm{AgNPs,} \mathrm{the} \mathrm{EC}_{50}$ estimated for ROS generation for AgNP_Chit was significantly higher than those of the other types (Fig. 2.3n).

TNF- $\alpha$ induction

AgNP_BSA were most potent in inducing TNF- $\alpha$, presenting marked increase relative to the control (Fig. 2.3q). The other nanoparticle types initially appeared to induce some TNF- $\alpha$, but this dropped below the reference (control) with increasing concentration, coinciding with the onset of cytotoxicity (Fig. $2.3 q-t$ ). A counter-size dependent effect 
with chitosan- and PVP-coated AgNPs can be noted, where the 50nm AgNPs more than the $20 \mathrm{~nm}$ (Fig. 2.3s) show some marginal induction of TNF- $\alpha$. An interesting observation was made with the two different types of PVP-coated AgNPs, where for TNF- $\alpha$ induction they gave different results (Fig. 2.3s and t) even though for all other assays they behaved similarly (Fig. 2.3). Also, there were significant differences in effects produced by the different sizes of AgNP_Chit and AgNP_PVP ( $p=0.002$ and 0.038 respectively), though TNF- $\alpha$ induction was relatively low (1.5 - 2 fold increase) compared to the induction observed with AgNP_BSA (Fig. $2.3 q-\mathrm{t}$ ).

\section{Discussion}

In this present study, we focused on two very important properties - size and surface coating/charge, identified from literature to be important in influencing the outcome of exposure to NPs. Our study showed similar cytotoxicity patterns for all tested AgNPs, differing only at specific modes of action.

\section{NP Synthesis, Dispersion and Characterization}

By varying the reaction parameters (temperature, seeding concentration and amount of precursor added), the desired AgNP size ranges 20 and 50nm were achieved. The average NP sizes as determined by TEM were found to be within expected ranges, and depending on the surface coating used, negative, positive and "neutral" charges were obtained. While coating with BSA and PVP is spontaneous and easy to monitor by the characterization techniques described above, that with chitosan resulted in AgNPs aggregation. This may likely be due to the interaction of the negatively charged citrate AgNP, an intermediate/pre-coated product of AgNPs synthesis, with the positively charged chitosan $[18,46]$. To overcome this effect, a fast mixing of relatively small volumes of AgNPs and an excess amounts of chitosan was used, resulting in a fast coating of the NPS.

Before coating, the particles showed SPR peaks and hydrodynamic sizes in accordance with expected results for the three different sizes [18]. A slight shift in the SPR peak was observed by UV-Vis spectroscopy after incubating the NPs for $24 \mathrm{~h}$ with the respective coating molecules. This shift is related to modifications in the close environment of the NPs and proves the affinity of the BSA, PVP and chitosan molecules for the silver surfaces and their spontaneous association [18]. The shape of the SPR peaks were preserved in both milliQ water and DMEM (Fig. 2.1d - $f$ and $g-i$, respectively), which 
means that the particles were dispersed and stable under these conditions. The DLS measurements in both milliQ water and DMEM however, systematically results in larger sizes than those obtained before lyophilisation. Despite the large hydrodynamic diameter seen in the particles coated with chitosan, we observe well dispersed particles by TEM (Fig. 2.1b).

Dispersed AgNP_Chit formed some aggregates in the suspensions media, and these may have led to an overestimation of the hydrodynamic sizes during the DLS measurements, resulting in rather high NP diameters (Supplementary Table 2.1). Because the DLS operates on Rayleigh's approximation principle of light scattering by particles where the intensity of scattering is proportional to the sixth power of the particle's radius, DLS technique is very sensitive to particle agglomerates and/or any aggregation in NP suspensions [47]. Hence, the occurrence of even minute amounts of agglomerates may skew the results. This aggregation observed with AgNP_Chit for instance, represents a small fraction of the NPs, otherwise the SPR peaks would not be preserved (Fig. 2.1d-i), and it would also be noticeable in the TEM images. Hence, the results indicate the formation of some aggregates but the majority of the Ag-NPs appear to be single NPs, even for AgNP_Chit.

Following dispersion in DMEM, the surface charges changed to negative values in all AgNPs. Positively charged particles were likely coated by negatively charged proteins in the media, and may explain the negative $\zeta$-potentials measured for all AgNPs. Z-potential measurements in a medium like DMEM containing an abundance of charged protein molecules is greatly influenced by the electrostatic interactions in the matrix. This was demonstrated by others $[48,49]$. Similarly, we observed more negative $\zeta$-potentials values (Supplementary Table 2.1) when AgNPs were re-suspended in water, with minimal effect on hydrodynamic sizes regardless of the dispersant used. Lyophilisation of the samples did not result in particles aggregation or surface modifications, and except for AgNP_Chit, they could be easily dispersed in water as TEM images above show (Fig. $2.1 \mathrm{a}-\mathrm{c})$ and DMEM. The SPR peaks and the surface charges were preserved as well.

\section{AgNPs localization and Uptake dynamics}

Uptake of the negatively charged AgNP_BSA was rapid and most significant based on an arbitrary unit (AU) of quantification. Due to agglomeration in the suspension and growth medium, it was not possible to assess uptake of AgNP_Chit by the cells. Supplementary Table S2.2 shows that the mean cellular uptake of AgNP_BSA was twice that of AgNP_PVP at similar exposure concentrations and time, though the uptake efficiency of individual cells does vary a lot. Several cells showed fast uptake, with up to $80 \%$ of the 
AgNPs observed to be taken up within the first 30 min of exposure (not shown). After 2.5 hours however, cytoplasmic fluorescence intensity levels reached a plateau for the different AgNPs tested (Table S2.2). In fact, there was no significant increase in the mean fluorescent intensity in the macrophages after $24 \mathrm{hr}$ exposure (Supplementary Table S2.2). This rapid AgNP uptake indicates that the 6 hours exposure duration used for the assessment of ROS production is sufficient for cells to internalise the AgNPs. With increasing exposure concentrations, the mean $\mathrm{AU}$ plateau value increased nonlinearly for all AgNPs. Fresh re-exposure at the same concentration and for an additional $24 \mathrm{~h}$, did not significantly increase the plateau value either. Even at the lower exposure ranges, it can be seen that the uptake after 2 hours is already reaching a plateau for the different AgNPs (Table S2.2) and may suggests that cells loose their uptake capacity over time.

Cellular vitality was monitored during uptake assays by intercellular dynamics and presence of membrane protrusions (Supplementary Fig. S2.4), the latter being typical for functional macrophages $[50,51]$. Over a period of $48 \mathrm{~h}$, no apparent cell death or abnormalities were observed while visualizing the subcellular bio-distribution of the AgNPs. Subcellular dynamics remained visible during standardized imaging, as well as after $48 \mathrm{~h}$ exposure to $5 \mathrm{\mu g} / \mathrm{ml}$ of $50 \mathrm{~nm}$ AgNP_BSA. The density of membrane protrusions however, slowly decreased over time (2.5 - $24 \mathrm{~h}$, not quantified). Only after prolonged local imaging were loss of membrane protrusions, amorphic membrane blebbing and cell fusion events triggered, indicating photon stress. We also demonstrated the uptake dynamics of AgNP_BSA sticking to a macrophage surface membrane protrusion, and consequently being transported to the cell body within 30 seconds. The time series shows the dynamics of individual vesicles of various sizes in the cytoplasm (Supplementary Fig. S2.5). Both dispersed small vesicles as well as vesicles with clustered accumulated AgNPs, occurred for all AgNPs. We cannot exclude the likelihood that free AgNPs were also present in the cytoplasm. Over time, more clustered vesicles appeared, indicating vesicle fusion. Multiple large endosomes or lysosomes with many AgNPs clustered together were observed, suggesting that uptake was not by diffusion. There are different types of active endocytotic pathways such as receptor mediated endocytosis (clathrin or caveolin mediated) and macropinocytosis, but the current study did not discriminate between those.

Vesicle density varied over the cytoplasmic domain, but no AgNPs were observed in the nucleoplasms (Supplementary Figs. S2.4 and S2.5). The absence of $50 \mathrm{~nm}$ AgNPs in the nuclei was expected since nuclear pores have an effective diameter of $9-10 \mathrm{~nm}$. After 24 hrs loading, cells were still viable and healthy as judged by the dynamics from the cells themselves as well as from the organelles within. The dynamic movements of the AgNPs within membrane domains indicate that accumulation does not imply clustering. 


\section{Effect Assessment}

The smaller $20 \mathrm{~nm}$ AgNPs tend to induce earlier effects than the $50 \mathrm{~nm}$ sizes in almost all assays reported here (Fig. 2.3 and Table 2.1). However, the differences were minimal and for all AgNPs tested, MTT reduction and MTP opening did not differ significantly $(p<0.05)$ between different sizes $(20 \mathrm{~nm}$ vs $50 \mathrm{~nm})$ and surface-coatings or charges. A concentration dependent decrease in MTT reduction was observed, with the 20nm NPs showing lower $\mathrm{EC}_{50}$ values than the $50 \mathrm{~nm}$ NPs (Fig. 2.3 and Table 2.1). AgNP_BSA nanoparticles appear to elicit the most effect. With the exception of AgNP_Chit 50nm where the $\mathrm{EC}_{50}$ exceeded the highest exposure concentration, $\mathrm{EC}_{50}$ s were between 10 and $15 \mu \mathrm{g} / \mathrm{ml}$ and 35 and $40 \mu \mathrm{g} / \mathrm{ml}$ for the $20 \mathrm{~nm}$ and $50 \mathrm{~nm}$ size groups respectively (Table 2.1). The influence of NP size on its ability to induce toxic effects has been demonstrated previously, $[52,53]$ for instance. Our findings partially agree with the proposition that size does matter as could be seen with ATP production, where the 20 $\mathrm{nm}$ AgNPs were more potent than the $50 \mathrm{~nm}$ for both AgNP_BSA and AgNP_Chit (Fig. 2.3i - I; Table 2.1).

ATP assay results indicated a significant decrease at low exposure concentrations of 10 $\mu \mathrm{g} / \mathrm{ml}$, at which the mitochondrial respiratory systems were also impaired (Fig. 2.3). This effect may likely be due to mitochondrial damage [54]. Interestingly and contrary to the cited report in which ATP depletion in the tested cells was observed only after $48 \mathrm{~h}$, ATP was depleted after $24 \mathrm{~h}$ exposure in our current study. The surface coating used for the AgNPs in the cited study was starch, and may have interacted differently with the cells, potentially delaying the onset of toxicity. We found an increased opening of the mitochondrial transition pore with increasing exposure concentration, leading to a rapid change in permeability. This is likely followed by membrane depolarization, release of intra-mitochondrial ions and metabolic intermediates amongst other effects [55]. Normally, the MTP remains closed unless under conditions of stress as found in for instance hypoxia, oxidative stress, and exposure to a calcium ionophore. AgNPs of all sizes and surface coating tested demonstrated ability to cause the MTP to open, leading to the quenching of the signal from the calcein which is now accessible to the $\mathrm{CoCl}_{2}$. In our study however, we could not demonstrate ROS production for most AgNPs tested (Fig. 2.3m-p). Thus, other factors including increased accumulation of intracellular fatty acids and lysophosphatidase, as well as glutathione oxidation [55], may also be responsible for activating MTP opening.

Intracellular ROS generation is an outcome of normal cellular metabolism and these radicals may be cleared by the cell's scavenging processes. Increase in ROS production however, is considered to be an early phase response to toxicants [56], and has been reported as one of the likely mechanisms of toxicity following exposure to AgNPs as well 
as other nanoparticles [57-59]. In this current study, ROS production was only slightly increased with $20 \mathrm{~nm} \mathrm{AgNP \_ Chit} \mathrm{which} \mathrm{showed} \mathrm{a} \mathrm{1.5x} \mathrm{increase} \mathrm{in} \mathrm{ROS} \mathrm{relative} \mathrm{to} \mathrm{the}$ control at the highest exposure concentration (Fig. 2.3n). Also, $20 \mathrm{~nm}$ AgNP_PVP showed an initial increase in ROS, then a decrease as exposure concentration increases. This decrease in ROS production is associated with the onset of cytotoxicity (Fig. 2.3), and perhaps other cytotoxic processes are initiated or progressing faster than ROS generation. For example, the opening of the MTP may lead to partial mitochondrial depolarization, which depending on $\mathrm{Ca}^{2+}$ concentrations, could result in a decrease in ROS production (low $\mathrm{Ca}^{2+}$ ) or an increase (high $\mathrm{Ca}^{2+}$ ) as reported earlier [60].

The initial increase in ROS generation at lower exposure concentrations (Fig. 2.3m-p) agrees with the findings of others where it was suggested that cytotoxic effects were as a result of ROS production, particularly at low exposure concentrations and short incubation times $[31,41,61]$. It may be that the cytotoxic effect of the AgNPs overwhelms the cell's capacity to generate ROS as a response, and rather progresses to cell death following other routes as suggested above. Again, positively charged NPs tend to interact more readily with cells due to the negative cell membrane charges [62]. This may enhance the exposure of cells to positively charged NPs, likely explaining the increased ROS production observed with the $20 \mathrm{~nm}$ positively charged AgNP_Chit (Fig. $2.3 n)$ where there was a significant difference between the two sizes tested $(p<0.001)$. Interestingly, ROS was rather decreased in macrophage cells with increasing exposure concentrations of the $50 \mathrm{~nm}$ size AgNP_Chit, similar to the other AgNP types tested. With increasing exposure concentrations, the resulting distortion in metabolic activity coupled with an open MTP, may eventually lead to ATP depletion and cell death. This process has also been associated with mitochondrial respiratory system impairment following oxidative stress [54]. In this current study, ROS production appears to have been inhibited as AgNPs exposure concentration increases relative to the control. Considering the early onset of cytotoxicity based on MTT, MTP and ATP assay results however, the downward plunge of the ROS curves could result from the inability of injured cells to produce oxidative radicals, since their viability has been impaired.

AgNPs have been reported to cause immunogenic response in cells, characterized by induction of cytokines like TNF- $\alpha$, macrophage inhibitory protein, interleukins, etc. [41, 52]. For the AgNPs tested in this current study, the negatively charged AgNP_BSA showed the most induction with both sizes resulting in an 80-fold increase between exposure concentrations 10 and $50 \mu \mathrm{g} / \mathrm{ml}$. Higher concentrations showed a downward plunge of the curves below the reference (control), coinciding with cytotoxicity (Fig. 2.3a, e, i, and q). There were no significant differences in the effects induced by the different sizes of AgNP_BSA (Fig. 2.3q). Interestingly, even when coated with similar biomolecules, the behaviour of NPs may still differ as can be seen with the $50 \mathrm{~nm}$ PVP- 
coated AgNPs commercially produced (negatively charged) and the synthesised one (uncharged). Although both behaved similarly for all other assays tested, the case was different with TNF- $\alpha$ induction (Figs. 2.3s and t) where AgNP_PVP was a significantly higher TNF- $\alpha$ inducer than AgNP_NC ( $p=0.002)$. This could likely be due to the type of synthesis procedure applied for making not only the nanoparticles $[63,64]$, but also the bioconjugate [18]. The type or composition of the coating agent influences the outcome of exposure, corroborating previous findings [65] where the influence of lignin concentration, incubation temperature and time in the synthesis of AgNPs were assessed. Also, the $\mathrm{pH}$ of the solution during the synthesis was important in determining the surface charge of the NPs, with acidic $\mathrm{pH}$ resulting in negatively charged NPs while basic $\mathrm{pH}$ leads to positively charged NPs. This phenomenon is important not only during synthesis of NPs, but also during exposure [66].

The greater the NP's relative surface area, the greater the potential for reactivity. Since the relative surface area is determined by the particle size, smaller NPs may interact more with the macrophages [10,33] when administered on an equal mass-basis as was done in the current study. Moreover, surface coatings and their interactions with biomolecules can influence dissolution rate of AgNPs $[32,67]$, leading to toxicities. Based on this, one could hypothesize that the synthesized AgNPs tested in this study are quite stable under the experimental conditions reported here. Longer exposure durations of 48- 72 h may likely present different outcomes.

Also, some studies have shown a counter-size dependent effect, e.g. with PVP-coated AgNP [64] where the larger particle produce higher effect. In this present study, this was observed with AgNP_Chit and AgNP_PVP in TNF- $\alpha$ induction assay, with the $50 \mathrm{~nm}$ sizes having lower $\mathrm{EC}_{50}$ values (Table 2.1). For the tested AgNPs in this study, cytotoxicity patterns were similar irrespective of types and size of the AgNPs. Looking at ROS and TNF- $\alpha$ induction on the other hand revealed differences between the different types of AgNPs. This is indicative of varying mechanisms of action involved, corroborating what has been opined by others $[10,33]$. These authors suggested that a combination of different physico-chemical properties of AgNPs is more likely responsible in inducing the observed toxicities, rather than only size or particle dissolution for instance, as the release of ions would be expected to be greater for smaller particles.

\section{Conclusion}

Our study used well established in vitro assays to investigate the influence of the physico-chemical properties of different types of AgNPs systematically synthesized to 
vary the properties of interest. The role of surface coating/charge in influencing TNF- $\alpha$ induction was demonstrated by the negatively charged AgNP_BSA. Effect of size was less prominent under our experimental conditions, showing mostly minimal differences that were not statistically significant. Overall, the negatively charged AgNP_BSA appears to be more potent in inducing adverse effects on the macrophages. The complexity in determining the fate and toxicity of AgNPs (also other NPs) using in vitro or in vivo models is as yet a challenge that needs further evaluation. Live confocal imaging of exposed cells allowed the monitoring of AgNPs uptake dynamics and subcellular cytoplasmic accumulation. A combination of several factors likely play a role in determining the outcome of exposure. These include the processes involved in the NP syntheses, presence and type of coating agents resulting in various physico-chemical properties (size, charge, hydrophobicity, etc.), as well as the toxicity tests models used and end-points studied. This has been observed in earlier reviews [10, 33, 68], and still remains a hindrance for conclusive risk assessment evaluation of AgNPs. Taken together, the results from MTT, ATP and MTP assays shows that adverse effects from exposure to the tested AgNPs were similar irrespective of type or size. However, for ROS and TNF- $\alpha$ induction, we do find significant toxicity differences with variations in the physicochemical properties of the AgNPs tested.

\section{Acknowledgements}

This work was financially supported by NanoNextNL, a micro- and nanotechnology consortium of the Government of The Netherlands and 130 partners; funding was also received from Managing Risks of Nanoparticles, MARINA (EU-FP7, contract CP-FP 263215), and; the Strategic Research Funds titled Novel technologies by the Ministry of Economic Affairs of The Netherlands. Synthesis and characterization of the AgNPs used in this study received support from the QualityNano Project http://www.qualitynano.eu/ which is financed by the European Community Research Infrastructures under the FP7 Capacities Program (Grant No. INFRA-2010-262163).

\section{Supplementary Material}

Supporting material associated with this manuscript is available below, after the reference list.

\section{Declaration of interest}

The authors declare no conflicts of interest. 


\section{$\underline{\text { References }}$}

[1] D. Kennell. Nanotechnology: An Industrial Revolution? Monthly Review MRZine. 2009.

[2] M. R. Gwinn, Vallyathan V. Nanoparticles: health effects--pros and cons. Environ Health Perspect. 2006, 114(12), 1818-1825. doi:10.1289/ehp.8871

[3] C. Peterson. Taking technology to the molecular level. Computer. 2000, 33(1), 46-+. doi: $10.1109 / 2.816268$

[4] S. W. P. Wijnhoven, Oomen A. G., Sips A. J. A. M., Bourgeois F. C., te Dorsthorst G. J. P. M., Kooi M. W., Bakker M. I. Development of an inventory for consumer products containing nanomaterials Final Report RIVM Report 000201006. 2010, 103.

[5] S. W. P. Wijnhoven, Peijnenburg W. J. G. M., Herberts C. A., Hagens W. I., Oomen A. G., Heugens E. H. W., Roszek B., Bisschops J., Gosens I., Van de Meent D., Dekkers S., De Jong W. H., Van Zijverden M., Sips A. J. A. M., Geertsma R. E. Nano-silver - a review of available data and knowledge gaps in human and environmental risk assessment. Nanotoxicology. 2009, 3(2), 109-U178. doi:10.1080/17435390902725914

[6] M. Ahamed, Alsalhi M. S., Siddiqui M. K. Silver nanoparticle applications and human health. Clin Chim Acta. 2010, 411(23-24), 1841-1848. doi:10.1016/j.cca.2010.08.016

[7] A. Haider, Kang I. K. Preparation of Silver Nanoparticles and Their Industrial and Biomedical Applications: A Comprehensive Review. Advances in Materials Science and Engineering. 2015, 2015, 16. doi:10.1155/2015/165257

[8] T. Benn, Cavanagh B., Hristovski K., Posner J. D., Westerhoff P. The Release of Nanosilver from Consumer Products Used in the Home. J Environ Qual. 2010, 39(6), 1875-1882. doi:10.2134/jeq2009.0363

[9] L. Geranio, Heuberger M., Nowack B. The behavior of silver nanotextiles during washing. Environ Sci Technol. 2009, 43(21), 8113-8118. doi:10.1021/es9018332

[10] B. Reidy, Haase A., Luch A., Dawson K. A., Lynch I. Mechanisms of Silver Nanoparticle Release, Transformation and Toxicity: A Critical Review of Current Knowledge and Recommendations for Future Studies and Applications. Materials. 2013, 6(6), 2295-2350. doi:10.3390/ma6062295

[11] M. E. Vance, Kuiken T., Vejerano E. P., McGinnis S. P., Hochella M. F., Jr., Rejeski D., Hull M. S. Nanotechnology in the real world: Redeveloping the nanomaterial consumer products inventory. Beilstein journal of nanotechnology. 2015, 6, 1769-1780. doi:10.3762/bjnano.6.181

[12] G. Franci, Falanga A., Galdiero S., Palomba L., Rai M., Morelli G., Galdiero M. Silver nanoparticles as potential antibacterial agents. Molecules (Basel, Switzerland). 2015, 20(5), 8856-8874. doi:10.3390/molecules20058856

[13] I. S. Hwang, Hwang J. H., Choi H., Kim K. J., Lee D. G. Synergistic effects between silver nanoparticles and antibiotics and the mechanisms involved. J Med Microbiol. 2012, 61(Pt 12), 1719-1726. doi:10.1099/jmm.0.047100-0

[14] S. Prabhu, Poulose E. K. Silver nanoparticles: mechanism of antimicrobial action, synthesis, medical applications, and toxicity effects. International Nano Letters. 2012, 2(1), 32. doi:10.1186/2228-5326-232

[15] S. Silver, Phung L. T. Bacterial heavy metal resistance: new surprises. Annu Rev Microbiol. 1996, 50, 753-789. doi:10.1146/annurev.micro.50.1.753

[16] I. Sondi, Salopek-Sondi B. Silver nanoparticles as antimicrobial agent: a case study on E. coli as a model for Gram-negative bacteria. I Colloid Interface Sci. 2004, 275(1), 177-182. doi:10.1016/j.jcis.2004.02.012

[17] H. H. Lara, Ayala-Nunez N. V., Ixtepan-Turrent L., Rodriguez-Padilla C. Mode of antiviral action of silver nanoparticles against HIV-1. Journal of nanobiotechnology. 2010, 8, 1. doi:10.1186/1477-3155-8-1

[18] N. G. Bastus, Merkoci F., Piella J., Puntes V. Synthesis of Highly Monodisperse Citrate-Stabilized Silver Nanoparticles of up to 200 nm: Kinetic Control and Catalytic Properties. Chem Mater. 2014, 26(9), 2836-2846. doi:10.1021/cm500316k

[19] D. D. Evanoff, Jr., Chumanov G. Synthesis and optical properties of silver nanoparticles and arrays. Chemphyschem. 2005, 6(7), 1221-1231. doi:10.1002/cphc.200500113

[20] M. A. Shenashen, El-Safty S. A., Elshehy E. A. Synthesis, Morphological Control, and Properties of Silver Nanoparticles in Potential Applications. Particle \& Particle Systems Characterization. 2014, 31(3), 293 316. doi:10.1002/ppsc.201300181 
[21] K. M. M. Abou El-Nour, Eftaiha A. a., Al-Warthan A., Ammar R. A. A. Synthesis and applications of silver nanoparticles. Arabian Journal of Chemistry. 2010, 3(3), 135-140. doi:10.1016/j.arabjc.2010.04.008

[22] M. Chanana, Liz-Marzán Luis M. in Nanophotonics 2012, pp. 199.

[23] J. Kreuter. Influence of the surface properties on nanoparticle-mediated transport of drugs to the brain. J Nanosci Nanotechnol. 2004, 4(5), 484-488.

[24] S. I. Roohani-Esfahani, Nouri-Khorasani S., Lu Z., Appleyard R., Zreiqat H. The influence hydroxyapatite nanoparticle shape and size on the properties of biphasic calcium phosphate scaffolds coated with hydroxyapatite-PCL composites. Biomaterials. 2010, 31(21), 5498-5509. doi:10.1016/j.biomaterials.2010.03.058

[25] W. A. Shoults-Wilson, Reinsch B. C., Tsyusko O. V., Bertsch P. M., Lowry G. V., Unrine J. M. Effect of silver nanoparticle surface coating on bioaccumulation and reproductive toxicity in earthworms (Eisenia fetida). Nanotoxicology. 2011, 5(3), 432-444. doi:10.3109/17435390.2010.537382

[26] R. Foldbjerg, Irving E. S., Hayashi Y., Sutherland D. S., Thorsen K., Autrup H., Beer C. Global gene expression profiling of human lung epithelial cells after exposure to nanosilver. Toxicol Sci. 2012, 130(1), 145-157. doi:10.1093/toxsci/kfs225

[27] M. J. van der Ploeg, Handy R. D., Waalewijn-Kool P. L., van den Berg J. H., Herrera Rivera Z. E., Bovenschen J., Molleman B., Baveco J. M., Tromp P., Peters R. J., Koopmans G. F., Rietjens I. M., van den Brink N. W. Effects of silver nanoparticles (NM-300K) on Lumbricus rubellus earthworms and particle characterization in relevant test matrices including soil. Environ Toxicol Chem. 2014, 33(4), 743-752. doi:10.1002/etc.2487

[28] M. J. van der Ploeg, van den Berg J. H., Bhattacharjee S., de Haan L. H., Ershov D. S., Fokkink R. G., Zuilhof H., Rietjens I. M., van den Brink N. W. In vitro nanoparticle toxicity to rat alveolar cells and coelomocytes from the earthworm Lumbricus rubellus. Nanotoxicology. 2014, 8(1), $28-37$. doi:10.3109/17435390.2012.744857

[29] S. J. Yu, Yin Y. G., Liu J. F. Silver nanoparticles in the environment. Environmental science Processes \& impacts. 2013, 15(1), 78-92. doi:10.1039/c2em30595j

[30] C. M. Powers, Badireddy A. R., Ryde I. T., Seidler F. J., Slotkin T. A. Silver nanoparticles compromise neurodevelopment in PC12 cells: critical contributions of silver ion, particle size, coating, and composition. Environ Health Perspect. 2011, 119(1), 37-44. doi:10.1289/ehp.1002337

[31] A. K. Suresh, Pelletier D. A., Wang W., Morrell-Falvey J. L., Gu B., Doktycz M. J. Cytotoxicity induced by engineered silver nanocrystallites is dependent on surface coatings and cell types. Langmuir. 2012, 28(5), 2727-2735. doi:10.1021/la2042058

[32] X. Yang, Gondikas A. P., Marinakos S. M., Auffan M., Liu J., Hsu-Kim H., Meyer J. N. Mechanism of silver nanoparticle toxicity is dependent on dissolved silver and surface coating in Caenorhabditis elegans. Environ Sci Technol. 2012, 46(2), 1119-1127. doi:10.1021/es202417t

[33] H. J. Johnston, Hutchison G., Christensen F. M., Peters S., Hankin S., Stone V. A review of the in vivo and in vitro toxicity of silver and gold particulates: particle attributes and biological mechanisms responsible for the observed toxicity. Crit Rev Toxicol. 2010, 40(4), 328-346. doi:10.3109/10408440903453074

[34] H. M. Braakhuis, Kloet S. K., Kezic S., Kuper F., Park M. V., Bellmann S., van der Zande M., Le Gac S., Krystek P., Peters R. J., Rietjens I. M., Bouwmeester H. Progress and future of in vitro models to study translocation of nanoparticles. Arch Toxicol. 2015, 89(9), 1469-1495. doi:10.1007/s00204-015-1518-5

[35] M. Connolly, Fernandez-Cruz M. L., Quesada-Garcia A., Alte L., Segner H., Navas J. M. Comparative Cytotoxicity Study of Silver Nanoparticles (AgNPs) in a Variety of Rainbow Trout Cell Lines (RTL-W1, RTH-149, RTG-2) and Primary Hepatocytes. Int J Environ Res Public Health. 2015, 12(5), 5386-5405. doi:10.3390/ijerph120505386

[36] G. Cornelis, Hund-Rinke K., Kuhlbusch T., Van den Brink N., Nickel C. Fate and Bioavailability of Engineered Nanoparticles in Soils: A Review. Crit Rev Environ Sci Technol. 2014, 44(24), 2720-2764. doi:10.1080/10643389.2013.829767

[37] R. Landsiedel, Fabian E., Ma-Hock L., van Ravenzwaay B., Wohlleben W., Wiench K., Oesch F. Toxico/biokinetics of nanomaterials. Arch Toxicol. 2012, 86(7), 1021-1060. doi:10.1007/s00204-012-0858-7

[38] S. Makama, Peters R., Undas A., van den Brink N. W. A novel method for the quantification, characterisation and speciation of silver nanoparticles in earthworms exposed in soil. Environmental Chemistry. 2015, 12(6), 643-651. doi:10.1071/EN15006 
[39] R. Nadesh, Narayanan D., P R. S., Vadakumpully S., Mony U., Koyakkutty M., Nair S. V., Menon D. Hematotoxicological analysis of surface-modified and -unmodified chitosan nanoparticles. J Biomed Mater Res A. 2013, 101(10), 2957-2966. doi:10.1002/jbm.a.34591

[40] L. M. Zhao, Shi L. E., Zhang Z. L., Chen J. M., Shi D. D., Yang J., Tang Z. X. Preparation and Application of Chitosan Nanoparticles and Nanofibers. Brazilian Journal of Chemical Engineering. 2011, 28(3), 353362.

[41] C. Carlson, Hussain S. M., Schrand A. M., Braydich-Stolle L. K., Hess K. L., Jones R. L., Schlager J. J. Unique cellular interaction of silver nanoparticles: size-dependent generation of reactive oxygen species. J Phys Chem B. 2008, 112(43), 13608-13619. doi:10.1021/jp712087m

[42] L. Shang, Nienhaus K., Jiang X., Yang L., Landfester K., Mailander V., Simmet T., Nienhaus G. U. Nanoparticle interactions with live cells: Quantitative fluorescence microscopy of nanoparticle size effects. Beilstein journal of nanotechnology. 2014, 5, 2388-2397. doi:10.3762/bjnano.5.248

[43] L. Shang, Nienhaus K., Nienhaus G. U. Engineered nanoparticles interacting with cells: size matters. Journal of nanobiotechnology. 2014, 12, 5. doi:10.1186/1477-3155-12-5

[44] S. K. Kloet, Walczak A. P., Louisse J., van den Berg H. H., Bouwmeester H., Tromp P., Fokkink R. G., Rietjens I. M. Translocation of positively and negatively charged polystyrene nanoparticles in an in vitro placental model. Toxicol In Vitro. 2015, 29(7), 1701-1710. doi:10.1016/j.tiv.2015.07.003

[45] Y. Eguchi, Shimizu S., Tsujimoto Y. Intracellular ATP levels determine cell death fate by apoptosis or necrosis. Cancer Res. 1997, 57(10), 1835-1840.

[46] D. P. Gnanadhas, Ben Thomas M., Thomas R., Raichur A. M., Chakravortty D. Interaction of silver nanoparticles with serum proteins affects their antimicrobial activity in vivo. Antimicrob Agents Chemother. 2013, 57(10), 4945-4955. doi:10.1128/AAC.00152-13

[47] H. Hagendorfer, Kaegi R., Parlinska M., Sinnet B., Ludwig C., Ulrich A. Characterization of silver nanoparticle products using asymmetric flow field flow fractionation with a multidetector approach--a comparison to transmission electron microscopy and batch dynamic light scattering. Anal Chem. 2012, 84(6), 2678-2685. doi:10.1021/ac202641d

[48] J. H. Shannahan, Lai X., Ke P. C., Podila R., Brown J. M., Witzmann F. A. Silver nanoparticle protein corona composition in cell culture media. PLoS One. 2013, 8(9), e74001. doi:10.1371/journal.pone.0074001

[49] M. Pavlin, Bregar V. Stability of nanoparticle suspension in different biologically relevant media. Digest Journal of Nanomaterials and Biostructures. 2012, 7(4), 1389-1400.

[50] G. Venter, Oerlemans F. T. J. J., Wijers M., Willemse M., Fransen J. A. M., Wieringa B. Glucose Controls Morphodynamics of LPS-Stimulated Macrophages. PLoS One. 2014, 9(5), e96786.

[51] L. Vonna, Wiedemann A., Aepfelbacher M., Sackmann E. Micromechanics of filopodia mediated capture of pathogens by macrophages. Eur Biophys J. 2007, 36(2), 145-151. doi:10.1007/s00249-0060118-y

[52] M. V. Park, Neigh A. M., Vermeulen J. P., de la Fonteyne L. J., Verharen H. W., Briede J. J., van Loveren H., de Jong W. H. The effect of particle size on the cytotoxicity, inflammation, developmental toxicity and genotoxicity of silver nanoparticles. Biomaterials. 2011, 32(36), 9810-9817. doi:10.1016/j.biomaterials.2011.08.085

[53] W. Liu, Wu Y., Wang C., Li H. C., Wang T., Liao C. Y., Cui L., Zhou Q. F., Yan B., Jiang G. B. Impact of silver nanoparticles on human cells: effect of particle size. Nanotoxicology. 2010, 4(3), 319-330. doi:10.3109/17435390.2010.483745

[54] P. V. AshaRani, Low Kah Mun G., Hande M. P., Valiyaveettil S. Cytotoxicity and genotoxicity of silver nanoparticles in human cells. ACS nano. 2009, 3(2), 279-290. doi:10.1021/nn800596w

[55] J. J. Lemasters, Nieminen A. L., Qian T., Trost L. C., Elmore S. P., Nishimura Y., Crowe R. A., Cascio W. E., Bradham C. A., Brenner D. A., Herman B. The mitochondrial permeability transition in cell death: a common mechanism in necrosis, apoptosis and autophagy. Biochim Biophys Acta. 1998, 1366(1-2), 177-196. doi:http://dx.doi.org/10.1016/S0005-2728(98)00112-1

[56] A. Aranda, Sequedo L., Tolosa L., Quintas G., Burello E., Castell J. V., Gombau L. Dichloro-dihydrofluorescein diacetate (DCFH-DA) assay: a quantitative method for oxidative stress assessment of nanoparticle-treated cells. Toxicol In Vitro. 2013, 27(2), 954-963. doi:10.1016/j.tiv.2013.01.016

[57] Y. S. Jeong, Oh W. K., Kim S., Jang J. Cellular uptake, cytotoxicity, and ROS generation with silica/conducting polymer core/shell nanospheres. Biomaterials. 2011, 32(29), 7217-7225. doi:10.1016/j.biomaterials.2011.06.020 
[58] P. V. Asharani, Lianwu Y., Gong Z., Valiyaveettil S. Comparison of the toxicity of silver, gold and platinum nanoparticles in developing zebrafish embryos. Nanotoxicology. 2011, 5(1), 43-54. doi:10.3109/17435390.2010.489207

[59] R. Foldbjerg, Dang D. A., Autrup H. Cytotoxicity and genotoxicity of silver nanoparticles in the human lung cancer cell line, A549. Arch Toxicol. 2011, 85(7), 743-750. doi:10.1007/s00204-010-0545-5

[60] O. V. Akopova, Kolchynskayia L. Y., Nosar V. Y., Smyrnov A. N., Malisheva M. K., Man'kovskaia Y. N., Sahach $V$. F. The effect of permeability transition pore opening on reactive oxygen species production in rat brain mitochondria. Ukrains'kyi biokhimichnyi zhurnal (1999). 2011, 83(6), 46-55.

[61] R. Foldbjerg, Jiang X., Miclăuş T., Chen C., Autrup H., Beer C. Silver nanoparticles - wolves in sheep's clothing? Toxicol Res. 2015, 4(3), 563-575. doi:10.1039/c4tx00110a

[62] N. Nafee, Schneider M., Schaefer U. F., Lehr C. M. Relevance of the colloidal stability of chitosan/PLGA nanoparticles on their cytotoxicity profile. Int J Pharm. 2009, 381(2), 130-139. doi:10.1016/j.ijpharm.2009.04.049

[63] M. E. Samberg, Orndorff P. E., Monteiro-Riviere N. A. Antibacterial efficacy of silver nanoparticles of different sizes, surface conditions and synthesis methods. Nanotoxicology. 2011, 5(2), 244-253. doi:10.3109/17435390.2010.525669

[64] C. M. Powers, Badireddy A. R., Ryde I. T., Seidler F. J., Slotkin T. A. Silver Nanoparticles Compromise Neurodevelopment in PC12 Cells: Critical Contributions of Silver lon, Particle Size, Coating, and Composition. Environ Health Perspect. 2011, 119(1), 37-44. doi:10.1289/ehp.1002337

[65] K. R. Aadil, Barapatre A., Meena A. S., Jha H. Hydrogen peroxide sensing and cytotoxicity activity of Acacia lignin stabilized silver nanoparticles. Int J Biol Macromol. 2016, 82, 39-47. doi:10.1016/j.ijbiomac.2015.09.072

[66] X. Deng, Wang Y., Zhang F., Yin Z., Hu Q., Xiao X., Zhou Z., Wu Y., Sheng W., Zeng Y. Acidic pH-induced charge-reversal nanoparticles for accelerated endosomal escape and enhanced microRNA modulation in cancer cells. Chem Commun (Camb). 2016, 52(15), 3243-3246. doi:10.1039/c5cc10396g

[67] H. J. Yen, Hsu S. H., Tsai C. L. Cytotoxicity and immunological response of gold and silver nanoparticles of different sizes. Small (Weinheim an der Bergstrasse, Germany). 2009, 5(13), 1553-1561. doi:10.1002/smll.200900126

[68] R. de Lima, Seabra A. B., Duran N. Silver nanoparticles: a brief review of cytotoxicity and genotoxicity of chemically and biogenically synthesized nanoparticles. J Appl Toxicol. 2012, 32(11), 867-879. doi:10.1002/jat.2780 


\section{Supplementary Material}

\section{Materials and methods}

\section{Synthesis of AgNPs}

MilliQ water (18.2 M $/ \mathrm{cm})$ was used for all AgNPs syntheses. Colloidal, dispersed AgNPs of two different sizes (20 and $50 \mathrm{~nm}$ ) were prepared separately, following a kinetically controlled seeded-growth method previously reported [1] with slight modifications. The approach is based on the reduction of silver nitrate $\left(\mathrm{AgNO}_{3}\right)$ in the presence of two competing reducing agents, tannic acid (TA) and trisodium citrate hexahydrate (SC) at $100^{\circ} \mathrm{C}$. In order to produce large amounts (grams) of AgNPs in the present study, a $10 \mathrm{~L}$ batch reactor was used and the concentration of the $\mathrm{AgNO}_{3}$ (AgNP precursor) was increased by a factor of 10 , while all other parameters remained the same with that reported previously [1].

First, early nucleated AgNP seeds were formed by injecting $5 \mathrm{~mL}$ of $2 \mathrm{M} \mathrm{AgNO}_{3}$ into a boiling solution containing SC $(5 \mathrm{mM})$ and TA $(0.025-0.075 \mathrm{mM})$, under continuous vigorous stirring. These seeds were further grown to the desired sizes by injecting more of the silver precursor dropwise to avoid formation of new seeds. During the growth phase of the seeds, the temperature of the solution was reduced to $90 \circ \mathrm{C}$, while slowly adding up to $15 \mathrm{ml}$ of the $2 \mathrm{M} \mathrm{AgNO}_{3}$ into the reactor. Under these conditions, $10-20 \mathrm{~L}$ of a stable, highly monodisperse and colloidal AgNP solutions (0.25-0.5 g/L or $2.3-4.6$ $\mathrm{mM}$ ) were produced for each size.

The solutions containing the synthesized AgNPs were concentrated to about $6 \%$ of their original volume by ultrafiltration using a tangential flow fractionation (TFF) system (KrosFlo ${ }^{\circledR}$ Research II TFF Systems, Spectrum Laboratories Inc.). Negative, positive, and neutral AgNPs were obtained by subsequently mixing about $200 \mathrm{ml}$ each of the concentrated solutions of AgNPs with either $0.01 \mathrm{mM}$ bovine serum albumin (BSA), 0.08 $\mathrm{mM}$ chitosan (Chit) or $0.05 \mathrm{mM}$ polyvinylpyrrolidone (PVP) to generate negative AgNP_BSA, positive AgNP_Chit and neutral AgNP_PVP, respectively. To prevent corrosion and facilitate easy transport, the AgNPs were lyophilized, layered over with argon and kept under dark conditions until use. Thus, six different AgNPs were synthesized consisting of three types based on surface coating/charge, each at two different sizes.

An aqueous suspension of a negatively charged $50 \mathrm{~nm}$ PVP-coated AgNP (AgNP_NC) was obtained from NanoComposix (San Diego, USA) and included in this study for comparison with the synthesized AgNPs. Based on the manufacturer's information, the 
AgNP_NC is reported to have mean core- and hydrodynamic diameters of $54.8 \pm 10 \mathrm{~nm}$ and $72 \pm 14.4 \mathrm{~nm}$ respectively. The stock suspension of the pristine AgNP has a mass concentration of $5.0 \mathrm{mg} \mathrm{Ag} / \mathrm{ml}$, and a particle number concentration of $5.2 \times 10^{12}$ particles/ml. The surface area was $9.8 \mathrm{~m}^{2} / \mathrm{g}$ while surface charge (zeta-potential) was $37.8 \mathrm{mV}$. The DLS and zeta potential in both milliQ and DMEM were confirmed in our laboratory, and details have been presented earlier [2].

\section{AgNP Characterization}

Prior to exposure experiments, pristine AgNPs were dispersed in Dulbecco's modified Eagle's medium, DMEM (Invitrogen Breda, The Netherlands), as well as milliQ water and characterized by transmission electron microscopy (TEM), UV-Vis spectroscopy, dynamic light scattering (DLS), and zeta-potential measurements ( $\zeta$-potential). A combination of different techniques was used to characterize the AgNPs and to monitor proper coating of NPs surfaces and their stability in the different media.

TEM images were acquired with a FEI Magellane 400L SEM electron microscope operating at scanning TEM (STEM) mode and low accelerating voltage (20 kV) and a JEOL 1010 electron microscope operating at an accelerating voltage of $80 \mathrm{kV}$. Samples for TEM were prepared by drop casting onto carbon-coated TEM grids. The grids were left to dry at room temperature. Images were acquired in different parts of the grid at different magnifications. More than 250 particles were computer-analysed and measured to calculate the size distribution of each type of AgNPs.

UV-Vis spectroscopy is a very common and well-known analytical technique $[3,4]$, and a Shimadzu UV-2400 spectrophotometer was used to measure the localized surface Plasmon resonance (SPR) peak. Here, $1 \mathrm{ml}$ of the AgNPs suspension was placed in a cuvette and the spectrum (UV-Vis) acquired in the $300-800 \mathrm{~nm}$ range. Several metallic NPs, such as gold and silver, exhibit a characteristic absorbance maximum in the visible range (SPR peak). This characteristic wavelength is highly sensitive to the ENP size, surface modifications and aggregation and thus a useful tool to characterize the state of the NPs in solution.

Hydrodynamic sizes of the AgNPs were estimated by DLS, while particle surface charges ( $\zeta$-pot) were measured using Malvern Zetasizer Nano ZS (Malvern Instruments, UK). A light source wavelength of $532 \mathrm{~nm}$ and a fixed scattering angle of $173^{\circ}$ were set for DLS measurement. AgNPs suspensions $(1 \mathrm{ml})$ were dispensed in a cuvette and the instrument was set with the specific parameters of refractive index and absorption coefficient of the material and the viscosity of the solvent. All measurements were 
conducted at least three times. AgNPs characterization was done in both milliQ water and DMEM since the exposure was carried out in the cell culture medium.

\section{Effect assessment:}

\section{MTT Assay:}

At the end of the $24 \mathrm{hr}$ exposure, $10 \mu \mathrm{L}$ of the tetrazolium salt 3-(4,5-dimethylthiazol-2yl)-2,5-diphenyltetrazolium bromide (MTT) solution at $5 \mathrm{mg} / \mathrm{ml}$ in PBS was added to each well and incubated under the same conditions as described above for $90 \mathrm{~min}$. The exposure medium containing MTT was then removed and $100 \mu \mathrm{L}$ pure dimethyl sulfoxide, DMSO (Acros Organics, Geel, Belgium) was added to solubilize the crystals of formazan salts. This was followed by shaking the plates in the dark for $10 \mathrm{~min}$. The dissolved formazan produces a purple colour and its absorbance was measured at 562 nm spectrophotometrically [5].

Adenosine Triphosphate (ATP) Assay

A bioluminescent somatic cell assay kit (Sigma-Aldrich ${ }^{\circledR}$, St Louis, MO, USA), was used to determine the ATP content of mouse macrophage cells after exposure. In this assay, ATP is the limiting reagent and the light emitted and measured is proportional to the amount of ATP released from the cells, which is in turn determined by the number of viable cells present. Exposure to AgNPs for this assay was conducted in white 96-well plates (Packard White plates, Perkin-Elmer ${ }^{\circ}$ ), using DMEM without phenol red, but with penicillin/streptomycin (Gibco $\left.{ }^{\circ}\right) \quad 1 \%(\mathrm{v} / \mathrm{v})$. After exposure, cell culture media was removed and replaced with $25 \mu \mathrm{L}$ each of fresh medium and somatic cell ATP releasing agent from the kit. The plates were placed on a shaker for 10 mins in the dark, then transferred to the luminometer where the ATP assay working mix (containing luciferin, luciferase and $\mathrm{MgSO}_{4}$ ) was added automatically to each well before measuring the luminescence.

\section{Mitochondrial permeability Transition-Pore (MTP) Assay}

A commercial kit from Molecular Probes (Leiden, NL), MitoProbe ${ }^{\mathrm{TM}}$ Transition Pore (MTP) Assay kit (M34153) was used for this assay. After exposure, the culture medium in all wells was replaced by Hank's balanced salt solution, HBSS (Invitrogen, Breda NL), containing calcium but without serum, phenol red or $\mathrm{NaHCO}_{3}$. Cells in all except the positive control wells were loaded with a mixture of cobalt chloride $\left(\mathrm{CoCl}_{2}\right)$ and an acetoxymethyl ester form of a calcein dye (Calcein AM) at $1 \mathrm{mM}$ and $5 \mu \mathrm{M}$ respectively, followed by a $15 \mathrm{~min}$ incubation. Calcein AM passively diffuses into cells and 
accumulates in the mitochondria, where it is de-esterified by intracellular esterases to liberate the highly fluorescent calcein. Subsequently, calcein does not cross the mitochondrial or plasma membrane in appreciable amounts over short periods of time, making it conducive for selective marking of the mitochondria [6]. This selectivity is achieved by adding $\mathrm{CoCl}_{2}$ which quenches the cytosolic fluorescence, while mitochondrial fluorescence is maintained in intact mitochondria since $\mathrm{CoCl}_{2}$ is incapable of entering this organelle.

The cells in positive control wells were treated during this loading step with an ionophore (ionomycin) at $10 \mu \mathrm{M}$, which was dissolved in the Calcein $\mathrm{AM} / \mathrm{CoCl}_{2}$ mixture above. Ionomycin allows the entry of $\mathrm{Ca}^{2+}$ into the mitochondria in excess, triggering the opening of the mitochondrial permeability transition pore (MTP). This results in the loss of calcein fluorescence into the cytosolic compartment where it is quenched. Fluorescence was measured at $\lambda 485 / 530 \mathrm{~nm}$. The relative intensity of fluorescence compared to the blank control $(100 \%)$ is indicative of the integrity of mitochondrial permeability transition pore after exposure to AgNPs.

Intracellular Reactive Oxygen Species (ROS) generation; DCF-Assay

The generation of intracellular ROS was determined using a slightly modified method earlier described [7]. Cells were preloaded with $20 \mu \mathrm{M} \mathrm{2',7'-dichlorodihydrofluorescein}$ diacetate ( $\mathrm{H}_{2}$ DCF-DA) dye from Molecular probes (Carlsbad, CA, USA) for $45 \mathrm{~min}$. After this, the medium containing the dye was removed and the cells were exposed to the various concentrations of AgNPs for 6h. Fluorescence was measured at $\lambda 485 / 520 \mathrm{~nm}$ at the end of the exposure and expressed as percentages relative to the blank control (optimal healthy cell ROS value set at 100\%).

\section{TNF- $\alpha$ induction}

At the end of the $24 \mathrm{~h}$ exposure period, $80 \mu \mathrm{L}$ supernatants containing cytokines were collected from each well and stored at $-80^{\circ} \mathrm{C}$ until analysed for secreted levels of TNF- $\alpha$ by a solid phase sandwich Enzyme-Linked Immuno-Sorbent Assay (ELISA) using a Mouse TNF- $\alpha$ ELISA kit (Invitrogen ${ }^{\mathrm{TM}}$, Paisley, UK). Analysis was conducted according to the manufacturer's instruction, running calibration and other standards for every $12 \times 8$ strip-well plates. Briefly, samples were added onto microtiter strip wells pre-coated with specific monoclonal TNF- $\alpha$ antibodies. Next, a polyclonal biotinylated conjugate was added as a second antibody and the plates were incubated at room temperature for 90 min. During incubation, any secreted TNF- $\alpha$ in the samples will form a sandwich with these antibodies. After a washing step to get rid of excess antibodies, streptavidinperoxidase was added to complete the four-member sandwich by binding to the biotinylated antibody during another 30 min incubation. A wash step gets rid of all 
unbound enzymes before a substrate solution is added to be acted upon by the bound enzymes to produce a colour whose optical density at $450 \mathrm{~nm}$ is directly proportional to the concentration of TNF- $\alpha$ in the sample.

\section{Controls of Assays}

\section{Effect assessment controls}

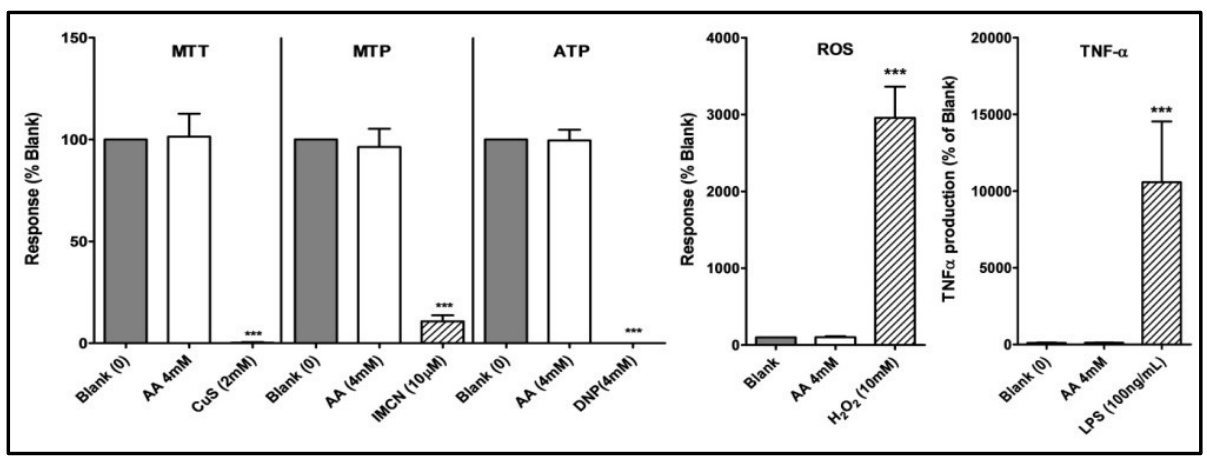

Fig. S2.1 Controls for effect assessment experiments - MTT (cell viability), MTP opening, ATP production, ROS generation, and TNF- $\alpha$ induction assays. Results are expressed as percentages (mean \pm standard deviation, $n=3$ ) relative to the blank, set at $100 \%$. Statistical significance compared to control is indicated by $* * *$ ( $p \leq$ 0.001). Positive controls showed clear effects, while exposure to acetic acid (AA) at $4 \mathrm{mM}$ was similar to the blank control. DNP, dinitrophenol; IMCN, ionomycin, LPS, lipopolysaccharide;

\section{AgNPs Characterization}

Table S2.1 AgNP characterization showing the hydrodynamic sizes of AgNPs measured by dynamic light scattering (DLS), surface Plasmon Resonance (SPR) peaks and ל-potentials. Measurements were performed before and after surface coating of NPS

\begin{tabular}{|c|c|c|c|c|c|c|c|}
\hline & & \multicolumn{2}{|c|}{ BSA (negative) } & \multicolumn{2}{|c|}{ Chitosan (positive) } & \multicolumn{2}{|c|}{ PVP (neutral) } \\
\hline & & $20 \mathrm{~nm}$ & $50 \mathrm{~nm}$ & $20 \mathrm{~nm}$ & $50 \mathrm{~nm}$ & $20 \mathrm{~nm}$ & $50 \mathrm{~nm}$ \\
\hline TEM Size & $\mathrm{nm}$ & $19.5 \pm 5.4$ & $51.1 \pm 5.7$ & $18.2 \pm 5.1$ & $51.9 \pm 6.4$ & $24.0 \pm 4.6$ & $51.0 \pm 6.1$ \\
\hline $\operatorname{Size}^{\mathrm{a}}$ & $\mathrm{nm}$ & $41.5 \pm 1.3$ & $65.3 \pm 0.1$ & $247.8 \pm 2.1$ & $241.8 \pm 5.1$ & $46.8 \pm 0.1$ & $68.4 \pm 0.6$ \\
\hline $\operatorname{Size}^{b}$ & $\mathrm{~nm}$ & $69.9 \pm 3.2$ & $86.3 \pm 1.0$ & $209.1 \pm 1.4$ & $234.5 \pm 1.2$ & $63.0 \pm 0.2$ & $71.3 \pm 2.0$ \\
\hline$\zeta$-potential $^{\mathrm{a}}$ & meV & $-29.0 \pm 2.0$ & $-37.0 \pm 2.0$ & $+8.0 \pm 2.0$ & $+7.0 \pm 1.0$ & $-16 \pm 2.0$ & $-25.0 \pm 2.0$ \\
\hline$\zeta$-potential $^{\text {b }}$ & meV & $-25.5 \pm 2.3$ & $-23.0 \pm 2.0$ & $-16.4 \pm 2.3$ & $-21.3 \pm 1.4$ & $-16.2 \pm 2.3$ & $-19.3 \pm 0.7$ \\
\hline UV-vis SPR peaks ${ }^{c}$ & $\mathrm{~nm}$ & 405 & 441 & 405 & 441 & 405 & 441 \\
\hline UV-vis SPR peaks ${ }^{a}$ & $\mathrm{~nm}$ & 413 & 448 & 413 & 449 & 408 & 443 \\
\hline UV-vis SPR peaks ${ }^{b}$ & $\mathrm{~nm}$ & 412 & 447 & 414 & 450 & 408 & 444 \\
\hline
\end{tabular}




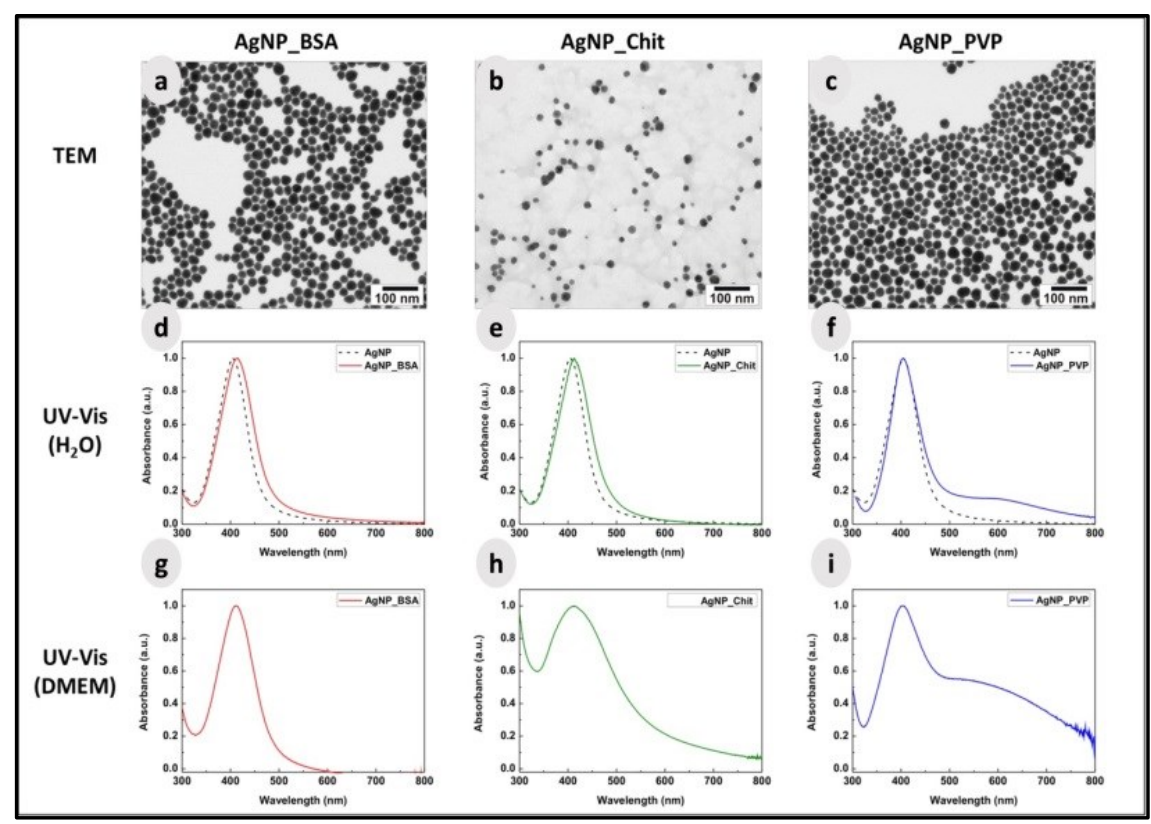

Fig. S2.2 AgNPs characterization results for $20 \mathrm{~nm}$ size group. TEM images $(a-c)$ of re-suspended AgNPs showing quasispherical particles within the expected size ranges, with overall average diameter of $20.6 \pm 5.0 \mathrm{~nm}$. UV-Vis also shows SPR peaks within the expected wavelength range $300-600 \mathrm{~nm}$ both in milliQ water and in cell culture medium ( $d-f$ and $g-i$, respectively). The UV-Vis SPR curves of coated and non-coated AgNPs nicely overlaps $(d-f)$, with the SPR curves of the coated NPs exhibiting a red-shift indicative of the effect of AgNPs coating. When AgNP_Chit and AgNP_PVP were diluted in Dulbecco's modified Eagle's medium (DMEM), some agglomerations appear to set in as indicated by the changes in the SPR curves (Fig.

S2.2e-f compared with S2.2h-i)

\section{Confocal localization and uptake dynamics of AgNPs}

RAW 264.7 cells were seeded in a glass bottom 8-well $\mu$-Slides (Ibidi $\mathrm{GmbH}$, Martinsried, Germany) at a density of $5 \times 10^{5}$ cells $/ \mathrm{ml}$ growth medium, and incubated at $37^{\circ} \mathrm{C}$ in humidified air (plus 5\% $\mathrm{CO}_{2}$ ) to attain 80\% adherent confluency. AgNPs exposures were performed only with the $50 \mathrm{~nm}$ AgNP_BSA and AgNP_PVP at $0.1-5 \mu \mathrm{g} / \mathrm{ml}$, and characterized after 2.5 and 24 hours of exposure. The exposure was carried out immediately before microscopic measurements.

Imaging was done on a Confocal Laser Scanning LSM 510-META on an Axiovert 200M microscope (Carl Zeiss, Jena, Germany) equipped with a 40x/1.3 Oil DIC Plan Neofluar or $63 x / 1.4$ Oil DIC Plan Apochromat objective. Localizations were obtained with optical $x y$ planes of 1.0 um depth ( $\mathrm{z}$ ) in adhered cells with $40 \%$ of a $1 \mathrm{~mW} 543 \mathrm{~nm}$ diode laser 
excitation using LP560 and standardised zoom and exposures (scan speed 6) and gain settings (839) for all acquisitions. By screening the fluorescence spectra of AgNPs after excitation by a $488 \mathrm{~nm}, 514 \mathrm{~nm}$ or $543 \mathrm{~nm}$ laser with a multi array of detectors in the META channel, it appeared that the $543 \mathrm{~nm}$ absorption and strong LP560 fluorescence provided the most sensitive and specific configuration to be used for imaging. Controls and exposed cells were imaged in the same way, with no background signal in the controls. Uptake dynamics were obtained by image acquisitions in time series over 2.5 and $24 \mathrm{~h}$ periods. Images were similarly processed with Zeiss ZEN software and ImageJ v.1.49o (Rasband, W.S., ImageJ, U. S. National Institutes of Health, Bethesda, Maryland, USA, http://imagej.nih.gov/ij/, 1997-2015).

In this study, AgNPs taken up by macrophages could be excited with $40 \%$ of a $1 \mathrm{~mW} 543$ $\mathrm{nm}$ laser and detected with a long pass (LP) $560 \mathrm{~nm}$ filter. Using a multi-detector array (i.e. the META detector in lambda channel mode of a Zeiss LSM510-M), emission wavelengths that could induce the most bright fluorescence were analysed. Base on this, the most sensitive channel mode imaging configuration, without any auto fluorescent signal from the cells was chosen. To obtain sensitive and specific detection of AgNPs, several laser/filter configurations were tested, and signals obtained were most bright at $543 \mathrm{~nm}$. A multi-detector array (560-750 nm) showed that emission photons induced after $543 \mathrm{~nm}$ excitation, originated from 560-600 nm emissions ( $\approx 80 \%$ of output) decreasing towards higher wavelengths. Since macrophage intrinsic fluorescence was not detected with these settings, we used a channel mode with 560 LP detection to localize the AgNPs. Due to the relatively slow point scanning speed, the AgNPs were best detected during and after cellular uptake since reduced dynamics increases signal detection. A dose dependent signal increase was observed (Table S2.2, Fig. S2.3) with different AgNPs tested, similar to earlier reports [8].

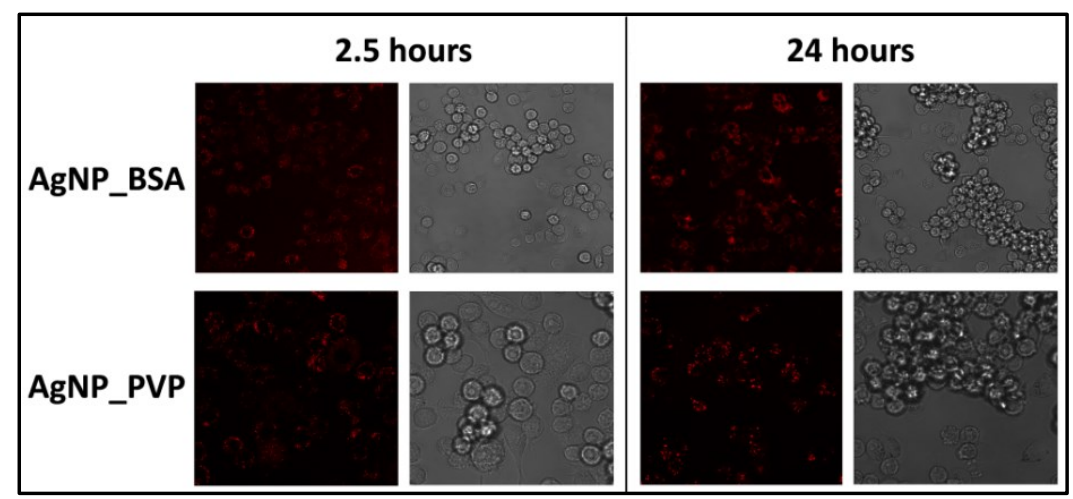

Fig. S2.3 Confocal microscopic images of AgNP uptake observed in RAW264.7 macrophage cells after 2.5 and $24 \mathrm{~h}$ exposure to $5 \mathrm{mg} / \mathrm{ml}$ AgNPs. Upper row: AgNP_BSA; lower row: AgNP_PVP. Left column 2.5 hours of exposure; Right column 24 hours of exposure. Left panes: signals from AgNPs; Right panes: bright-field micrographs of the same field. Size of all squares: BSA: $225^{*} 225 \mu \mathrm{m}$; PVP: $112.5^{*} 112.5 \mu \mathrm{m}$ 
Table S2.2 Uptake of different types of AgNPs by RAW264.7 cells exposed for 2.5 and 24 hours to different concentrations of AgNPs

\begin{tabular}{ccccc}
\hline $\begin{array}{c}\text { Concentration } \mu \mathrm{g} / \mathrm{ml} \\
\text { /Duration }\end{array}$ & \multicolumn{2}{c}{ AgNP_BSA } & \multicolumn{2}{c}{ AgNP_PVP } \\
\hline 0.1 & $\mathbf{2 . 5} \mathrm{h}$ & $\mathbf{2 4 h}$ & $\mathbf{2 . 5} \mathrm{h}$ & $\mathbf{2 4} \mathrm{h}$ \\
0.5 & $12.2 \pm 3.4$ & $10.6 \pm 1.6$ & $6.5 \pm 1.6$ & $6.3 \pm 1.1$ \\
1 & n.m. & n.m. & $7.7 \pm 1.1$ & $6.5 \pm 0.5$ \\
5 & $9.8 \pm 1.5$ & $10.9 \pm 1.3$ & $8.7 \pm 1.6$ & $6.3 \pm 1.3$ \\
\hline
\end{tabular}

n.m., not measured

The fluorescence signals correlating to the AgNPs were quantified based on mean pixel intensity of fields of view of representative cytoplasmic domains (Fig. S2.3 and S2.4), and were expressed as arbitrary units (AU). At identical exposures as well as imaging and processing conditions, these fluorescence intensity values reflect uptake of the different AgNPs by macrophage cells. To allow AgNP uptake comparisons, quantifications of cytoplasmic dense regions from randomly selected cells with similar cellular confluency (70 - 80\%) and $z$-depths were made (Fig. S2.3). The selection of representative cytoplasm dense regions was based on the visual images. This selection was then applied to the fluorescence signal, and the $A U$ quantified. In this way, regions analysed were selected based on the occurrence of cytoplasm, without the bias of occurrence of silver signal. Based on the AUs estimated, the uptake of the negatively charged AgNP_BSA was rapid and most significant. Due to agglomeration in the suspension and growth medium, it was not possible to assess the uptake of AgNP_Chit and will not be discussed further. The cellular uptake of AgNP_BSA was twice that of AgNP_PVP at similar exposure concentrations and time (Table S2.2), although the uptake efficiency of individual cells does vary a lot. 


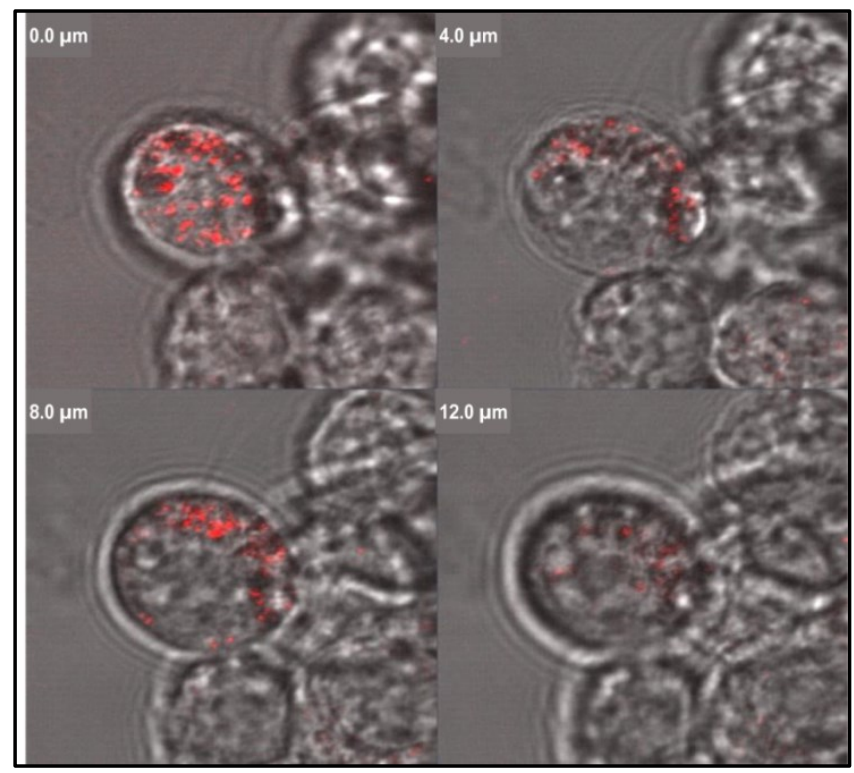

Fig. S2.4 A subset of a $z$-series of a $15 \mu \mathrm{m}$ diameter macrophage with AgNPs clusters in red throughout the cytoplasm, excluding the nucleus. Cells were exposed for 22 hrs with negatively charged AgNP_NC. Images display $1 \mu \mathrm{m}$ optical slices of AgNP fluorescence as overlay on a (non-confocal) transmission image

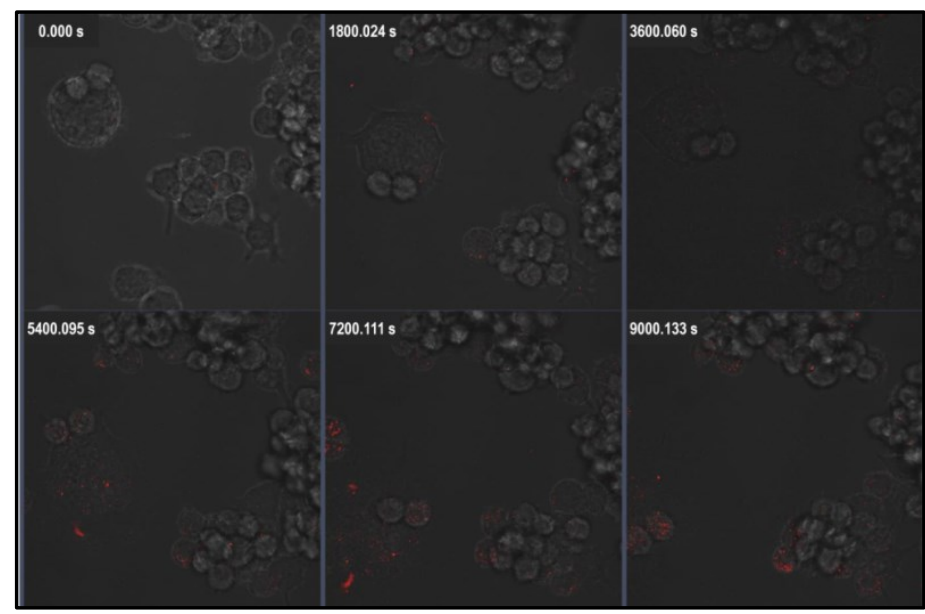

Fig. S2.5 Frames of a time series of macrophages imaged in $t z$ intervals for 2.5 hrs during exposure to $5 \mu \mathrm{M}$

AgNP_BSA. Maximal intensity z-projections were made of optical sections in the 7-14 $\mu \mathrm{m}$ midrange, representing the maximal FL signal of individual time-points. Note cells move in $x y$ plane over time $(0-9000 \mathrm{sec})$ 


\section{References}

[1] N. G. Bastus, Merkoci F., Piella J., Puntes V. Synthesis of Highly Monodisperse Citrate-Stabilized Silver Nanoparticles of up to 200 nm: Kinetic Control and Catalytic Properties. Chem Mater. 2014, 26(9), 2836-2846. doi:10.1021/cm500316k

[2] S. Makama, Peters R., Undas A., van den Brink N. W. A novel method for the quantification, characterisation and speciation of silver nanoparticles in earthworms exposed in soil. Environmental Chemistry. 2015, 12(6), 643-651. doi:10.1071/EN15006

[3] D. D. Evanoff, Jr., Chumanov G. Synthesis and optical properties of silver nanoparticles and arrays. Chemphyschem. 2005, 6(7), 1221-1231. doi:10.1002/cphc.200500113

[4] Y. L. Pan. Detection and characterization of biological and other organic-carbon aerosol particles in atmosphere using fluorescence. J Quant Spectrosc Ra. 2015, 150, 12-35. doi:10.1016/j.jqsrt.2014.06.007

[5] S. K. Kloet, Walczak A. P., Louisse J., van den Berg H. H., Bouwmeester H., Tromp P., Fokkink R. G., Rietjens I. M. Translocation of positively and negatively charged polystyrene nanoparticles in an in vitro placental model. Toxicol In Vitro. 2015, 29(7), 1701-1710. doi:10.1016/j.tiv.2015.07.003

[6] C. Martel, Huynh le H., Garnier A., Ventura-Clapier R., Brenner C. Inhibition of the Mitochondrial Permeability Transition for Cytoprotection: Direct versus Indirect Mechanisms. Biochem Res Int. 2012, 2012, 213403. doi:10.1155/2012/213403

[7] S. M. Hussain, Javorina A. K., Schrand A. M., Duhart H. M., Ali S. F., Schlager J. J. The interaction of manganese nanoparticles with PC-12 cells induces dopamine depletion. Toxicol Sci. 2006, 92(2), 456463. doi:10.1093/toxsci/kfl020

[8] R. M. Zucker, Daniel K. M., Massaro E. J., Karafas S. J., Degn L. L., Boyes W. K. Detection of silver nanoparticles in cells by flow cytometry using light scatter and far-red fluorescence. Cytometry Part $A$. 2013, 83(10), 962-972. doi:10.1002/cyto.a.22342 




\title{
Chapter 3
}

\section{A novel method for the quantification, characterisation and speciation of silver nanoparticles in earthworms exposed in soil}

\author{
Based on: \\ A novel method for the quantification, characterisation and speciation of silver \\ nanoparticles in earthworms exposed in soil \\ Sunday Makama, Ruud Peters, Anna Undas and Nico W. van den Brink
}

Environmental Chemistry (2015) 12, 643-651 


\section{Abstract}

Currently, metal engineered nanoparticles (ENPs) in tissues are generally quantified based on total concentrations after acid digestion of samples. Electron microscopy has also been used for non-quantitative characterisation of NPs in situ, and can be enhanced with tissue-processing methods that can extract NPs with minimal destruction. For a proper risk assessment, it is essential to quantify and characterise the ENPs in both exposure media and organisms. For this, we developed a method using a combination of enzymatic tissue processing, followed by single particle inductively coupled plasmamass spectrometry (sp-ICP-MS) to characterise and quantify AgNPs in tissues of earthworms after in vivo exposure in soil to $50 \mathrm{~nm} A g N P s$ or $\mathrm{AgNO}_{3}$. Tissue concentration of $\mathrm{Ag}$ in worms exposed to $250 \mathrm{mg} \mathrm{AgNP} / \mathrm{kg}$ soil (dry weight) was $0.502 \pm 0.219 \mathrm{mg} / \mathrm{kg}$ (dry weight) reflecting a bioaccumulation factor of 0.002 . In both AgNP- and $\mathrm{AgNO}_{3}$-treated groups, the metal-rich granule fraction contained the highest Ag concentrations (77 and $64 \%$ respectively). Total Ag contained in the earthworm tissue of the $\mathrm{AgNP}$ - and $\mathrm{AgNO}_{3}$-treated groups comprised $\sim 34$ and $<5 \%$ particulate $\mathrm{Ag}$ respectively. Average particle size of AgNPs extracted from tissues was consistent with exposure material (44 v. $43 \mathrm{~nm}$ respectively). High resolution field-emission gun scanning electron microscopy in combination with energy-dispersive X-ray (FEGSEM/EDX) identified individual AgNPs in tissue extracts with corresponding spectral elemental peaks, providing further evidence of tissue particle uptake and composition.

Keywords: accumulation, enzymatic digestion, particle characterisation, sp-ICP-MS, tissue concentration.

Environmental context: Increasing production and application of engineered nanoparticles has led to an increased potential for their environmental release, raising ecotoxicological concerns. To appropriately characterise the fate, effects and risks of engineered nanoparticles in environmental systems, methods are essential to characterise nanoparticles in complex biological matrices. This study reports a method that extracts nanoparticles from tissues of organisms, enabling their detection, quantification and characterisation. 


\section{Introduction}

Nanotechnology has sustained its growth [1], finding many uses with a potential for opening even newer frontiers. Discovery of new applications and increase in use of this technology mean an attendant increased potential for environmental release. Concerns about the potential environmental impact of engineered nanoparticles (ENPs) have therefore attracted the attention of researchers and other stakeholders in society. ENPs are defined by their minute size, which is in the range of 1 to $100 \mathrm{~nm}$. The small particle size and increased surface area of ENPs, coupled with 'engineered' physicochemical properties resulting from, for example, surface coating or functionality, charge or hydrophobicity, lead to potential new behaviours and environmental fate and effects that can be markedly different from those of conventional chemicals [2-4]. The persistent uncertainty surrounding the potential risks associated with ENPs, though a common problem inherent with emerging technologies [5], has made current global risk assessment and management of ENPs difficult.

Nanoecotoxicology research has received considerable attention within the last decade and investigations targeting bioaccumulation and effects of nanoparticles (NPs) on organisms and environmental systems have increased [6-15]. To understand the fate of ENPs and their potential hazards to the environment, analytical tools for both quantification and characterisation are essential [16-19]. Such tools should aim to not only quantify the amount of NPs present in the tissue of exposed organisms, but also characterise the properties of the NPs. Measuring accumulation of ENPs in complex matrices (both biological and environmental), however, presents new challenges due to the interactions between the matrix and the ENPs.

Critical reviews of the analyses of ENPs in complex matrices concluded that lack of adequate techniques for quantification in complex environmental and biological matrices has hampered the advances made in the study of the environmental fate, transport and ecotoxicological effects of these materials [20,21]. Several available analytical tools employed in other science disciplines may be adapted and applied to the analysis of ENPs and have extensively been reviewed [17,21,22]. The processes necessary for the extraction of the particles for observation (characterisation) and quantification currently available, however, have the inherent potential to change the physicochemical properties of the ENPs, thus introducing artefacts [18]. The development of techniques for extraction, clean-up, separation and sample storage that introduce minimal artefacts and assist the characterisation of ENPs has been identified as an important research need [21]. 
Some studies report separating and extracting ENPs from the tissues of exposed organisms using chemical digestion steps or tissue digestion with enzymes $[23,24]$. In chemical digestion, the target metal NPs are dissolved by acids and total tissue burden is measured. This is limited to only quantifying total tissue metal concentration, at the same time the particle form cannot be determined. Recently, alkaline digestion using tetramethylammonium hydroxide (TMAH) was used to extract ENPs from tissues of earthworms, after which the ENPs were characterised by single-particle inductively coupled plasma-mass spectrometry (sp-ICP-MS) [6]. The use of strong alkalis like TMAH, however, can potentially alter the particle properties, in addition to being potentially very hazardous for the person performing the procedure.

The use of enzyme digestion for NP extraction and characterisation has also been reported. An example is a novel method involving enzymatic tissue lysis and sucrose cushion gradient centrifugation for NP elution [23]. This method was used to isolate $\mathrm{SiO}_{2}$ particles from rat liver and lung samples, and more importantly, distinguish between nano- and submicrometre-sized particles using sedimentation field-flow fractionation (SdFFF). Similar enzyme extraction methods have also been reported by others [25]. Common in these studies, however, is the use of direct tissue-spiking of ENPs, which does not adequately reflect real biological uptake. No studies are known to the present authors where in vivo-exposed organisms have been analysed using the approach proposed in the present study.

In the current study, a novel approach is presented in which silver NPs can be characterised and quantified in tissues from earthworms exposed in vivo. To our knowledge, this is the first attempt to perform such characterisation and quantification in an in vivo-exposed soil invertebrate species. Subcellular fractionation of tissues to investigate likely association of AgNPs with the cellular fraction containing metallothionein (MT) of the red earthworm (Lumbricus rubellus) was also explored and is presented for the first time to the best of our knowledge.

\section{Materials and methods}

\section{Experimental design}

All chemicals used were analytical grade, and unless where otherwise stated chemicals, reagents and enzymes were from Sigma-Aldrich Chemie B.V. (Zwijndrecht, Netherlands). All glassware was first washed in $21 \% \mathrm{HNO}_{3}$ overnight and rinsed three times in milliQ water $(18.2 \mathrm{M} \Omega / \mathrm{cm})$, then allowed to dry in a fume hood overnight before use. The experimental design was developed in our laboratory [26] and is described briefly here. 
During a 28-day exposure period, earthworms at a density of five individuals per experimental unit and in triplicate were exposed through soil to AgNPs (250 mg Ag/kg soil) and $\mathrm{AgNO}_{3}(15 \mathrm{mg} \mathrm{Ag} / \mathrm{kg}$ soil dry weight, DW). Control groups received the spiking and moisturising media without $\mathrm{AgNPs}$ or $\mathrm{AgNO}_{3}$. On termination of exposure, earthworms were collected and tissues analysed for both ionic and particulate $\mathrm{Ag}$ as further elaborated below.

\section{Primary AgNP Characterization}

Silver NPs of $50 \mathrm{~nm}$ were commercially obtained from NanoComposix (San Diego, CA) as an aqueous suspension. The NPs were polyvinyl pyrrolidone (PVP)-coated, with reported mean core and hydrodynamic diameters of $54.8 \pm 10$ and $72 \pm 14.4 \mathrm{~nm}$ respectively. The stock suspension of the primary AgNPs has a mass concentration of $4.73 \mathrm{mg} \mathrm{Ag} / \mathrm{ml}$, and a particle number concentration of $5.2 \times 10^{12}$ particles $/ \mathrm{ml}$. The particles were reported to have a surface area of $9.8 \mathrm{~m}^{2} / \mathrm{g}$ and zeta potential of $-37.8 \mathrm{mV}$. Prior to exposure experiments, primary AgNP suspensions in both soil extract and milliQ water were characterised by dynamic light scattering (DLS) and zeta potential measurement (Malvern Zetasizer 3000, Malvern Instruments, Malvern, UK). Particle size distributions were also ascertained by sp-ICP-MS [25]. In addition, primary particles were examined by high-resolution field-emission gun scanning electron microscopy in combination with energy-dispersive X-ray analysis (FEG-SEM/EDX) [27]. These methods will be discussed briefly later since full details have been provided elsewhere $[25,27]$.

\section{Earthworms}

Earthworms (Lumbricus rubellus) were obtained from an uncontaminated site in the Netherlands (Nijkerkerveen) and used in the current study. Clitellated earthworms, having no gross lesions and weighing between 1 and $2.5 \mathrm{~g}$ live weight were selected and placed in uncontaminated soil to acclimatise for 2 weeks under constant conditions (24h light, $15^{\circ} \mathrm{C}, 61 \%$ relative humidity) in a climate-controlled room.

\section{Soil preparation and exposure experiment}

Soil of $\mathrm{pH} 5.1$ and $3.8 \%$ organic matter content was obtained from a reference experimental organic farm (Proefboerderij Kooijenburg, Marwijksoord, Netherlands), airdried and stored in polythene bags at room temperature until use. One week before 
exposure experiments, the soil was sifted through a $5 \mathrm{~mm}$ sieve, then weighed out into glass jars with lids (650 g dry weight per unit). Soil extract used for the resuspension of NPs and dissolution of $\mathrm{AgNO}_{3}$ was made from the same soil [26]. This method of preparing AgNP suspensions ensures well-dispersed suspension with minimal formation of agglomerates $[13,26]$. Nominal exposure concentrations of $250 \mathrm{mg} \mathrm{Ag} / \mathrm{kg}$ soil (for $\mathrm{AgNP}$ ) and $15 \mathrm{mg} \mathrm{Ag} / \mathrm{kg}$ soil (for $\mathrm{AgNO}_{3}$ ) were selected based on earlier research in our laboratory to ensure measurable and similar tissue concentrations among treatments. Control units received only equivalent quantities of soil extract and de-ionised water (Millipore; resistivity $18.2 \mathrm{M} \Omega / \mathrm{cm}$ ), to bring the final moisture content by weight of the soil to $17.5 \%$. Concentrations were prepared in triplicate. Soil spiking and moisturisation were done $24 \mathrm{~h}$ before adding the earthworms, during which moisturised soil was kept under the same condition as above to equilibrate.

Acclimatised earthworms were weighed and distributed randomly in the experimental unit at a density of five per jar (three jars per treatment; $n=3$ ). Dried alder leaves (Alnus glutinosa), from an uncontaminated location (Vossemeerdijk, Dronten, Netherlands), were provided weekly for feed ad libitum. All jars were placed in the climate-controlled room for the 28-day exposure study under the same climate-controlled conditions as above.

\section{Tissue NP Quantification and Characterization:}

Sample preparation and processing:

At the end of the 28-day exposure period, live earthworms were counted, collected, weighed, placed in glass Petri dishes with moistened filter paper (Whatman filter number 597, Fisher Scientific, Pittsburgh, PA) and incubated for $48 \mathrm{~h}$ to facilitate gutemptying. Worms were kept under the same condition as during exposure. A period of $48 \mathrm{~h}$ of depuration was chosen because although up to $98 \%$ gut depuration has been reported to be achieved by earthworms in $6 \mathrm{~h} \mathrm{[28],} \mathrm{large} \mathrm{oligochaetes} \mathrm{like} \mathrm{members} \mathrm{of}$ the family Lumbricidae may require a longer time [29]. After depuration, earthworms were washed with demineralised water, patted dry with absorbent paper and snapfrozen in liquid nitrogen. Samples were preserved at $-80^{\circ} \mathrm{C}$ before further analysis. Before analysis, earthworm tissues were ground to powder in liquid nitrogen using a mortar and pestle, pooling two individuals per experimental unit. 
The technique described here is an adaptation of a novel enzyme digestion method reported by Deering et al. [23], combined with differential centrifugation as a modification for tissue fractionation and subcellular compartmentalisation [30-33]. A schematic diagram illustrating the steps in the methodology is provided in the Supplementary material (Fig. S3.1). All enzymes and chemicals used, unless otherwise stated, were purchased from Sigma-Aldrich.

Powdered tissue was dispersed in a low-salt buffer (20 mM 4-(2hydroxyethyl)piperazine-1-ethanesulfonic acid (HEPES), pH 7.9, 25 \% glycerol, $1.5 \mathrm{mM}$ $\mathrm{MgCl}_{2}, 0.02 \mathrm{M} \mathrm{KCl}, 0.2 \mathrm{mM}$ ethylene diamine tetra acetic acid (EDTA), $0.2 \mathrm{mM}$ phenylmethylsulfonyl fluoride and $0.5 \mathrm{mM}$ dithiothreitol) at $333 \mathrm{mg} / \mathrm{ml}$. Samples were homogenised using a Teflon-glass homogeniser (Potter-Elvehjem, Fisher Scientific) at $900 \mathrm{rpm}$ for several passes. Homogenates were fractionated by differential centrifugation into three subcellular fractions to assess compartmentalisation of AgNPs in tissues. For fractionation, the homogenates were centrifuged at $1450 \mathrm{~g}$ for $15 \mathrm{~min}$ at $4{ }^{\circ} \mathrm{C}$, after which the supernatant was collected. This is the protein fraction including MT and cytosol with intact cell organelles (fraction F1). The pellet was digested in $1 \mathrm{~N} \mathrm{NaOH}$

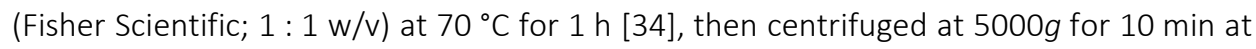
$4{ }^{\circ} \mathrm{C}$ to obtain the cell debris fraction (supernatant) and metal-rich granules (pellet) fractions (fractions 2 and 3 respectively) [32,35].

All fractions were enzymatically digested in two steps. The first step used $500 \mu \mathrm{L}$ of collagenase $(10 \mathrm{mg} / \mathrm{ml})$ and $1.5 \mathrm{ml}$ of hyaluronidase (300 enzyme units $(U) / \mathrm{ml}$, $90 \mu \mathrm{g} / \mathrm{ml}$ equivalent) in an overnight incubation ( $18 \mathrm{~h}$ ) at $37^{\circ} \mathrm{C}$ with shaking. In the second step, $500 \mu \mathrm{L}$ of proteinase $\mathrm{K}(1 \mathrm{mg} / \mathrm{ml})$ was added and the sample incubated for $2 \mathrm{~h}$ at $65^{\circ} \mathrm{C}$. After cooling down to room temperature, the digests were layered over 3 $\mathrm{ml}$ of saturated sucrose cushion (130\%) in a $15 \mathrm{ml}$ centrifuge tube, and centrifuged at $21000 \mathrm{~g}$ for $25 \mathrm{~min}$ (Eppendorf North America, Westbury, NY). Extracted particles in the suspension were spun into the sucrose cushion and collect at the bottom of the tube. The entire non-sucrose portion was removed and the upper $2 \mathrm{ml}$ sucrose portion pipetted out leaving an $\sim 1 \mathrm{ml}$ portion containing the AgNPs. These were resuspended in $3 \mathrm{ml}$ of $0.1 \% \mathrm{FL}-70$ (Fischer Scientific, NJ) and vortex-mixed vigorously. Ethanol (Merck $\mathrm{KGaA}$, Darmstadt, Germany) was used at $75 \%$ for the final wash step (1:1; v/v) and the mixture centrifuged as above. The ethanol-washed NPs were resuspended in $0.1 \% \mathrm{FL}-70$ (Fisher Scientific) with $0.01 \%$ sodium azide (Acros Organics BVBA, Geel, Belgium), brought to a final volume of $10 \mathrm{ml}$ and placed in a table-top ultrasonic bath (Sonicor, Distrilab, Leusden, Netherlands) with a $50-\mathrm{Hz}$ cycle for $10 \mathrm{~min}$. Of the processed 
samples, $1 \mathrm{ml}$ was analysed for total Ag body concentrations by ICP-MS, and $5 \mathrm{ml}$ was used for sp-ICP-MS.

Inductively-coupled plasma - mass spectrometry (ICP-MS)

To quantify total Ag concentrations, samples were digested in aqua regia. Briefly, $1 \mathrm{ml}$ subsamples of the final eluted particles from all enzyme digested fractions were aciddigested with $0.5 \mathrm{ml}$ of $65 \% \mathrm{HNO}_{3}$ and $1.5 \mathrm{ml}$ of $37 \% \mathrm{HCl}$, with incubation in a water bath for $30 \mathrm{~min}$ at $60{ }^{\circ} \mathrm{C}$. Following dilution, ICP-MS was employed for measuring total $\mathrm{Ag}$ in the acid-digested samples. The ICP-MS analysis was conducted using a Thermo $\mathrm{X}$ Series 2 ICP-MS equipped with an autosampler and a conical glass concentric nebuliser and operated at a radio frequency power of $1400 \mathrm{~W}$. Data acquisition was performed in the selected ion mode at the $\mathrm{m} / \mathrm{z}$ ratio of 107 characteristic for silver. Quantification was based on ionic silver standards diluted in the same acidic matrix. The detection limit for total Ag concentration using the described procedure for ICP-MS is $50 \mu \mathrm{g} / \mathrm{kg}$ (DW) tissue.

Single particle (sp)-ICP-MS

Sp-ICP-MS measurements were performed according to Peters et al. [25]. A Thermo Scientific $X$ Series 2 ICP-MS equipped with a conical glass concentric nebuliser and a quartz impact bead spray chamber was used in the current study. The ICP-MS was operated at a forward power of $1400 \mathrm{~W}$; gas flow settings: plasma, $13 \mathrm{~L} / \mathrm{min}$; nebuliser, $1.1 \mathrm{~L} / \mathrm{min}$; and auxiliary, $0.7 \mathrm{~L} / \mathrm{min}$. Using the integrated peristaltic pump, the sample flow rate to the nebuliser was set at $0.5 \mathrm{ml} / \mathrm{min}$. Data acquisition was carried out using the Thermo PlasmaLab software in time-resolved analysis (TRA) mode. Dwell time was set at $3 \mathrm{~ms}$ with total acquisition time of $60 \mathrm{~s}$ per measurement. The sample series contained system blank controls (Milli-Q water) and $50 \mathrm{ng} / \mathrm{L} 60-\mathrm{nm}$ AuNP standard to determine the nebulisation efficiency; ionic silver standards in a concentration range of 0.1-10 $\mu \mathrm{g} / \mathrm{L}$ for calibration, and the diluted sample suspensions from the enzyme digestion, including method blanks and matrix-matched recovery standards; a processed blank sample to which the analyte is added just before the instrumental analyses. Massbased concentrations were calculated from the determined particle number concentrations [25]. The detection limit for the sp-ICP-MS analyses was $1 \mu \mathrm{g} / \mathrm{kg}$ DW. 
High resolution Field Emission Gun scanning electron microscopy in combination with Energy dispersive $X$-ray analysis (FEG-SEM/EDX)

Droplets of $25 \mu \mathrm{l}$ of samples were deposited on nickel-coated polycarbonate filters. To evaporate moisture, the filters were placed under a hot lamp at $40{ }^{\circ} \mathrm{C}$. Samples were analysed with FEG-SEM/EDX [27] using a Tescan MIRA-LMH FEG-SEM operated at an accelerating voltage of $15 \mathrm{kV}, 10-\mathrm{mm}$ working distance and spot size of $5 \mathrm{~nm}$. EDX spectrometry utilised a Bruker AXS spectrometer. This was equipped with a Quantax 800 workstation and an XFlash 4010 detector with an active area of $10 \mathrm{~mm}^{2}$ and super-light element window, achieving X-ray detection of elements higher on the periodic table than borium ( $Z>5$ ). The spectral resolution of the detector is $123 \mathrm{eV}$ at $\mathrm{Mn} \mathrm{K \alpha}$ (10 kilo counts per second, kcps), to achieve full width at half of the maximum (FWHM). To ensure detection of both single particles and agglomerates, three different magnifications (10 000x, $25000 \times$ and $50000 \times$ ) were systematically applied. On particle recognition, an X-ray spectrum was acquired and analysed.

\section{Results}

\section{Primary AgNP Characterization}

AgNPs had an average hydrodynamic size of $60.3 \pm 1.1 \mathrm{~nm}$ and were negatively charged $(-51.2 \pm 0.9 \mathrm{mV})$ when suspended in milliQ water. Hydrodynamic size was $53.3 \pm 0.1 \mathrm{~nm}$ and zeta potential was $-24.5 \pm 0.2 \mathrm{mV}$ for suspensions prepared in soil extract. These results are similar to the manufacturer's information, where hydrodynamic size was $72 \mathrm{~nm}$ and zeta potential $-37.8 \mathrm{mV}$ (both in ultrapure water). The primary particle size determined by sp-ICP-MS of the AgNP suspension in milliQ water was on average $43 \mathrm{~nm}$ (Fig. 3.1A). A SEM micrograph of primary AgNP suspensions shows Ag particles with a particle diameter of $\sim 50 \mathrm{~nm}$, and spectral analysis of the EDX shows appropriate $\mathrm{Ag}$ peaks in the spectrum (Fig. 3.2). 


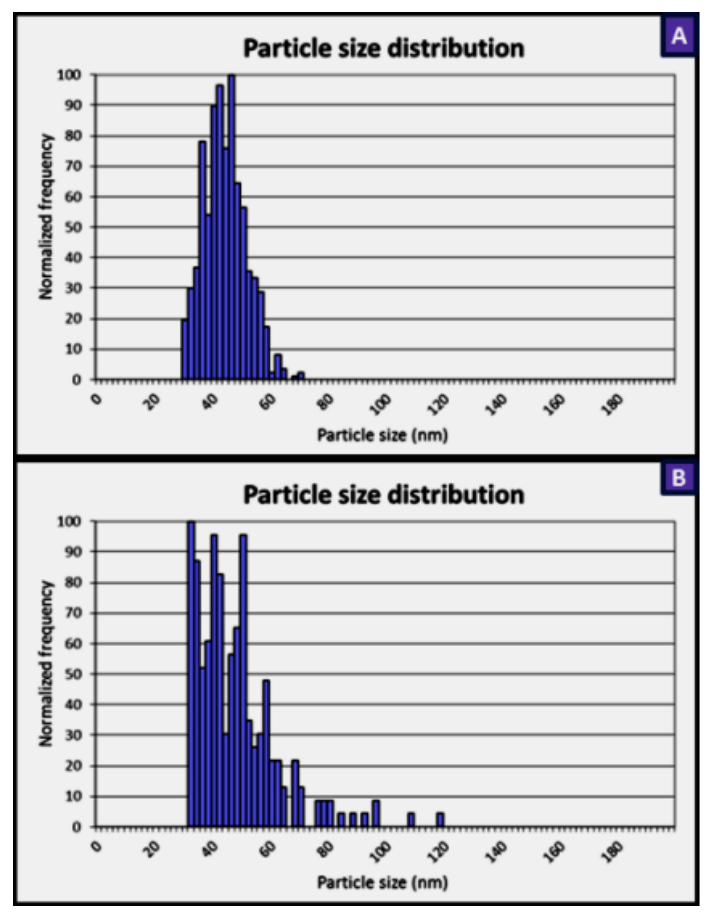

Fig. 3.1. Particle size distribution: primary $50 \mathrm{~nm} \mathrm{AgNP} \mathrm{in} \mathrm{miliQ} \mathrm{water} \mathrm{(A)} \mathrm{and} \mathrm{AgNP} \mathrm{extracted} \mathrm{from} \mathrm{tissues} \mathrm{(B)}$ showing average size distribution of 43 and $44 \mathrm{~nm}$ respectively. Size detection limit for the Sp-ICP-MS was 30 $\mathrm{nm}$, thus no information on NPs $<30 \mathrm{~nm}$

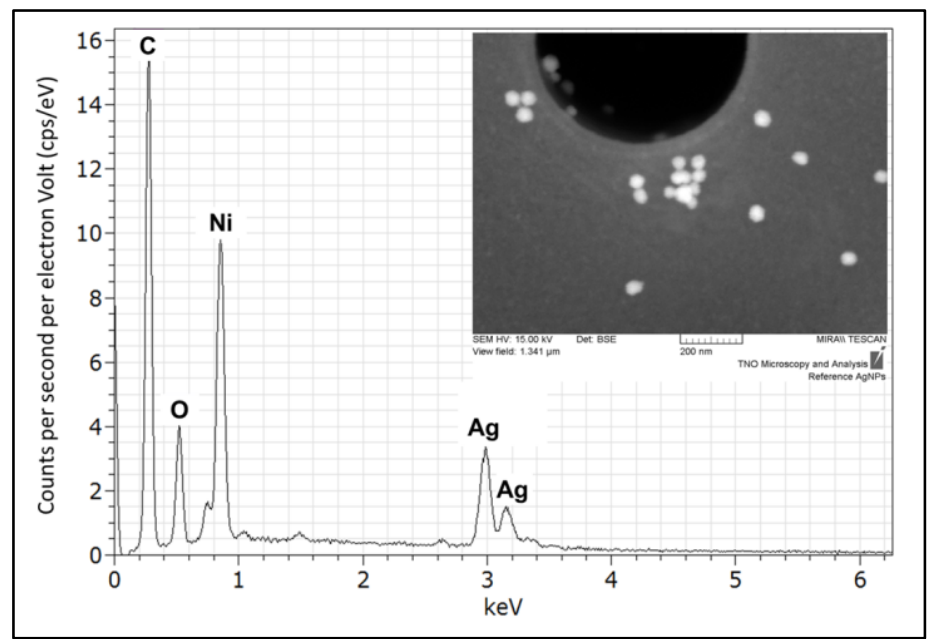

Fig. 3.2. Energy dispersive X-ray (EDX) spectrum of primary $50 \mathrm{~nm}$ Ag nanoparticles (NPs) suspended in milliQ water. Single AgNPs are seen as white dots in the scanning electron microscopy (SEM) image (insert) and spectral analysis reveals clear Ag peaks. (cps, counts per second) 


\section{Ag Quantification and Characterization in earthworm tissues:}

\section{Quantification}

Total tissue concentration of Ag in worms measured by ICP-MS following aqua regia digestion showed that earthworms exposed to $\mathrm{AgNP}$ or $\mathrm{AgNO}_{3}$ accumulated $0.502 \pm 0.219 \mathrm{mg} \mathrm{Ag} / \mathrm{kg}$ (DW) and $0.491 \pm 0.116 \mathrm{mg} \mathrm{Ag} / \mathrm{kg}$ (DW) respectively (Fig. 3.3). Concentrations of particulate $\mathrm{Ag}$ in the NP-exposed earthworms were $0.172 \pm 0.078 \mathrm{mg} \mathrm{Ag} / \mathrm{kg} \mathrm{DW}$, whereas in ionic Ag-exposed worms, low particulate concentrations $(0.025 \pm 0.013 \mathrm{mg} \mathrm{Ag} / \mathrm{kg} \mathrm{DW})$ were detected (Fig. 3.4). Silver concentrations based on number of particles per kilogram of tissue (DW) were $2.73 \times 10^{14}$ and $4.07 \times 10^{13}$ for NP and ionic Ag exposure groups respectively. Particulate silver, therefore, accounted for $\sim 34$ and $<5 \%$ of total Ag measured in the AgNP and $\mathrm{AgNO}_{3}$ treatment groups respectively (Fig. 3.3). The metal-rich granule fraction (F3 fraction) showed the highest Ag tissue concentration, accounting for $\sim 77$ and $64 \%$ of total $\mathrm{Ag}$ for AgNP and $\mathrm{AgNO}_{3}$ treatment groups respectively (Fig. 3.4; Table 3.1).

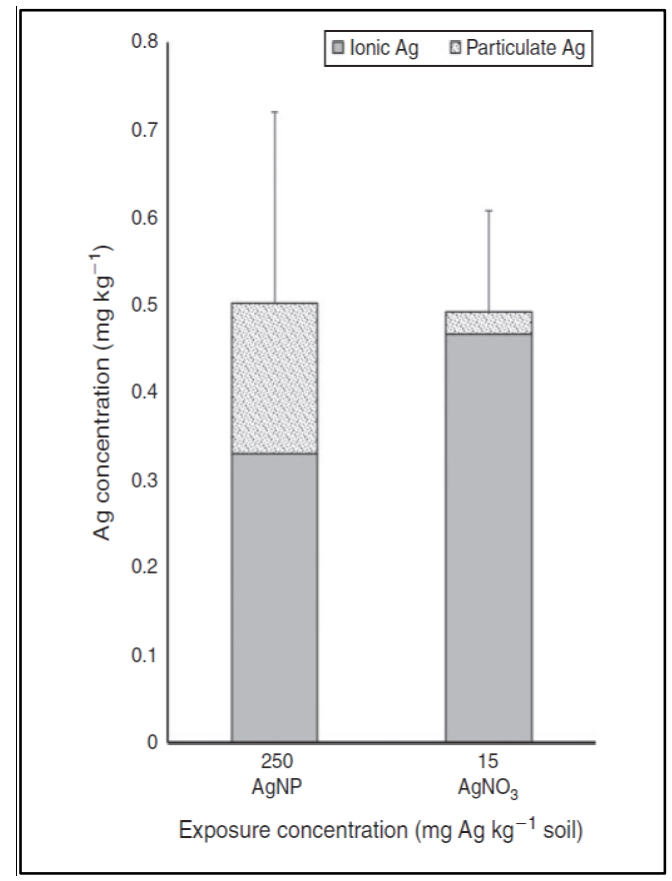

Fig. 3.3. Speciation of accumulated silver: particulate-Ag vs ionic-Ag in tissues of earthworms exposed to AgNP or $\mathrm{AgNO}_{3}$ with particulate silver constituting $34 \%$ and $<5 \%$ of total Ag respectively. 


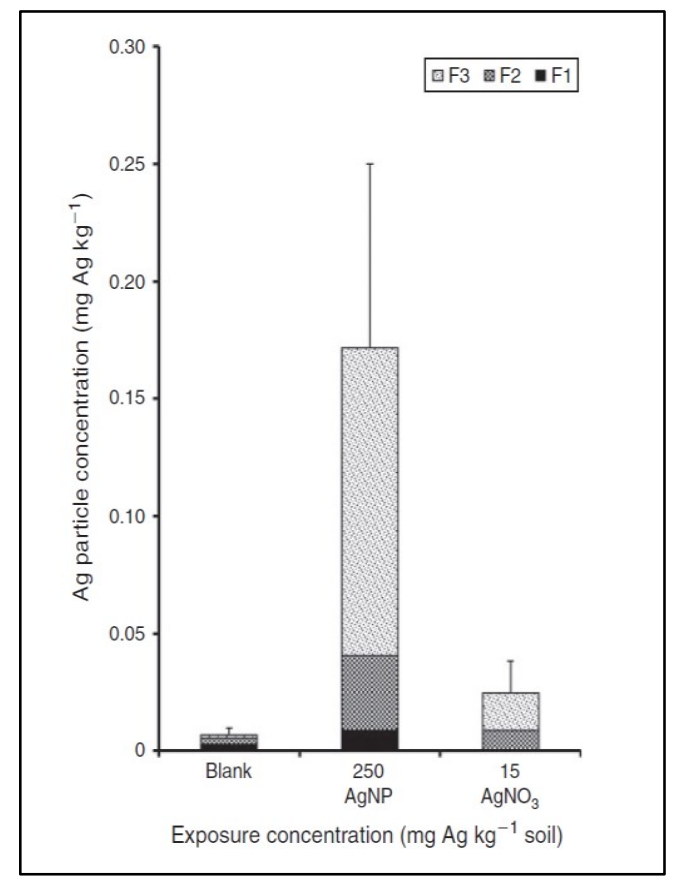

Fig. 3.4. Particulate Ag Tissue concentration measured in enzymatically processed samples by single-particle inductively coupled plasma-mass spectrometry (sp-ICP-MS). Stacked bars shows the fractional distribution of Ag particles with $~ 77 \%$ ( $\mathrm{Ag}$ nanoparticle (NP) exposure) and $64 \%\left(\mathrm{AgNO}_{3}\right.$ exposure) sequestered in the debris fraction (F3). Values are presented as mean ( \pm s.d.)

\section{Particle size distribution}

Nanosilver was detected in earthworm tissue processed enzymatically and showed particle size distribution in the expected range, having an average size of $44 \mathrm{~nm}$ (Fig. 3.1B). The size distribution of the particles from the tissues is somewhat wider than for the primary particles, showing smaller particles but also some large agglomerates. High resolution FEG-SEM-EDX confirmed the occurrence of Ag-NPs with the size of approximately $50 \mathrm{~nm}$ in tissues from Ag-NP exposed earthworms, indicating primary particles. The EDX analyses showed that the particles were mainly Ag, with minor traces of sulphur (Fig. 3.5). 


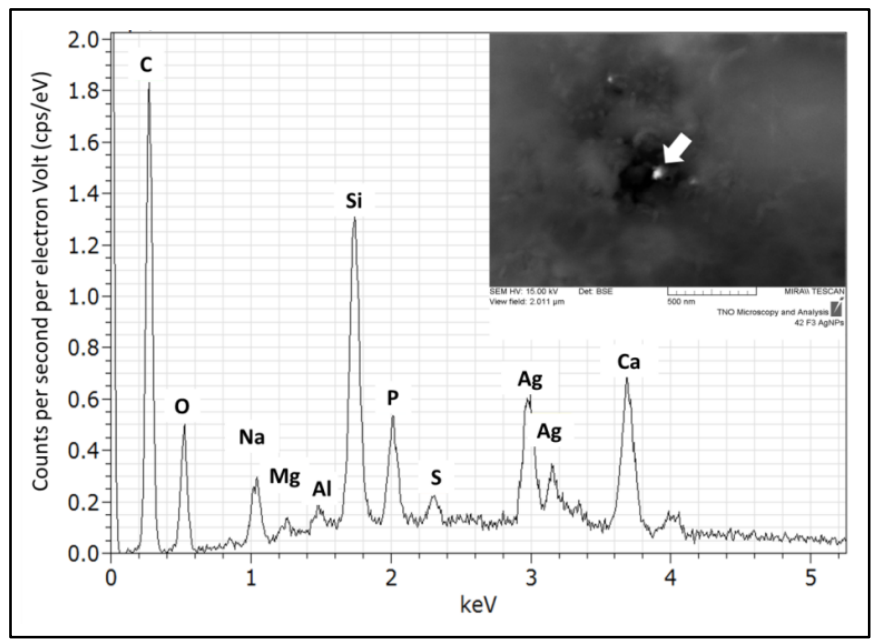

Fig. 3.5. EDX spectrum of eluted AgNP from tissue of L. rubellus exposed to $250 \mathrm{mg} \mathrm{AgNP/kg}$ soil and obtained by the enzymatic tissue processing method. Single AgNP indicated by the white arrow in the SEM image (insert).

\section{Discussion}

\section{Nanoparticle quantification}

Analytical methods that not only quantify body burden, but also provide additional information on characterisation of ENPs in tissues of organisms, for example ionic/particulate forms of nanoparticles, will enhance our interpretation of toxicological data generated during exposure experiments [21]. Not only quantification, but also characterisation is essential to understand NP behaviour in relevant environmental matrices [17, 18, 22]. Measuring accumulation of ENPs in complex biological matrices, however, presents challenges due to the interactions between the matrix and the NPs following exposure. In the present study, the strengths of available analytical methods and tools were combined to obtain information on accumulation, subcellular compartmentalisation, particle size distribution and NP speciation in biological tissue. This was enabled by first processing earthworm tissues using the less destructive ETP technique, instead of strong acids or alkali digestion. The use of protease enzymes to digest tissues for elemental analysis is a well-known procedure [36, 37], which is also applied to ENPs $[23,27]$. That the properties of ENPs are preserved during an enzymatic digestion followed by sp-ICP-MS analysis was shown in a validation study of AgNPs in chicken meat [25]. An additional preliminary check for the effect of enzymatic processing on AgNP (data not included) and analysis of final samples in the present study also 
showed that AgNPs can be extracted from the tissues of earthworms while preserving measured properties comparable with the primary particles.

Accumulation of ENPs under real exposure scenarios, however, involves many dynamic interactions between ENPs, exposure matrix and the physiological processes of the target organism. This is a problem hampering method development and validation of analytical methods for NPs in particular. Another challenge is there are as yet no biologically relevant reference materials [25]. Earlier reports on analysis of ENPs in complex matrices generally employ direct tissue spiking before their analysis [6,2325]. Our study, however, aimed to develop a method that would be capable of extracting ENPs accumulated under a realistic uptake scenario in vivo. By directly spiking the tissues with ENPs, normal biological processes critical in determining the fate of these ENPs in tissues would not be accounted for. Also, investigating subcellular compartmentalisation of ENPs involving fractionation steps in the present study would not be feasible using direct tissue spiking.

The biota-soil accumulation factor (BSAF) or bioconcentration factor (BCF) can be used to compare the accumulation of AgNP in tissues across several studies. Accumulation of AgNP in earthworms based on total concentrations is generally fairly low $[12,13,38-$ 41]. Similarly, the total tissue concentrations of $\mathrm{Ag}$ in our study were also low (Fig. 3.3 and Table 3.1), measuring $0.502 \pm 0.219 \mathrm{mg} \mathrm{Ag} / \mathrm{kg}$ (DW) in worms exposed to AgNPs, resulting in an average BSAF of 0.002 . Tissue burden in individuals exposed to $\mathrm{AgNO}_{3}$ was on average $0.491 \pm 0.12 \mathrm{ng} / \mathrm{g} \mathrm{DW}$, resulting in an average BSAF of $\sim 0.033$. The higher $\mathrm{BSAF}$ for $\mathrm{AgNO}_{3}$ in the current study indicates $\mathrm{AgNO}_{3}$ is more bioavailable, similar to other reports [12]. An earlier study in our laboratory using comparable conditions to the current study showed a BSAF of 0.018 [13], but it utilised smaller AgNPs ( $\sim 15 \mathrm{~nm}$ ). During preliminary experiments on the method reported here (data not shown), using the same 15-nm AgNPs, enzyme-extracted Ag showed accumulation of $\mathrm{Ag}$ in the same order of magnitude as that reported earlier [13]. Because sp-ICP-MS could not distinguish $15 \mathrm{~nm}$ AgNPs from ionic background, we focus here on the experiments with $50 \mathrm{~nm}$ AgNPs.

Other studies using soil as a medium of exposure found BSAFs in earthworms ranging from 0.01 to 0.02 (Table 3.1). The uptake of NPs may be affected by size, charge, shape and potentially other particle properties as well as the organism involved and the properties of the exposure medium driving the availability of chemicals $[12,20,40,42]$. These factors may account for the wide range in BSAFs observed. Accumulation in aquatic organisms seems typically relatively high when compared with terrestrial organisms. Daphnia magna [6] or rainbow trout [43] showed BCFs of 22 and 76 respectively. This was likely related to the fact that the guts of the organisms in those 
Table 3.1. Biota-soil-Accumulation Factor (BSAF) of Ag in earthworms. Some examples of BSAF estimates of Ag concentrations in earthworm tissues exposed to silver nanoparticles reported in the literature. ICP-MS, inductively coupled plasma mass spectrophotometry; AES, atomic emission spectrometry; OES, optical emission spectrometry; GFAAS, graphite furnace atomic absorption spectrometry

\begin{tabular}{|c|c|c|c|c|c|c|c|c|}
\hline \multirow{2}{*}{$\begin{array}{l}\text { Size } \\
(\mathrm{nm})\end{array}$} & & \multirow[t]{2}{*}{ Specie } & \multicolumn{2}{|c|}{ Exposure } & \multirow{2}{*}{$\begin{array}{c}\text { Ag Tissue } \\
\text { Concentration } \\
\text { Mean }\end{array}$} & \multirow[t]{2}{*}{ Measurement } & \multirow[t]{2}{*}{ BSAFs } & \multirow[t]{2}{*}{ Reference } \\
\hline & & & Medium & Concentration & & & & \\
\hline 50 & Earthworm & Lumbricus. rubellus & soil & $250 \mathrm{mg} / \mathrm{kg}$ & $0.502 \mathrm{mg} / \mathrm{kg}$ & ICP-MS & 0.002 & Present study \\
\hline$\sim 15$ & Earthworm & L. rubellus & soil & 154 mg/kg & $2.7 \mathrm{mg} / \mathrm{kg}$ & ICP-MS & 0.018 & [13] \\
\hline $30-80$ & Earthworm & L. variegatus & sediment & $400 \mathrm{mg} / \mathrm{kg}$ & $\sim 20 \mathrm{mg} / \mathrm{kg}^{\mathrm{A}}$ & ICP-MS/AES & 0.060 & {$[56]$} \\
\hline $40-60$ & Earthworm & Eisenia fetida & soil & $1000 \mathrm{mg} / \mathrm{kg}$ & $\sim 10 \mathrm{mg} / \mathrm{kg}^{\mathrm{A}}$ & ICP-MS & 0.010 & {$[12,40]$} \\
\hline$\sim 15$ & Earthworm & E. fetida & soil & 200 mg/kg & $11.2 \mathrm{mg} / \mathrm{kg}$ & ICP-OES & 0.060 & {$[57]$} \\
\hline 20 & Earthworm & E. fetida & manure (feed) & $0.77 \mu \mathrm{g} / \mathrm{g}$ & - & y-Spectrometry & 0.040 & [38] \\
\hline 82 & Earthworm & E. fetida & soil & $500 \mathrm{mg} / \mathrm{kg}$ & $10-15 \mathrm{mg} / \mathrm{kg}$ & Flame AAS & $0.02-0.030$ & [58] \\
\hline$<100$ & Worm & Nereis diversicolor & sediment & $50 \mu \mathrm{g} / \mathrm{g}$ & 8.56 mg/kg & GFAAS & 0.171 & [59] \\
\hline
\end{tabular}

${ }^{A}$ Estimated based on the BSAF reported. 
studies were not depurated, so the NPs may have been retained in the specimens. Gut clearance of $>98 \%$ in oligochaetes was determined to be achieved in $6 \mathrm{~h}$ [28]. In the current study, we used a prolonged depuration period of $48 \mathrm{~h}$ in order to obtain a more efficient clearance of particles from the gut, likely contributing to the fairly low tissue concentrations obtained [44].

Earthworms exposed to AgNPs contained 34 \% of measured Ag in its particulate form (Fig. 3.3), indicating accumulation of AgNPs as particles. To our knowledge, this is the first report of quantification and speciation of $\mathrm{Ag}$ in earthworms exposed in vivo to AgNPs in soil. An earlier study in our laboratory identified AgNPs localised in tissue of earthworms using non-quantitative SEM/EDX [13]. The metal-rich granule fraction (F3 fraction) contained the highest Ag tissue burden, accounting for 77 and $64 \%$ of total $\mathrm{Ag}$ for $\mathrm{AgNP}$ and $\mathrm{AgNO}_{3}$ treated groups respectively (Fig. 3.4). Tissue concentrations in the $\mathrm{AgNO}_{3}$ treatment groups were quite similar to those of the AgNPs group even though the nominal exposure concentrations in soil on a mass basis were $\sim 1$ order of magnitude lower. This further confirms the higher bioavailability of $\mathrm{Ag}$ in its ionic form than in particulate form. Nevertheless, nanoparticulate $\mathrm{Ag}$ was measured in tissues of depurated earthworms, confirming uptake of $\mathrm{Ag}$ in this form $[12,13,40]$.

\section{Characterization}

High-resolution FEG-SEM/EDX showed that the size and shape of the Ag particles in the tissues (Fig. 3.3) were of similar dimensions and composition to the primary particles as supplied. This confirms the actual uptake of primary particles across tissue membranes, as was also shown earlier [13]. The particle size distributions obtained from sp-ICP-MS analysis shows varying sizes of AgNPs in both primary particles and enzyme-extracted NPs. The wider particle size distribution of the NPs in the tissues (Fig. 3.1B) could indicate some dissolution (resulting in smaller particles) and some agglomeration (resulting in larger particles). Both processes have been reported in the literature $[13,45,46]$, similarly to our observations.

\section{Fractionation of AgNPs}

Organisms exposed to metals may protect themselves by production of $\mathrm{MT}$, which may sequester the metals [31,47-50]. This has also been suggested for ENPs [51-54]. There is growing evidence of the likely involvement of the MT system in the detoxification processes for some ENPs [51-54]. Reports regarding the involvement of the MT system 
in AgNP toxicity in the literature are generally targeted at MT gene induction using mostly in vitro models, so are difficult to compare with our study. In the current study, MT would collect in the F1 fraction [55], together with membrane-bound vesicles including mitochondria, lysosomes and microsomes, and heat-denatured proteins (HDPs). The F3 fraction contains metal-rich granules (MRG), whereas tissue fragments of digested materials are contained in the F2 fraction $[32,35]$. In the present study, however, the $\mathrm{F} 3$ fraction contained the highest Ag concentration, likely owing but not limited to preferential biochemical binding of both particulate and ionic $\mathrm{Ag}$. This fraction accounted for $\sim 77$ and $64 \%$ of total $\mathrm{Ag}$ for $\mathrm{AgNP}$ - and $\mathrm{AgNO}_{3}$-treated groups respectively (Fig. 3.3). Thus, neither particulate nor ionic forms of $\mathrm{Ag}$ seem to be associated with MTs, suggesting that Ag sequestration by MTs is unlikely to be an important detoxification process. However, further investigations will be required to confirm this because we did not measure MT amounts directly.

\section{Conclusion}

The present study demonstrates the ability of enzymes to digest earthworm tissues and facilitate the extraction of ENPs from these under realistic exposure condition, similarly to earlier reports involving direct tissue spiking [23-25]. The proposed procedure uses less-particle-destructive processing methods, enabling the characterisation of ENP properties in biological tissues as shown for this species under the stated experimental conditions. Estimates of tissue Ag concentrations in both particulate and ionic forms provided the first observation of speciation and quantification of $\mathrm{Ag}$ in earthworms exposed in vivo to AgNPs in soil, showing fairly low uptake of Ag. Approximately $34 \%$ of the total Ag in the tissues of earthworms exposed to AgNPs was in particulate form. This indicates that although NPs were accumulated in primary form, the dissolution of $\mathrm{Ag}$ in soil in the organism or both plays an important role in its environmental fate, as discussed previously $[12,21]$. Sequestration of Ag by MTs does not appear to be an important route of detoxification. The method is expected to be applicable to other ENPs, though limited to metal-based ENPs when using sp-ICP-MS [56]. Although the biological uptake of AgNPs was generally low, the method described above was still capable of extracting NPs in quantities sufficient for identification, quantification and characterisation. With the increasing optimisation of analytical systems that combine spICP-MS, or other detection methods with, for example, asymmetric flow field-flow fractionation AF4 which pre-sort different particle sizes, the potential for application of methods described in this publication will even be greater. 


\section{Acknowledgements}

The authors will like to thank Peter Tromp (TNO, Utrecht The Netherlands) for his assistance with the high resolution FEG-SEM/EDX. This work was financially supported by NanoNextNL, a micro and nano-technology consortium of the Government of The Netherlands and 130 partners; MARINA (EU-FP7, contract CP-FP 263215), and; Nanoeffect-KB, the strategic research program Technology Development of the Ministry of Economic Affairs of the Netherlands.

\section{Declaration of interest}

The authors report no conflicts of interest and are responsible for the content and writing of this paper. 


\section{$\underline{\text { References }}$}

[1] A. McWilliams. Nanotechnology: A Realistic Market Assessment. BCC Research. 2014.

[2] P. J. Borm, Robbins D., Haubold S., Kuhlbusch T., Fissan H., Donaldson K., Schins R., Stone V., Kreyling W., Lademann J., Krutmann J., Warheit D., Oberdorster E. The potential risks of nanomaterials: a review carried out for ECETOC. Part Fibre Toxicol. 2006, 3, 11. doi:10.1186/1743-8977-3-11

[3] M. Pal, Rakshit R., Mandal K. Surface modification of $\mathrm{MnFe}(2) \mathrm{O}(4)$ nanoparticles to impart intrinsic multiple fluorescence and novel photocatalytic properties. ACS App/ Mater Interfaces. 2014, 6(7), 4903-4910. doi:10.1021/am405950q

[4] K. Qian, Sweeny B. C., Johnston-Peck A. C., Niu W., Graham J. O., DuChene J. S., Qiu J., Wang Y. C., Engelhard M. H., Su D., Stach E. A., Wei W. D. Surface plasmon-driven water reduction: gold nanoparticle size matters. J Am Chem Soc. 2014, 136(28), 9842-9845. doi:10.1021/ja504097v

[5] R. Falkner, Jaspers N. Regulating Nanotechnologies: Risk, Uncertainty and the Global Governance Gap. Global Environmental Politics. 2012, 12(1), 30-55. doi:10.1162/GLEP_a_00096

[6] E. P. Gray, Coleman J. G., Bednar A. J., Kennedy A. J., Ranville J. F., Higgins C. P. Extraction and analysis of silver and gold nanoparticles from biological tissues using single particle inductively coupled plasma mass spectrometry. Environ Sci Technol. 2013, 47(24), 14315-14323. doi:10.1021/es403558c

[7] J. Hu, Wang D., Wang J., Wang J. Bioaccumulation of Fe2O3(magnetic) nanoparticles in Ceriodaphnia dubia. Environ Pollut. 2012, 162, 216-222. doi:10.1016/j.envpol.2011.11.016

[8] B. P. Jackson, Bugge D., Ranville J. F., Chen C. Y. Bioavailability, toxicity, and bioaccumulation of quantum dot nanoparticles to the amphipod Leptocheirus plumulosus. Environ Sci Technol. 2012, 46(10), 5550-5556. doi:10.1021/es202864r

[9] C. Lasagna-Reeves, Gonzalez-Romero D., Barria M. A., Olmedo I., Clos A., Sadagopa Ramanujam V. M., Urayama A., Vergara L., Kogan M. J., Soto C. Bioaccumulation and toxicity of gold nanoparticles after repeated administration in mice. Biochem Biophys Res Commun. 2010, 393(4), 649-655. doi:10.1016/j.bbrc.2010.02.046

[10] S. Novak, Drobne D., Valant J., Pelicon P. Internalization of Consumed TiO2 Nanoparticles by a Model Invertebrate Organism. Journal of Nanomaterials. 2012, 2012, 8. doi:10.1155/2012/658752

[11] J. F. Pan, Buffet P. E., Poirier L., Amiard-Triquet C., Gilliland D., Joubert Y., Pilet P., Guibbolini M., Risso de Faverney C., Romeo M., Valsami-Jones E., Mouneyrac C. Size dependent bioaccumulation and ecotoxicity of gold nanoparticles in an endobenthic invertebrate: the Tellinid clam Scrobicularia plana. Environ Pollut. 2012, 168, 37-43. doi:10.1016/j.envpol.2012.03.051

[12] W. A. Shoults-Wilson, Reinsch B. C., Tsyusko O. V., Bertsch P. M., Lowry G. V., Unrine J. M. Effect of silver nanoparticle surface coating on bioaccumulation and reproductive toxicity in earthworms (Eisenia fetida). Nanotoxicology. 2011, 5(3), 432-444. doi:10.3109/17435390.2010.537382

[13] M. J. van der Ploeg, Handy R. D., Waalewijn-Kool P. L., van den Berg J. H., Herrera Rivera Z. E., Bovenschen J., Molleman B., Baveco J. M., Tromp P., Peters R. J., Koopmans G. F., Rietjens I. M., van den Brink N. W. Effects of silver nanoparticles (NM-300K) on Lumbricus rubellus earthworms and particle characterization in relevant test matrices including soil. Environ Toxicol Chem. 2014, 33(4), 743-752. doi:10.1002/etc.2487

[14] M. J. van der Ploeg, van den Berg J. H., Bhattacharjee S., de Haan L. H., Ershov D. S., Fokkink R. G., Zuilhof H., Rietjens I. M., van den Brink N. W. In vitro nanoparticle toxicity to rat alveolar cells and coelomocytes from the earthworm Lumbricus rubellus. Nanotoxicology. 2014, 8(1), $28-37$. doi:10.3109/17435390.2012.744857

[15] P. Zhang, He X., Ma Y., Lu K., Zhao Y., Zhang Z. Distribution and bioavailability of ceria nanoparticles in an aquatic ecosystem model. Chemosphere. 2012, 89(5), 530-535. doi:10.1016/j.chemosphere.2012.05.044

[16] Y. Cong, Pang C., Dai L., Banta G. T., Selck H., Forbes V. E. Importance of characterizing nanoparticles before conducting toxicity tests. Integr Environ Assess Manag. 2011, 7(3), 502-503. doi:10.1002/ieam.204

[17] R. D. Handy, van den Brink N., Chappell M., Muhling M., Behra R., Dusinska M., Simpson P., Ahtiainen J., Jha A. N., Seiter J., Bednar A., Kennedy A., Fernandes T. F., Riediker M. Practical considerations for conducting ecotoxicity test methods with manufactured nanomaterials: what have we learnt so far? Ecotoxicology. 2012, 21(4), 933-972. doi:10.1007/s10646-012-0862-y 
[18] A. R. Poda, Bednar A. J., Kennedy A. J., Harmon A., Hull M., Mitrano D. M., Ranville J. F., Steevens J. Characterization of silver nanoparticles using flow-field flow fractionation interfaced to inductively coupled plasma mass spectrometry. J Chromatogr A. 2011, 1218(27), 4219-4225. doi:10.1016/j.chroma.2010.12.076

[19] N. J. Rogers, Franklin N. M., Apte S. C., Batley G. E. The importance of physical and chemical characterization in nanoparticle toxicity studies. Integr Environ Assess Manag. 2007, 3(2), 303-304. doi:10.1002/ieam.5630030219

[20] P. S. Tourinho, van Gestel C. A., Lofts S., Svendsen C., Soares A. M., Loureiro S. Metal-based nanoparticles in soil: fate, behavior, and effects on soil invertebrates. Environ Toxicol Chem. 2012, 31(8), 1679-1692. doi:10.1002/etc.1880

[21] F. von der Kammer, Ferguson P. L., Holden P. A., Masion A., Rogers K. R., Klaine S. J., Koelmans A. A., Horne N., Unrine J. M. Analysis of engineered nanomaterials in complex matrices (environment and biota): general considerations and conceptual case studies. Environ Toxicol Chem. 2012, 31(1), 32-49. doi:10.1002/etc.723

[22] R. D. Handy, Cornelis G., Fernandes T., Tsyusko O., Decho A., Sabo-Attwood T., Metcalfe C., Steevens J. A., Klaine S. J., Koelmans A. A., Horne N. Ecotoxicity test methods for engineered nanomaterials: practical experiences and recommendations from the bench. Environ Toxicol Chem. 2012, 31(1), 1531. doi:10.1002/etc.706

[23] C. E. Deering, Tadjiki S., Assemi S., Miller J. D., Yost G. S., Veranth J. M. A novel method to detect unlabeled inorganic nanoparticles and submicron particles in tissue by sedimentation field-flow fractionation. Part Fibre Toxicol. 2008, 5, 18. doi:10.1186/1743-8977-5-18

[24] M. van der Zande, Vandebriel R. J., Van Doren E., Kramer E., Herrera Rivera Z., Serrano-Rojero C. S., Gremmer E. R., Mast J., Peters R. J., Hollman P. C., Hendriksen P. J., Marvin H. J., Peijnenburg A. A., Bouwmeester $\mathrm{H}$. Distribution, elimination, and toxicity of silver nanoparticles and silver ions in rats after 28-day oral exposure. ACS Nano. 2012, 6(8), 7427-7442. doi:10.1021/nn302649p

[25] R. J. Peters, Rivera Z. H., van Bemmel G., Marvin H. J., Weigel S., Bouwmeester H. Development and validation of single particle ICP-MS for sizing and quantitative determination of nano-silver in chicken meat. Anal Bioanal Chem. 2014, 406(16), 3875-3885. doi:10.1007/s00216-013-7571-0

[26] M. J. van der Ploeg, Baveco J. M., van der Hout A., Bakker R., Rietjens I. M., van den Brink N. W. Effects of C60 nanoparticle exposure on earthworms (Lumbricus rubellus) and implications for population dynamics. Environ Pollut. 2011, 159(1), 198-203. doi:10.1016/j.envpol.2010.09.003

[27] R. J. Peters, van Bemmel G., Herrera-Rivera Z., Helsper H. P., Marvin H. J., Weigel S., Tromp P. C., Oomen A. G., Rietveld A. G., Bouwmeester H. Characterization of titanium dioxide nanoparticles in food products: analytical methods to define nanoparticles. J Agric Food Chem. 2014, 62(27), 62856293. doi:10.1021/jf5011885

[28] D. R. Mount, Dawson T. D., Burkhard L. P. Implications of gut purging for tissue residues determined in bioaccumulation testing of sediment with Lumbriculus variegatus. Environ Toxicol Chem. 1999, 18(6), 1244-1249. doi:Doi 10.1897/1551-5028(1999)018<1244:logpft>2.3.Co;2

[29] C. J. Langdon, Piearce T. G., Meharg A. A., Semple K. T. Interactions between earthworms and arsenic in the soil environment: a review. Environ Pollut. 2003, 124(3), 361-373. doi:10.1016/S02697491(03)00047-2

[30] R. P. Jones, Bednar A. J., Inouye L. S. Subcellular compartmentalization of lead in the earthworm, Eisenia fetida: Relationship to survival and reproduction. Ecotoxicol Environ Saf. 2009, 72(4), 1045 1052. doi:10.1016/j.ecoenv.2008.12.011

[31] M. G. Vijver, van Gestel C. A. M., van Straalen N. M., Lanno R. P., Peijnenburg W. J. G. M. Biological significance of metals partitioned to subcellular fractions within earthworms (Aporrectodea caliginosa). Environ Toxicol Chem. 2006, 25(3), 807-814. doi:Doi 10.1897/05-128r.1

[32] W. G. Wallace, Lee B. G., Luoma S. N. Subcellular compartmentalization of Cd and Zn in two bivalves. I. Significance of metal-sensitive fractions (MSF) and biologically detoxified metal (BDM). Mar Ecol Prog Ser. 2003, 249, 183-197. doi:Doi 10.3354/Meps249183

[33] S. Yu. 2009, The Ohio State University.

[34] H. Silverman, Steffens W. L., Dietz T. H. Calcium concretions in the gills of a freshwater mussel serve as a calcium reservoir during periods of hypoxia. J Exp Zool. 1983, 227(2), 177-189. doi:10.1002/jez.1402270203 
[35] J. Garcia-Alonso, Khan F. R., Misra S. K., Turmaine M., Smith B. D., Rainbow P. S., Luoma S. N., ValsamiJones E. Cellular internalization of silver nanoparticles in gut epithelia of the estuarine polychaete Nereis diversicolor. Environ Sci Technol. 2011, 45(10), 4630-4636. doi:10.1021/es2005122

[36] P. Campbell, Ma S., Schmalzried T., Amstutz H. C. Tissue digestion for wear debris particle isolation. J Biomed Mater Res. 1994, 28(4), 523-526. doi:10.1002/jbm.820280415

[37] C. Yu, Penn L. D., Hollembaek J., Li W., Cohen L. H. Enzymatic tissue digestion as an alternative sample preparation approach for quantitative analysis using liquid chromatography-tandem mass spectrometry. Anal Chem. 2004, 76(6), 1761-1767. doi:10.1021/ac035077v

[38] C. Coutris, Hertel-Aas T., Lapied E., Joner E. J., Oughton D. H. Bioavailability of cobalt and silver nanoparticles to the earthworm Eisenia fetida. Nanotoxicology. 2012, 6(2), 186-195. doi:10.3109/17435390.2011.569094

[39] F. Gottschalk, Sonderer T., Scholz R. W., Nowack B. Modeled environmental concentrations of engineered nanomaterials ( $\mathrm{TiO}(2), \mathrm{ZnO}, \mathrm{Ag}, \mathrm{CNT}$, Fullerenes) for different regions. Environ Sci Technol. 2009, 43(24), 9216-9222. doi:10.1021/es9015553

[40] W. A. Shoults-Wilson, Reinsch B. C., Tsyusko O. V., Bertsch P. M., Lowry G. V., Unrine J. M. Role of Particle Size and Soil Type in Toxicity of Silver Nanoparticles to Earthworms. Soil Sci Soc Am J. 2011, 75(2), 365-377. doi:DOI 10.2136/sssaj2010.0127nps

[41] M. J. Van Der Ploeg, Handy R. D., Heckmann L. H., Van Der Hout A., Van Den Brink N. W. C60 exposure induced tissue damage and gene expression alterations in the earthworm Lumbricus rubellus. Nanotoxicology. 2013, 7(4), 432-440. doi:10.3109/17435390.2012.668569

[42] J. M. Unrine, Tsyusko O. V., Hunyadi S. E., Judy J. D., Bertsch P. M. Effects of particle size on chemical speciation and bioavailability of copper to earthworms (Eisenia fetida) exposed to copper nanoparticles. J Environ Qual. 2010, 39(6), 1942-1953. doi:10.2134/jeq2009.0387

[43] H. Salari Joo, Kalbassi M. R., Yu I. J., Lee J. H., Johari S. A. Bioaccumulation of silver nanoparticles in rainbow trout (Oncorhynchus mykiss): influence of concentration and salinity. Aquat Toxicol. 2013, 140-141, 398-406. doi:10.1016/j.aquatox.2013.07.003

[44] E. J. Petersen, Huang Q., Weber W. J. Ecological uptake and depuration of carbon nanotubes by Lumbriculus variegatus. Environ Health Perspect. 2008, 116(4), 496-500. doi:10.1289/ehp.10883

[45] L. V. Stebounova, Guio E., Grassian V. H. Silver nanoparticles in simulated biological media: a study of aggregation, sedimentation, and dissolution. I Nanopart Res. 2011, 13(1), 233-244. doi:10.1007/s11051-010-0022-3

[46] A. P. Walczak, Fokkink R., Peters R., Tromp P., Herrera Rivera Z. E., Rietjens I. M., Hendriksen P. J., Bouwmeester $\mathrm{H}$. Behaviour of silver nanoparticles and silver ions in an in vitro human gastrointestinal digestion model. Nanotoxicology. 2013, 7(7), 1198-1210. doi:10.3109/17435390.2012.726382

[47] S. N. Luoma, Rainbow P. S. Why Is Metal Bioaccumulation So Variable? Biodynamics as a Unifying Concept. Environ Sci Technol. 2005, 39(7), 1921-1931. doi:10.1021/es048947e

[48] A. J. Morgan, Sturzenbaum S. R., Winters C., Kille P. Cellular and molecular aspects of metal sequestration and toxicity in earthworms. Invertebr Reprod Dev. 1999, 36(1-3), 17-24. doi:Doi 10.1080/07924259.1999.9652673

[49] C. A. van Gestel. Soil ecotoxicology: state of the art and future directions. Zookeys. 2012, 176(176), 275-296. doi:10.3897/zookeys.176.2275

[50] M. G. Vijver, Van Gestel C. A., Lanno R. P., Van Straalen N. M., Peijnenburg W. J. Internal metal sequestration and its ecotoxicological relevance: a review. Environ Sci Technol. 2004, 38(18), 47054712. doi:10.1021/es040354g

[51] W. Fan, Cui M., Liu H., Wang C., Shi Z., Tan C., Yang X. Nano-TiO2 enhances the toxicity of copper in natural water to Daphnia magna. Environ Pollut. 2011, 159(3), 729-734. doi:10.1016/j.envpol.2010.11.030

[52] R. Foldbjerg, Irving E. S., Hayashi Y., Sutherland D. S., Thorsen K., Autrup H., Beer C. Global gene expression profiling of human lung epithelial cells after exposure to nanosilver. Toxicol Sci. 2012, 130(1), 145-157. doi:10.1093/toxsci/kfs225

[53] S. Renault, Baudrimont M., Mesmer-Dudons N., Gonzalez P., Mornet S., Brisson A. Impacts of gold nanoparticle exposure on two freshwater species: a phytoplanktonic alga (Scenedesmus subspicatus) and a benthic bivalve (Corbicula fluminea). Gold Bulletin. 2008, 41(2), 116-126. doi:10.1007/bf03216589 
[54] K. Shalini, Jeyanthi G. Free Radical Scavenging Activity of Metallothioneins from Peripheral Blood Lymphocytes of Gold Jewellery Karigars. International Research Journal of Medical Sciences. 2014, 2(1), 15-20.

[55] A. Giguere, Campbell P. G., Hare L., Couture P. Sub-cellular partitioning of cadmium, copper, nickel and zinc in indigenous yellow perch (Perca flavescens) sampled along a polymetallic gradient. Aquat Toxicol. 2006, 77(2), 178-189. doi:10.1016/j.aquatox.2005.12.001

[56] J. G. Coleman, Kennedy A. J., Bednar A. J., Ranville J. F., Laird J. G., Harmon A. R., Hayes C. A., Gray E. P., Higgins C. P., Lotufo G., Steevens J. A. Comparing the effects of nanosilver size and coating variations on bioavailability, internalization, and elimination, using Lumbriculus variegatus. Environ Toxicol Chem. 2013, 32(9), 2069-2077. doi:10.1002/etc.2278

[57] K. Schlich, Klawonn T., Terytze K., Hund-Rinke K. Effects of silver nanoparticles and silver nitrate in the earthworm reproduction test. Environ Toxicol Chem. 2013, 32(1), 181-188. doi:10.1002/etc.2030

[58] Y. Hayashi, Heckmann L. H., Simonsen V., Scott-Fordsmand J. J. Time-course profiling of molecular stress responses to silver nanoparticles in the earthworm Eisenia fetida. Ecotoxicol Environ Saf. 2013, 98, 219-226. doi:10.1016/j.ecoenv.2013.08.017

[59] Y. Cong, Banta G. T., Selck H., Berhanu D., Valsami-Jones E., Forbes V. E. Toxic effects and bioaccumulation of nano-, micron- and ionic-Ag in the polychaete, Nereis diversicolor. Aquat Toxicol. 2011, 105(3-4), 403-411. doi:10.1016/j.aquatox.2011.07.014

[60] Peters R, Herrera-Rivera Z, Undas A, van der Lee M, Marvin H, Bouwmeester H, et al. Single particle ICP-MS combined with a data evaluation tool as a routine technique for the analysis of nanoparticles in complex matrices. Journal of Analytical Atomic Spectrometry. 2015, 30(6), 1274-85. doi10.1039/C4JA00357H 


\section{Supporting Material}

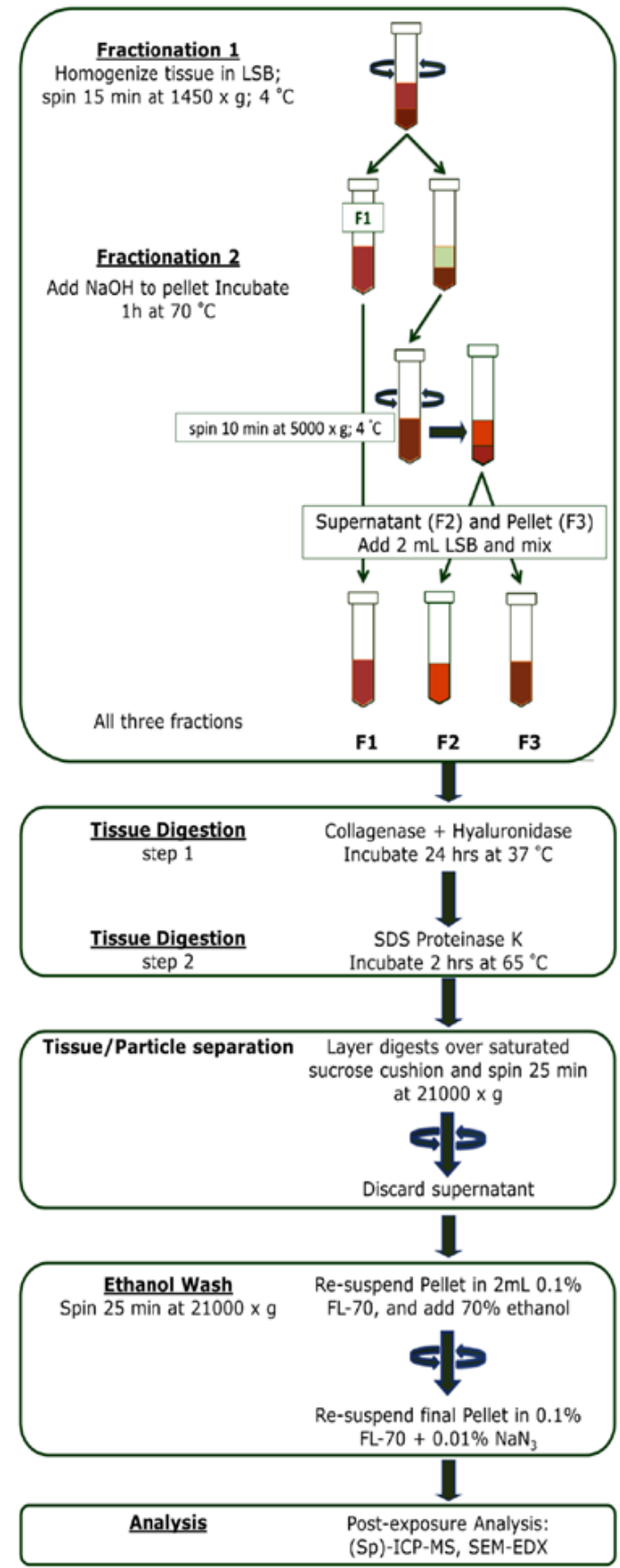

Fig. S3.1: Schematic representation of methodology. LSB, low salt buffer 



\title{
Chapter 4
}

\section{Physico-chemical properties of silver nanoparticles influencing their uptake in and toxicity to the earthworm Lumbricus rubellus following exposure in soil}

\begin{abstract}
Based on:
Physico-chemical properties of silver nanoparticles influencing their uptake in and toxicity to the earthworm Lumbricus rubellus following exposure in soil Sunday Makama, Jordi Piella, Anna Undas, Wim J. Dimmers, Ruud JB. Peters, Victor F. Puntes, and Nico W. van den Brink
\end{abstract}

Environmental Pollution (2016) Published online 


\section{Abstract}

Physico-chemical properties of nanoparticles influence their environmental fate and toxicity, and studies investigating this are vital for a holistic approach towards a comprehensive and adequate environmental risk assessment. In this study, we investigated the effects of size, surface coating (charge) of silver nanoparticles (AgNPs) a most commonly-used nanoparticle-type, on the bioaccumulation in, and toxicity (survival, growth, cocoon production) to the earthworm Lumbricus rubellus. AgNPs were synthesized in three sizes: 20, 35 and $50 \mathrm{~nm}$. Surface-coating with bovine serum albumin (AgNP_BSA), chitosan (AgNP_Chit), or polyvinylpyrrolidone (AgNP_PVP) produced negative, positive and neutral particles respectively. In a 28-day sub-chronic reproduction toxicity test, earthworms were exposed to these AgNPs in soil (0-250 mg $\mathrm{Ag} / \mathrm{kg}$ soil DW). Earthworms were also exposed to $\mathrm{AgNO}_{3}$ at concentrations below known $\mathrm{EC}_{50}$. Total Ag tissue concentration indicated a concentration-dependent uptake in earthworms. Uptake was generally highest for the AgNP_BSA especially at the lower exposure concentration ranges, and seem to reach a plateau level between 50-100 mg $\mathrm{Ag} / \mathrm{kg}$ soil DW. Reproduction was impaired at high concentrations of all AgNPs tested, with AgNP_BSA particles being the most toxic. The EC $_{50}$ for the $20 \mathrm{~nm}$ AgNP_BSA was $66.8 \mathrm{mg} \mathrm{Ag} / \mathrm{kg}$ soil, with exposure to $<60 \mathrm{mg} \mathrm{Ag} / \mathrm{kg}$ soil already showing a decrease in the cocoon production. Thus, based on reproductive toxicity, the particles ranked: AgNP_BSA (negative) > AgNP_PVP (neutral) > Chitosan (positive). Size had an influence on uptake and toxicity of the AgNP_PVP, but not for AgNP_BSA nor AgNP_Chit. This study provides essential information on the role of physico-chemical properties of AgNPs in influencing uptake by a terrestrial organism L. rubellus under environmentally relevant conditions. It also provides evidence of the influence of surface coating (charge) and the limited effect of size in the range of $20-50 \mathrm{~nm}$, in driving uptake and toxicity of the AgNPs tested.

\section{Capsule}

Evidence of the influence of surface coating (charge) and limited effect of size in the range of $20-50 \mathrm{~nm}$, in driving uptake in and toxicity of AgNPs to earthworms was demonstrated.

Keywords: cocoon production, particle characterization, soil organism, surface coating, toxicodynamics, toxicokinetics 


\section{Introduction}

The anticipated increase in the production and use of nanotechnology in the design and manufacture of numerous consumer products [1-3], is likely to result in an increase in the environmental release of nanoparticles (NPs), potentially causing harmful impacts [4-8]. At the nanoscale $(1-100 \mathrm{~nm})$, the small size and increased surface area of NPs result in novel properties, which can be enhanced by their stabilization or functionalization using biocompatible molecules. Essentially, the type of surface coating and process used in stabilizing NPs during synthesis determine their surface charges, solubility and/or hydrophobicity [9-12]. This in turn, influences the behaviour and environmental fate of NPs, as well as their effects on organisms [13-16]. Considering the barrage of nano-based products entering the global market annually and the necessary regulatory requirements for assessing the health and environmental risks of these engineered NPs, studies elucidating the synthesis, fate and outcome of NP exposure are essential and are increasing [6, 17-21].

Currently, silver nanoparticles (AgNPs) constitute the most frequent nanomaterial used in products on the European market [3], attributable to the well demonstrated antimicrobial properties of silver [22-25]. In recent times, our understanding of the fate and effect of various NPs has been improved from investigations utilizing both in vivo and in vitro models $[20,26,27]$. In addition to the exposure matrix-associated factors, the importance of physico-chemical properties of the NPs including size and size dispersion (both mono- and polydispersity), shape, zeta potential, surface coating (charge) and agglomeration and dissolution rates [6] in influencing their fate and toxicity has been highlighted. However, available information on this issue varies widely and are often inconsistent [20, 28]. Some studies have implicated size [29], charge [30], or surface coating and dissolved ions [31,32] to be of eminent importance. In another study however, no significant impact of the influence of AgNPs surface coating (PVP or oleate) on toxicity to Eisenia fetida was observed [16]. Also, the debate on the involvement of particulate $\mathrm{Ag}$ in the toxicity of AgNPs has remained. With the development of techniques that can characterize NPs in biological matrices [28, 33, 34], it has become more evident that both particulate and ionic Ag are involved.

Certainly, a better understanding of the properties that influence both fate and effects of AgNPs in organisms will facilitate appropriate risk assessment, which in turn will assist the regulation of nanomaterials. This is especially applicable for soil organisms where available data are limited. In a previous study investigating the effect of AgNPs (NM$300 \mathrm{~K}$ ) on Lumbricus rubellus populations during a 28-day exposure experiment, reproduction was especially impaired with number of cocoons laid dropping to $18 \%$ [35]. Van der Ploeg et al. [35] also exposed coelomocytes from L. rubellus to the AgNPs (NM- 
$300 \mathrm{~K})$, resulting in reduced cell viability of these immune cells. In a Chapter 2, we investigated the influence of size $(20,35$ and $50 \mathrm{~nm})$ and surface coating (BSA, chitosan and PVP) of AgNPs on toxicity to mammalian macrophages and found that reduced overall viability was observed to a similar extent irrespective of AgNPs coating type or size. On specific mechanisms of toxicity (TNF- $\alpha$ and ROS) however, we found that the AgNPs differed significantly. Also, negatively charged BSA-coated AgNPs were the most potent in inducing cellular effects. To validate these in vitro observations, we used an in vivo model in this present study. Here, we systematically investigated the influence of physico-chemical properties of AgNPs on their uptake in and toxicity to a model soil organism common in Europe, the red earthworm L. rubellus. To achieve this, AgNPs were synthesized that differed in size and surface charge, two important properties influencing uptake and effects of engineered NPs [6]. The outcome of the current study will provide a valuable insight into how AgNP properties determine their fate and effects in soil organisms.

\section{Materials and methods}

\section{Experimental design}

During a 28-day exposure period, earthworms at a density of 5 individuals per experimental unit and in triplicates $(n=3)$, were exposed to the different AgNPs at nominal exposure concentrations of 0, 15.6, 31.3, 62.5, 125 and $250 \mathrm{mg} \mathrm{Ag} / \mathrm{kg}$ soil dry weight (DW). To compare the effects of the AgNPs to those of ionic silver $\left(\mathrm{Ag}^{+}\right)$, two concentrations of $\mathrm{AgNO}_{3}$ solution ( 1.5 and $15 \mathrm{mg} \mathrm{Ag} / \mathrm{kg}$ soil DW) were also included. Soil for the control groups were spiked with only the dispersing and moisturizing media, without AgNPs nor $\mathrm{AgNO}_{3}$. Upon termination of exposure, whole earthworms were collected and their tissues analysed for both ionic and particulate Ag content. Additionally, population dynamic parameters like cocoon production, mortality (survival) and growth rates were assessed. The AgNPs used in this study were synthesized at the Catalonia Institute of Nanoscience and Nanotechnology (ICN2), Barcelona, Spain by methods earlier reported Bastus et al. [9] with modifications (Chapter 2), necessitating only a brief description here.

Results were processed with Microsoft Excel (2013), and data are presented as mean \pm standard deviations. Where appropriate, the experimental data generated were subjected to one-way analysis of variance (ANOVA) with the aid of GraphPad Prism 5.04 for Windows (GraphPad Software, San Diego California USA, www.graphpad.com"), and 
logistic regression was done using GenStat 17th ed. (17.1.0.14713; VSN International, Hemel Hempstead, UK, GenStat.co.uk). A $p$ value of $<0.05$ is considered to be significant.

\section{Reagents and instruments}

Chemicals, enzymes and reagents were of analytical grade. All glassware used in this study were first acid-washed by soaking in a $21 \% \mathrm{HNO}_{3}$ solution overnight, then rinsed 3 times in milliQ water (Millipore, resistivity $18.2 \mathrm{M} \Omega / \mathrm{cm}$ ) and allowed to dry under a fume hood. Unless where otherwise stated, all chemicals, enzymes and reagents were purchased from Sigma-Aldrich (Zwijndrecht, The Netherlands).

\section{AgNPs synthesis and pre-exposure characterization}

The details of the synthesis and characterization of these AgNPs have been provided previously (Chapter 2), with additional information included in the online Supporting Information (SI) accompanying this manuscript. Colloidal, dispersed AgNPs of three different sizes $(20,35$ and $50 \mathrm{~nm})$ were prepared separately, following a kinetically controlled seeded-growth method previously reported [9] with slight modifications (Chapter 2). The approach is based on the reduction of silver nitrate $\left(\mathrm{AgNO}_{3}\right)$ at $100^{\circ} \mathrm{C}$ by tannic acid (TA) and trisodium citrate hexahydrate (SC). In order to generate negative, positive and neutral NPs, the AgNPs were subsequently surface-coated with bovine serum albumin (AgNP_BSA), chitosan (AgNP_Chit) or polyvinylpyrrolidone (AgNP_PVP), respectively.

All nine AgNPs were characterized in re-suspension media (i. e. soil extract), moisturizing media (milliQ water), or both, using a combination of different techniques in order to enhance a more adequate characterization of the AgNPs. This also allows the monitoring of proper coating and stability of the AgNPs in the exposure media [9]. Particle size distributions were assessed by single-particle inductively coupled plasmamass spectrometry (sp-ICP-MS), while core mean sizes were determined by transmission electron microscopy (TEM). UV-Vis (Shimadzu UV-2400 spectrophotometer), dynamic light scattering (DLS), and zeta-potentials ( $\zeta$-potentials) were measured (Malvern Zetasizer Nano ZS, Malvern Instruments UK) to monitor the stability of the AgNPs in different media and to determine their surface charges. Details of these are provided in the electronic supporting information.

TEM images were acquired with a FEI Magellane 400L SEM electron microscope operating at scanning TEM (STEM) mode and low accelerating voltage (20 kV) and a JEOL 
1010 electron microscope operating at an accelerating voltage of $80 \mathrm{kV}$. A Shimadzu UV2400 spectrophotometer was used to measure the localized surface Plasmon resonance (SPR) peak of the different AgNPs. For this, $1 \mathrm{ml}$ of each AgNPs suspension was placed in a cuvette, and the spectrum (UV-Vis) acquired in the $300-800 \mathrm{~nm}$ range. Hydrodynamic sizes of the AgNPs were estimated by DLS, with a light source set at a wavelength of 532 $\mathrm{nm}$ and a fixed scattering angle of $173^{\circ}$. All measurements were conducted at least three times. The particle surface charges ( $\zeta$-potentials) were measured using Malvern Zetasizer Nano ZS (Malvern Instruments, UK).

\section{Soil preparation and earthworm exposure experiment}

Soil preparation and wet-spiking exposure experiments using soil extract were performed according to an earlier report [35]. Shortly, sifted air-dried natural soil $\mathrm{pH} 5.0$ and organic matter content 3.8\%) obtained from a reference experimental organic farm (Proefboerderij Kooijenburg, Marwijksoord, The Netherlands), was weighed out (650 g DW per unit) into glass jars with lids and used for the experiment. From the same clean soil, soil extract was prepared and used to disperse the AgNPs in suspensions, as well as making the solution of $\mathrm{AgNO}_{3}$ [35]. Nominal exposure concentrations 0, 15.6, 31.3, 62.5, 125 and $250 \mathrm{mg} \mathrm{Ag} / \mathrm{kg}$ soil for the AgNPs, and 1.5 and $15 \mathrm{mg} \mathrm{Ag} / \mathrm{kg}$ soil for $\mathrm{AgNO}_{3}$ were selected based on AgNP toxicity [35]. Soil for exposure was spiked and/or moistened accordingly to attain a readjusted moisture content of $17.5 \%$ by weight in all units. Equivalent quantities of soil extract and milliQ water served as exposure material for the control units. Soil in the glass jars prepared for exposure were allowed to equilibrate for $24 \mathrm{~h}$ under climate-controlled conditions of $24 \mathrm{~h}$ light, $15^{\circ} \mathrm{C}$, and $61 \%$ relative humidity before placing the earthworms.

Clitellated adult earthworms (Lumbricus rubellus), weighing $1-2.5 \mathrm{~g}$ live weight were obtained from an uncontaminated site in The Netherlands (Nijkerkerveen). These were placed in uncontaminated soil for two weeks under the same climatic conditions as described above. Acclimatized earthworms confirmed to have no gross lesions were selected, weighed and distributed randomly in the experimental units (jar), each treatment prepared in triplicates at a density of 5 earthworms per jar. Weekly feeding consisted of moistened dried and hand-crushed alder leaves (Alnus glutinosa), also collected from an uncontaminated location (Vossemeerdijk, Dronten, The Netherlands). All experimental jars were placed in the climate controlled room throughout the 28-day exposure under the same conditions as described above. At the end of the exposure period, live whole earthworms were collected and counted to ascertain mortality. Those alive were weighed and placed in glass petri-dishes lined with moistened Whatman ${ }^{\circledR}$ 
filter paper no. 597 (Fisher Scientific, Pittsburg, PA). Earthworms were returned to the climate controlled room and allowed to depurate over a period of 48h [28]. Afterwards, the earthworms were washed in demineralized water, padded dry with absorbent paper and snapped frozen in liquid nitrogen. Frozen samples were ground to powder in liquid nitrogen, pooling two individuals each per experimental unit, and the ground tissues were preserved at $-80^{\circ} \mathrm{C}$ until analysed.

\section{Quantification and Characterization of AgNPs in earthworm tissues}

Inductively-coupled plasma - mass spectrometry (ICP-MS)

A $300 \mathrm{mg}$ subsample of the ground earthworm tissue from each replicate was weighed into a digestion tube. To this, $1.0 \mathrm{ml}$ of milliQ water, $0.5 \mathrm{ml}$ of $65 \% \mathrm{HNO}_{3}$ and $1.5 \mathrm{ml}$ of a $37 \% \mathrm{HCl}$ solution were added. The digestion tubes were capped and the contents were mixed by gentle swirling. The tubes were placed in a water bath and incubated for 30 min at $60{ }^{\circ} \mathrm{C}$, resulting in destructing the tissues and dissolution of the $\mathrm{Ag}$. Then the samples were allowed to cool down to room temperature, diluted and total Ag content was measured by ICP-MS using a Thermo X Series 2 ICP-MS instrument. This ICP-MS was equipped with an auto-sampler and a conical glass concentric nebuliser and operated at a radio frequency power of $1400 \mathrm{~W}$. Acquisition of data was performed in the selected ion mode characteristic for silver ( $\mathrm{m} / \mathrm{z}$ ratio of 107 ), and quantification was based on an ionic silver standard diluted in the same acidic matrix used for tissue samples, with a detection limit of $50 \mathrm{ng} / \mathrm{kg}$ DW tissue.

Single particle ICP-MS (sp-ICP-MS)

In order to analyse for particulate $\mathrm{Ag}$ in earthworm tissues, ground samples were first processed enzymatically [28]. Briefly, $500 \mathrm{mg}$ subsamples of the powdered earthworm tissues were weighed into digestion tubes and homogenized in a low-salt buffer $(20 \mathrm{mM}$ 4-(2-hydroxyethyl)piperazine-ethanesulfonic acid (HEPES), pH 7.9, 25\% glycerol, $1.5 \mathrm{mM}$ $\mathrm{MgCl}_{2}, 0.02 \mathrm{M} \mathrm{KCl}, 0.2 \mathrm{mM}$ ethylene diamine tetra acetic acid, $0.2 \mathrm{mM}$ phenylmethylsulfonyl fluoride and $0.5 \mathrm{mM}$ dithiothreitol). In the first digestion step, 500 $\mu \mathrm{l}$ collagenase $(10 \mathrm{mg} / \mathrm{ml})$ and $1.5 \mathrm{ml}$ hyaluronidase $(90 \mu \mathrm{g} / \mathrm{ml})$ were added to the mixture above, and incubated in a water bath overnight at $37{ }^{\circ} \mathrm{C}$ with shaking. The second digestion step involved adding $500 \mu \mathrm{l}$ proteinase $\mathrm{K}(1 \mathrm{mg} / \mathrm{ml})$ to the first digest, with subsequent incubation of the mixture for another $2 \mathrm{~h}$ at $65{ }^{\circ} \mathrm{C}$. The final digests were allowed to cool down to room temperature, then layered over saturated sucrose $(130 \%)$ cushion in $15-\mathrm{ml}$ centrifuge tubes and centrifuged at $21000 \mathrm{~g}$ for $25 \mathrm{~min}$ (Eppendorf North America, Westbury, NY). The force of centrifugation allows the 
extracted particles to collect at the bottom of the tube, while the upper sucrose supernatant was discarded leaving $1 \mathrm{ml}$ portions containing AgNPs. Extracted AgNPs were then re-suspended in 0.1\% FL-70 (Fisher Scientific) with $0.01 \%$ sodium azide (Acros Organics BVBA, Geel, Belgium).

Of the processed samples, $5 \mathrm{ml}$ was further diluted in milliQ for sp-ICP-MS measurements according to methods we have previously reported [28, 36]. This facilitated particle size distribution comparisons between the pristine AgNPs and NPs extracted from the earthworm tissues. The sp-ICP-MS measurements were carried out using a Thermo Scientific X Series 2 ICP-MS instrument equipped with a standard nebuliser and a quartz impact bead spray chamber $[28,36]$. Dwell time was set at $3 \mathrm{~ms}$ with acquisition time typically for $60 \mathrm{~s}$ per measurement. The detection limit for the spICP-MS analyses was $1 \mu \mathrm{g} / \mathrm{kg}$ tissue DW. Data obtained were processed by the data evaluation tool in Microsoft Excel developed by RIKILT, the Netherlands Institute for Food Safety [36].

\section{Results}

\section{Characterization of synthesized AgNPs}

Fig. 4.1 presents the TEM images of the tested AgNPs showing that the primary particle sizes targeted by the synthesis of AgNPs were attained for all coating types. Also, the morphology of the particles were preserved after conjugation and lyophilisation processes (see SI Fig. S4.1). The average particle sizes (Table 4.1) and their distributions (Fig. 4.2) as assessed by TEM analyses were within target ranges, with the frequency curves shifting from left to right as particle sizes increases. Sp-ICP-MS results of pristine NPs also showed particle size distributions within expected ranges for all AgNPs (Fig. 4.4 top panels, and SI Fig. S4.2). Mean particle sizes were AgNP_BSA (20, 36 and $47 \mathrm{~nm}$ ), AgNP_Chit (22, 32 and $43 \mathrm{~nm})$, and AgNP_PVP (24, 36 and $47 \mathrm{~nm})$, for 20, 35 and $50 \mathrm{~nm}$ sizes, respectively. However, the particle size distributions of the 35 and $50 \mathrm{~nm}$ AgNP_Chit indicated the formation of agglomerates (SI Fig. S4.2 and Fig. 4.4). Before coating the AgNPs, the SPR peaks were centred at 405, 430 and $441 \mathrm{~nm}$ (SI Fig. S4.1, dashed lines), while the hydrodynamic sizes for 20, 35 and $50 \mathrm{~nm}$ AgNPs were 36, 46 and $55 \mathrm{~nm}$, respectively. The SPR peaks shifted 6-8 $\mathrm{nm}$ in the case of AgNP_BSA, 9-10 nm for the AgNPs_Chit and 2-3 nm for the AgNPs_PVP (Table S4.1). The shape of the SPR peaks were preserved in both milliQ water and soil extract (SI Fig. S4.1) with the exception of the $20 \mathrm{~nm}$ AgNP_PVP and $35 \mathrm{~nm}$ AgNP_Chit suspensions in soil extract, whose SPR peaks were not as distinct indicative of formation of some agglomerates. 


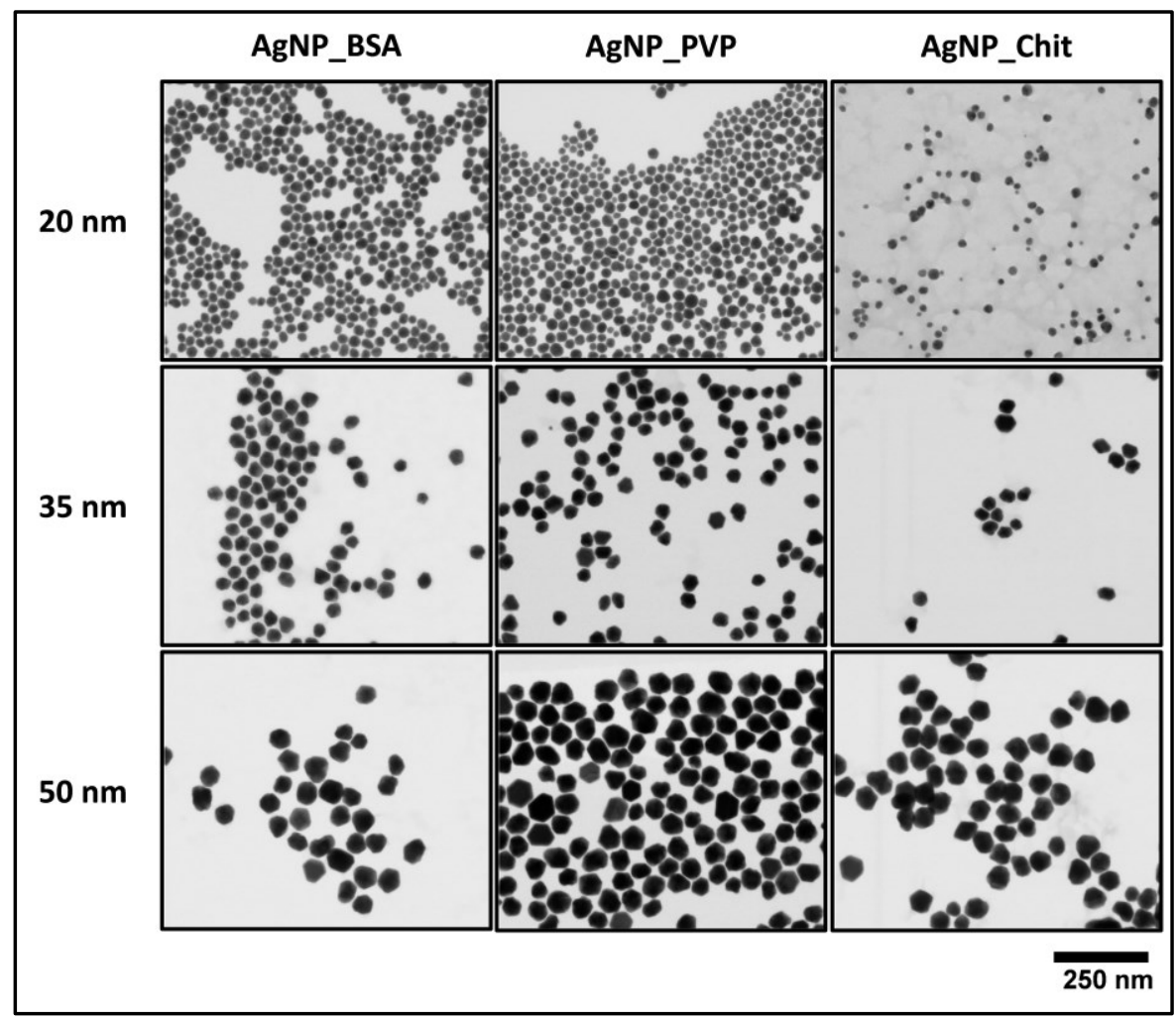

Fig. 4.1 TEM images of re-suspended AgNPs (in milliQ water) showing quasi-spherical nanoparticles within the expected size ranges, with overall average diameter of $20.5 \pm 5.0 \mathrm{~nm}, 37.6 \pm 4.2 \mathrm{~nm}$ and $51.3 \pm 6.1 \mathrm{~nm}$ for 20 $\mathrm{nm}$ (top panels), $35 \mathrm{~nm}$ (middle panels) and $50 \mathrm{~nm}$ (bottom panels) size groups, respectively.

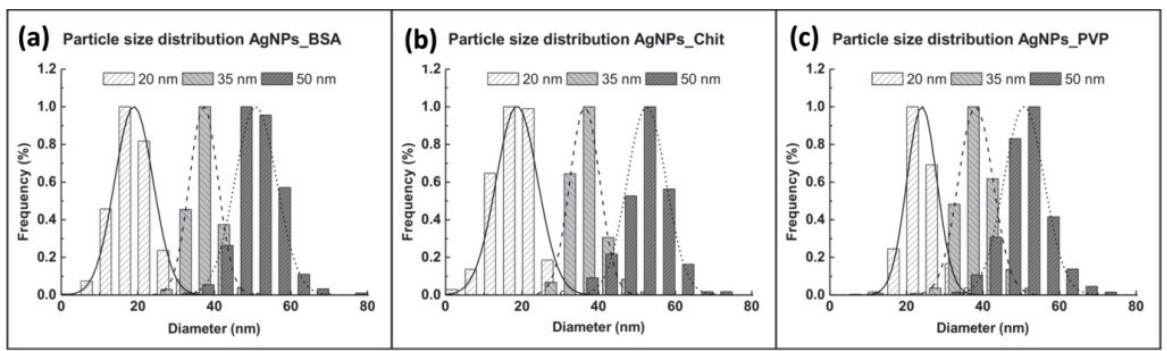

Fig. 4.2 Particle size distribution of AgNP_BSA (a), AgNP_Chit (b) \& AgNP_PVP (c) showing frequency counts as determined by transmission electron microscopy (TEM). The frequency curves for the different sizes of AgNPs cantered at 20nm (solid lines); $35 \mathrm{~nm}$ (broken lines); $50 \mathrm{~nm}$ (dotted lines). 
Table 4.1. AgNP characterization showing both TEM and hydrodynamic (DLS) sizes of AgNPs, their surface Plasmon Resonance (SPR) peaks from UV-Vis, and $\zeta$-potentials ( $\mathrm{meV}$, milli-electron volts). Measurements were performed in milliQ water or soil extract (S.E.), and data are presented as mean \pm standard deviations ( $\mathrm{n}=3$ ). Soil extract $\mathrm{pH}$ was 5.5

\begin{tabular}{|c|c|c|c|c|c|c|c|c|c|c|}
\hline & & \multicolumn{3}{|c|}{ AgNP_BSA (negative) } & \multicolumn{3}{|c|}{ AgNP_Chit (positive) } & \multicolumn{3}{|c|}{ AgNP_PVP ('neutral') } \\
\hline & & $20 \mathrm{~nm}$ & $35 \mathrm{~nm}$ & $50 \mathrm{~nm}$ & $20 \mathrm{~nm}$ & $35 \mathrm{~nm}$ & $50 \mathrm{~nm}$ & $20 \mathrm{~nm}$ & $35 \mathrm{~nm}$ & $50 \mathrm{~nm}$ \\
\hline TEM Size (nm) & water & $19.5 \pm 5.4$ & $37.4 \pm 3.7$ & $51.1 \pm 5.7$ & $18.2 \pm 5.1$ & $37.2 \pm 4.3$ & $51.9 \pm 6.4$ & $24.0 \pm 4.6$ & $38.2 \pm 4.5$ & $51.0 \pm 6.1$ \\
\hline Hydrodynamic size & water & $41.5 \pm 1.3$ & $55.0 \pm 0.5$ & $65.3 \pm 0.1$ & $247.8 \pm 2.1$ & $238.8 \pm 3.1$ & $241.8 \pm 5.1$ & $46.8 \pm 0.1$ & $57.6 \pm 0.7$ & $68.4 \pm 0.6$ \\
\hline Hydrodynamic size & S.E. & $112.0 \pm 1.4$ & $172.1 \pm 4.0$ & $284.2 \pm 2.3$ & $215.1 \pm 1.4$ & $225.1 \pm 1.7$ & $234.5 \pm 1.2$ & $132.8 \pm 2.3$ & $73.7 \pm 0.6$ & $104.2 \pm 0.7$ \\
\hline ל-potential (meV) & water & $-29.0 \pm 2.0$ & $-33.1 \pm 1.6$ & $-37.0 \pm 2.0$ & $+8.0 \pm 2.0$ & $+6.9 \pm 0.1$ & $+7.0 \pm 1.0$ & $-16 \pm 2.0$ & $-23.0 \pm 2.1$ & $-25.0 \pm 2.0$ \\
\hline$\zeta$-potential (meV) & S.E. & $-38.3 \pm 1.6$ & $-44.2 \pm 0.7$ & $-42.5 \pm 0.9$ & $+11.2 \pm 0.4$ & $+19.2 \pm 0.2$ & $+14.1 \pm 2.2$ & $-15.2 \pm 0.1$ & $-20.6 \pm 0.7$ & $-20.8 \pm 0.5$ \\
\hline SPR peaks (nm) & water & 413 & 437 & 448 & 413 & 438 & 449 & 408 & 432 & 443 \\
\hline SPR peaks (nm) & S.E. & 412 & 435 & 447 & 413 & 446 & 450 & 405 & 431 & 444 \\
\hline
\end{tabular}


DLS measurements in milliQ water and soil extract showed larger particles sizes (Table 4.1) than those obtained from TEM as would be expected [37]. AgNP_Chit formed agglomerates during re-suspension, and the large particles led to a large average diameter between 200 and $350 \mathrm{~nm}$ regardless of core sizes. The surface charges of the AgNPs measured in water and soil extract showed comparable $\zeta$-potentials for all AgNPs (Table 4.1).

\section{Quantification and characterization of AgNPs in earthworm tissues:}

Measured total tissue concentrations of Ag in whole earthworms (Fig. 4.3) showed that accumulation of Ag for all tested AgNPs occurred in a concentration-dependent manner. Overall, uptake was highest for the AgNP_BSA, especially at the lower exposure concentration ranges, and seem to reach a plateau level at soil concentrations between 50 - $100 \mathrm{mg} \mathrm{Ag/kg}$ soil DW (Fig. 4.3a). Total Ag tissue concentrations in earthworms exposed to AgNP_BSA were overall significantly higher than those observed for AgNP_Chit and AgNP_PVP treated groups ( $p$ values of 0.007 and 0.002 , respectively), while the latter did not differ significantly from each other. While the uptake of $20 \mathrm{~nm}$ AgNP_Chit was significantly higher compared to its other sizes, there were no statistically significant differences in tissue Ag concentrations between the 35 and $50 \mathrm{~nm}$ size groups (Fig. 4.3b). With the AgNP_PVP, the $20 \mathrm{~nm}$ sizes were significantly accumulated more than the other sizes. The resulting uptake profile was similar to that of the AgNP_BSA, attaining a plateau Ag tissue concentration at low exposures (Fig. 4.3c). Earthworms exposed to the 35 and $50 \mathrm{~nm}$ sizes of AgNP_PVP, had the lowest Ag

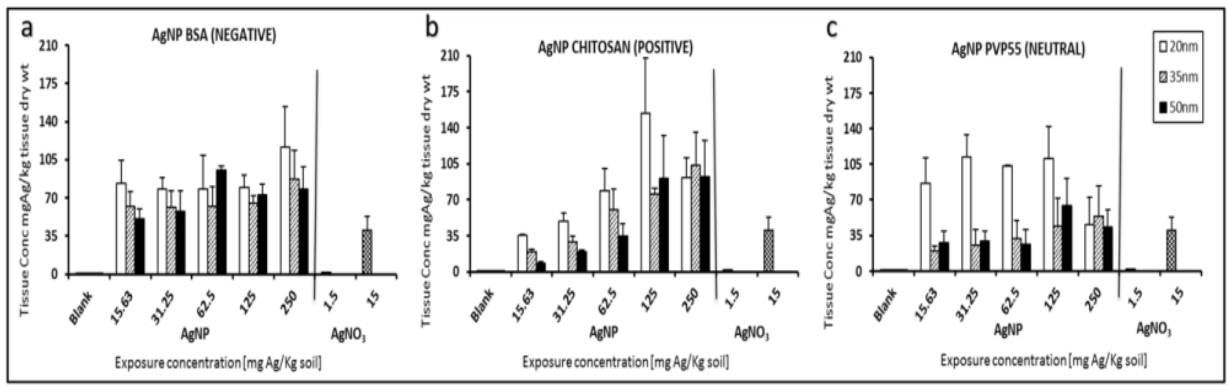

Fig. 4.3. Total Ag tissue concentration in earthworms exposed to different AgNPs in a 28-days sub-chronic reproduction toxicity test measured by ICP-MS. Nominal exposure concentrations ranged from $0-250 \mathrm{mg}$

$\mathrm{AgNP} / \mathrm{kg}$ soil DW Checkerboard-filled bars to the right of each graph represents uptake of $\mathrm{AgNO}_{3}$

tissue concentration measured, with the highest exposure resulting in about $50 \mathrm{mg}$ $\mathrm{Ag} / \mathrm{kg} \mathrm{DW}$ (Fig. 4.3c). Uptake of ionic $\mathrm{Ag}$ (mg Ag/kg tissue DW) for the high $\mathrm{AgNO}_{3}$ 
exposure was in the same order of magnitude as that of particulate exposure. Although size and surface coating of AgNPs had some effect, exposure concentrations had the most effect on internal tissue concentrations $(p<0.001)$.

Characterization of AgNPs by sp-ICP-MS in earthworm tissues was performed only for the $50 \mathrm{~nm}$ treatment groups only due to the limit of resolution of the sp-ICP-MS method (ca. $30 \mathrm{~nm}$ for a quadrupole ICP-MS instrument). Particulate Ag was detected in earthworm tissue showing size distributions in the expected ranges with average sizes of 51, 53 and 49 nm for AgNP_BSA, AgNP_Chit and AgNP_PVP, respectively (Fig. 4.4). The size distributions of the particles extracted from the tissues of earthworms are somewhat narrower than for the pristine particles, but also presenting some large agglomerates. This was best observed with the AgNP_Chit where tissue AgNPs appear to be more monodispersed than those in pristine particle suspensions (Fig. 4.4). Mean particle sizes of pristine and tissue extracted AgNPs were however comparable - pristine (extracted): AgNP_BSA 47 (51); AgNP_Chit 43 (53), and; AgNP_PVP 47 (49).
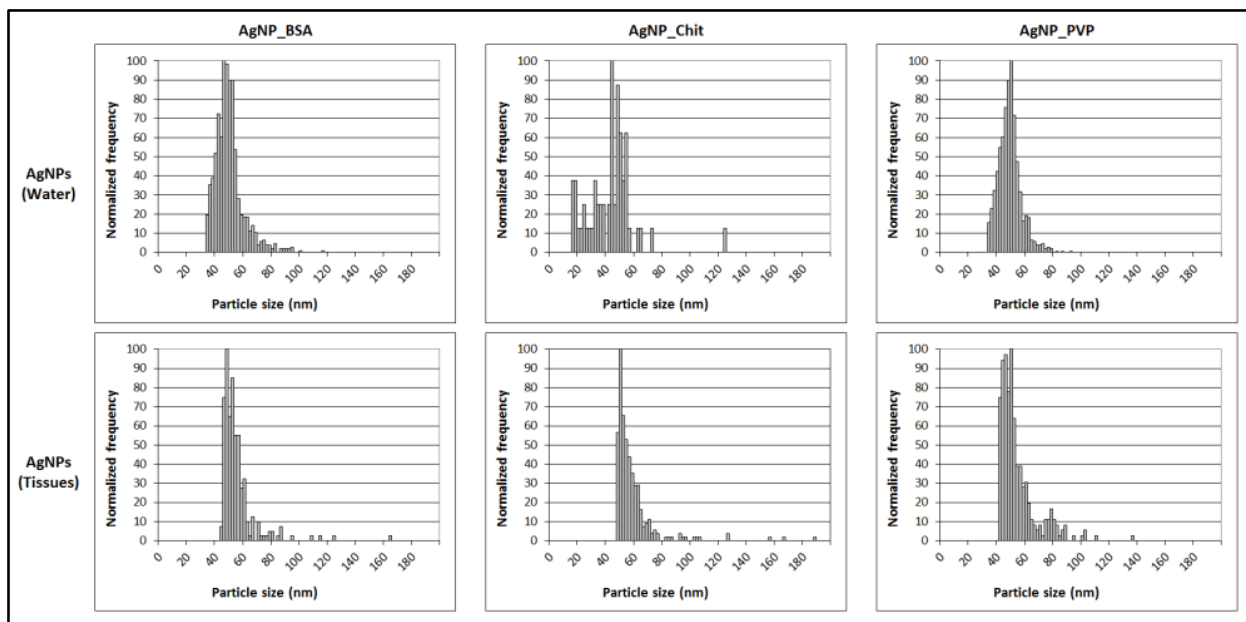

Fig. 4.4. Representative sp-ICP-MS particle size distribution of $50 \mathrm{~nm}$ AgNPs before soil exposure (top frames), and eluted from tissue of Lumbricus rubellus exposed for 28 days to $250 \mathrm{mg} \mathrm{AgNP/kg} \mathrm{soil} \mathrm{(bottom} \mathrm{frames).}$ Mean particle sizes of eluted AgNPs $(51,53,49 \mathrm{~nm})$ were comparable with pre-exposure averages $(47,43,47$ $\mathrm{nm}$ ) for AgNP_BSA, AgNP_Chit and AgNP_PVP, respectively. Limit of resolution was $30 \mathrm{~nm}$ (quadrupole ICP-MS instrument)

\section{Effects of AgNPs on survival, growth rate and cocoon production}

Although internal concentrations of Ag vary between treatments, this had no effect on survival of earthworms. Daily growth rate was affected by exposure concentration, 
tissue concentration and type of coating, but not by size of AgNPs. AgNP_BSA and AgNP_Chit treated earthworms showed similar growth patterns, while AgNP_PVP had significantly less effect on growth (Table 4.2, and also see SI, Fig. S4.3). The number of cocoons laid was observed to be most affected overall by AgNP_BSA particles (Fig. 4.5) whose $\mathrm{EC}_{50}$ for the $20 \mathrm{~nm}$ size was $66.8 \mathrm{mg} \mathrm{Ag} / \mathrm{kg}$ tissue DW (Table 4.2).

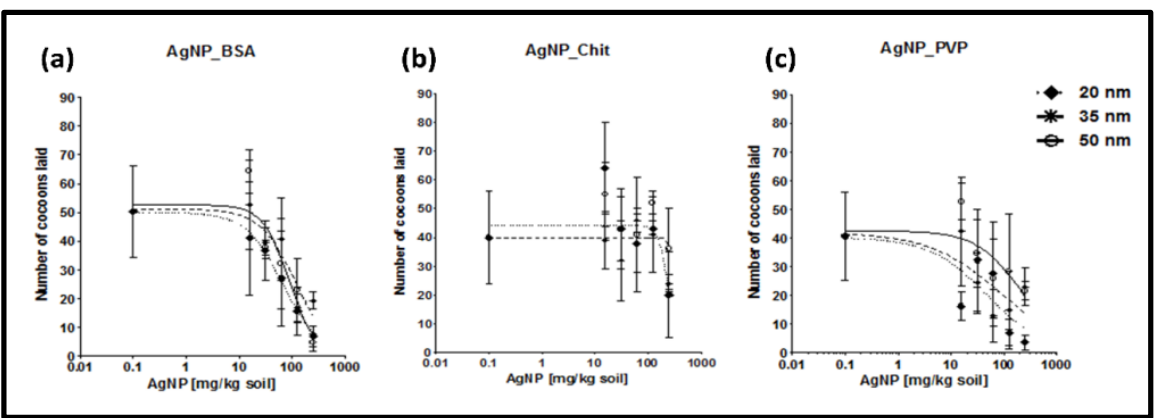

Fig. 4.5 Reproductive toxicity of Lumbricus rubellus exposed to AgNP_BSA, AgNP_Chit and AgNP_PVP expressed as average cocoon production (number of cocoons laid). Results are expressed as mean \pm standard deviation, $\mathrm{n}=3$. Dotted lines and filled diamonds $(20 \mathrm{~nm})$; broken lines and asterix $(35 \mathrm{~nm})$, solid lines and empty circles $(50 \mathrm{~nm})$. The regression curve for $50 \mathrm{~nm}$ AgNP_Chit could not be fitted; data did not meet statistical criteria

Table 4.2. $\mathrm{EC}_{50} \mathrm{~S}$ based on cocoon production (number of cocoon laid). ${ }^{\mathrm{a}}$ Values greater than the highest exposure concentration ( $250 \mathrm{mg} \mathrm{Ag} / \mathrm{Kg}$ soil)

\begin{tabular}{lccccccccc}
\hline EC 50 s (mg Ag/Kg soil) & \multicolumn{3}{c}{ AgNP_BSA } & \multicolumn{3}{c}{ AgNP_Chit } & \multicolumn{4}{c}{ AgNP_PVP } \\
\hline \multicolumn{1}{c}{ Size $(\mathrm{nm})$} & 20 & 35 & 50 & 20 & 35 & 50 & 20 & 35 & 50 \\
\hline Growth & $>250^{\mathrm{a}}$ & $>250$ & 142 & $>250$ & $>250$ & NA & 117 & NA & NA \\
Mortality & NA & NA & NA & NA & NA & NA & NA & NA & NA \\
Cocoon production & 66.8 & 118.0 & 87.9 & 242.0 & $>250$ & $>250$ & 48.5 & 88.7 & 217.0 \\
\hline
\end{tabular}

N.A. not available; analyses did not meet statistical criteria hence $\mathrm{EC}_{50} \mathrm{~S}$ could not be derived

\section{Discussion}

\section{NP synthesis, dispersion and characterization}

The desired AgNP size ranges 20, 35 and $50 \mathrm{~nm}$ were achieved by synthesis, and ascertained by TEM and UV-Vis to be within expected desired target size ranges (SI Fig. 
S4.1). The $\zeta$-potentials measured for all AgNPs confirmed that their surface charges were as expected. Re-suspending the 35 and $50 \mathrm{~nm} \mathrm{AgNP \_ Chit} \mathrm{powders} \mathrm{in} \mathrm{soil} \mathrm{extract}$ however resulted in the formation of agglomerates potentially due to formation of micelles by free chitosan [17]. These agglomerates might have led to an overestimation of the hydrodynamic sizes during the DLS measurements, resulting in rather large NP diameters (Table 4.1). Because the DLS operates on Rayleigh's approximation principle of light scattering by particles, this technique is very sensitive to particle agglomerates and/or any aggregation in NP suspensions [38]. Therefore, the occurrence of even low numbers of agglomerates may suggest much larger particles sizes than actually may be the case. The large particles observed with AgNP_Chit represent a small fraction of the NPs, otherwise the SPR peaks would not be preserved (SI Fig. S4.1). The UV-Vis spectra demonstrated that although agglomerates were formed, AgNPs were within expected ranges. Mostly, only slight red shifts in the SPR peaks around $400-450 \mathrm{~nm}$ were observed by UV-Vis spectroscopy after re-suspending the AgNPs in soil extract (SI Fig. S4.1).

Determination of particle size distributions of pristine 20 and $35 \mathrm{~nm}$ AgNPs was not possible by sp-ICP-MS since the resolution of ICP-MS used for the measurements is set at $30 \mathrm{~nm}$ lower cut-off. Moreover, the concentration of ionic $\mathrm{Ag}^{+}$in the tissue samples was high and created noise signals that overshadowed AgNPs spikes hampering resolution. The presence of some agglomerates may indicate that this is the likely fate of AgNPs following a release in soil. The acute effect of the AgNPs could therefore be limited due to the formation of these agglomerates, thereby making the NPs less bioavailable, similar to what has been reported for C60 [39]. However, this may not necessary connote an absence of adverse effects as the toxic potential of the AgNPs may be altered following ageing and decay processes in the soil, leading to the release of $\mathrm{Ag}$ as NPs or dissolved $\mathrm{Ag}^{+}$ions $[6,17,40,41]$. Contrarily, it is also possible that the evolution of AgNPs in ageing soil may lead to loss of toxicity.

\section{AgNPs uptake and characterization in tissues}

Uptake of AgNPs under environmentally realistic conditions has been shown to be relatively low $[16,28,35,42]$, likely due to the dynamic interactions between the NPs' physical and chemical properties, exposure matrices and the physiological processes in the target organism. In the present study, we observed higher uptake of the tested AgNPs but tissue concentrations of Ag were mostly less than $150 \mathrm{mg} \mathrm{Ag/Kg}$ tissue DW for the highest exposures (Fig. 4.3) representing a biota-soil accumulation factor (BASF) of < 1. We also observed that tissue Ag concentrations rapidly approach a plateau as has also 
been alluded to by an earlier report on the uptake and toxicity of three forms of $\mathrm{Ag}$ (citrate or PVP-coated AgNPs, and ionic $\mathrm{Ag}^{+}$) to Enchytraeus crypticus [19]. The investigators reported that uptake of $\mathrm{Ag}$ by E. crypticus reached a steady state after only 7-10 days of exposure to aqueous solutions of the AgNPs added to an inert quartz sand medium. Generally, total tissue concentrations of Ag in whole earthworms (Fig. 4.3) did not seem to be affected by the sizes of AgNPs tested similar to earlier reports [42, 43]. Only with AgNP_PVP were differences in uptake observed, with higher tissue Ag concentrations in earthworms exposed to the $20 \mathrm{~nm}$ sized group. This may be indicative of the effect of size due to their corresponding larger specific surface area, which increases their reactivity and dissolution $[44,45]$.

Particulate Ag quantified in earthworm tissues was around 1\% of total tissue Ag burden which was low compared to the ratio of particulate:ionic Ag concentrations measured in an earlier report where particulate Ag comprised about 33\% of total concentration in tissues [28]. This may be due to several reasons including high dissolution of the AgNPs used in the present study after uptake, as well as the different capping molecules. In the previous study cited above, the AgNPs we tested were commercially obtained as aqueous nanospheres and were coated with PVP. Indeed, total Ag uptake from the AgNP_PVP exposures in this current study was less compared to the AgNP_BSA or AgNP_Chit counterparts. This may potentially be due to the relatively low uptake of PVPcoated AgNPs generally and even lower uptake of high molecular weight PVP-coated AgNPs [46].

\section{Survival, growth and cocoon production}

Within the exposure duration of 28-days applied in our investigations, mortality and growth rates were not significantly affected by exposure to the AgNPs tested in the current study (see SI Fig. S4.3). Similar to our observations, findings following exposure of E. crypticus to AgNP_Citrate and AgNP_PVP for up to 10 days showed no evidence of NP-specific effects on mortality [19]. In another study, AgNPs also elicited effects mainly on reproduction, reducing the number of cocoons laid to $18 \%$, while mortality in adult $L$. rubellus was not observed with all earthworms surviving the 28-day exposure [35]. Similar to other end-points tested, growth was affected by the exposure concentration, tissue concentration and type of AgNPs tested, but not by size. AgNP_BSA and AgNP_Chit treated earthworms showed similar growth patterns, while AgNP_PVP had significantly lower effects on growth. The number of cocoons laid was observed to be most affected overall by AgNP_BSA particles, but the $\mathrm{EC}_{50} \mathrm{~S}$ of AgNP_PVP 20 and $35 \mathrm{~nm}$ were similar to those of AgNP_BSA (Fig. 4.5 and Table 4.2). 
The size of the tested AgNPs seem to have little or no effect on their uptake or toxicity perhaps due to the narrow range tested. Therefore inclusion of larger NPs to cover the full size range $10-100 \mathrm{~nm}$ could have revealed an effect of size on fate and toxicity of AgNPs. Although some studies with gold nanoparticles in the sub $10 \mathrm{~nm}$ size range showed effects of size [47], it has been proposed that there may be an optimal size for uptake of NPs, likely in the range of $30-50 \mathrm{~nm}$ [48]. In our study, exposure concentration of AgNPs in soil was most important in explaining the observed effects, with toxicity increasing as exposure concentration increases. This is as expected since higher exposure concentrations resulted in higher internal concentrations of $\mathrm{Ag}$ in earthworms. Interestingly, although AgNP_Chit was expected to be more toxic owing to its positive surface charge favouring its higher uptake $[27,49]$, this was not the case. Likely explanation for the lesser effect of the positively charged AgNP_Chit could be due to the formation of agglomerates in soil pore water similarly as described for citrated AgNP which formed agglomerates due to citrate's electrostatic stabilization [19], leading to less bioavailability and uptake. Generally, the highest uptake and effects of AgNPs exposure were observed with the AgNP_BSA negatively charged particles. The observations made here are in agreement with our earlier report on the cellular interactions of these AgNPs with macrophages (Chapter 2) where the same AgNP_BSA were found to be more potent in inducing cytotoxicity. This may be related to the electrostatic interactions between the BSA-coated NPs and the negatively charged cellular membrane $[50,51]$ enhanced by the surface chemistry ascribed by the protein corona.

The predicted environmental concentrations (PEC) of AgNPs reported in literature, range from 0.02 to $0.1 \mu \mathrm{g} / \mathrm{kg}$ [52]. Taking the lowest $\mathrm{EC}_{50}$ value among all tested AgNPs of 48.5 mg Ag/kg DW for AgNP_PVP (Table 4.1) in the current study based on cocoon production, an estimate of a Predicted No-Effect-Concentration (PNEC) could be determined. Assuming an assessment factor of $10^{3}$ considering low accuracy of data [52], accounting for only a single species, and including the fact that this was a subchronic EC 50 , the estimated PNEC for AgNPs is $48.5 \mu \mathrm{g} / \mathrm{kg}$. This implies that the current risk quotients (PEC/PNEC) would be far below 1, indicating low risks for AgNPs in agreement with earlier reports [53]. Similarly, van der Ploeg et al. [35] reported a significant decrease in cocoon production at $154 \mathrm{mg} \mathrm{AgNP/kg}$ soil exposure, resulting in an estimated PEC of about $154 \mu \mathrm{g} / \mathrm{kg}$ and a PEC/PNEC also far below 1 . Modelled population growth rates in the cited study showed a significant decrease already at 1.5 $\mathrm{mg} / \mathrm{kg}$ soil, indicating a PNEC value of $1.5 \mu \mathrm{g} / \mathrm{kg}$. Since natural background concentration of AgNP in soil are not known, it should be noted that predictions of this nature may likely underestimate the risks. Nevertheless, the result of the current study and those of others, together with the fact that the presence of AgNPs in the environment, even in 
soils treated with biosolids, is currently in the range of $<1 \mu \mathrm{g} / \mathrm{kg}$ [53], may indicate low concern.

\section{Conclusion}

Based on the findings in this study the effect of size on the uptake and toxicity of AgNPs was not particularly apparent within the size range of AgNPs tested. Surface coating demonstrated effects on reproduction, with AgNP_BSA and small AgNP_PVP being more potent. Also, the negatively charged AgNP_BSA NPs accumulated more in the tissues of exposed earthworms. AgNPs coated with BSA and similar biological molecules will have higher uptake from the soil, leading to higher potential for toxicity in organisms. This study will add to the much needed data on fate and effect of AgNPs in especially soil and soil organisms and it is essential towards developing comprehensive environmental risk assessment of AgNPs. By improving our understanding of exposure and hazard in the soil, adequate and comprehensive environmental risk assessment of AgNPs is enabled.

\section{Acknowledgements}

This work was financially supported by NanoNextNL, a micro- and nano-technology consortium of the Government of The Netherlands and 130 partners; funding was also received from Managing Risks of Nanoparticles, MARINA (EU-FP7, contract CP-FP 263215), and; the Strategic Research Funds titled Novel technologies by the Ministry of Economic Affairs of The Netherlands. Synthesis and characterization of the AgNPs used in this study received support from the QualityNano Project http://www.qualitynano.eu/ which is financed by the European Community Research Infrastructures under the FP7 Capacities Programme (Grant No. INFRA-2010-262163).

\section{Supplementary Material}

Supporting material associated with this manuscript is available on the online version.

\section{Declaration of interest}

The authors declare no conflicts of interest. 


\section{$\underline{\text { References }}$}

[1] Ahamed M, Alsalhi MS, Siddiqui MK. Silver nanoparticle applications and human health. Clin Chim Acta. 2010, 411(23-24), 1841-8. doi10.1016/j.cca.2010.08.016

[2] Haider A, Kang IK. Preparation of Silver Nanoparticles and Their Industrial and Biomedical Applications: A Comprehensive Review. Advances in Materials Science and Engineering. 2015, 2015, 16. doi10.1155/2015/165257

[3] Vance ME, Kuiken T, Vejerano EP, McGinnis SP, Hochella MF, Jr., Rejeski D, et al. Nanotechnology in the real world: Redeveloping the nanomaterial consumer products inventory. Beilstein journal of nanotechnology. 2015, 6, 1769-80. doi10.3762/bjnano.6.181

[4] Benn T, Cavanagh B, Hristovski K, Posner JD, Westerhoff P. The Release of Nanosilver from Consumer Products Used in the Home. J Environ Qual. 2010, 39(6), 1875-82. doi10.2134/jeq2009.0363

[5] Geranio L, Heuberger M, Nowack B. The behavior of silver nanotextiles during washing. Environ Sci Technol. 2009, 43(21), 8113-8. doi10.1021/es9018332

[6] Reidy B, Haase A, Luch A, Dawson K, Lynch I. Mechanisms of Silver Nanoparticle Release, Transformation and Toxicity: A Critical Review of Current Knowledge and Recommendations for Future Studies and Applications. Materials. 2013, 6(6), 2295-350. doi10.3390/ma6062295

[7] Wijnhoven SWP, Peijnenburg WJGM, Herberts CA, Hagens WI, Oomen AG, Heugens EHW, et al. Nanosilver - a review of available data and knowledge gaps in human and environmental risk assessment. Nanotoxicology. 2009, 3(2), 109-38. doi10.1080/17435390902725914

[8] Wijnhoven SWP, Oomen AG, Sips AJAM, Bourgeois FC, te Dorsthorst JPM, Kooi MW, et al. Development of an inventory for consumer products containing nanomaterials Final Report. RIVM Report. 2010, (070307/2010/580587/SER/D3), 1-103.

[9] Bastús NG, Merkoçi F, Piella J, Puntes V. Synthesis of Highly Monodisperse Citrate-Stabilized Silver Nanoparticles of up to 200 nm: Kinetic Control and Catalytic Properties. Chem Mater. 2014, 26(9), 2836-46. doi10.1021/cm500316k

[10] Evanoff DD, Jr., Chumanov G. Synthesis and optical properties of silver nanoparticles and arrays. Chemphyschem. 2005, 6(7), 1221-31. doi10.1002/cphc.200500113

[11] Shenashen MA, El-Safty SA, Elshehy EA. Synthesis, Morphological Control, and Properties of Silver Nanoparticles in Potential Applications. Particle \& Particle Systems Characterization. 2014, 31(3), $293-$ 316. doi10.1002/ppsc.201300181

[12] Abou El-Nour KMM, Eftaiha Aa, Al-Warthan A, Ammar RAA. Synthesis and applications of silver nanoparticles. Arabian Journal of Chemistry. 2010, 3(3), 135-40. doi10.1016/j.arabjc.2010.04.008

[13] Chanana M, Liz-Marzán Luis M. in Nanophotonics 2012, pp. 199.

[14] Kreuter J. Influence of the surface properties on nanoparticle-mediated transport of drugs to the brain. Journal of nanoscience and nanotechnology. 2004, 4(5), 484-8. doi10.1166/jnn.2003.077

[15] Roohani-Esfahani SI, Nouri-Khorasani S, Lu Z, Appleyard R, Zreiqat H. The influence hydroxyapatite nanoparticle shape and size on the properties of biphasic calcium phosphate scaffolds coated with hydroxyapatite-PCL composites. Biomaterials. 2010, 31(21), 5498-509. doi10.1016/j.biomaterials.2010.03.058

[16] Shoults-Wilson WA, Reinsch BC, Tsyusko OV, Bertsch PM, Lowry GV, Unrine JM. Effect of silver nanoparticle surface coating on bioaccumulation and reproductive toxicity in earthworms (Eisenia fetida). Nanotoxicology. 2011, 5(3), 432-44. doi10.3109/17435390.2010.537382

[17] Izak-Nau E, Huk A, Reidy B, Uggerud H, Vadset M, Eiden S, et al. Impact of storage conditions and storage time on silver nanoparticles' physicochemical properties and implications for their biological effects. RSC Advances. 2015, 5(102), 84172-85. doi10.1039/c5ra10187e

[18] Sharma VK, Filip J, Zboril R, Varma RS. Natural inorganic nanoparticles--formation, fate, and toxicity in the environment. Chem Soc Rev. 2015, 44(23), 8410-23. doi10.1039/c5cs00236b

[19] Topuz E, van Gestel CA. Toxicokinetics and toxicodynamics of differently coated silver nanoparticles and silver nitrate in Enchytraeus crypticus upon aqueous exposure in an inert sand medium. Environ Toxicol Chem. 2015, 34(12), 2816-23. doi10.1002/etc.3123

[20] Yu SJ, Yin YG, Liu JF. Silver nanoparticles in the environment. Environ Sci Process Impacts. 2013, 15(1), 78-92. doi10.1039/C2EM30595J 
[21] Baalousha M, Cornelis G, Kuhlbusch TAJ, Lynch I, Nickel C, Peijnenburg W, et al. Modeling nanomaterial fate and uptake in the environment: current knowledge and future trends. Environ Sci: Nano. 2016, 3(2), 323-45. doi10.1039/c5en00207a

[22] Franci G, Falanga A, Galdiero S, Palomba L, Rai M, Morelli G, et al. Silver nanoparticles as potential antibacterial agents. Molecules (Basel, Switzerland). 2015, 20(5), 8856-74. doi10.3390/molecules20058856

[23] Hwang IS, Hwang JH, Choi H, Kim KJ, Lee DG. Synergistic effects between silver nanoparticles and antibiotics and the mechanisms involved. J Med Microbiol. 2012, 61(Pt 12), $1719-26$. doi10.1099/jmm.0.047100-0

[24] Sondi I, Salopek-Sondi B. Silver nanoparticles as antimicrobial agent: a case study on E. coli as a model for Gram-negative bacteria. J Colloid Interface Sci. 2004, 275(1), 177-82. doi10.1016/j.jcis.2004.02.012

[25] Lara HH, Ayala-Nunez NV, Ixtepan-Turrent L, Rodriguez-Padilla C. Mode of antiviral action of silver nanoparticles against HIV-1. Journal of nanobiotechnology. 2010, 8, 1. doi10.1186/1477-3155-8-1

[26] Foldbjerg R, Irving ES, Hayashi Y, Sutherland DS, Thorsen K, Autrup H, et al. Global gene expression profiling of human lung epithelial cells after exposure to nanosilver. Toxicol Sci. 2012, 130(1), 145-57. doi10.1093/toxsci/kfs225

[27] van der Ploeg MJ, van den Berg JH, Bhattacharjee S, de Haan LH, Ershov DS, Fokkink RG, et al. In vitro nanoparticle toxicity to rat alveolar cells and coelomocytes from the earthworm Lumbricus rubellus. Nanotoxicology. 2014, 8(1), 28-37. doi10.3109/17435390.2012.744857

[28] Makama S, Peters R, Undas A, van den Brink NW. A novel method for the quantification, characterisation and speciation of silver nanoparticles in earthworms exposed in soil. Environmental Chemistry. 2015, 12(6), 643. doi10.1071/en15006

[29] Powers CM, Badireddy AR, Ryde IT, Seidler FJ, Slotkin TA. Silver nanoparticles compromise neurodevelopment in PC12 cells: critical contributions of silver ion, particle size, coating, and composition. Environ Health Perspect. 2011, 119(1), 37-44. doi10.1289/ehp.1002337

[30] Suresh AK, Pelletier DA, Wang W, Morrell-Falvey JL, Gu B, Doktycz MJ. Cytotoxicity induced by engineered silver nanocrystallites is dependent on surface coatings and cell types. Langmuir. 2012, 28(5), 2727-35. doi10.1021/la2042058

[31] Tan C, Fan WH, Wang WX. Role of titanium dioxide nanoparticles in the elevated uptake and retention of cadmium and zinc in Daphnia magna. Environ Sci Technol. 2012, 46(1), 469-76. doi10.1021/es202110d

[32] Yang X, Gondikas AP, Marinakos SM, Auffan M, Liu J, Hsu-Kim H, et al. Mechanism of silver nanoparticle toxicity is dependent on dissolved silver and surface coating in Caenorhabditis elegans. Environ Sci Technol. 2012, 46(2), 1119-27. doi10.1021/es202417t

[33] Peters RJ, Rivera ZH, van Bemmel G, Marvin HJ, Weigel S, Bouwmeester H. Development and validation of single particle ICP-MS for sizing and quantitative determination of nano-silver in chicken meat. Anal Bioanal Chem. 2014, 406(16), 3875-85. doi10.1007/s00216-013-7571-0

[34] van der Zande M, Vandebriel RJ, Van Doren E, Kramer E, Herrera Rivera Z, Serrano-Rojero CS, et al. Distribution, elimination, and toxicity of silver nanoparticles and silver ions in rats after 28-day oral exposure. ACS nano. 2012, 6(8), 7427-42. doi10.1021/nn302649p

[35] van der Ploeg MJ, Handy RD, Waalewijn-Kool PL, van den Berg JH, Herrera Rivera ZE, Bovenschen J, et al. Effects of silver nanoparticles (NM-300K) on Lumbricus rubellus earthworms and particle characterization in relevant test matrices including soil. Environ Toxicol Chem. 2014, 33(4), 743-52. doi10.1002/etc. 2487

[36] Peters R, Herrera-Rivera Z, Undas A, van der Lee M, Marvin H, Bouwmeester H, et al. Single particle ICP-MS combined with a data evaluation tool as a routine technique for the analysis of nanoparticles in complex matrices. J Anal At Spectrom. 2015, 30(6), 1274-85. doi10.1039/c4ja00357h

[37] Foldbjerg R, Olesen P, Hougaard M, Dang DA, Hoffmann HJ, Autrup H. PVP-coated silver nanoparticles and silver ions induce reactive oxygen species, apoptosis and necrosis in THP-1 monocytes. Toxicol Lett. 2009, 190(2), 156-62. doihttp://dx.doi.org/10.1016/j.toxlet.2009.07.009

[38] Hagendorfer H, Kaegi R, Parlinska M, Sinnet B, Ludwig C, Ulrich A. Characterization of silver nanoparticle products using asymmetric flow field flow fractionation with a multidetector approach--a comparison to transmission electron microscopy and batch dynamic light scattering. Anal Chem. 2012, 84(6), 2678-85. doi10.1021/ac202641d

[39] Lyon DY, Fortner JD, Sayes CM, Colvin VL, Hughe JB. Bacterial cell association and antimicrobial activity of a C60 water suspension. Environ Toxicol Chem. 2005, 24(11), 2757-62. doi10.1897/04-649R.1 
[40] Kittler S, Greulich C, Diendorf J, Köller M, Epple M. Toxicity of Silver Nanoparticles Increases during Storage Because of Slow Dissolution under Release of Silver lons. Chem Mater. 2010, 22(16), 4548-54. doi10.1021/cm100023p

[41] Sekine R, Brunetti G, Donner E, Khaksar M, Vasilev K, Jamting AK, et al. Speciation and lability of Ag-, $\mathrm{AgCl}$-, and $\mathrm{Ag} 2 \mathrm{~S}$-nanoparticles in soil determined by X-ray absorption spectroscopy and diffusive gradients in thin films. Environ Sci Technol. 2015, 49(2), 897-905. doi10.1021/es504229h

[42] Shoults-Wilson WA, Reinsch BC, Tsyusko OV, Bertsch PM, Lowry GV, Unrine JM. Role of Particle Size and Soil Type in Toxicity of Silver Nanoparticles to Earthworms. Soil Sci Soc Am J. 2011, 75(2), 365. doi10.2136/sssaj2010.0127nps

[43] Lee JH, Kim YS, Song KS, Ryu HR, Sung JH, Park JD, et al. Biopersistence of silver nanoparticles in tissues from Sprague-Dawley rats. Part Fibre Toxicol. 2013, 10(1), 36. doi10.1186/1743-8977-10-36

[44] Liu J, Sonshine DA, Shervani S, Hurt RH. Controlled release of biologically active silver from nanosilver surfaces. ACS nano. 2010, 4(11), 6903-13. doi10.1021/nn102272n

[45] Liu J, Wang Z, Liu FD, Kane AB, Hurt RH. Chemical transformations of nanosilver in biological environments. ACS nano. 2012, 6(11), 9887-99. doi10.1021/nn303449n

[46] Jang I, Song K, Park J-H, Kim M, Kim D-W, Oh S-G. Effect of PVP molecular weight on the formation of Ag nanoparticles on echinoid-like TiO2. Materials Letters. 2013, 96, 214-7. doi10.1016/j.matlet.2013.01.045

[47] Jiang Y, Huo S, Mizuhara T, Das R, Lee YW, Hou S, et al. The Interplay of Size and Surface Functionality on the Cellular Uptake of Sub-10 nm Gold Nanoparticles. ACS nano. 2015, 9(10), 9986-93. doi10.1021/acsnano.5b03521

[48] Shang L, Nienhaus K, Nienhaus GU. Engineered nanoparticles interacting with cells: size matters. Journal of nanobiotechnology. 2014, 12, 5. doi10.1186/1477-3155-12-5

[49] Shin S, Song I, Um S. Role of Physicochemical Properties in Nanoparticle Toxicity. Nanomaterials. 2015, 5(3), 1351-65. doi10.3390/nano5031351

[50] Treuel L, Brandholt S, Maffre P, Wiegele S, Shang L, Nienhaus GU. Impact of Protein Modification on the Protein Corona on Nanoparticles and Nanoparticle-Cell Interactions. ACS nano. 2014, 8(1), $503-$ 13. doi10.1021/nn405019v

[51] Fleischer CC, Payne CK. Nanoparticle-Cell Interactions: Molecular Structure of the Protein Corona and Cellular Outcomes. Acc Chem Res. 2014, 47(8), 2651-9. doi10.1021/ar500190q

[52] Mueller NC, Nowack B. Exposure modeling of engineered nanoparticles in the environment. Environ Sci Technol. 2008, 42(12), 4447-53. doi10.1021/es7029637

[53] Gottschalk F, Sun T, Nowack B. Environmental concentrations of engineered nanomaterials: review of modeling and analytical studies. Environ Pollut. 2013, 181, 287-300. doi10.1016/j.envpol.2013.06.003 


\section{Supplementary Material}

\section{Materials and methods}

\section{AgNPs synthesis and pre-exposure characterization}

AgNPs used in this study were synthesized at the Catalonia Institute of Nanoscience and Nanotechnology: Institut Català de Nanociència i Nanotecnologia (ICN2), Barcelona, Spain and details of the synthesis and characterization of these AgNPs have been provided previously (Chapter 2). Colloidal, dispersed AgNPs of three different sizes (20, 35 and $50 \mathrm{~nm}$ ) were prepared separately, following a kinetically controlled seededgrowth method previously reported [1] with slight modifications (Chapter 2). The approach is based on the reduction of silver nitrate $\left(\mathrm{AgNO}_{3}\right)$ at $100^{\circ} \mathrm{C}$ by tannic acid (TA) and trisodium citrate hexahydrate (SC). In order to generate negative, positive and neutral NPs, the AgNPs were subsequently surface-coated with bovine serum albumin (AgNP_BSA), chitosan (AgNP_Chit) or polyvinylpyrrolidone (AgNP_PVP), respectively.

AgNP seeds were formed by injecting $5 \mathrm{ml}$ of $2 \mathrm{M} \mathrm{AgNO}_{3}$ into a boiling and continuously stirred solution of SC (5 mM) and TA (0.025-0.075 mM). These AgNP seeds were then grown to the desired sizes by injecting more of the $\mathrm{AgNO}_{3}$ dropwise to avoid formation of new nucleation. During the growth phase of these seeds, the temperature of the solution was reduced to $90^{\circ} \mathrm{C}$, while slowly adding about $15 \mathrm{ml}$ of the $2 \mathrm{M} \mathrm{AgNO}_{3}$ into the reactor. Under these conditions, monodispersed and stable colloidal AgNP solutions (0.25-0.5 g/L or $2.3-4.6 \mathrm{mM})$ were produced for each size. This is followed by a concentration step where the solutions of the synthesized AgNPs were passed through an ultrafiltration system (KrosFlo Research II TFF Systems, Spectrum Laboratories Inc.) that utilizes tangential flow fractionation (TFF). AgNPs with Negative, positive, and neutral surface charges were obtained by subsequently mixing about $200 \mathrm{ml}$ of each of the concentrated solutions of AgNPs with $0.01 \mathrm{mM}$ BSA (AgNP_BSA), $5 \mathrm{mg} / \mathrm{ml}(0.091$ $\mu \mathrm{M}$ ) chitosan (AgNP_Chit) or polyvinylpyrrolidone (neutral AgNP_PVP, $0.05 \mathrm{mM}$ ), respectively. The AgNPs were lyophilized, layered over with argon and kept under dark conditions until use.

All nine AgNPs were characterized in re-suspension media (i. e. soil extract), moisturizing media (milliQ water), or both, using a combination of different techniques in order to enhance a more adequate characterization of the AgNPs. A Shimadzu UV-2400 spectrophotometer was used to measure the localized Surface Plasmon Resonance (SPR) peak of the different AgNPs. For this, $1 \mathrm{ml}$ of each AgNPs suspension was placed in a cuvette, and the spectrum (UV-Vis) acquired in the $300-800 \mathrm{~nm}$ range. Hydrodynamic sizes of the AgNPs were estimated by DLS, with a light source set at a wavelength of 532 
$\mathrm{nm}$ and a fixed scattering angle of $173^{\circ}$. All measurements were conducted at least three times.

\section{Results}

\section{Characterization of synthesized AgNPs}

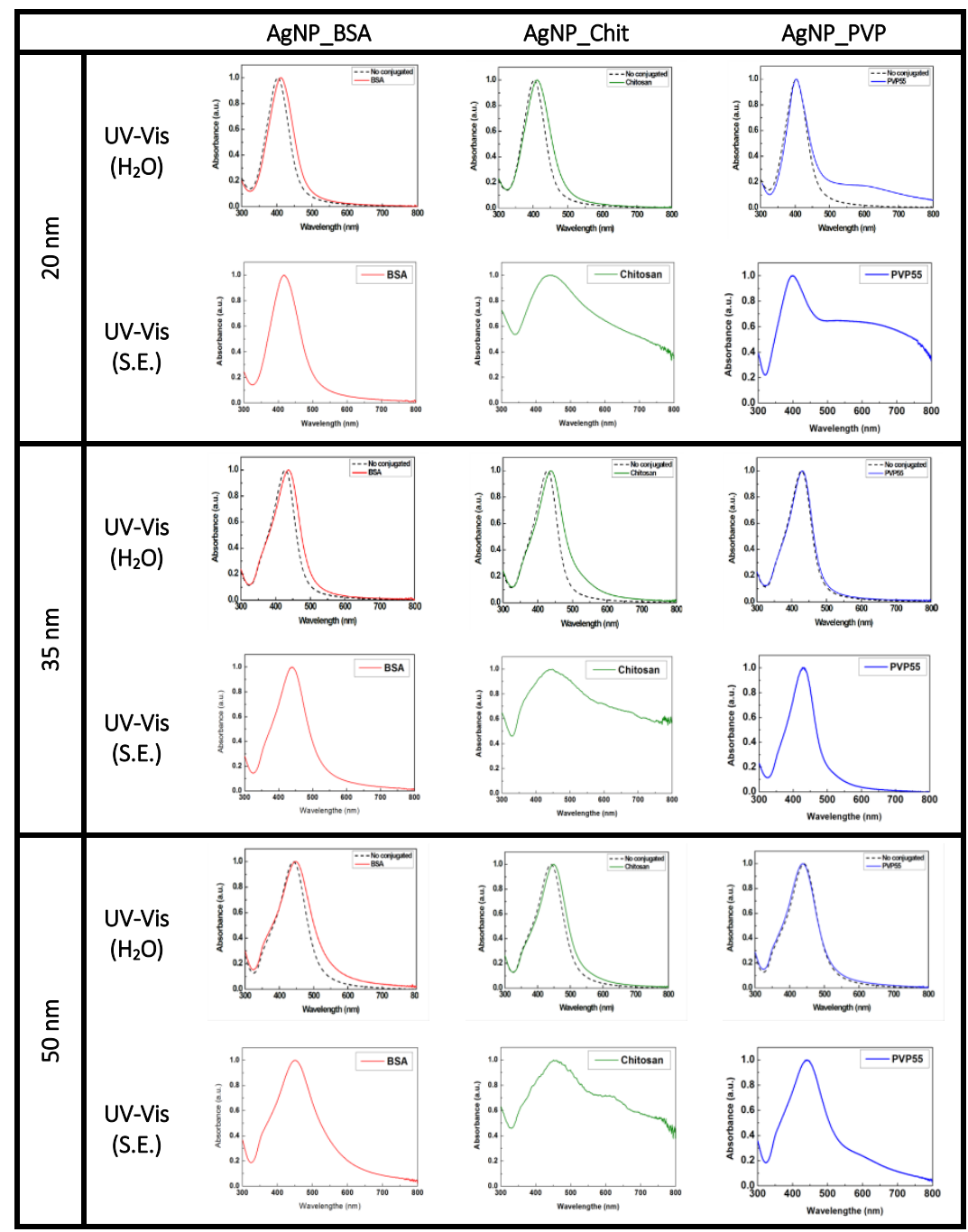

Fig. S4.1 AgNPs UV-Vis spectra showing SPR peaks within the expected wavelength range $300-600 \mathrm{~nm}$ as determined in both milliQ water and in soil extract (S.E.). The SPR curves of conjugated and non-conjugated AgNPs overlaps, with the post-conjugation SPR curves exhibiting a slight red-shift indicative of the effect of AgNPs coating. 
Before coating the AgNPs, the SPR peaks were centred at 405, 430 and $441 \mathrm{~nm}$ (Fig. S4.1, dashed lines), while the hydrodynamic sizes for 20, 35 and $50 \mathrm{~nm}$ AgNPs were 36, 46 and $55 \mathrm{~nm}$, respectively. The SPR peaks shifted 6-8 nm in the case of AgNP_BSA, 9-10 $\mathrm{nm}$ for the AgNPs_Chit and 2-3 nm for the AgNPs_PVP. The shape of the SPR peaks were preserved in both milliQ water and soil extract (Fig. S4.1), which means that the particles were dispersed and stable under these conditions. For the $20 \mathrm{~nm}$ AgNP_PVP, and 35 and $50 \mathrm{~nm}$ AgNP_Chit suspensions in soil extract, the SPR peaks were not as distinct indicating that some agglomerates were formed.

Table S4.1 Monitoring silver nanoparticles synthesis by measuring the Surface Plasmon Resonance (SPR) peaks from UV-Vis before (a) and after (b) surface coating of silver nanoparticles (AgNPs) with bovine serum albumin (BSA), chitosan or polyvinylpyrollidone (PVP) for negative, positive and neutral charges.

\begin{tabular}{|c|c|c|c|c|c|c|c|c|c|c|}
\hline & & \multicolumn{3}{|c|}{ AgNP_BSA (negative) } & \multicolumn{3}{|c|}{ AgNP_Chit (positive) } & \multicolumn{3}{|c|}{ AgNP_PVP (neutral) } \\
\hline & & $20 \mathrm{~nm}$ & $35 \mathrm{~nm}$ & $50 \mathrm{~nm}$ & $20 \mathrm{~nm}$ & $35 \mathrm{~nm}$ & $50 \mathrm{~nm}$ & $20 \mathrm{~nm}$ & $35 \mathrm{~nm}$ & $50 \mathrm{~nm}$ \\
\hline UV-vis SPR peaks ${ }^{a}$ & $\mathrm{~nm}$ & 405 & 430 & 441 & 405 & 430 & 441 & 405 & 430 & 441 \\
\hline UV-vis SPR peaks ${ }^{b}$ & $\mathrm{~nm}$ & 412 & 435 & 447 & 413 & 446 & 450 & 405 & 431 & 444 \\
\hline
\end{tabular}

meV, milli-electron volts

Particle size distributions of pristine AgNPs

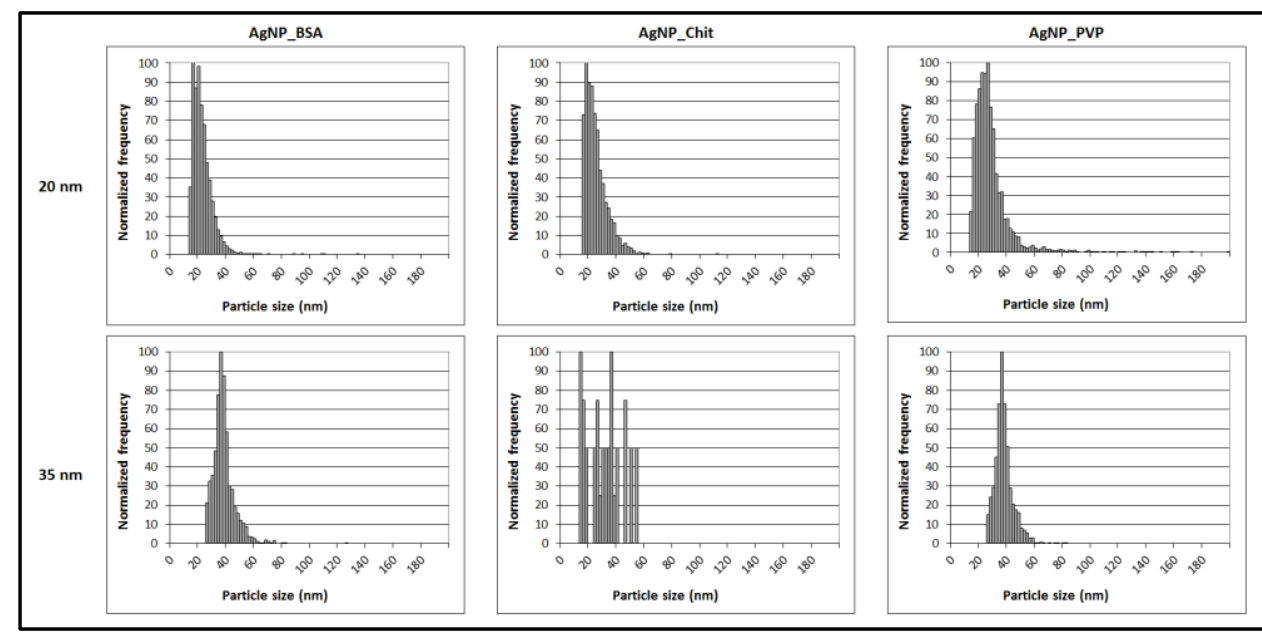

Fig. S4.2 Sp-ICP-MS particle size distributions of pristine 20 and $35 \mathrm{~nm}$ AgNPs dispersed in milliQ water. Targeted mean particle sizes of AgNPs were achieved for AgNP_BSA (20 and $36 \mathrm{~nm}$ ), AgNP_Chit (22 and 32 $\mathrm{nm}$ ), and AgNP_PVP (24 and $36 \mathrm{~nm}$ ). Limit of resolution was $30 \mathrm{~nm}$ (quadrupole ICP-MS instrument) 


\section{Effects of AgNPs on survival and growth rate}

Although the internal tissue concentrations of Ag vary between treatments, this had no effect on survival, and neither were there any significant relationships between survival and soil concentrations or type or size. Growth (weight gain \%) was affected by exposure concentration, tissue concentration and type, but not by size. AgNP_BSA and AgNP_Chit treated earthworms showed similar growth patterns, while AgNP_PVP had significantly lower effects on growth (Fig. 4.3 and Table 4.2).

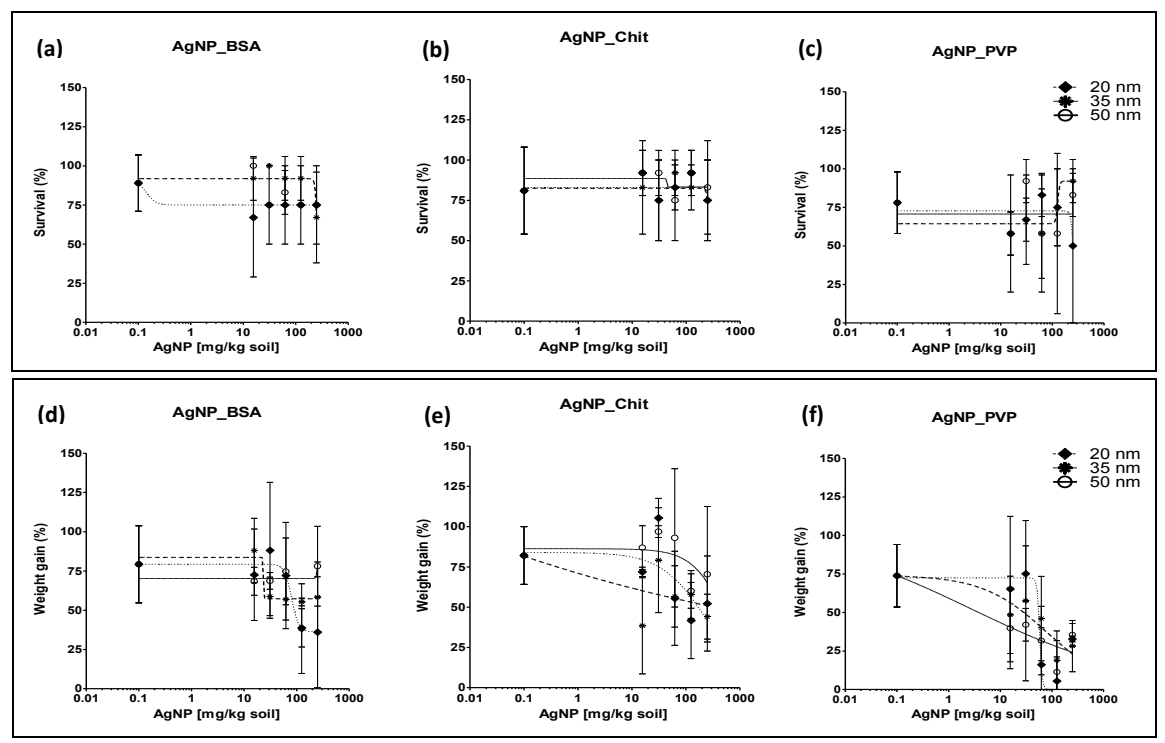

Fig. S4.3 Effect on survival (a-c) and growth (d-f) of 20, 35 and 50 nm AgNPs (, AgNP_Chit, AgNP_PVP) exposed to Lumbricus rubellus. Results are expressed as mean \pm standard deviation, $n=3$. Dotted lines and filled diamonds (20 nm); broken lines and asterix ( $35 \mathrm{~nm}$ ), solid lines and empty circles $(50 \mathrm{~nm})$. The regression curves that could not be fitted were due to data not meeting statistical criteria 




\section{Chapter 5}

\section{Transcriptome analysis reveals the importance of surface coating in driving effects of silver nanoparticles on the earthworm Lumbricus rubellus}

Based on:

Transcriptome analysis reveals the importance of surface coating in driving effects of silver nanoparticles on the earthworm Lumbricus rubellus

Sunday Makama, Dick Roelofs TFM, Riet H. Vooijs, Tjalf E. de Boer, Cornelis AM van Gestel, and Nico W. van den Brink

Submitted for publication 


\section{Abstract}

Considering their rapidly increasing production and use, understanding the effects of silver nanoparticles (AgNPs) on soil organisms at all ecosystem levels is crucial for an adequate environmental risk assessment. Although AgNPs have been increasingly investigated, information regarding their effect on the gene expression profile of especially soil organisms is yet inadequate. Using RNAseq, we investigated the transcriptome and gene expression profiles of the earthworm Lumbricus rubellus, following exposure to nine AgNPs synthesized to differ in surface coating/charge (bovine serum albumin/negative AgNP_BSA; chitosan/positive AgNP_Chit, and; polyvinylpyrrolidone/neutral AgNP_PVP), and sizes (20, 35 and $50 \mathrm{~nm}$ ). Overall, exposure to medium sized AgNPs at a concentration close to the EC50 for effects on cocoon production caused most pronounced responses at the transcriptional level. There was a correlation however, between the numbers of differentially expressed genes (DEGs) and internal Ag concentrations in the earthworms. Within the medium size AgNPs, AgNP_BSA caused extensive transcriptional responses, with 684 genes affected. In contrast ionic silver $\left(\mathrm{AgNO}_{3}\right)$ did not affect gene expression at low as well as higher exposure levels. Only one gene was regulated by all AgNP and $\mathrm{Ag}^{+}$treatments, indicating that there was hardly any functional overlap between the responses of the organisms to AgNPs with different coatings. Remarkably, this gene was metallothionein, a cysteinerich peptide known to strongly bind free metal ions for chelation and detoxification, which was strongly up-regulated. Gene ontology enrichment analysis for $35 \mathrm{~nm}$ AgNP_BSA exposures revealed a total of 33 significantly enriched gene ontology terms related to biological processes. These included responses to $\mathrm{pH}$, proton transport, cell differentiation and microtubule organisation. Surface coating (BSA) was important in triggering the AgNP-induced differential gene expression profiles in earthworms. The importance of physico-chemical properties of NPs in influencing their fate and toxicity is thus elucidated in the current study.

Keywords: agrin, antistasin, ankyrin, caspase 7, earthworm, RNAseq, silver nanoparticles, soil 


\section{Introduction}

The nanotechnology industry continues to grow, with silver nanoparticles (AgNPs) recognised as the most commonly used nanomaterial in many applications owing to its excellent antimicrobial activity and superior physico-chemical characteristics $[1,2]$. The global market demand for AgNPs has been projected to reach $\$ 2.5$ billion by the year 2022 [3]. This raises environmental health hazard concerns over the likelihood of its release into the environment, a potential outcome supported by a 130 times increase in the predicted concentrations of AgNPs in the soil in the United States [4-7]. In recent years therefore, AgNPs have been increasingly investigated $[2,8]$. Nevertheless, the environmental effects of AgNPs are as yet poorly understood and information on toxicogenomic studies on soil organisms exposed to AgNPs are especially limited.

Generally, the available literature has revealed possible mechanisms that may be involved in the toxicity of AgNPs. Common among these is oxidative stress due to an increased generation of reactive oxygen species (ROS), or failure of the organism's protective mechanisms against these radicals. Increase in ROS production has been reported both in vitro and in vivo in mammalian cells [9, 10], bacteria [11], and in rodents [12] and earthworms [13] exposed to AgNPs. Also, the role of silver ions $\left(\mathrm{Ag}^{+}\right)$ released from AgNPs in mediating toxic effects has been described [14]. This does not exclude the involvement of AgNPs directly, as several studies showed that the toxicity was caused by the NPs $[13,14]$. Also, evidence is available for the uptake of particulate Ag in earthworms $[15,16]$ and mice/rat [17] exposed to AgNPs.

Recently, investigations utilizing both in vivo and in vitro models $[18,19]$ have enhanced our knowledge on the fate and effects of various NPs following different exposure scenarios. These studies point at a number of physico-chemical properties of the tested NPs including size, shape, surface chemistry (charge), and agglomeration and dissolution rates [20], playing significant roles in influencing the fate and toxicity of NPs. The importance of the different properties, however, was not consistent and often varied between studies [19]. Some studies have reported clear effects of size [21], while charge was more important in others [22]. Other investigators found no effect of NP size nor charge, but rather pointed at the roles of dissolved silver ions and surface coating, not related to the charge of the NPs [23]. Considering these conflicting results, a better understanding of the influence of the physico-chemical properties of AgNPs on their fate and effects in organisms will facilitate an appropriate risk assessment.

The work described in this paper is part of a series of studies on the influence of size and surface coating (charge) on the toxicity of different AgNPs. For that purpose, we used both in vitro and in vivo models to assess the effects of three types of coating and three 
sizes of AgNPs. Cytotoxic effects on a mammalian macrophage cell line (RAW 264.7) were not significantly different between and within the different types of the AgNPs tested. Negatively charged BSA-coated AgNPs exerted the most effect on Tumour Necrosis Factor (TNF)- $\alpha$ induction (Chapter 2), and were also the most toxic in vivo to the earthworm Lumbricus rubellus (Chapter 4).

The emergence of RNA-sequencing (RNAseq) as a powerful technology for an in-depth transcriptome profiling $[24,25]$ has made it possible to investigate the genes that are actively being expressed by specific cells at any given time. For instance Poynton et al. [26] used a 15k microarray to investigate differences in the response of daphnids to AgNPs that were either citrate coated or PVP coated. When the different AgNP coatings were compared to $\mathrm{AgNO}_{3}$ exposures, very distinct transcriptional profiles were revealed between particulate and ionic Ag. This suggests that AgNPs induced toxicity profiles that were mechanistically different from ionic Ag toxicity profiles. Main processes affected by the AgNPs were protein metabolism and signal transduction, while $\mathrm{AgNO}_{3}$ caused downregulation of developmental processes and more specifically of sensory development [26]. In the nematode Caenorhabditis elegans, toxicogenomic investigation of AgNP toxicity revealed a clear signature of oxidative stress and activation of proteins involved in dauer larvae formation that could directly be linked to reproductive failure [27]. Such studies indicate that it is possible to obtain a more comprehensive mechanistic understanding of toxicological effects caused by nanoparticles via studies on gene expression profiles. Also, it may be possible to distinguish these effects from the ones caused by metal ion exposures. The effects of PVP-coated AgNPs and $\mathrm{AgNO}_{3}$ on the differential gene expression (microarray) response of Enchytraeus albidus following exposure in soil revealed higher toxicity due to the $\mathrm{AgNO}_{3}$ [4]. The authors also indicated that the responses observed due to exposure to AgNPs reflected an effect of $\mathrm{Ag}^{+}$ions, given the extent of similar or dissimilar genes activated. Genes relating to developmental processes were activated in response to both treatments, while only the $\mathrm{AgNO}_{3}$ treated groups showed activation of genes relating to reproduction, cellular and metabolic processes.

In the current study, we tested the hypothesis that both size and surface coating (charge) of AgNPs affect the gene expression profile of an exposed model terrestrial invertebrate. Exposures were performed using specifically synthesized AgNPs that differed in size and surface chemistry (charge). The red earthworm L. rubellus was used as the model species, representing an ecologically relevant species that is a very common upper soil-dwelling detrivore in most parts of Europe. Being an abundant species in the soil, $L$. rubellus could serve as an indicator for the risks of soil contaminants. It has commonly been used in ecotoxicological studies on NPs [28, 29] and other contaminants like zinc, lead and polycyclic hydrocarbons [30]. Here, we 
extend on the approach described by Poynton et al [26] and included three different coating types on AgNPs varying in mean core size. RNAseq techniques were used to monitor the gene expression profiles occurring in the earthworms exposed to concentrations of different forms of AgNPs at concentrations corresponding to the

EC50s for effects on earthworm cocoon production. Ionic $\mathrm{Ag}\left(\mathrm{AgNO}_{3}\right)$ exposures were also included at the level of EC50 for cocoon production. The outcome of this study will provide insight into the gene expression profile of a model terrestrial invertebrate as a result of AgNP exposure under environmentally relevant conditions, and how AgNP properties may influence these. Subtle (mild) effects, not easily detectable by other toxicological endpoints may be identified based on gene ontology, shedding light on the likely mechanisms of toxicity involved in the outcomes observed at the population level determined in earlier studies (Chapter 4).

\section{Materials and Methods}

\section{Experimental design}

Earthworms were exposed for $72 \mathrm{~h}$ to nine different AgNPs spiked in a natural soil at different concentrations (0, 15.63, 31.25, 62.5, 125 and 250) $\mathrm{mg} \mathrm{Ag} / \mathrm{kg}$ soil dry weight (DW). To compare the effect of ionic silver $\left(\mathrm{Ag}^{+}\right)$, two $\mathrm{AgNO}_{3}$ concentrations were also included. Control earthworms were kept in clean soil without $\mathrm{AgNPs}$ or $\mathrm{AgNO}_{3}$. At the end of the exposures, earthworms were collected and analysed for total $\mathrm{Ag}$ bioaccumulation, and for gene expression profiles.

\section{Synthesis and characterisation of AgNPs}

AgNPs used in this study were synthesized at the Catalonia Institute of Nanoscience and Nanotechnology: Institut Català de Nanociència i Nanotecnologia (ICN2), Barcelona, Spain. Details of the synthesis and characterisation of the AgNPs have been reported previously (Chapters 2 and 4 ) and are only briefly discussed here. Colloidal, dispersed AgNPs of three different sizes $(20,35$ and $50 \mathrm{~nm}$ ) were prepared separately, following a kinetically controlled seeded-growth method [31] with slight modifications. The approach is based on the reduction of silver nitrate $\left(\mathrm{AgNO}_{3}\right)$ in the presence of two competing reducing agents, tannic acid (TA) and trisodium citrate hexahydrate (SC) at $100^{\circ} \mathrm{C}$. These AgNPs were surface-coated with bovine serum albumin (BSA), chitosan (Chit) or polyvinylpyrrolidone (PVP) to generate negative AgNP_BSA, positive AgNP_Chit and neutral AgNP_PVP, respectively. All nine AgNPs were dispersed in soil extract as well 
as milliQ water and characterised by a combination of different techniques (Chapters 2 and 4). Particle size distributions were assessed by single-particle inductively coupled plasma-mass spectrometry (sp-ICP-MS), while core mean sizes were determined by transmission electron microscopy (TEM). UV-Vis, dynamic light scattering (DLS), and zeta-potential measurements ( $\zeta$-potential) were used to monitor the stability of the AgNPs in different media and to determine their surface charges. Results of characterisation is only discussed briefly here, and the reader is referred to our earlier work (Chapters 2 and 4) for more details.

\section{Soil preparation and earthworm exposure experiment}

Soil preparation and spiking using soil extract were performed according to van der Ploeg et al. [32]. Shortly, sifted air-dried natural soil of $\mathrm{pH}_{\mathrm{KCl}} 5.1$ and $3.8 \%$ organic matter, obtained from a reference experimental organic farm (Proefboerderij Kooijenburg, Marwijksoord, The Netherlands) was used for the experiment. Soil extract made from the same soil was used to prepare AgNP suspensions and solutions of $\mathrm{AgNO}_{3}$ as previously reported [16]. Nominal exposure concentrations 0, 15.63, 31.25, 62.5, 125 and $250 \mathrm{mg} \mathrm{Ag} / \mathrm{kg}$ soil for the AgNPs, and 1.5 and $15 \mathrm{mg} \mathrm{Ag} / \mathrm{kg}$ soil for $\mathrm{AgNO}_{3}$ were selected based on the toxicity of AgNPs reported in the literature [15]. Control soil received only soil extract and de-ionised water (Millipore; resistivity $=18.2 \mathrm{M} \Omega / \mathrm{cm}$ ). Soil spiking and/or moistening was done $24 \mathrm{~h}$ before introducing the earthworms during which moistened soil was allowed to equilibrate under climate-controlled conditions of $24 \mathrm{~h}$ light cycle, $15^{\circ} \mathrm{C}$, and $61 \%$ relative humidity. The moisture content of the soil was re-adjusted to attain $50 \%$ of its water holding capacity.

Clitellated adult earthworms (L. rubellus), having no gross lesions and of between $1-2.5$ g live weight were obtained from an uncontaminated site in the Netherlands (Nijkerkerveen). These were initially acclimatized in uncontaminated soil for two weeks under the same conditions as described above, weighed and distributed randomly in the experimental units (jar). Each treatment was prepared in triplicate at a density of 5 animals per jar. Weekly feeding was provided ad libitum and consisted of about $50 \mathrm{~g}$ of moistened alder leaves (Alnus glutinosa) collected from an uncontaminated location (Vossemeerdijk, Dronten, The Netherlands), dried and crushed into coarse particles. Crushed leaves were spread over the soil in the glass jars enough to cover the soil surface but prevent avoidance behaviour by the earthworms. All experimental jars were placed in the climate control room under the same climate controlled conditions as described above. 


\section{Sample collection and preparation}

At the end of the $72 \mathrm{~h}$ exposure period, from each replicate, surviving earthworms were collected, weighed, placed in glass petri-dishes lined with moistened Whatman ${ }^{\circledR}$ filter paper no. 597 (Fisher Scientific, Pittsburg, PA) and allowed to depurate over 48h [16]. The earthworms were kept under the same environmental condition as during exposure. Following gut-emptying, the earthworms were washed in demineralized water, paddried with absorbent paper and snap frozen in liquid nitrogen. Samples were preserved at $-80^{\circ} \mathrm{C}$ until analysed. One earthworm from each replicate was used for gene expression analysis, while before quantification of total $\mathrm{Ag}$ concentration, whole earthworm tissues were ground to powder in liquid nitrogen using mortar and pestle, pooling two individuals per experimental unit.

\section{Quantification and Characterisation of AgNPs in earthworm tissues}

To quantify total Ag tissue concentrations in earthworm samples, $250 \mathrm{mg}$ of the crushed tissue from each replicate were weighed into digestion tubes and $1.0 \mathrm{ml}$ of milliQ water, $0.5 \mathrm{ml}$ of $65 \% \mathrm{HNO}_{3}$ and $1.5 \mathrm{ml}$ of $37 \% \mathrm{HCl}$ were added and mixed gently by swirling the capped tubes. The tubes were then incubated for $30 \mathrm{~min}$ in a water bath at $60{ }^{\circ} \mathrm{C}$, and subsequently the resulting digest was allowed to cool down to room temperature, diluted and total $\mathrm{Ag}$ content measured by inductively-coupled plasma mass spectrometer (ICP-MS). The ICP-MS analysis was conducted using a Thermo X Series 2 ICP-MS equipped with an auto-sampler and a conical glass concentric nebuliser and operated at a radio frequency power of $1400 \mathrm{~W}$. Data acquisition was performed in the selected ion mode at the $\mathrm{m} / \mathrm{z}$ ratio of 107 characteristic for silver. Quantification was based on ionic silver standards diluted in the same acidic matrix. The detection limit for total tissue Ag concentration using the described procedure for ICP-MS was about 50 $\mathrm{ng} / \mathrm{kg}$ tissue DW.

\section{RNAseq}

\section{RNA isolation and normalization}

All controls and treatments contained 3 replicates of exposed worms. The earthworms selected for RNAseq were sampled from experimental units treated to AgNP exposure concentrations closest to the EC50s for effects on earthworm reproduction (number of cocoons laid) which was the most sensitive toxicity endpoint in a 28-day sub-chronic study using the same AgNPs (Chapters 2 and 4). For each coating we analysed gene 
expression of earthworms exposed to small, medium and large sized AgNPs. In addition, two ionic $\mathrm{AgNO}_{3}$ control exposures $(1.5 \mathrm{mg} / \mathrm{kg}$ and $15 \mathrm{mg} / \mathrm{kg}$ ) and a blank control were taken along for each coating type. In total, 54 samples were prepared for RNA extraction and subsequent sequencing. Each earthworm (representing a single replicate) was crushed in liquid nitrogen and a sub sample of 25 mg was taken for total RNA extraction using the SV Total RNA isolation system according to manufacturer's instructions (Promega, US). Slight modifications included addition of $500 \mu$ lilution buffer, $285 \mu \mathrm{l}$ ethanol and $800 \mu \mathrm{l}$ wash buffer. Total RNA was quantified using NanoDrop ND-1000 UVVis spectrometer (Thermo Fisher Scientific). About $1 \mu \mathrm{g}$ of Total RNA was subjected to cDNA synthesis using TruSeq RNA Sample Preparation Kit v2 according to manufacturer's instructions (Illumina, US). Subsequently, samples were quality checked and quantified by running them on a BioAnalyzer lab-on-a-chip (Agilent, US).

\section{RNA sequencing}

The 54 samples were assigned a unique sequencing barcode and total RNA from each sample was prepared for Illumina HiSeq sequencing. Sequence libraries were prepared by adding equal amounts of each sample to the library pool. Paired-end $125 \mathrm{bp}$ sequencing was performed on an Illumina HiSeq 2500 by dividing the samples over three lanes of a flow cell. After sequencing the individual samples were demultiplexed by barcode.

\section{Assembly and data analysis}

FastQC was applied to quality control the raw sequence reads. Low quality bases were trimmed using Trimmomatic (quality cut-off of 24 using the Phred33 encoding) [33]. The mapping references represented an assembled transcriptome previously generated and kindly provided by Prof. P. Kille (University of Cardiff). Mapping and read quantification was done using a combination of Bowtie2 and express [34, 35]. Differential gene expression analysis was performed in R using the EdgeR package [36] which applies a general linear model by contrasting each particle size per coating to the control conditions followed by a correction for multiple testing using the false discovery rate method [37]. This yielded five sets of significant genes per coating (20, 35 and $50 \mathrm{~nm}$ AgNPs, and low and high ionic $\mathrm{Ag}^{+}$) that were each subjected to Gene Ontology (GO) enrichment analysis using the TopGO package in $\mathrm{R}$ [38]. We focused on Biological Processes and Molecular Functions as these two are the most informative categories. In total, 5667 GO terms were associated to annotated genes, which was taken as a reference list in the enrichment analysis. Enriched GO terms that only contained one transcript were removed from the significant GO term list and omitted from further analysis. 
Uptake data obtained for the 72 hour exposure were processed with Microsoft Excel (2013) and where appropriate, the data were subjected to one-way analysis of variance (ANOVA) with the aid of GraphPad Prism 5.04 for Windows (GraphPad Software, San Diego California USA, www.graphpad.com"). All results are presented as mean \pm standard deviation (s.d.), and a $p$ value of $<0.05$ is considered to be significant.

\section{Results and discussions}

\section{AgNPs pre-exposure characterisation}

The AgNPs used in this study have been fully characterised by the authors earlier, and detailed information on this can be found in Chapters 2 and 4. TEM images and UV-Vis spectra of AgNP characterisation indicated that the primary particle sizes targeted by the synthesis were achieved. Also, the morphology of the particles was preserved after conjugation and lyophilisation processes for all coatings. Average particle sizes (nm) obtained by analysis of over 250 nanoparticles by TEM were $19.5 \pm 5.4,37.4 \pm 3.7$ and $51.1 \pm 5.7 \mathrm{~nm}$ (AgNP_BSA); $18.2 \pm 5.1,37.2 \pm 4.3$ and $51.9 \pm 6.4 \mathrm{~nm}$ (AgNP_Chit), and; $24.0 \pm 4.6,38.2 \pm 4.5$ and $51.0 \pm 6.1 \mathrm{~nm}$ (AgNP_PVP) for 20, 35 and $50 \mathrm{~nm}$ size groups, respectively. The shape of the SPR peaks in both milliQ water and soil extract were generally preserved except for the $20 \mathrm{~nm}$ AgNP_PVP and 35 and $50 \mathrm{~nm} \mathrm{AgNP \_ Chit}$ suspensions in soil extract, whose SPR peaks suggested formation of some agglomerates.

Formation of agglomerates in the soil solution may explain the lower toxicity of these AgNPs, due to becoming less bioavailable, as was similarly observed with C60 exposure [39]. Nevertheless, agglomeration may not necessarily imply absence of adverse effects as the toxic potential of the AgNPs may change following ageing and decay, leading to release of $\mathrm{Ag}$ as NPs or dissolved $\mathrm{Ag}^{+}$ions [20,40-42]. Depending on the surface coating used in our study, negative (AgNP_BSA), positive (AgNP_Chit) and "neutral" (AgNP_PVP) charges were obtained. Dispersion in soil extract also showed preserved $\zeta$-potentials for AgNP_BSA and AgNP_Chit. All sizes of AgNP_PVP, however, presented negative $\zeta$ potentials, but the values were less negative than those for the AgNP_BSA (Chapters 2 and 4).

\section{$\mathrm{Ag}$ uptake in earthworms}

Total tissue concentrations showed that earthworms exposed to $\mathrm{AgNP}$ or $\mathrm{AgNO}_{3}$ accumulated $\mathrm{Ag}$ to varying degrees with mean values ranging from $15-80 \mathrm{mg} \mathrm{Ag} / \mathrm{kg}$ 
tissue DW (Fig. 5.1). Uptake of AgNPs showed a concentration dependent increase, and the negatively charged AgNP_BSA were taken up most indicating some influence of surface coating on Ag uptake. There were no statistically significant differences in uptake when comparing the three NP size ranges for each coating type. The fact that the negatively charged AgNP_BSA were the most toxic could partly be explained by the higher internal concentrations especially for the $35 \mathrm{~nm}$ sizes (Fig. 5.2 and Fig. S5.1). AgNP_BSA previously showed the most effect on in vivo reproduction (Chapter 4) as well as the highest in vitro induction of TNF- $\alpha$ in mammalian macrophage cells (Chapter 2). Uptake of $\mathrm{Ag}$ from the $\mathrm{AgNO}_{3}$ was in the same order of magnitude as that with AgNPs when comparing nominal exposure concentrations on a mass basis (Table 5.1).

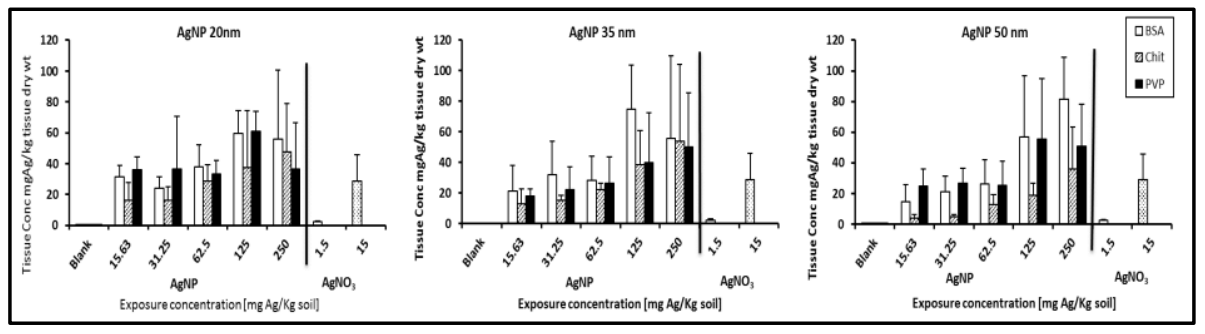

Fig. 5.1 Total Ag concentrations in tissues of earthworms (Lumbricus rubellus) exposed for 72 hours to different concentrations of silver nanoparticles (AgNPs) with different surface coatings (charge) and different particle sizes (20, 35 and $50 \mathrm{~nm}$ ), or to $\mathrm{AgNO}_{3}$ in a natural soil. AgNP_BSA (negative, bovine serum albumin-coated); AgNP_Chit (positive, chitosan-coated); AgNP_PVP (neutral, polyvinylpyrrolidone-coated).

\section{Gene expression (RNAseq)}

The 54 samples were randomly distributed over three libraries of which each was sequenced on a single Illumina HiSeq 2500 lane. On average, 98.3\% of both forward and reverse reads remained available for further analysis, indicating that the sequences were of high quality. The library sizes per sample were 1.10 million reads on average with variation ranging from 0.85 up to 1.37 million reads. Reads were, subsequently, mapped to transcriptome with contigs with an average mapping success rate of $69.4 \%$. The variation in mapping rate ranged from $50 \%$ to $80 \%$ between samples, and was randomly distributed over treatments and biological replicates. We speculate that this could possibly be caused by genetic variation among the test animals, because they were directly taken from the field. Nevertheless, statistical analysis to obtain significantly regulated gene expression patterns was successfully executed.

Table 5.1 gives a general overview of the total number of differentially expressed genes (DEGs) in adult L. rubellus following 72 hour exposure to the different AgNPs in natural 
soil at an exposure concentration around the EC50s for effects on reproduction. Generally, exposure to the medium sized AgNPs caused most pronounced responses at the transcriptional level, accounting for $90.34 \%$ of the differentially regulated transcripts. Among the different coating types, AgNP_BSA caused extensive transcriptional responses; 684 genes (95\%) were up- or down-regulated upon exposure to the $35 \mathrm{~nm}$ AgNP_BSA (Table 5.1 and Fig. 5.2). In contrast, ionic $\mathrm{Ag}^{+}$had only a minor effect on gene expression at both low and high concentrations tested. When looking at the medium sized AgNPs, there was a clear influence of internal tissue Ag concentrations on the number of DEGs (Fig. 5.2). For the other NP sizes however, the number of DEGs were not different between coating types. Irrespective of the surface coatings and internal tissue Ag concentrations in the earthworms, exposure to the 20 and $50 \mathrm{~nm}$ sized AgNPs produced similar numbers of DEGs with averages of 25 and 11, respectively (Table 5.1, Fig. 5.2). This observation may suggest an optimal size for uptake in agreement with other reports [43].

Table 5.1. Uptake of $\mathrm{Ag}$ from $\mathrm{AgNP}$ and ionic $\mathrm{Ag}^{+}$, and the number of differentially regulated transcripts identified in RNAseq analysis in the earthworm Lumbricus rubellus exposed for $72 \mathrm{~h}$ to differently coated 20, 35 and $50 \mathrm{~nm}$ AgNPs in a natural soil. AgNP_BSA (negative, bovine serum albumin-coated); AgNP_Chit (positive, chitosan-coated); AgNP_PVP (neutral, polyvinylpyrrolidone-coated).

\begin{tabular}{|c|c|c|c|c|c|c|c|}
\hline & & \multicolumn{2}{|c|}{ AgNP_BSA (Negative) } & \multicolumn{2}{|c|}{ AgNP_Chit (Positive) } & \multicolumn{2}{|c|}{ AgNP_PVP (Neutral) } \\
\hline & & $\begin{array}{c}\text { [mg/kg] } \\
\text { tissue }\end{array}$ & $\begin{array}{l}\text { No of } \\
\text { genes }\end{array}$ & $\begin{array}{c}\text { [mg/kg] } \\
\text { tissue }\end{array}$ & $\begin{array}{l}\text { No of } \\
\text { genes }\end{array}$ & $\begin{array}{c}\text { [mg/kg] } \\
\text { tissue }\end{array}$ & $\begin{array}{l}\text { No of } \\
\text { genes }\end{array}$ \\
\hline \multicolumn{2}{|c|}{ Small (20 nm) } & $37.8 \pm 14.2$ & 29 & $47.5 \pm 31.4$ & 23 & $33.4 \pm 8.6$ & 24 \\
\hline \multicolumn{2}{|c|}{ Medium (35 nm) } & $74.9 \pm 28.7$ & 684 & $53.8 \pm 50.5$ & 246 & $26.6 \pm 17.2$ & 80 \\
\hline \multicolumn{2}{|c|}{ Large (50 nm) } & $26.0 \pm 6.7$ & 11 & $35.9 \pm 27.5$ & 12 & $50.7 \pm 27.3$ & 9 \\
\hline \multirow{2}{*}{$\mathrm{AgNO}_{3}$} & Low (L) & $3.1 \pm 0.5$ & 4 & $2.2 \pm 0.9$ & 12 & $1.7 \pm 0.3$ & 1 \\
\hline & High (H) & $38.3 \pm 26.2$ & 29 & $26.1 \pm 9.7$ & 31 & $22.2 \pm 14.8$ & 16 \\
\hline
\end{tabular}

In Fig. 5.3a (left panel), the Venn diagram is presented of all genes significantly regulated following exposure to $35 \mathrm{~nm}$ AgNPs for three coating treatments. Only one gene was differentially regulated among all treatments, indicating that there was hardly any functional overlap between the responses to exposures to the differently coated AgNPs. Remarkably, this gene was metallothionein (MT), a cysteine-rich peptide known to strongly bind free metal ions for chelation and detoxification. AgNP_BSA and AgNP_Chit showed most overlap with 61 genes. Comparing AgNP exposure with ionic Ag exposure, we did find considerable overlap. A total of 37 genes were shared among AgNP and ionic Ag treatments (Fig. 5.3b). This included about $44 \%$ of all genes differentially expressed upon ionic Ag treatment. This suggests that a considerable part of transcriptional responses caused by the AgNPs can be attributed to the release of $\mathrm{Ag}^{+}$ions from the core. This observation was further supported when we compared the specific transcriptional profile of the 37 genes (Fig. 5.4). 


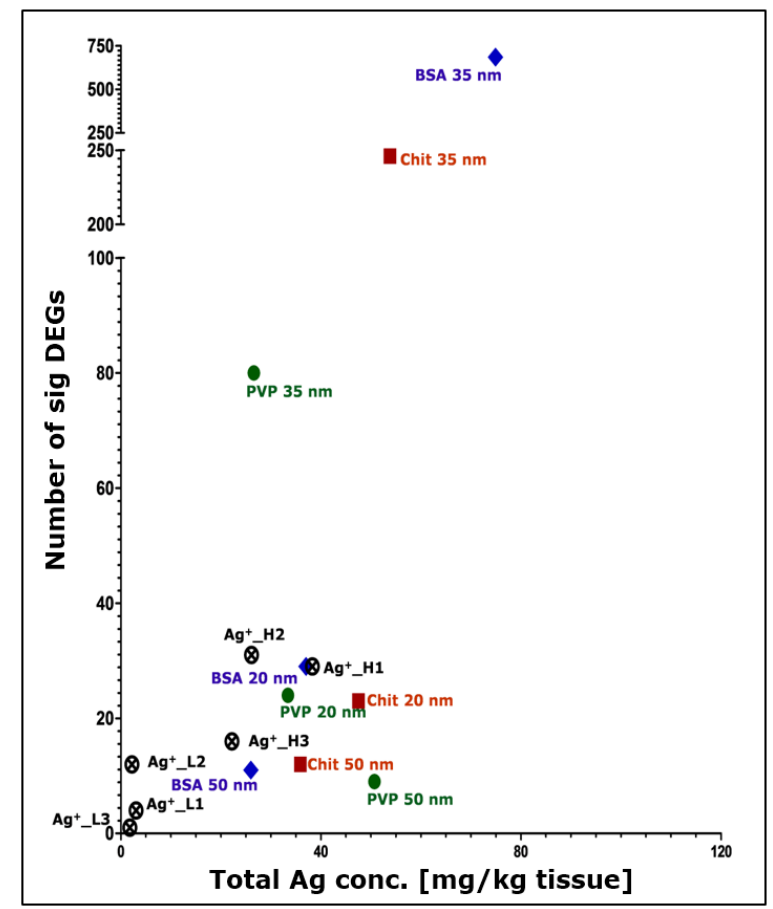

Fig. 5.2 Relationship between the numbers of significant differentially expressed genes (DEGs) and the tissue Ag concentrations in the earthworms Lumbricus rubellus exposed for $72 \mathrm{~h}$ to 20, 35 and $50 \mathrm{~nm}$ AgNPs with different surface coatings: AgNP_BSA (negative, bovine serum albumin-coated); AgNP_Chit (positive, chitosancoated); AgNP_PVP (neutral, polyvinylpyrrolidone-coated). DEGs produced by $\mathrm{AgNO}_{3}$ low $(\mathrm{L})$ and high $(\mathrm{H})$ exposures are also included.

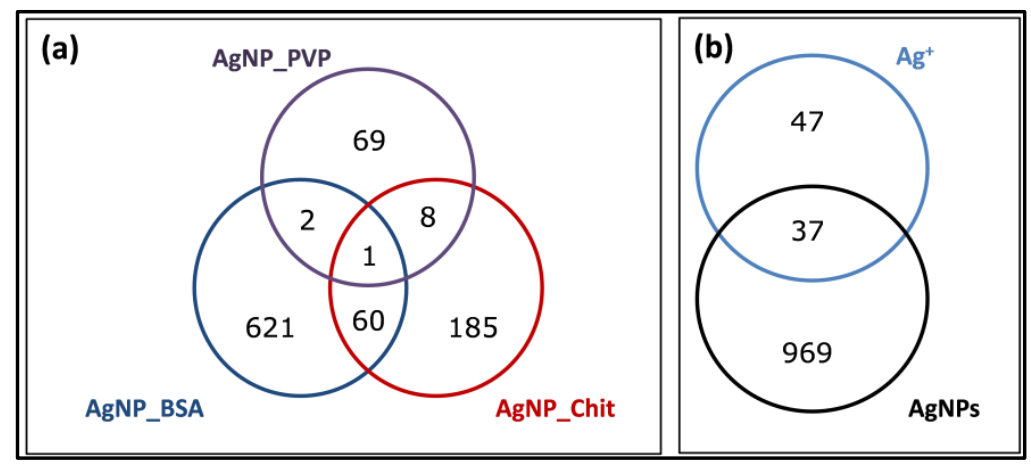

Fig. 5.3 Venn diagrams of significant differentially expressed genes (DEGs) in the earthworm Lumbricus rubellus after $72 \mathrm{~h}$ exposure to AgNPs and ionic $\mathrm{Ag}\left(\mathrm{AgNO}_{3}\right)$ showing overlaps of significantly regulated genes produced by treatments with all three coating types of $35 \mathrm{~nm}$ sized AgNPs (left panel), and between all AgNPs combined and ionic $\mathrm{Ag}^{+}$(right panel). AgNP_BSA (negative, bovine serum albumin-coated); AgNP_Chit (positive, chitosancoated); AgNP_PVP (neutral, polyvinylpyrrolidone-coated). 


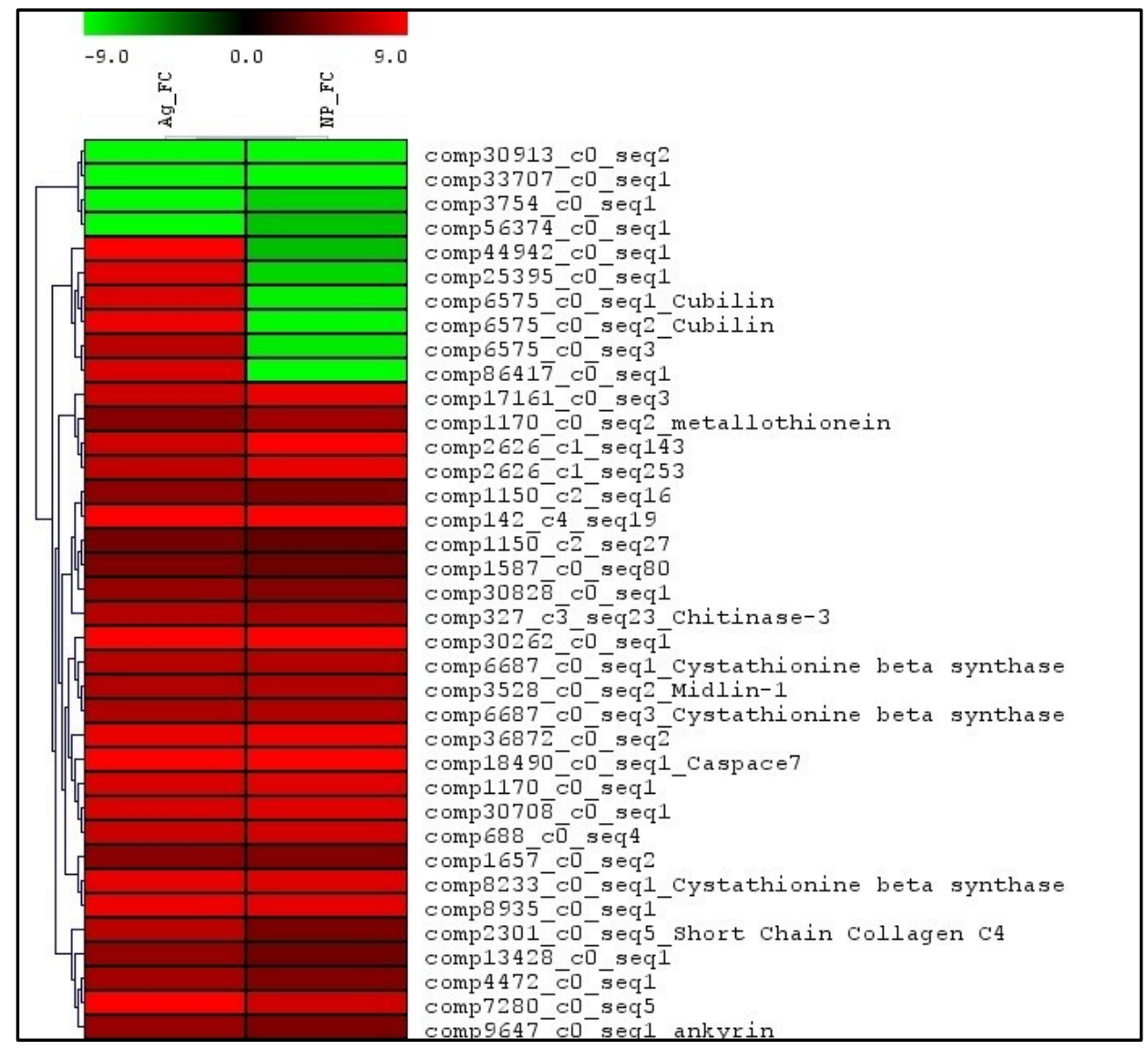

Fig. 5.4 Heat map of the overlapping 37 transcripts shared among significant differentially expressed genes (DEGs) in the earthworm Lumbricus rubellus exposed for $72 \mathrm{~h}$ to $\mathrm{AgNO}_{3}$ and $\mathrm{AgNPs}$ with different surface coatings. Red color: up-regulation, green color: down-regulation. Ag_FC, fold change due to ionic $\mathrm{Ag}^{+}$exposure (both low and high), NP_FC, fold change due to AgNP exposure (all sizes and coatings combined).

Figure 5.4 shows the heat map of these regulated transcripts. Interestingly, 31 genes showed highly similar responses, when comparing responses to $\mathrm{Ag}^{+}$and $\mathrm{AgNPs}$. From these, 27 are coordinately up-regulated, while 4 are coordinately down-regulated (Table S5.1). However, 6 transcripts showed opposite regulation; they were up-regulated due to ionic $\mathrm{Ag}^{+}$, but down-regulated in response to AgNP exposure. Among the coordinately up-regulated genes, MT was identified. Three transcripts showed high homology to cystathionine beta synthase, which is involved in cysteine biosynthesis. It is well known that MTs are cysteine-rich proteins present in bacteria, plants, invertebrates and vertebrates [44] and have a high affinity for metal binding, storage and detoxification $[45,46]$. The up-regulation of cystathionine beta synthase suggests an increased cysteine supply to facilitate increased MT translation to detoxify free $\mathrm{Ag}^{+}$ions. 
Another annotated gene among the list of shared up-regulated genes was Caspase 7, an apoptosis-related cysteine peptidase. Together with caspase 3, caspase 7 is called an executioner, because it takes care of bulk proteolysis during cell demolition after programmed cell death has been initialized [47]. Pathogenic infection was reported to induce apoptosis in macrophages by modulating signaling that leads to TNF- $\alpha$ production [48]. So, caspase 7 induction by ionic Ag and AgNPs seems to mimic some kind of immune response. Indeed, we have previously demonstrated a high induction of TNF- $\alpha$ in macrophages exposed to AgNP_BSA (Chapter 2). Furthermore ankyrin and midlin-1 were coordinately up-regulated genes, and are both involved in the formation of multiprotein structures that act as anchor points in the cell. Ankyrin is involved in maintaining plasma membrane structure and positioning of ion channels in the plasma membrane.

Most of the genes up-regulated by the ionic $\mathrm{Ag}^{+}$were similarly up-regulated by the AgNPs, suggesting that ionic $\mathrm{Ag}^{+}$may have been responsible. This does not, however, exclude the role of particulate AgNPs otherwise all overlapping genes should have been regulated in the same direction and this was not the case in this study. Of the 37 overlapping DEGs between the particulate and ionic Ag treatments, 6 that were upregulated following ionic $\mathrm{Ag}^{+}$treatment were down-regulated with AgNPs exposure. If all the effects were due to the $\mathrm{Ag}^{+}$ions, the expression of these genes should have been in the same direction. We could therefore not exclude the role of particulate Ag causing some effects. Although studies have shown that the uptake of Ag may be in ionic form following dissolution of AgNPs, either form of $\mathrm{Ag}$ can be transformed to particulate $\mathrm{Ag}$ with $\mathrm{AgS}_{2}$ and $\mathrm{AgCl}$ being the common forms reported in literature [20]. The role of either or both particulate and ionic forms of $\mathrm{Ag}$ in determining the outcome of exposures, with transformation from particulate to ionic Ag or vice-versa, has been reported [49-53]. It was shown that after 28 days of exposure, more than $98 \%$ of the tissue Ag concentration of earthworms exposed to the same AgNPs as the current study was in the form of ionic $\mathrm{Ag}^{+}$(Chapter 4). This suggests that dissolution plays a significant role, however it is not known how that affect the exposure after just 72 hours, which was the exposure duration of the current study.

Comparing gene expression responses due to different sizes of AgNPs for each coating hardly revealed any overlap. Specifically, only 4 genes were differentially regulated among all sizes of AgNP_BSA, while among all AgNP_Chit NPs only 3 genes were differentially regulated. Finally, we found no overlap in differential expression among different sizes of AgNP_PVP. This may likely be a result of the low numbers of DEGs induced by especially the 20 and $50 \mathrm{~nm}$ sized AgNPs (Table 5.1), or even the role of size. Unfortunately, the level of annotation among the significantly regulated genes was generally low except for AgNP_BSA $35 \mathrm{~nm}$, therefore only limited information on mechanistic aspects of the exposure to AgNPs could be retrieved. We were able to 
perform a gene ontology enrichment analysis for the medium sized AgNP_BSA exposure, because the number of significantly regulated genes in response to this exposure was high and the level of annotation reasonable. In total 27 gene ontology terms relating to biological process were significantly enriched in response to medium-sized AgNP_BSA (Table S5.1). Using the REVIGO tree map view, the main processes were categorized and shown (Fig. 5.5). Several biological processes were affected, including response to $\mathrm{pH} /$ regulation of intracellular $\mathrm{pH}$, proton transport, cell differentiation and microtubule organisation. Indeed, proton transport and response to $\mathrm{pH}$ are clearly supported by the strong up-regulation of two sodium hydrogen exchangers and four V-type ATPases (SI, Sequence data File S1). Gene ontology enrichment with respect to molecular function supports the observation that the earthworms responded to changes in their physiologic $\mathrm{pH}$, because hydrogen ion transmembrane activity was significantly affected.

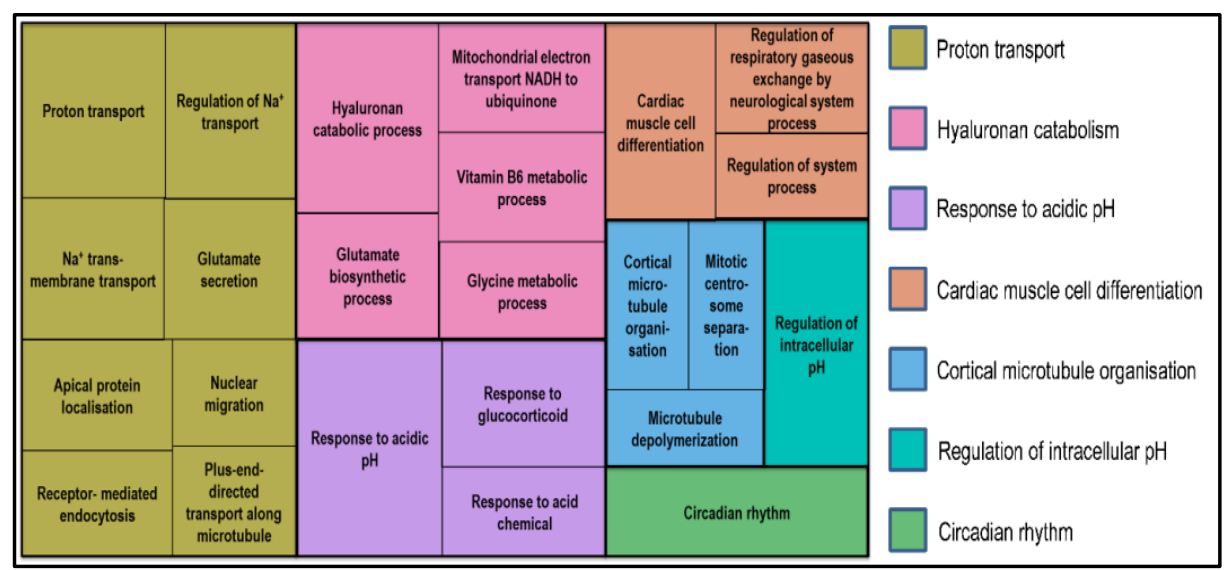

Fig. 5.5 TreeMap from REVIGO for significantly affected GO terms of regulated genes in the earthworm Lumbricus rubellus upon $72 \mathrm{~h}$ exposure to medium-sized BSA AgNP in a natural soil. The input GO terms were generated by GO enrichment analysis by using the TopGO package in R. Each rectangle is a cluster representative; larger rectangles represent 'superclusters' including loosely related terms. The size of the rectangles reflects their significance ( $p$-value).

When comparing AgNP_BSA and AgNP_Chit, two annotated genes could be identified that were strongly activated in response to both NPs: agrin and antistasin. Both proteins are expressed and active in the extracellular matrix and can bind macromolecules. Agrin is a multidomain extracellular matrix associated heparin sulfate proteoglycan (HSPG) essential in postsynaptic specialization at the neuromuscular junction in vertebrates and invertebrates [54]. It is also important in the development of the blood brain barrier (BBB) and its role in T-cell activation has been described [54]. Husain et al. [55] showed in Drosophila that secretion of an agrin homolog into the apical matrix is critical for the 
formation of epithelial lumina in the eye retina [55]. The Agrin homolog in C. elegans seems to be associated with pharynx development [56]. In any case, agrin can directly elicit signaling responses in nearby cells [57]. Antistasin is a prototype serine-proteinase inhibitor and a potent inhibitor of blood coagulation factor $\mathrm{Xa}$ found in leeches [58]. These genes are implicated in resistance to pathogenic microorganisms and immune defense [59]. The activation of these genes may likely suggest their important role in binding to not only macromolecular [60], but also nano-molecular cargo like the AgNPs. Their exact role in nanotoxicity is yet unknown, but likely associated with the functions above indicating neurotoxicity and immunotoxicity. Reports on the characterisation of proteoglycans in earthworms are generally lacking, and to the best of our knowledge, this is the first report of the activation of these genes in earthworms following exposure to AgNPs.

\section{Conclusion}

$\mathrm{Ag}$ was accumulated in tissues of earthworms in a concentration dependent manner following a $72 \mathrm{~h}$ exposure in soil, indicating early uptake for the different AgNPs, as well as the ionic $\mathrm{Ag}^{+}$. Ag from AgNP_BSA was accumulated more, and alterations in the gene expression profiles of earthworms reflected this, as the highest number of DEGs were encountered with exposures to these negatively charged AgNPs. Surface coating (charge) therefore influenced the uptake and effect of the AgNPs in the current study. The $35 \mathrm{~nm}$ medium sized AgNPs induced more DEGs than the 20 or $50 \mathrm{~nm}$ sizes for all tested AgNPs, suggesting the likely role of optimal size. For the $35 \mathrm{~nm}$ sized group, tissue $\mathrm{Ag}$ concentrations appear to partly explain our observations, since the highest DEGs were expressed in earthworms accumulating Ag the most. About $84 \%$ of the genes shared by both particulate and ionic $\mathrm{Ag}^{+}$treated earthworms were regulated in the same direction, and MT genes were commonly expressed by earthworms from all treatment groups. Therefore, the role of $\mathrm{Ag}^{+}$ions in inducing gene expression effects following AgNP exposure was also indicated.

\section{Acknowledgements}

This work was financially supported by NanoNextNL, a micro- and nano-technology consortium of the Government of The Netherlands and 130 partners; funding was also received from Managing Risks of Nanoparticles, MARINA (EU-FP7, contract CP-FP 263215), and the Strategic Research Fund entitled Novel technologies provided by the 
Ministry of Economic Affairs of The Netherlands. Synthesis and characterization of the AgNPs used in this study received support from the QualityNano Project http://www.qualitynano.eu/ which is financed by the European Community Research Infrastructures under the FP7 Capacities Programme (Grant No. INFRA-2010-262163).

\section{Declaration of interest}

The authors report no conflicts of interest and are responsible for the content and writing of this paper. 


\section{$\underline{\text { References }}$}

[1] Vance ME, Kuiken T, Vejerano EP, McGinnis SP, Hochella MF, Jr., Rejeski D, et al. Nanotechnology in the real world: Redeveloping the nanomaterial consumer products inventory. Beilstein journal of nanotechnology. 2015, 6, 1769-80. doi10.3762/bjnano.6.181

[2] Foldbjerg R, Jiang X, Miclăuş T, Chen C, Autrup H, Beer C. Silver nanoparticles - wolves in sheep's clothing? Toxicol Res. 2015, 4(3), 563-75. doi10.1039/c4tx00110a

[3] TechNavio IRL. Global Silver Nanoparticles Market 2015-2019. 2015, 60.

[4] Gomes SI, Soares AM, Scott-Fordsmand JJ, Amorim MJ. Mechanisms of response to silver nanoparticles on Enchytraeus albidus (Oligochaeta): survival, reproduction and gene expression profile. J Hazard Mater. 2013, 254-255(0), 336-44. doi10.1016/j.jhazmat.2013.04.005

[5] Gottschalk F, Sonderer T, Scholz RW, Nowack B. Modeled environmental concentrations of engineered nanomaterials ( $\mathrm{TiO}(2), \mathrm{ZnO}, \mathrm{Ag}, \mathrm{CNT}$, Fullerenes) for different regions. Environ Sci Technol. 2009, 43(24), 9216-22. doi10.1021/es9015553

[6] Mueller NC, Nowack B. Exposure Modeling of Engineered Nanoparticles in the Environment. Environ Sci Technol. 2008, 42(12), 4447-53. doi10.1021/es7029637

[7] Schlich K, Klawonn T, Terytze K, Hund-Rinke K. Hazard assessment of a silver nanoparticle in soil applied via sewage sludge. Environmental Sciences Europe. 2013, 25(1), 17. doi10.1186/2190-471525-17

[8] Quang Huy T, Van Quy N, Anh-Tuan L. Silver nanoparticles: synthesis, properties, toxicology, applications and perspectives. Advances in Natural Sciences: Nanoscience and Nanotechnology. 2013, 4(3), 033001.

[9] Rajanahalli P, Stucke CJ, Hong Y. The effects of silver nanoparticles on mouse embryonic stem cell selfrenewal and proliferation. Toxicology Reports. 2015, 2, 758-64. doihttp://dx.doi.org/10.1016/j.toxrep.2015.05.005

[10] Yoisungnern T, Choi Y-J, Woong Han J, Kang M-H, Das J, Gurunathan S, et al. Internalization of silver nanoparticles into mouse spermatozoa results in poor fertilization and compromised embryo development. Sci Rep. 2015, 5, 11170. doi10.1038/srep11170. http://www.nature.com/articles/srep11170\#supplementary-information

[11] Xu H, Qu F, Xu H, Lai W, Andrew Wang Y, Aguilar ZP, et al. Role of reactive oxygen species in the antibacterial mechanism of silver nanoparticles on Escherichia coli 0157:H7. Biometals. 2012, 25(1), 45-53. doi10.1007/s10534-011-9482-x

[12] Tiwari DK, Jin T, Behari J. Dose-dependent in-vivo toxicity assessment of silver nanoparticle in Wistar rats. Toxicol Mech Methods. 2011, 21(1), 13-24. doi10.3109/15376516.2010.529184

[13] Gomes SI, Hansen D, Scott-Fordsmand JJ, Amorim MJ. Effects of silver nanoparticles to soil invertebrates: oxidative stress biomarkers in Eisenia fetida. Environ Pollut. 2015, 199, 49-55. doi10.1016/j.envpol.2015.01.012

[14] Greulich C, Braun D, Peetsch A, Diendorf J, Siebers B, Epple M, et al. The toxic effect of silver ions and silver nanoparticles towards bacteria and human cells occurs in the same concentration range. RSC Advances. 2012, 2(17), 6981-7. doi10.1039/C2RA20684F

[15] van der Ploeg MJ, Handy RD, Waalewijn-Kool PL, van den Berg JH, Herrera Rivera ZE, Bovenschen J, et al. Effects of silver nanoparticles (NM-300K) on Lumbricus rubellus earthworms and particle characterization in relevant test matrices including soil. Environ Toxicol Chem. 2014, 33(4), 743-52. doi10.1002/etc.2487

[16] Makama S, Peters R, Undas A, van den Brink NW. A novel method for the quantification, characterisation and speciation of silver nanoparticles in earthworms exposed in soil. Environmental Chemistry. 2015, 12(6), 643. doi10.1071/en15006

[17] van der Zande M, Vandebriel RJ, Van Doren E, Kramer E, Herrera Rivera Z, Serrano-Rojero CS, et al. Distribution, elimination, and toxicity of silver nanoparticles and silver ions in rats after 28-day oral exposure. ACS nano. 2012, 6(8), 7427-42. doi10.1021/nn302649p

[18] Foldbjerg R, Irving ES, Hayashi Y, Sutherland DS, Thorsen K, Autrup H, et al. Global gene expression profiling of human lung epithelial cells after exposure to nanosilver. Toxicol Sci. 2012, 130(1), 145-57. doi10.1093/toxsci/kfs225

[19] Yu SJ, Yin YG, Liu JF. Silver nanoparticles in the environment. Environ Sci Process Impacts. 2013, 15(1), 78-92. doi10.1039/C2EM30595J 
[20] Reidy B, Haase A, Luch A, Dawson K, Lynch I. Mechanisms of Silver Nanoparticle Release, Transformation and Toxicity: A Critical Review of Current Knowledge and Recommendations for Future Studies and Applications. Materials. 2013, 6(6), 2295-350. doi10.3390/ma6062295

[21] Powers CM, Badireddy AR, Ryde IT, Seidler FJ, Slotkin TA. Silver nanoparticles compromise neurodevelopment in PC12 cells: critical contributions of silver ion, particle size, coating, and composition. Environ Health Perspect. 2011, 119(1), 37-44. doi10.1289/ehp.1002337

[22] Suresh AK, Pelletier DA, Wang W, Morrell-Falvey JL, Gu B, Doktycz MJ. Cytotoxicity induced by engineered silver nanocrystallites is dependent on surface coatings and cell types. Langmuir. 2012, 28(5), 2727-35. doi10.1021/la2042058

[23] Yang X, Gondikas AP, Marinakos SM, Auffan M, Liu J, Hsu-Kim H, et al. Mechanism of silver nanoparticle toxicity is dependent on dissolved silver and surface coating in Caenorhabditis elegans. Environ Sci Technol. 2012, 46(2), 1119-27. doi10.1021/es202417t

[24] Zhao S, Xi L, Zhang B. Union Exon Based Approach for RNA-Seq Gene Quantification: To Be or Not to Be? PLoS One. 2015, 10(11), e0141910. doi10.1371/journal.pone.0141910

[25] Mutz KO, Heilkenbrinker A, Lonne M, Walter JG, Stahl F. Transcriptome analysis using next-generation sequencing. Curr Opin Biotechnol. 2013, 24(1), 22-30. doi10.1016/j.copbio.2012.09.004

[26] Poynton HC, Lazorchak JM, Impellitteri CA, Blalock BJ, Rogers K, Allen HJ, et al. Toxicogenomic responses of nanotoxicity in Daphnia magna exposed to silver nitrate and coated silver nanoparticles. Environmental Science and Technology. 2012, 46(11), 6288-96. doi10.1021/es3001618

[27] Roh JY, Sim SJ, Yi J, Park K, Chung KH, Ryu DY, et al. Ecotoxicity of Silver Nanoparticles on the Soil Nematode Caenorhabditis elegans Using Functional Ecotoxicogenomics. Environmental Science \& Technology. 2009, 43(10), 3933-40. doi10.1021/es803477u

[28] van der Ploeg MJ, van den Berg JH, Bhattacharjee S, de Haan LH, Ershov DS, Fokkink RG, et al. In vitro nanoparticle toxicity to rat alveolar cells and coelomocytes from the earthworm Lumbricus rubellus. Nanotoxicology. 2014, 8(1), 28-37. doi10.3109/17435390.2012.744857

[29] Van Der Ploeg MJ, Handy RD, Heckmann LH, Van Der Hout A, Van Den Brink NW. C60 exposure induced tissue damage and gene expression alterations in the earthworm Lumbricus rubellus. Nanotoxicology. 2013, 7(4), 432-40. doi10.3109/17435390.2012.668569

[30] Lionetto MG, Calisi A, Schettino T. Earthworm Biomarkers as Tools for Soil Pollution Assessment. Soil Health and Land Use Management, Dr Maria C Hernandez Soriano (Ed). 2012.

[31] Bastús NG, Merkoçi F, Piella J, Puntes V. Synthesis of Highly Monodisperse Citrate-Stabilized Silver Nanoparticles of up to 200 nm: Kinetic Control and Catalytic Properties. Chem Mater. 2014, 26(9), 2836-46. doi10.1021/cm500316k

[32] van der Ploeg MJC, Baveco JM, van der Hout A, Bakker R, Rietjens IMCM, van den Brink NW. Effects of C60 nanoparticle exposure on earthworms (Lumbricus rubellus) and implications for population dynamics. Environ Pollut. 2011, 159(1), 198-203. doihttp://dx.doi.org/10.1016/j.envpol.2010.09.003

[33] Bolger AM, Lohse M, Usadel B. Trimmomatic: a flexible trimmer for Illumina sequence data. Bioinformatics. 2014. doi10.1093/bioinformatics/btu170

[34] Langmead B, Salzberg SL. Fast gapped-read alignment with Bowtie 2. Nat Methods. 2012, 9(4), 357-9. doi10.1038/nmeth.1923

[35] Roberts A, Pachter L. Streaming fragment assignment for real-time analysis of sequencing experiments. Nat Meth. 2013, 10(1), 71-3. doi10.1038/nmeth.2251. http://www.nature.com/nmeth/journal/v10/n1/abs/nmeth.2251.html\#supplementary-information

[36] McCarthy DJ, Chen Y, Smyth GK. Differential expression analysis of multifactor RNA-Seq experiments with respect to biological variation. Nucleic Acids Research. 2012, 40(10), 4288-97. doi10.1093/nar/gks042

[37] Benjamini Y, Hochberg Y. Controlling the False Discovery Rate - a Practical and Powerful Approach to Multiple Testing. Journal of the Royal Statistical Society Series B-Methodological. 1995, 57(1), 289-300.

[38] Alexa A, Rahnenfuhrer J, Lengauer T. Improved scoring of functional groups from gene expression data by decorrelating GO graph structure. Bioinformatics. 2006, 22(13), 1600-7. doi10.1093/bioinformatics/btl140

[39] Lyon DY, Fortner JD, Sayes CM, Colvin VL, Hughe JB. Bacterial cell association and antimicrobial activity of a C60 water suspension. Environ Toxicol Chem. 2005, 24(11), 2757-62. doi10.1897/04-649R.1

[40] Izak-Nau E, Huk A, Reidy B, Uggerud H, Vadset M, Eiden S, et al. Impact of storage conditions and storage time on silver nanoparticles' physicochemical properties and implications for their biological effects. RSC Advances. 2015, 5(102), 84172-85. doi10.1039/c5ra10187e 
[41] Kittler S, Greulich C, Diendorf J, Köller M, Epple M. Toxicity of Silver Nanoparticles Increases during Storage Because of Slow Dissolution under Release of Silver lons. Chem Mater. 2010, 22(16), 4548-54. doi10.1021/cm100023p

[42] Sekine R, Brunetti G, Donner E, Khaksar M, Vasilev K, Jamting AK, et al. Speciation and lability of Ag-, $\mathrm{AgCl}$-, and $\mathrm{Ag} 2 \mathrm{~S}$-nanoparticles in soil determined by $\mathrm{X}$-ray absorption spectroscopy and diffusive gradients in thin films. Environ Sci Technol. 2015, 49(2), 897-905. doi10.1021/es504229h

[43] Shang L, Nienhaus K, Nienhaus GU. Engineered nanoparticles interacting with cells: size matters. Journal of nanobiotechnology. 2014, 12, 5. doi10.1186/1477-3155-12-5

[44] Ruttkay-Nedecky B, Nejdl L, Gumulec J, Zitka O, Masarik M, Eckschlager T, et al. The role of metallothionein in oxidative stress. International journal of molecular sciences. 2013, 14(3), 6044-66. doi10.3390/ijms14036044

[45] Coyle P, Philcox JC, Carey LC, Rofe AM. Metallothionein: the multipurpose protein. Cell Mol Life Sci. 2002, 59(4), 627-47.

[46] Deb SC, Fukushima T. Metals in aquatic ecosystems: mechanisms of uptake, accumulation and release-Ecotoxicological perspectives. Int J Environ Stud. 1999, 56(3), 385-417. doi10.1080/00207239908711212

[47] Walsh JG, Cullen SP, Sheridan C, Luethi AU, Gerner C, Martin SJ. Executioner caspase-3 and caspase-7 are functionally distinct proteases. Proceedings of the National Academy of Sciences of the United States of America. 2008, 105(35), 12815-9. doi10.1073/pnas.0707715105

[48] Navarre WW, Zychlinsky A. Pathogen-induced apoptosis of macrophages: a common end for different pathogenic strategies. Cellular Microbiology. 2000, 2(4), 265-73. doi10.1046/j.14625822.2000.00056.x

[49] Liu J, Hurt RH. Ion release kinetics and particle persistence in aqueous nano-silver colloids. Environ Sci Technol. 2010, 44(6), 2169-75. doi10.1021/es9035557

[50] Navarro E, Piccapietra F, Wagner B, Marconi F, Kaegi R, Odzak N, et al. Toxicity of silver nanoparticles to Chlamydomonas reinhardtii. Environ Sci Technol. 2008, 42(23), 8959-64. doi10.1021/es801785m

[51] Asharani PV, Lian Wu Y, Gong Z, Valiyaveettil S. Toxicity of silver nanoparticles in zebrafish models. Nanotechnology. 2008, 19(25), 255102. doi10.1088/0957-4484/19/25/255102

[52] Mwilu SK, El Badawy AM, Bradham K, Nelson C, Thomas D, Scheckel KG, et al. Changes in silver nanoparticles exposed to human synthetic stomach fluid: effects of particle size and surface chemistry. Sci Total Environ. 2013, 447, 90-8. doi10.1016/j.scitotenv.2012.12.036

[53] Rogers KR, Bradham K, Tolaymat T, Thomas DJ, Hartmann T, Ma L, et al. Alterations in physical state of silver nanoparticles exposed to synthetic human stomach fluid. Sci Total Environ. 2012, 420, 334-9. doi10.1016/j.scitotenv.2012.01.044

[54] Bezakova G, Ruegg MA. New insights into the roles of agrin. Nat Rev Mol Cell Biol. 2003, 4(4), $295-308$. doi10.1038/nrm1074

[55] Husain N, Pellikka M, Hong H, Klimentova T, Choe KM, Clandinin TR, et al. The agrin/perlecan-related protein eyes shut is essential for epithelial lumen formation in the Drosophila retina. Developmental Cell. 2006, 11(4), 483-93. doi10.1016/j.devcel.2006.08.012

[56] Hrus A, Lau G, Hutter H, Schenk S, Ferralli J, Brown-Luedi M, et al. C. elegans Agrin Is Expressed in Pharynx, IL1 Neurons and Distal Tip Cells and Does Not Genetically Interact with Genes Involved in Synaptogenesis or Muscle Function. Plos One. 2007, 2(8). doi10.1371/journal.pone.0000731

[57] Sarrazin S, Lamanna WC, Esko JD. Heparan Sulfate Proteoglycans. Cold Spring Harb Perspect Biol. 2011, 3(7), a004952. doi10.1101/cshperspect.a004952

[58] Sollner C, Mentele R, Eckerskorn C, Fritz H, Sommerhoff CP. Isolation and characterization of hirustasin, an antistasin-type serine-proteinase inhibitor from the medical leech Hirudo medicinalis. Eur J Biochem. 1994, 219(3), 937-43.

[59] Zhao P, Dong ZM, Duan J, Wang GH, Wang LY, Li YS, et al. Genome-Wide Identification and Immune Response Analysis of Serine Protease Inhibitor Genes in the Silkworm, Bombyx mori. Plos One. 2012, 7(2). doi10.1371/journal.pone.0031168

[60] Christianson HC, Belting M. Heparan sulfate proteoglycan as a cell-surface endocytosis receptor. Matrix Biol. 2014, 35, 51-5. doi10.1016/j.matbio.2013.10.004 


\section{Supplementary Material}

Supplementary materials associated with this manuscript are listed and presented below.

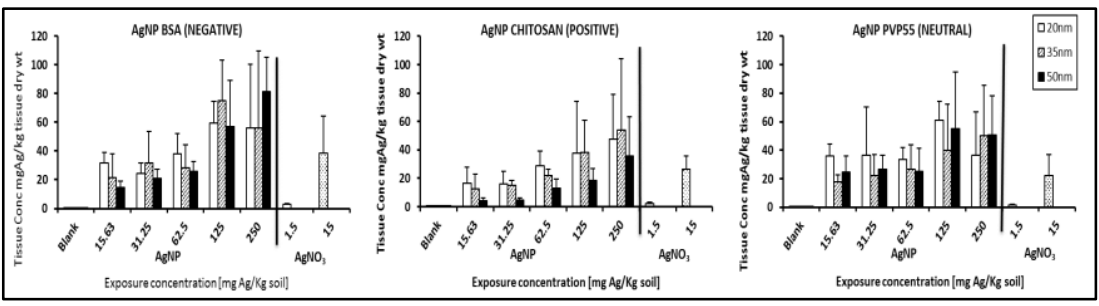

Fig. S5.1 Total Ag concentrations in tissues of earthworms (Lumbricus rubellus) exposed for 72 hours to different concentrations of silver nanoparticles (AgNPs) with different surface coatings (charge) and different particle sizes $(20,35$ and $50 \mathrm{~nm})$, or to $\mathrm{AgNO}_{3}$ in a natural soil. AgNP_BSA (negative, bovine serum albumin-coated); AgNP_Chit (positive, chitosan-coated); AgNP_PVP

(neutral, polyvinylpyrrolidone-coated). Results grouped according the type of AgNPs.

Table S5.1 Gene Ontology (GO) terms and descriptions of 27 significantly enriched genes relating to biological processes in the earthworm Lumbricus rubellus in response to medium-sized AgNP_BSA $72 \mathrm{~h}$ exposure.

\begin{tabular}{llcccc}
\hline GO.ID & Term description & Annotated & Significant & Expected & p-value \\
\hline GO:0010447 & response to acidic pH & 6 & 2 & 0.04 & 0.00045 \\
GO:0030214 & hyaluronan catabolic process & 10 & 2 & 0.06 & 0.00133 \\
GO:0051453 & regulation of intracellular pH & 12 & 2 & 0.07 & 0.00194 \\
GO:0015992 & proton transport & 13 & 2 & 0.08 & 0.00229 \\
GO:0007623 & circadian rhythm & 16 & 2 & 0.09 & 0.00349 \\
GO:0002028 & regulation of sodium ion transport & 17 & 2 & 0.1 & 0.00395 \\
GO:0055007 & cardiac muscle cell differentiation & 20 & 2 & 0.12 & 0.00547 \\
GO:0051384 & response to glucocorticoid & 22 & 2 & 0.13 & 0.00661 \\
GO:0035725 & sodium ion transmembrane transport & 24 & 2 & 0.14 & 0.00785 \\
GO:0006120 & mitochondrial electron transport, NADH to ubiquinone & 2 & 1 & 0.01 & 0.01174 \\
GO:0006537 & glutamate biosynthetic process & 2 & 1 & 0.01 & 0.01174 \\
GO:0014047 & glutamate secretion & 2 & 1 & 0.01 & 0.01174 \\
GO:0042816 & vitamin B6 metabolic process & 2 & 1 & 0.01 & 0.01174 \\
GO:0002087 & regulation of respiratory gaseous exchange & 3 & 1 & 0.02 & 0.01757 \\
GO:0006544 & glycine metabolic process & 3 & 1 & 0.02 & 0.01757 \\
GO:0006563 & L-serine metabolic process & 3 & 1 & 0.02 & 0.01757 \\
GO:0045176 & apical protein localization & 3 & 1 & 0.02 & 0.01757 \\
GO:0006898 & receptor-mediated endocytosis & 40 & 2 & 0.24 & 0.02115 \\
GO:0009071 & serine family amino acid catabolic process & 4 & 1 & 0.02 & 0.02337 \\
GO:0001101 & response to acid chemical & 50 & 2 & 0.29 & 0.03224 \\
GO:0043622 & cortical microtubule organization & 6 & 1 & 0.04 & 0.03487 \\
GO:0007097 & nuclear migration & 7 & 1 & 0.04 & 0.04057 \\
GO:0007100 & mitotic centrosome separation & 7 & 1 & 0.04 & 0.04057 \\
GO:0072383 & plus-end-directed vesicle transport along microtubule & 7 & 1 & 0.04 & 0.04057 \\
GO:0044057 & regulation of system process & 71 & 3 & 0.42 & 0.0442 \\
GO:0007019 & microtubule depolymerization & 8 & 1 & 0.05 & 0.04625 \\
GO:0008089 & anterograde axon cargo transport & 8 & 1 & 0.05 & 0.04625 \\
\hline & & & & \\
\hline & & & 1 &
\end{tabular}





\section{Chapter 6}

General discussion, future perspectives and conclusions 


\section{General discussion, future perspectives and conclusion}

\section{General}

Nanotechnology has been astutely described as an important catalyst in the twenty-first century industrial revolution [1,2] following what some prefer to term its rediscovery in especially the last two-and-half decades. With so many applications for nanoparticles (NPs) affecting virtually all industrial sectors [3, 4], increase in their production has been sustained globally. Inadvertently, potentials for both environmental deposition of NPs and exposure of living organisms are also increasing and this raises concerns regarding public and environmental health and safety. This is mainly because the novel physical and chemical properties of NPs that make them useful for various applications, also confer on them the potential to negatively impact the ecosystem. The fate and effects of NPs are influenced by both intrinsic (particle-related) factors, as well as factors associated with the exposure matrix. Various physico-chemical properties of NPs such as size and size distribution, surface chemistry and coating as well as charge, hydrophobicity, shape, stability in terms of dissolution rate, agglomeration and aggregation may affect the biological interactions of NPs in target organisms.

As mentioned in Chapter 1, AgNPs have been recognised as the most commonly used nanomaterial in many applications owing to their excellent antimicrobial activity and excellent physico-chemical characteristics for other applications $[5,6]$. Recently, the global market demand for AgNPs was projected to reach \$2.5 billion by the year 2022 [7]. This raises specific environmental health hazard concerns for AgNPs as well as concerns over the likelihood of their release and deposition in the environment. Predicted concentrations of AgNPs in the soil in for example the United States were projected at up to $13 \mu \mathrm{g} \mathrm{Ag/kg}$ soil which implied a 130-fold increase between 2008 and 2009 [8-11]. Although AgNPs have been increasingly investigated in recent years (Fig. 6.1), their environmental fate and effects are as yet poorly understood, and information on studies involving soil organisms is especially limited [6]. Looking at the trend in published research articles on the topic of AgNPs (in soil), there has been a steady increase. Articles investigating AgNPs gained in proportion from about $5 \%$ in the early 2000s to about 9\% currently. However, research focusing on soil and/or soil organisms has remained quite limited, showing that $<1 \%$ (1097) of the total publications on NPs generally (125660) focused on soil and/or soil organisms. Similarly, of the 10198 publications on AgNPs, only 2\% (238) studied AgNPs in soil and/or soil organisms. Nevertheless, AgNPs are increasingly being investigated (Fig. 6.1), adding credence to the importance of the impact of AgNPs in the environment. This trend agrees well with those earlier reported by others [12] based on data extracted from ISI web of Science. 

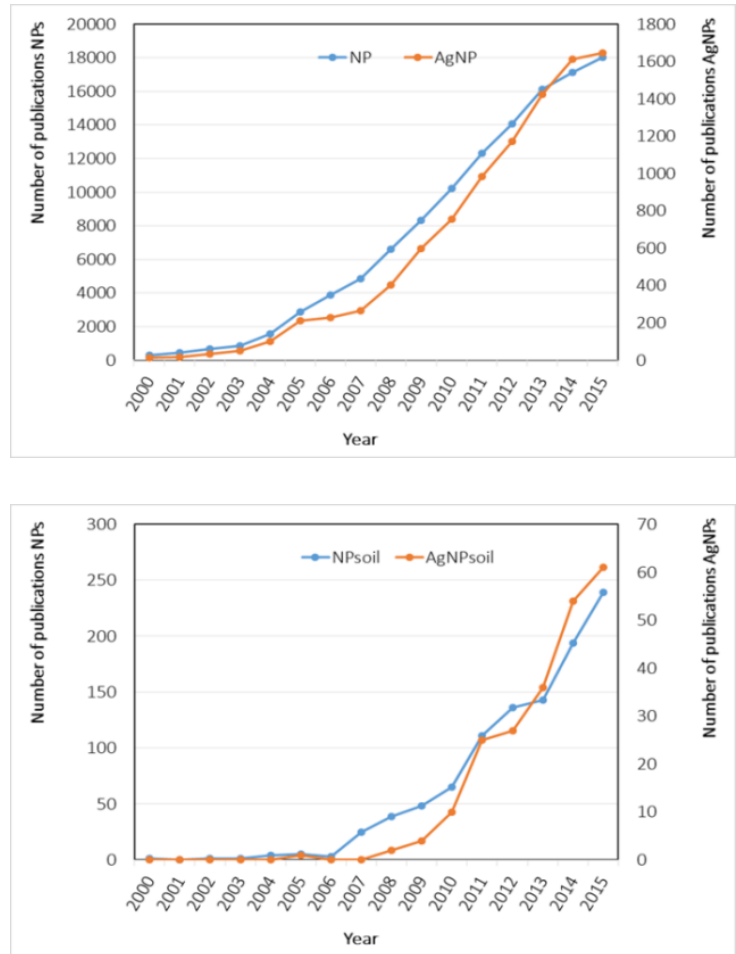

Fig. 6.1. The trend in published research articles on the topic of silver nanoparticles (AgNPs). These data were collected from PubMed Central using the keywords 'nanoparticle' (NP), 'silver nanoparticle' (AgNP) for the graph on the left; 'nanoparticle AND soil' (NPsoil), and 'silver nanoparticle AND soil' (AgNPsoil) for the graph to the right on 9th May at 23:30h. Number of publications on all NPs (left vertical axes); AgNPs (right vertical axes).

Although certain exposure matrix (soil)-associated factors like soil organic matter content, pore water ionic strength, presence of other metals, etc. are influential to the outcome of NPs exposure in the environment, in this study we focused our investigation on some physico-chemical properties of the AgNPs and how these influence the interactions of the AgNPs in a model soil organism Lumbricus rubellus at molecular, cellular and individual levels. An insight into this is critical for the environmental risk assessment (ERA) of this high-volume use NP-type that can potentially be deposited in the environment. To this end, we applied an in vitro- in vivo-integrated approach. Exposure to AgNPs via soil under the experimental conditions described in this research required large quantities of AgNPs sometimes very difficult to easily obtain commercially. Therefore, AgNPs were systematically synthesised and characterized to differ at the specific properties of interest. This also ensured appropriate comparisons. 


\section{Synthesis of AgNPs and pre-exposure characterization}

The physico-chemical properties of NPs are determined by the methods of synthesis used $[13,14]$, as well as the type or composition of the coating agent $[15,16]$. The $\mathrm{pH}$ of the solution during synthesis is also important in determining the surface charges of NPs, with acidic $\mathrm{pH}$ resulting in negatively charged NPs while basic $\mathrm{pH}$ leads to positively charged NPs. This phenomenon is important not only during synthesis of NPs, but also for their ultimate environmental fate [17]. Molecular weight of the coating material can also lead to different observations upon experimental exposure as was demonstrated for NPs that were coated with PVP of small and large molecular weights [18]. Therefore, chemically similar NPs of the same size and surface coating may not necessarily have the same surface properties. Essentially, it can be said that for toxicities relating to a NP, how it is made is what it does. How AgNPs are prepared, what types of surface coating are used, and the conditions under which they are used, affects their environmental fate which as a result is highly variable. Synthesis parameters like surface coatings can therefore make similar NPs hazardous or biocompatible [19].

AgNPs are commonly synthesized by the reduction of $\mathrm{Ag}^{+}$ions with sodium citrate [20], because citrate-reduced colloids are very easily prepared, stable for long periods, and yield very intense surface-enhanced Raman scattering (SERS) spectra [21]. The surface charges on the uncoated AgNPs are also influenced by the type of reducing agent used. Using sodium citrate or hydroxylamine, yields AgNPs with negative surface charge [20, 21]. Reduction of $\mathrm{Ag}^{+}$with sodium tetrahydroborate $\left(\mathrm{NaBH}_{4}\right)$ generates positively charged AgNPs, but these are less stable than the ones produced by citrate reduction $[20,21]$. In the present thesis, well monodispersed AgNPs were synthesised and coated with different biomolecules following the method of Bastus et al. [16] with slight modifications detailed in Chapters 2 and 4 . This method utilises the preferred bottom-up approach, based mainly on solution-phase chemistry also known as wet synthesis [22]. In the top-down approach, physical means are used to reduce solid crystals into NPs. Although the top-down method usually allows for the production of large quantities of NPs, controlling particle geometry or uniformity of sizes is very difficult. Wet synthesis of the AgNPs used in the present thesis was carried out in three size batches, and for each size batch three surface coatings were applied (Fig. 6.2).

A major challenge encountered with the synthesised AgNPs was the re-dispersion of especially the chitosan-coated AgNPs after they had been lyophilised into powder, which was necessary to prevent corrosion and facilitate ease of transport. While the BSA- and PVP-coated AgNPs were easily re-dispersed in the different media used, AgNP_Chit formed agglomerates. Where practicable, it might be best to carry out the exposures 
using synthesised colloids without lyophilisation. In this way, the challenge of agglomeration during re-dispersion will be eliminated.

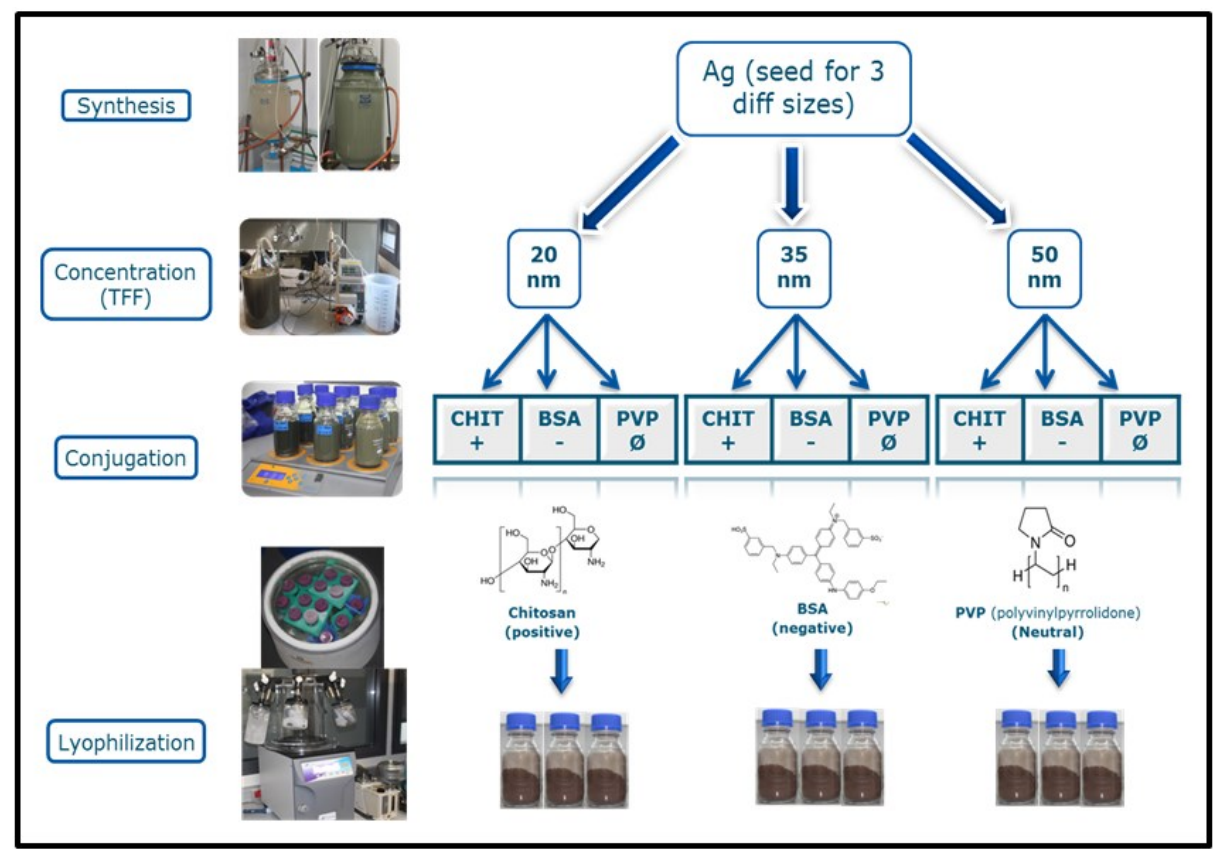

Fig. 6.2 Synthesis of AgNPs by a kinetically controlled seeded-growth method involving the reduction of silver nitrate $\left(\mathrm{AgNO}_{3}\right)$ in the presence of two competing reducing agents, tannic acid (TA) and trisodium citrate hexahydrate (SC) at $100^{\circ} \mathrm{C}$. Tangential flow fractionation (TFF) was employed to concentrate the AgNPs in the solution before surface-coating with biocompatible molecules at the conjugation step. Bovine serum albumin (BSA), chitosan (CHIT) and polyvinylpyrollidone (PVP) were used for surface coating, forming negative, positive and neutral AgNPs respectively. The NPs were then lyophilised into powder using liquid nitrogen and a freeze dryer and layered over with argon.

To perform the in vitro exposure experiments, the AgNP_Chit required an initial stock preparation in $50 \mathrm{mM}$ acetic acid (AA) before further dilution in cell culture medium and reducing the $A A$ concentration to a non-cytotoxic level of $0.02 \%$ (Chapter 2). The dynamic viscosity of chitosan has been reported to decrease in the presence of acetic acid due to polymer degradation [23]. For in vivo exposure experiments, suspensions of powdered NPs were prepared in soil extract with continuous stirring for 72 hours which has been used before for experiments in which earthworms were exposed to C60 fullerenes [24]. For the in vivo studies reported in this thesis (Chapters 4 and 5), this resuspension process was mostly efficient for the AgNP_BSA and AgNP_PVP, but to a 
lesser extent for the AgNP_Chit. Dispersing the powdered AgNP_Chit in soil extract resulted in the formation of some agglomerates, likely due to the formation of micelles by free chitosan [25]. The agglomerates likely led to an overestimation of the hydrodynamic sizes during the DLS measurements, resulting in rather large reported NP diameters since this technique is very sensitive to particle agglomerates or any aggregation in NP suspensions [26]. The large particles observed with AgNP_Chit represent a small fraction of the NPs, and TEM images showed core particles sizes within expected ranges (Chapter 4 and 5). Hence, the results of the characterization of the AgNPs indicated the formation of some agglomerates, but the AgNPs appear to be in dispersed states, even for AgNP_Chit.

When dispersed in Dulbecco's Modified Eagle Medium (DMEM) for use in in vitro experiments, the surface charges changed to negative values for all AgNPs. Positively charged particles were likely coated by negatively charged proteins in the media, and this may explain the negative $\zeta$-potentials measured for all AgNPs. However, the negative charge was smallest in the originally positively charged AgNP_Chit and most negative for the originally negatively charged AgNP_BSA. The overall negative charge for all AgNP types may be due to the fact that DMEM contains an abundance of charged protein molecules, thus $\zeta$-potentials measurements were greatly influenced by the electrostatic interactions in the matrix. This was demonstrated by others $[27,28]$. We also observed more negative $\zeta$-potential values when AgNPs were re-suspended in water than when re-suspended in DMEM, with minimal effect on hydrodynamic sizes regardless of the dispersant used (Chapter 2). As outlined above, lyophilisation of the samples did not result in particle aggregation or surface modifications, except for AgNP_Chit, and most AgNPs could be easily dispersed in different media as revealed by results of characterisation (Chapter 2 ).

Unlike in DMEM where all AgNPs showed negative values, ל-potentials of AgNPs in soil extract were preserved for the positive AgNPs. This is likely due to repulsion with the positively charged humic acid in the soil extract. The 'neutral' AgNP_PVP however had negative $\zeta$-potentials, but the values were less negative than those for the negative AgNP_BSA (Chapter 4). AgNP_Chit formed agglomerates when dispersed in soil extract, but not in suspensions prepared in DMEM. Formation of agglomerates in soil extract may indicate the likely general fate of AgNPs following environmental release in soil, possibly making the AgNPs less bioavailable, similar to what has been reported for 660 [29]. However, this may not necessarily connote an absence of adverse effects as the toxic potential of the AgNPs may unfold following ageing and decay, leading to release of $\mathrm{Ag}$ as NPs or dissolved $\mathrm{Ag}^{+}$ions [25, 30-32]. On the other hand, it is likely that the evolution of AgNPs in ageing soil may also lead to loss of toxicity due to sulfidation. 
Sulfidation strongly affects the surface charge and dissolution rate of AgNPs, potentially affecting the reactivity, transport, and toxicity of AgNPs in soils [33, 34].

Based on the above mentioned characterisations, it can be concluded that the preparations of the exposure media for both in vitro as well as in vivo experiments were successful, although for AgNP_Chit some agglomerates were formed. Notwithstanding that the charges in the in vitro medium were all negative, the order of charges was still as planned, AgNP_BSA being the most negatively charged and AgNP_Chit the least negatively charged. In soil extracts, the charges were maintained and the agglomeration state seemed to be mimicking environmentally relevant conditions. These 9 AgNPs and a commercially obtained negatively charged PVP-coated AgNP completed the set of NPs tested in the current research. For our in vitro studies, only the small $(20 \mathrm{~nm})$ and the large $(50 \mathrm{~nm})$ sizes were tested, while the in vivo studies in Chapters 4 and 5 evaluated only the 9 synthesized AgNPs.

\section{In vitro assessment of AgNP exposures and effects}

\section{In vitro uptake and cellular dynamics}

Although the use of in vitro models presents its own unique challenges and a comprehensive risk assessment may not be entirely based upon in vitro data [35], the opportunities presented by available in vitro models are worth exploring and can be integrated with in vivo tests [36] as was done in this thesis. By first investigating with the RAW 264.7 macrophage in vitro model, we obtained insights in the uptake, toxicity and possible modes of action of AgNPs at the cellular level (Chapter 2), potentially furthering our understanding of in vivo observations (Chapters 4 and 5). In vitro models have generally proven to have high throughput and from an ethical perspective they are also more desirable than in vivo models, explaining why they are increasingly exploited. Using in vitro models in risk assessments of chemicals facilitates the definition of hazards and the setting of priorities for further in vivo testing, thereby reducing the number of animals required [37]. Also, an interesting prospect for using in vitro models is the potential for read-across and extrapolating in vitro toxicity information to in vivo situations. Such information could be used in a weight of evidence approach [38] to define priorities for further in vivo testing.

Using imaging techniques (confocal laser scanning microscopy, CLSM), we demonstrated the uptake dynamics of the tested AgNPs in macrophage cells (Chapter 2). Some particles from the AgNP_BSA exposure were seen sticking to a macrophage surface membrane protrusion, and consequently being transported to the cell body within 30 
seconds. This was evidence that the AgNPs were internalised by the cells, and not only attached to the cell membrane. Of note was the fact that several cells showed fast uptake within the first 30 minutes of exposure, and cytoplasmic fluorescence intensity levels reached a plateau for the different AgNPs tested after already 2.5 hours (Chapter 2). With increasing exposure concentrations, the mean plateau value (based on an arbitrary unit) increased nonlinearly for all AgNPs. Fresh re-exposure to the initial nominal NP concentrations for an additional 24 hours did not significantly alter the uptake of AgNPs by the cells. Even at the lower exposure ranges, it can be seen that the uptake after 2 hours had already reached a plateau for the different AgNPs (Chapter 2). This may suggest that although NP uptake by the cells is quite rapid, it diminishes over time. Uptake of the negatively charged AgNP_BSA was rapid and most significant. In agreement with the findings of this thesis, uptake of short-interfering RNA (siRNA) NPS by mouse mammary tumour $4 \mathrm{~T} 1$ cells was improved due to coating with BSA which prevented the interaction of NPs with other serum proteins [39].

Microscopic observations of several large endosomes or lysosomes containing clusters of AgNPs, suggested that the uptake of the NPs involved active pathways. Our study however, did not differentiate between the different types of active endocytotic pathways that exist, such as the receptor mediated endocytosis involving both clathrin and caveolin mediated pathways and macropinocytosis. The uptake of both negativelyand positively-charged tri-block copolymer NPs by both coelomocytes (earthworm macrophage immune cells) and rat macrophage cells (NR8383 cell line) was previously shown to partly proceed via the caveolin - and clathrin - mediated active pathways, indicating the involvement of endocytosis in NP uptake [40]. In our experiment, both dispersed small vesicles as well as vesicles with clustered accumulated AgNPs occurred for all AgNPs within the cells. Over time, more clustered and larger vesicles became apparent, indicating vesicle fusion. Multiple large endosomes or lysosomes with many AgNPs clustered together were observed, suggesting that uptake was not by diffusion. The dynamic movements of the AgNPs within membrane domains however, indicated that accumulation does not necessarily imply that the NPs will form clusters in vesicles. The potential for CLSM can be further optimised for assessing cellular interactions of NPS like AgNPs which possesses unique optical properties without the need for adding fluorescent dyes. AgNPs are quite efficient at absorbing and scattering light whose colour depends upon the size and the shape of the NPs. The conduction electrons on the surface of AgNPs undergo a collective oscillation when excited by light at specific wavelengths, producing a surface Plasmon resonance (SPR) with an unusually strong scattering and absorption properties. The effective extinction cross sections of AgNPs are strong, easily allowing visualization of NPs that are less than $100 \mathrm{~nm}$ in size with a conventional (e.g. dark-field) microscope $[41,42]$. 


\section{In vitro effect assessment}

From the in vitro experiments reported in Chapter 2, the role of surface coating/charge in influencing TNF- $\alpha$ induction was demonstrated by the fact that the negatively charged AgNP_BSA showed effects in contrast to the other NP types. Effect of size was less prominent under our experimental conditions, showing mostly minimal differences between sizes that were not statistically significant. Overall, the negatively charged AgNP_BSA appeared to be more potent in inducing adverse effects in the macrophages. Additionally, when evaluating the induction of TNF- $\alpha$, we observed more effects in cells exposed to the $50 \mathrm{~nm}$ sized AgNP_Chit or AgNP_PVP, than in cells treated with the 20 $\mathrm{nm}$ sized ones, similar to what others have reported for other NPs [14, 43]. The smaller $20 \mathrm{~nm}$ AgNPs tended to induce more effects at lower concentrations than observed with the $50 \mathrm{~nm}$ sizes for almost all effects (Chapter 2). However, the differences were minimal and for all AgNPs tested, MTT reduction and MTP opening did not differ significantly $(p>0.05)$ between different sizes (20 nm vs $50 \mathrm{~nm}$ ), surface-coatings or charges. A concentration dependent decrease in cell viability was observed, with the 20 $\mathrm{nm}$ NPs showing lower $\mathrm{EC}_{50}$ values than the $50 \mathrm{~nm}$ NPs, while AgNP_BSA NPs appeared to elicit the most effect. With the exception of AgNP_Chit $50 \mathrm{~nm}$ for which the $E_{50}$ exceeded the highest exposure concentration, all $\mathrm{EC}_{50} \mathrm{~S}$ were between 10 and $15 \mu \mathrm{g} / \mathrm{mL}$ and 35 and $40 \mu \mathrm{g} / \mathrm{mL}$ for the $20 \mathrm{~nm}$ and $50 \mathrm{~nm}$ size groups respectively. The influence of NP size on their ability to induce toxic effects has been demonstrated previously [44, 45]. Our findings partly agree with the proposition that size does matter, as could be seen with ATP production, where the $20 \mathrm{~nm}$ AgNPs were more potent than the $50 \mathrm{~nm}$ for both AgNP_BSA and AgNP_Chit.

Depletion of ATP was significant at low exposure concentrations where mitochondrial respiratory systems were also impaired (Chapter 2), and may likely be due to mitochondrial damage [46]. Increased opening of the mitochondrial transition pore with increasing exposure concentration will lead to changes in permeability. This is likely followed by membrane depolarization, release of intra-mitochondrial ions and metabolic intermediates [47]. Normally, the MTP remains closed unless under conditions of stress as found in for instance hypoxia, oxidative stress, and exposure to a calcium ionophore. AgNPs of all sizes and surface coatings tested, demonstrated ability to cause the MTP to open. In our study however, we could not demonstrate ROS production for most AgNPs tested (Chapter 2). Other factors including increased accumulation of intracellular fatty acids and lysophosphatidase, as well as glutathione oxidation [47], have been indicated to be responsible for activating MTP opening.

Increase in ROS production is considered to be an early phase response [48] when oxidative stress is involved, and has been reported as one of the likely mechanisms of 
toxicity following exposure to AgNPs as well as other NPs [49-51]. In this current study, ROS production was only slightly increased with $20 \mathrm{~nm} \mathrm{AgNP \_ Chit} \mathrm{at} \mathrm{the} \mathrm{highest}$ exposure concentration (Chapter 2). Also, $20 \mathrm{~nm}$ AgNP_PVP showed an increase in ROS, but a decrease as exposure concentration further increased. This decrease in ROS production was associated with the onset of cytotoxicity, and perhaps other cytotoxic processes were initiated or progressing faster than ROS generation. For example, the opening of the MTP may lead to partial mitochondrial depolarization, which depending on $\mathrm{Ca}^{2+}$ concentrations, could result in a decrease in ROS production (low $\mathrm{Ca}^{2+}$ ) or an increase (high $\mathrm{Ca}^{2+}$ ) as reported earlier [52].

The initial increase in ROS generation at relatively low exposure concentrations and short incubation times has been reported by others $[6,53,54]$. It may be that the cytotoxic effect of the AgNPs overwhelmed the cell's capacity to generate ROS as a response, and rather progressed to cell death following other non ROS-related routes. Again, positively charged NPs tend to interact more readily with cells, likely due to the negative cell membrane charges [55]. This may enhance the exposure of cells to positively charged NPs, likely explaining the increased ROS production observed with the $20 \mathrm{~nm}$ positively charged AgNP_Chit. Interestingly, ROS was rather decreased in macrophage cells with increasing exposure concentrations of the $50 \mathrm{~nm}$ size AgNP_Chit, similar to the other AgNP types tested. With increasing exposure concentrations, the resulting distortion in metabolic activity coupled with an open MTP, may eventually have led to ATP depletion and cell death. This process has also been associated with mitochondrial respiratory system impairment following oxidative stress [46]. In the current study, ROS production levels were not significantly elevated above the control with increasing exposure concentrations of AgNPs. Considering the early onset of cytotoxicity based on MTT, MTP and ATP assay results however, the downward plunge of the ROS curves could result from the inability of injured cells to produce oxidative radicals, since their viability has been impaired.

AgNPs have been reported to cause immunogenic responses in cells, characterized by induction of cytokines like TNF- $\alpha$, macrophage inhibitory protein, or interleukins [44, 54]. For the AgNPs tested in the current study, the negatively charged AgNP_BSA showed the most induction of TNF- $\alpha$ upon exposure of the cells to both 20 and $50 \mathrm{~nm} \mathrm{NPs}$, resulting in an 80-fold increase between exposure concentrations 10 and $50 \mu \mathrm{g} / \mathrm{ml}$. There were no significant differences in the effects induced by the different sizes of AgNP_BSA. Interestingly, even when coated with similar biomolecules, the behaviour of NPs may still differ as can be seen with the $50 \mathrm{~nm}$ PVP-coated AgNPs commercially procured (negatively charged) and the AgNP_PVP synthesised by the author (uncharged). Although both AgNPs behaved similar for all other assays tested, the induction of TNF- $\alpha$ by the synthesized AgNP_PVP was significantly higher than the TNF- $\alpha$ induction by the 
commercially obtained AgNP. As already alluded to, this difference could result from the type of synthesis method used for making not only the NPs [13, 14], but also the bioconjugate [16]. The type and composition of the coating agent applied on a NP influences the outcome of exposure [15]. Also, the $\mathrm{pH}$ of the solution during the synthesis determines the surface charge of the NPs, with acidic $\mathrm{pH}$ resulting in negatively charged NPs while basic pH leads to positively charged NPs. This phenomenon is important not only during synthesis of NPs, but also during exposure [17].

For all tested AgNPs in this study, cytotoxicity patterns were generally similar irrespective of the type and size of AgNPs tested. Looking at ROS and TNF- $\alpha$ induction on the other hand revealed differences between the different types of AgNPs. This is indicative of varying mechanisms of action involved, corroborating what has been suggested by others $[31,56]$ that a combination of different physico-chemical properties of AgNPs is more likely responsible in inducing the observed toxicities, rather than only size or particle dissolution for instance.

\section{In vivo assessment of AgNP exposures and effects}

\section{In vivo quantification of uptake in earthworm tissues}

Uptake of Ag by earthworms in our in vivo exposure experiments was generally low, in agreement with results reported by others [9, 57-61]. This may likely be due to the dynamic interactions between the NPs' physical and chemical properties, exposure matrices and the physiological processes in the target organism. Accumulation in aquatic organisms like Daphnia magna [62] or rainbow trout [63] seems relatively high when compared to uptake so far reported for terrestrial organisms. The higher uptake levels in the studies with aquatic organisms may have been an overestimation, since the guts of the organisms in those studies were not depurated and still may have contained NPs. Gut clearance of $>98 \%$ in oligochaetes was determined to be achieved in 6 hours [64]. In our studies, we used a prolonged depuration period of 48 hours in order to reach a more efficient clearance of particles from the gut, likely contributing to the relatively low $\mathrm{Ag}$ concentrations obtained [65].

Similar to what was observed in vitro, in vivo uptake of AgNPs by earthworms was fast and tissue concentration levels were already elevated and detectable after 72 hours of exposure (Chapter 5). Uptake was highest for AgNP_BSA and tissue concentrations of this NP appeared to reach plateau levels at lower exposure concentrations. Generally, the smaller the size of NPs the greater the surface area that is available for interaction with biologic matrices either in exposure media or in the target cell or organism, which 
in turn may enhance uptake and subsequent effects $[66,67]$. For instance, translocation of NPs across epithelial barriers in animal models was affected by the size of the NPs tested [67-69]. Bio-distribution in rats [70] and toxicity of gold NPs in cells [71] and D. magna [72], were reported to be size-dependent. Irrespective of the different NP size ranges investigated in the cited studies (2 - $6 \mathrm{~nm}$ [71], $10-80 \mathrm{~nm}$ [72] and $10-250 \mathrm{~nm}$ [70]), the smaller sizes were better distributed and more potent than the larger sized NPs. In the study presented in Chapter 4, size appeared to have only a limited effect on the uptake of AgNPs. Uptake of the $20 \mathrm{~nm}$ AgNP_PVP by earthworms was higher than for the larger 35 and $50 \mathrm{~nm}$ sizes of the same coating. A likely explanation could be that the $20 \mathrm{~nm}$ AgNP_PVP may have dissolved faster due to their larger surface area, resulting in higher uptake than their larger sized 35 and $50 \mathrm{~nm}$ counterparts. Yang et al. [73] reported that AgNPs toxicity to Caenorhabditis elegans was dependent on dissolved silver and surface coating and not on size. Total tissue concentrations of $\mathrm{Ag}$ in earthworms were not significantly affected by the sizes of AgNPs tested, similar to earlier reports $[61,74]$.

Earthworm tissue concentrations of Ag also approached a plateau, similar to observations of others [75] who reported that the uptake of three forms of Ag (citrate or PVP-coated AgNPs, and as $\mathrm{AgNO}_{3}$ ), reached a steady state in Enchytraeus crypticus after only 7-10 days of exposure. In the studies detailed in Chapters 2, 4 and 5 of this thesis using the synthesised AgNPs, uptake of AgNPs was observed both in vitro (in less than 2 hours) and in vivo (within 72 hours). In our studies, tissue Ag concentrations in earthworms were measured only at 72 hours and 28 days. It could be that the plateau tissue levels of Ag measured after 28 days of exposure had already been attained earlier. Future studies could evaluate the uptake kinetics of AgNPs over the exposure duration of 28 days and determine at what time this steady state is attained.

From the findings of the current study, the size of the tested AgNPs seemed to have little or no effect on their uptake (and toxicity) both in vitro (Chapter 2) and in vivo (Chapters 4 and 5). This may likely be due to the relatively narrow size range tested, and including sizes less than $10 \mathrm{~nm}$ and up to $100 \mathrm{~nm}$ may have revealed effects of size on fate and toxicity of AgNPs. Others have also suggested that size-dependent toxicity only exists between particles of certain size classes including the sub $10 \mathrm{~nm}$ [61]. Had sizes ranging from less than $10 \mathrm{~nm}$ to $100 \mathrm{~nm}$ been included, effects of size on fate and toxicity of AgNPs might have been more apparent. Although some studies with gold NPs in the sub $10 \mathrm{~nm}$ size range revealed effects of size [71], it has been proposed that there may be an optimal size for uptake of NPs, likely in the range of $30-50 \mathrm{~nm}$ [76]. This may possibly be related to the efficiency of endocytosis in the uptake of NPs, often showing a nonunidirectional relationship with NP size at an optimum size range between $20-50 \mathrm{~nm}$ since larger NPs require non-specific slow uptake, while smaller NPs $(<20 \mathrm{~nm})$ do not 
generate enough cellular response [77]. But for metal NPs like Ag and gold, higher uptake and larger effects may still be induced at the sub $10 \mathrm{~nm}$ size ranges due to higher dissolution rates, and future efforts for hazard and risk assessment may have to include NPs of such sub $10 \mathrm{~nm}$ size range.

\section{AgNP characterisation in earthworm tissues}

The present thesis presented a novel method for quantification of AgNPs in earthworm tissues (Chapter 3). Analytical methods that can provide additional information on characterization of NPs accumulated in tissues of organisms will enhance our interpretation of toxicological data generated during exposure experiments [78]. Characterization and quantification of NPs is essential to understand their behaviour in relevant environmental matrices [79-81]. Measuring accumulation of NPs in complex biological matrices however, presents challenges due to the interactions between the matrix and the NPs. The development of techniques for extraction, clean-up, separation and sample storage that introduce minimal artefacts and assist the characterisation and quantification of NPs has been identified as an important research need [78]. Some studies report separating and extracting NPs from the tissues of exposed organisms using chemical digestion steps or tissue digestion with enzymes [82, 83]. In this research, the strengths of available analytical methods and tools were combined to obtain information on accumulation, subcellular compartmentalization, particle size distribution and NP speciation in biological tissue. This was enabled by first processing earthworm tissues using enzymes to digest tissues for elemental analysis [84, 85]. Such methods have been applied in the analyses of NPs in rat [82] or chicken [86] tissues, without distorting their size. In the present thesis, an enzymatic method was developed for the extraction, quantification and characterisation of AgNPs in earthworm tissues.

It is of importance to note that analyses of NPs in complex biological matrices like the ones cited above, generally employ direct tissue spiking of the NPs prior to their analysis $[62,87]$. NP accumulation under real exposure conditions however, involves many dynamic interactions between the NPs, the exposure matrix and the physiological processes of the target tissue or organism. This is a problem hampering method development and validation of analytical methods for especially NPs. In our study, we processed tissue samples to quantify AgNPs accumulated by earthworms under a realistic uptake condition in soil. Normal biological processes critical in determining the fates of these AgNPs in tissues were thus accounted for. Using realistic exposure conditions, we could introduce intermediate fractionation steps to investigate the subcellular compartmentalization of the AgNPs in tissues of earthworms. 
Further characterisations were done with sp-ICP-MS and high resolution Field Emission Gun Scanning Electron Microscopy in combination with Energy Dispersive X-ray analysis (FEG-SEM-EDX), confirming the actual uptake of primary particles into the tissue. Only earthworms treated with the $50 \mathrm{~nm}$ AgNPs were characterised by sp-ICP-MS due to the limit of resolution of the ICP-MS instrument which was at $30 \mathrm{~nm}$, and therefore even for the $50 \mathrm{~nm}$ treated samples information on NPs $<30 \mathrm{~nm}$ were unaccounted for (Chapters 3 and 4). Nevertheless, the particle size distributions obtained from sp-ICP-MS showed average diameters of AgNPs to be within expected ranges in both pristine particle suspensions and re-suspended AgNPs extracted from tissues by the enzymatic method described in Chapter 3. The NP size distributions for both pristine dispersed NPs in milliQ and NPs extracted from the tissues of earthworms using sp-ICP-MS, showed smaller particles as well as some large agglomerates, but mean NP sizes were within expected ranges. High resolution FEG-SEM-EDX confirmed the occurrence of AgNPs with the size of approximately $50 \mathrm{~nm}$ in tissues from AgNP exposed earthworms, indicating primary particles. The EDX analyses showed that the particles consisted of mainly Ag, with minor traces of sulphur (Chapter 3).

\section{Particulate versus ionic Ag tissue concentration}

Unlike in our first exposure experiment using a commercially obtained AgNP coated with PVP (AgNP_NC), the proportion of particulate $\mathrm{Ag}$ to total ionic $\mathrm{Ag}^{+}$in the tissues of earthworms exposed to the synthesised AgNPs were low: 33\% (Chapter 3) vs. 1\% (Chapter 4). Differences in the type of surface coatings used, as well as differences in molecular weights of even the same (PVP) coatings, likely explain this finding $[18,88]$. The molecular weight of the PVP coating used for the synthesised AgNP_PVP was 55 kDa while that of the PVP used in the commercially obtained AgNP_NC consisted of smaller molecules of $40 \mathrm{kDa}$. It is likely that the smaller the molecular weight of PVP applied, the more efficient the NP surface coating is [89]. The better coating provided by the lower molecular weight PVP may have resulted in lower dissolution of the commercially obtained AgNPs. This may explain why the proportion of particulate Ag measured in the earthworms exposed to the commercially sourced AgNPs (Chapter 3) was higher than what was measured in earthworms treated with the synthesised AgNPs (Chapter 4). Uptake of ionic $\mathrm{Ag}^{+}$from $\mathrm{AgNO}_{3}$ by earthworms was similar to that of the particulate, even though the nominal exposure concentrations of AgNPs in soil by mass base were approximately 1 order of magnitude higher than soil concentrations of $\mathrm{AgNO}_{3}$. This further affirms the higher bioavailability of $\mathrm{Ag}$ in its ionic form than as particulate. Nevertheless, nano-particulate Ag was quantified in tissues of depurated earthworms confirming uptake of $\mathrm{Ag}$ in this form in agreement to earlier reports [59-61]. 
Organisms exposed to metals may protect themselves by production of metallothionein (MT) to which the metals may sequester $[90,91]$. This has also been suggested for engineered NPs $[92,93]$. There is a growing evidence of the likely involvement of MT in the detoxification processes of some engineered NPs. In the enzymatic tissue processing method described in Chapter 3, MT would collect in the lighter tissue fraction [94], together with membrane-bound vesicles including mitochondria, lysosomes and microsomes, and heat denatured proteins (HDPs). The highest tissue concentrations of $\mathrm{Ag}$ were however measured in the heavier fraction for both particulate and ionic $\mathrm{Ag}$ exposures. Thus, neither particulate nor ionic forms of Ag seemed to be associated with MTs. It is possible that Ag ions are sequestered in the insoluble granules, as was suggested for isopods in which an inert fraction of internalised Ag was assumed after exposure to AgNPs [95] The presumed role of MTs in AgNP toxicity to earthworms is generally based on indirect observations, quantifying this protein in tissues after exposure or looking at gene expression profiles. An interesting approach is by tissue fractionation [90, 96], as was done in the current thesis (Chapter 5). Our results showed increased expression of MT genes (see section on the gene expression study below), however this increase was not accompanied by the actual storage of Ag in MT and Ag was not specifically associated with the MT-rich tissue fraction (Chapter 3).

\section{Effects on survival, growth and cocoon production}

Within the exposure duration of 28-days applied in our investigations, mortality and growth rates of earthworms were less affected by exposure to the AgNPs tested compared to reproduction. Growth was related to the exposure concentration, tissue concentration and type of AgNPs tested, but not to NP size. AgNP_BSA and AgNP_Chit treated earthworms showed similar effect levels, while AgNP_PVP had less effect on growth. The number of cocoons laid was observed to be most affected overall by AgNP_BSA particles indicating effect of surface coating. The $20 \mathrm{~nm}$ AgNP_PVP had more effect on reproduction than the larger size counterparts. However, the size of the tested AgNPs seemed to have limited overall effect on their uptake or toxicity perhaps due to the narrow range tested as already discussed above. In the 28-day sub-chronic reproduction toxicity study, the exposure concentrations of AgNPs in soil were most important in explaining the observed effects, with toxicity increasing when exposure concentration increased. This is as expected since higher exposure concentrations means higher internal levels in the earthworms. Generally, the most uptake and the largest effects in earthworms exposed to AgNPs were observed with the AgNP_BSA 
negatively charged particles. These observations are in agreement with our earlier report on the cellular interactions of these AgNPs with macrophages (Chapter 2) where the same AgNP_BSA were found to be more potent in inducing cytotoxicity.

Similar to our observations, exposure of E. crypticus to AgNP_Citrate and AgNP_PVP for up to 10 days did not result in mortality [75]. In another study on effects of AgNPs, reproduction of $L$. rubellus was most affected and the number of cocoons laid was reduced to $18 \%$ [59]. The $\mathrm{EC}_{50} \mathrm{~S}$ for the AgNP_BSA and AgNP_PVP used in our studies were between $45-120 \mathrm{mg} / \mathrm{kg}$ soil dry weight (DW) except for the $50 \mathrm{~nm}$ AgNP_PVP for which the $E_{50}$ was over $200 \mathrm{mg} / \mathrm{kg}$ soil DW. AgNP_Chit induced the least effect on reproduction, having $\mathrm{EC}_{50} \mathrm{~S}$ greater than the highest exposure concentration used in our study $(250 \mathrm{mg} / \mathrm{kg}$ soil DW). In a reproduction toxicity study of $E$. andrei exposed to AgNPs NM-300K, $\mathrm{EC}_{50} \mathrm{~S}$ for $\mathrm{AgNPs}$ and $\mathrm{AgNO}_{3}$ were similar between the treatments (74 $80 \mathrm{mg} / \mathrm{kg}$ soil DW) [97], although there was significant toxicity already at AgNP concentration of $30 \mathrm{mg} / \mathrm{kg}$ soil. It should be noted however, that the toxicity endpoint for reproduction investigated was the number of offspring and not cocoons laid, and the earthworm species was also different from the one used in the current study. Another study on the toxicity of PVP-coated AgNPs to the earthworm E. fetida at exposure concentration of $1,000 \mathrm{mg} / \mathrm{kg}$ soil in a natural soil did not have any effect on mortality, but only on reproduction. In fact, even though about $98 \%$ of the earthworms survived in the AgNPs treatment group, no cocoon was produced by the surviving earthworms [98].

In another study using artificial soil, the influence of surface coating on the bioaccumulation and reproduction toxicity of AgNPs coated with either PVP or oleic acid (30 to $50 \mathrm{~nm}$ ) in E. fetida was also investigated [60]. None of the Ag treatments, including $\mathrm{AgNO}_{3}$ affected growth or mortality of earthworms in these tests. On earthworm reproduction however, there was a significant effect although at really high exposure concentrations of $773.3 \mathrm{mg} / \mathrm{kg}$ for PVP-coated AgNPs and $727.6 \mathrm{mg} / \mathrm{kg}$ for oleic acidcoated AgNPs. $\mathrm{AgNO}_{3}$ was more toxic, showing a significant effect at $94.12 \mathrm{mg} / \mathrm{kg}$ soil. The differences observed were likely due to the different types of AgNPs (with different physical and chemical properties), the species of earthworms, and the exposure matrices (natural or artificial soils) used, as well as the endpoints assessed (juveniles or number of cocoons produced). Regardless of these differences however, all data indicated reproduction as the most sensitive endpoint and it is strongly affected by exposure to AgNPs. The studies discussed above and others, indicate that the toxicity of AgNPs is strongly dependent on the properties of test medium (e.g., organic matter) and the coating of the NPs [97]. 


\section{Effects of AgNPs on gene expression}

In order to further elucidate the likely mechanisms by which the synthesised AgNPs exerted their effects, we conducted a toxicogenomic study. Generally, exposure to the medium sized ( $35 \mathrm{~nm}$ ) AgNPs caused most pronounced responses at the transcriptional level, accounting for about $90 \%$ of the differentially expressed genes (DEGs). This was an interesting observation considering the limited effect of size on toxicity during the 28day exposure study (Chapter 4). The exact reasons for this observation is yet unknown. A likely explanation for the NP-size effect observed at 72 hours but limited in 28-day exposure tests, might be related to ageing of NPs in soil. In the case of the 72 hour exposure, a NP property-specific effect of size was likely demonstrated, possibly because exposure duration was still relatively short and NP dissolution may have been incomplete. Hence the NP properties may still affect uptake kinetics. However, in the 28day exposure, most tissue Ag was possibly in the ionic form during most of the exposure period, likely minimizing the impact of other particle-specific properties on effects that are induced at a later stage. Unfortunately, we could only determine particulate Ag concentrations in the earthworms exposed to the $50 \mathrm{~nm}$ sized group and only for the 28day exposure study due to the challenge of the instrumental resolution limit which was around $30 \mathrm{~nm}$ for the ICP-MS used. Another likely explanation indicated earlier could be that there is an optimal size range within which different NPs exert their effects, and 35 $\mathrm{nm}$ seemed to be the optimal AgNP size affecting the gene expressions of earthworms in our study (Chapter 5).

In Chapter 5, gene expression analyses showed that among the NPs with different coating types, AgNP_BSA caused extensive transcriptional responses. A total of 684 genes were up- or down-regulated in earthworms exposed to the $35 \mathrm{~nm}$ AgNP_BSA. In contrast, ionic $\mathrm{Ag}^{+}$had less effect on gene expression at the concentrations tested. When looking at the medium sized AgNPs, there was a clear influence of internal tissue Ag concentrations on the number of DEGs. For the other NP sizes however, the number of DEGs were not different between coating types. Irrespective of the surface coatings and internal tissue Ag concentrations in the earthworms, exposure to the 20 and $50 \mathrm{~nm}$ sized AgNPs produced similar numbers of DEGs. Only one gene was regulated among all treatments, indicating that there was hardly any functional overlap between the DEGs resulting from exposure to the differently coated AgNPs. Remarkably, this gene was MT, a cysteine-rich peptide present in bacteria, plants, invertebrates and vertebrates [99]. It is known to strongly bind free metal ions for chelation and detoxification [100], and it was strongly up-regulated in all treatments in the current thesis. The induction of the MT-gene does imply the role of MT as defense mechanisms towards exposure to Ag. However, in Chapter 2, Ag concentrations were not associated with the MT-fraction of 
earthworm tissues, indicating that although MT-genes were up-regulated, this did not seem to be an important mode of storage and detoxification of the AgNPs.

When we selected all DEGs of all NP-treated earthworms as a group and compared them to the group comprising all DEGs from the ionic $\mathrm{Ag}^{+}$treated earthworms, 37 DEGs overlapped. Of these shared genes, 31 were regulated in the same direction by both particulate and ionic $\mathrm{Ag}^{+}$treated earthworms. This would indicate the role of $\mathrm{Ag}^{+}$ions in inducing gene expression effects following AgNP exposure. It should be noted however, that there were also a large number of significant DEGs (969) that were expressed in earthworms exposed to AgNPs but not in earthworms exposed to $\mathrm{Ag}^{+}$ions. Therefore, the role of particulate silver was also indicated. A specific annotated gene, caspase 7, was expressed in earthworms exposed to AgNP_PVP and $\mathrm{Ag}^{+}$only. Together with caspase 3, caspase 7 is involved in bulk proteolysis during cell clean up after programmed cell death has been initialized [101]. So, caspase 7 induction seems to indicate some kind of apoptotic response [102]. Interestingly, we did not find any genes indicative of ROS induction in response to any AgNP exposure. This means that induction of ROS may not always result from exposure to AgNPs, which was shown in both in vitro studies and in vivo gene expression studies.

Gene ontology enrichment analysis for the medium sized AgNP_BSA exposure was performed, and the main processes induced by exposure to AgNPs were categorized using the REVIGO tree map view. Several biological processes were affected, including response to changes in physiologic $\mathrm{pH}$, proton transport, cell differentiation and microtubule organisation (a process involved in cell division and proliferation). Proton transport and response to $\mathrm{pH}$ were clearly supported by the strong up-regulation of some sodium hydrogen exchangers and vacuolar-type ATPases. Additionally, in vitro exposure of macrophages to AgNPs in Chapter 2 also resulted in depletion in ATP levels compared to the control. With depletion in energy, it has been shown that the earthworms' energy balance is shifted away from reproduction [103], which would explain the significantly reduced number of cocoons laid in the in vivo experiments (Chapter 4).

Furthermore, two annotated genes (agrin and antistasin) could be identified that were strongly activated in response to both AgNP_BSA and AgNP_Chit. Agrin is a multidomain extracellular matrix associated heparin sulfate proteoglycan (HSPG) essential in postsynaptic specialization at the neuromuscular junction in vertebrates and invertebrates, and its role in T-cell activation has been described [104]. Husain et al. (2006) [105] showed in Drosophila that secretion of an agrin homolog into the apical matrix is critical for the formation of epithelial lumina in the eye retina [106]. The agrin homolog in C. elegans seems to be associated with pharyngeal development [107]. In 
any case, agrin can directly elicit signaling responses in nearby cells [108]. Antistasin is the prototype serine-proteinase inhibitor and a potent inhibitor of blood coagulation factor Xa found in leeches [109]. Agrin and antistasin are implicated in resistance to pathogenic microorganisms and immune defense [110]. Both proteins are generally expressed and active in the extracellular matrix and can bind macromolecules. The activation of these genes may likely suggest the important role of the coded proteins in binding to not only macromolecular [111], but also nano-molecular cargo like the AgNPs. The exact role of agrin and antistasin in nanotoxicity is yet unknown, but likely associated with neurotoxicity and immunotoxicity as suggested by some of their known functions mentioned above. Reports on the characterisation of proteoglycans (proteins bonded to mucopolysaccharide groups, present especially in connective tissues) in earthworms are generally lacking, and to the best of our knowledge, this is the first report of the activation of these genes in earthworms exposed to AgNPs.

Taking all together, results of the current studies showed that within the range of 20 to $50 \mathrm{~nm}$, effects of the size of AgNPs at cellular and individual levels are limited, although alterations in gene expression profiles of earthworms were mostly induced by the $35 \mathrm{~nm}$ AgNPs. Effects of surface coating were consistent at the different levels of biological integration. Generally, the negatively charged AgNP_BSA accumulated to a relatively higher extent in the earthworms, especially at lower concentrations. The in vitro uptake was fast for all NPs, but also showed the highest uptake of AgNP_BSA. These negatively charged AgNPs were also the most toxic, likely related to their increased uptake. This was evident at all levels: gene expression, cellular, and individual (and population) levels. At the in vitro level, this applied mostly to effects on specific mode of action (TNF- $\alpha$ induction, ROS production). For more general cytotoxic effects, the impact of surface coatings was less evident. Except in cells exposed to $20 \mathrm{~nm}$ AgNP_Chit in which there was a slight increase in ROS production, these sets of AgNPs under the experimental conditions applied, did not appear to induce the production of ROS. This was supported by the lack of expression of any ROS-related gene in the gene expression profile analyses. Integrating the results obtained from the studies described in this thesis showed that the effects of NP properties on their toxicokinetics and toxicodyanimcs, appear to be in similar directions at different levels of biological organisation. This supports the use of in vitro models to study especially some well-defined biological effects of NPs. 


\section{Considerations for AgNP investigations}

\section{Environmental release and levels of AgNPS}

Several studies have demonstrated the potential of AgNPs applied in consumer products to end up in the environment [112-115]. Air, water, and soil environments are all likely contaminated with NPs from these products [114], but also from other anthropogenic and natural sources [116]. Based on the cited and related studies, several models have predicted the environmental fate of AgNPs [31 and references cited therein]. However, the usually very low predicted environmental levels of NPs, combined with the difficulty in distinguishing NPs from other background particles in especially biological matrices, limits the precision of such predictions. In addition, conventional analytical tools like ICPMS in standard modes are incapable of differentiating ionic from particulate forms of Ag, requiring additional separation or extraction steps as reported in this thesis. Indeed, appreciable progress has been made in the analyses of NPs both in terms of developing more sensitive equipment, as well as new methodologies for particularly the extraction of NPs from tissues [62, 82, 86, 87]. Nevertheless, as already mentioned, data on the environmental levels of AgNPs are still lacking, making risk quantification quite uncertain, and therefore difficult [117].

\section{Synthesis of NPS}

The studies described in this thesis and those of others, have shown that the fate and effects of NPs are influenced by their physical and chemical characteristics [31 and references therein], which are in turn determined by the processes of synthesis [43]. Although wet synthesis is commonly used and preferred [22], the precise control over size and size distributions [118], as well as reproducing the specific surface charge and hydrophobicity [17, 119] are challenges often encountered. A number of optimised synthesis methods have been reported to achieve highly monodispersed AgNPs with narrow size distributions. These include for instance, the use of PVP as surfactant to optimise a polyol synthesis method [43], or a kinetically controlled seeded growth method with careful adjustments of $\mathrm{pH}$, temperature and $\mathrm{Ag}$ nucleation [16], as adapted with slight modifications in the current study (Chapters 2 and 4). By using AgNPs synthesised in the same series and systematically differing at the target properties of interest as reported in this thesis, a systematic and scientifically sound comparison was facilitated.

Analytical methods for quantifications and characterisation, implications for our results

Several methods for quantification and characterisation of NPs including AgNPs have evolved over the years, improving the accuracy of results. Dynamic Light Scattering (DLS) 
is a very common and easy to use method for determining the size of NPs by calculating their ability to scatter light. The size estimates from this method are therefore hydrodynamic sizes, and can provide information on NP size distribution and its polydispersity index. Because the DLS operates on Rayleigh's approximation principle of light scattering by particles where the intensity of scattering is proportional to the sixth power of the particle's radius, the DLS technique is very sensitive to any particle agglomeration and/or aggregation in NP suspensions [26]. Hence, the occurrence of even minute amounts of agglomerates may skew the results, which was shown to be the case with the AgNP_Chit. In the current thesis, several characterisation techniques were used to monitor the proper coating and stability of AgNPs in the different media. Despite the large hydrodynamic diameter (DLS) seen for the particles coated with chitosan, we observed well dispersed particles by TEM, and also UV-Vis spectra were generally preserved. This indicates that although some larger aggregates may have formed in case of the AgNP_Chit, the vast majority of the NPs seemed to be well dispersed. Another challenge for DLS is its inability to analyse heterogeneous mixtures or NPs in the presence of proteins as contained in many cell culture media. This means, characterisations of NPs in many studies cannot be conducted in the exposure media. This should be considered when drawing inferences from results obtained as such, since the behaviour of the tested NPs in water for example will markedly differ from that in cell culture medium.

Transmission or scanning electron microscopy (TEM/SEM), as well as high-resolution FEG-SEM/EDX are other tools useful for the analysis of NPs [87, 120]. With these tools, the particle and aggregate sizes of NPs as well as their shapes and crystallinity can be determined. The number of NPs are counted and should be statistically high enough to permit reliable size distribution information, and this could be time consuming. To characterise the AgNPs synthesised and used for the experiments in Chapters 2, 4 and 5, at least 250 particles were counted and analysed to calculate the size distribution of each type of AgNPs. In tissues and other complex matrices, this is even a greater challenge due to low concentrations. Furthermore, the pre-treatment needed for TEM observations may have large impacts on the agglomeration state of the NPs and sample preparation may therefore, interfere with the efficiency of either technique. For instance, samples need to be dried, likely increasing the probability of NPs sticking together.

In addition to the techniques using visual signals, single particle ICP-MS has emerged as a very robust and relevant tool in NP analysis and has been advanced as an appropriate method for determining the actual particle size distributions in a more quantitative way [121]. This technique measures the plumes of metal ions produced when single NPs are vaporised in the plasma [31]. It is capable of determining not only size distributions, but 
also numbers of metallic NPs like AgNPs. This is because the number of peaks generated per observation period is a reflection of the number of NPs in the suspension, and the peak heights reflect the mass of the individual particles. This technique is however limited by the instrumental resolution, being unable to distinguish smaller NPs from ionic background signals. Also, only a single element can currently be measured at a time and may therefore estimate the sizes for compound NPs (e.g. $\mathrm{Ag}_{2} \mathrm{~S}$ ) to be smaller than the elemental AgNPs [31]. The instrument used for our studies was a Thermo Scientific $X$ Series 2 ICP-MS instrument equipped with a standard nebuliser and a quartz impact bead spray chamber. It had a lower cut-off size of approximately $30 \mathrm{~nm}$. The lower cutoff of $30 \mathrm{~nm}$ resulted in the fact that NPs of smaller particle sizes could not be analysed. Decreasing the dwell time in the sp-ICP-MS analysis was shown to improve the sensitivity and accuracy of results $[122,123]$, making it possible to detect particles of about $20 \mathrm{~nm}$. But this was not possible to such an extent that it would have improved our ability to detect AgNPs in the smaller size treatments. Increasingly, many hyphenated techniques that combine two or more analytical tools have emerged as viable options for NP quantification and characterisation [124], and these might be useful for not only size determination, but also for speciation of NP forms. Examples include hydrodynamic chromatography (HDC) coupled with ICP-MS, and asymmetrical-flow field-flow fractionation (AF4) also coupled with ICP-MS. It should be noted however, that these techniques are quite sensitive to the matrix the NPs are in and as such may not be applicable yet for analyses of NPs in tissues.

A common limitation with the methods of NP size characterization mentioned above is that they work best on monodispersed primary (pristine) NPs, but real samples are often complex and hardly monodispersed. Separating the NPs from complex matrices is a crucial step that can enhance the detection and versatility of some of the tools discussed above. An approach developed in this thesis (Chapter 3 ), based on tissue processing using enzymes $[82,86,121]$, was shown to be an important step forward in the analyses of NPs present in complex matrices. Another difficulty for analysis of many NPs is the absence of a standard reference material. Fortunately, some progress has been made towards establishing standard reference materials for NPs. Examples include gold NPs (RM8011 - 13) from the National Institute of Standards and Technology (NIST), and the NM-300K AgNP from Mercator GmbH (Germany), which have already been used in conducting research $[59,121]$.

\section{Biological mechanisms driving the toxicity of AgNPs}

Elucidating the mechanisms of effects arising from AgNP exposures in vitro or in vivo is difficult due to several reasons. Two reviews $[31,56]$ elaborated on this, and will therefore be briefly summarised. Evidence available in literature indicates that 
inflammatory, oxidative, genotoxic, and cytotoxic consequences are commonly investigated in exposures involving AgNPs. Although these toxicity processes are associated with AgNP exposures, and may even be inherently linked [31], there is still not enough data available to conclude what the toxic effects of AgNPs and the underlying modes of action might be. Indeed, the effects observed in many studies are determined by the types of NPs investigated and the models used (Chapter 2). Often, there is only limited characterization and quantification, if at all, of the AgNPs dispersion properties, and information on the stability of the tested AgNPs over the exposure time is likewise limited. Also, distinguishing between effects arising from ionic $\mathrm{Ag}^{+}$exposures and those that are particle related is difficult. Intermediate steps for extracting AgNPs from tissues for example, present viable options for improvements that could be optimised and standardised to assist with speciation analysis. In the current studies we characterised both exposure media as well as concentrations in tissues and subcellular fractions as a proxy for internal exposure (Chapters 3 and 4). We assessed both ionic Ag, as well as particulate AgNPs when technically feasible. The results show that when employing different types of techniques (DLS, TEM, UV-Vis, ICP-MS, sp-ICP-MS, కpotential) it is feasible to properly characterise and quantify the actual exposure. However, it is evident that this is very resource demanding, and not something that can be performed on a regular basis in standardised risk assessment of NPs. Therefore, there is high demand for simplified techniques that can be used to assess actual NP exposure under standard lab-conditions, while demanding fewer resources.

The choice of the animal model to use depends on the focus of the study and the endpoints targeted. The lungs (aerosol exposures) and the liver (primary site for localisation) are two major organs that have been identified as relevant for exposure studies in lung breathing vertebrates. Therefore, the relevance of using cell lines corresponding to these organs that are the target sites for accumulation and toxicity is justified [31]. For earthworms however, results of a recent study using an established approach of gluing the mouth of earthworms ( $L$. rubellus), indicated that a significant part of the Ag uptake was by the oral route for both AgNPs and $\mathrm{Ag}^{+}$ions [125]. For the AgNP exposure, high concentrations were associated with the gut wall, liver-like chloragogenous tissue, and nephridia, which suggest a pathway for AgNP uptake, detoxification, and excretion via these organs. The authors justifiably questioned the applicability of the current bioavailability assessment and modelling of metal-based NPs, since these models consider the dominant route of exposure to be via the dermal route. Experiments and physiologically-based kinetic (PBK) modelling used in ERA should therefore ensure that exposure via the oral route is adequately considered.

A main hazard posed by AgNPs to earthworms is thought to be effects on reproduction [126] and this has been discussed in Chapter 4. For mammals, it was shown in vitro that 
AgNPs may affect the development of spermatogonial stem cells [127]. Also, the embryos of the zebrafish Danio rerio showed abnormalities due to exposure to AgNPs $[128,129]$. Although many studies indicate reproductive effects of AgNPs to varying degrees, a critical review highlighted the limited number of studies available as well as the limited sample sizes investigated [56]. Common among these studies also, was the absence of any focus on toxicity to other organs or cell types of the reproductive system that may indicate potential side effects. The impact of ionic $\mathrm{Ag}^{+}$was indicated to be important from the results of the current research, based on uptake of the AgNPs by earthworms, as well as the highly up-regulated MT genes in the gene expression profiles of exposed earthworms. Generally, reproductive toxicity seems to be a sensitive toxicity endpoint for other NPs as well, including nickel, titanium, gold, etc. [130-132].

\section{Effects of size and surface coating (charge) of AgNPs}

The results of this research mainly indicated effects of surface coating on the uptake and toxicity of AgNPs. Size had only limited effect, which may be related to the relative narrow range of sizes used in the current study. The impact of AgNPs have been found to be related to their size $[56,133]$, but not always $[14,73]$. The explanation for the potency of the smaller sizes of AgNPs, or otherwise, is yet to be fully understood. Often, the higher specific surface area of the smaller NPs is thought to facilitate their dissolution and release of ionic $\mathrm{Ag}^{+}$, thus enhancing uptake [31]. Correlation between smaller NP size and more dissolved Ag was not always found [134, 135], suggesting the involvement of surface coatings and other biomolecules in influencing the dissolution rates. Biomolecular species and ions in exposure media could affect the size and size distributions of AgNPs, therefore characterisation of NPs in the exposure medium is always essential. AgNPs have been coated with various types of bio-conjugates and for various purposes, as was also the case with the AgNPs used in the current research. Surface coatings can be used to stabilise NPs and prevent agglomerations or dissolution in media $[136,137]$. More specifically, surface coatings are used to alter the biological activity of AgNPs [73, 137], and their surface coating essentially determines their effects as was described in the current research as well as by others [14, 53, 73]. The interaction of AgNPs in biological media and organisms, and therefore their toxicity, is partly determined by their surface charge. The surface charges of NPs are governed by the type of coating used, and so types of coating used should be considered when interpreting exposure data and should be measured in the relevant exposure media. As with size however, the correlation between the surface charge of NPs and the effects induced is not always the same. It should be noted that although the discussion in this section focused on AgNPs, similar influence of physical and chemical properties of NPs hold true for many other NPs including gold, titanium, cerium, carbon, iron, etc. [129, 138-145]. 


\section{Future perspective}

It is quite evident that the production and application of NPs will continue to increase, and so also will their global environmental impact. As technologies continue to advance, ever newer applications of NPs will emerge. Composite products made from more than one type of NP, and even smaller "pico" particles are examples of emerging types of NPS that may present peculiar challenges that could further complicate the current ERA approaches. The need for a continuing effort towards advancing our knowledge of the fate and effects of AgNPs and NPs is therefore evident. One important type of information lacking at the moment is a comprehensive exposure characterization to know the levels and properties of AgNPs (and indeed other NPs) in the environment. This is quite a challenge considering the different sources of NPs both natural and anthropogenic, and the current instrumental limitations. Certain advancements have been made in the ability to detect even low concentrations of some NPs and separating these into their composite sizes by tuning the dwell time of ICP-MS instruments. Decreasing the dwell time from 10 to 0.1 microseconds in sp-ICP-MS increased resolution, allowed for accurate sizing of NPs by avoiding coincidence, and vastly improved the working range of this technique [122]. Where these short dwell times are applied, the likelihood of obtaining particle-by-particle elemental compositions is enhanced and even two elements or isotopes in the same nanoparticle can be detected.

Also, the use of hyphenated techniques, though currently encumbered by many challenges for optimization, can improve the detection and characterization of NPs. Already, some advancements have been made with coupling various methods that can determine physical (size and distribution) and chemical (elemental) compositions and concentrations [146]. A good example mentioned above is the coupling of a hyphenated sp-ICP-MS and an AF4 for characterising NPs size and numbers [147]. The need for optimising existing options for quantification and characterization of AgNPs in complex matrices should be pursued further. For NPs in complex biological matrices (e.g. animal tissues), introducing extraction techniques as was demonstrated in this thesis (Chapter 3) before applying methods like sp-ICP-MS and high resolution FEG-SEM/EDX facilitated and improved our analyses. Hence, the prospect for less destructive methods like the use of enzyme digestion and mild chemical separation of NPs from complex matrices, should continue to be explored. Different approaches to optimize current methods could involve other types of enzymes and enzyme combinations, under different incubation conditions.

Another approach to quantify and characterise NPs that is also evolving is the use of imaging techniques. Scanning and Transmission Electron Microscopy have both been traditionally used for the characterization of the core particle sizes, shapes and numbers 
[120]. Other promising imaging and/or fluorescent techniques being explored for their versatility are confocal laser scanning microscopy (CLSM) as used in Chapter 2, and flow cytometry which uses fluorescent-activated cell sorting (FACS) to assay uptake [148150]. We employed a CLSM technique in the in vitro studies in Chapter 2, and AgNPs were imaged to follow their cellular uptake, localization and accumulation behaviour over time. In our study, we did not discriminate between the different types of active endocytotic pathways such as receptor mediated endocytosis (clathrin or caveolin mediated) and micropinocytosis. It would be interesting to quantify the different pathways involved in the uptake of these AgNPs, since it was shown earlier that both receptor mediated pathways were involved in the uptake of fluorescent tri-block copolymer NPs [40].

Since soil is a sink for many toxicants including NPs, exposures potentially affecting soil organisms are inevitable and understanding the impact of such exposures is essential for ERA. Therefore, the need for established sensitive methods to detect the impact of NPs on organisms is great. Several methods are increasingly being investigated in effect assessments of NPs $[56,151]$, including both in vitro and in vivo models. In vitro models have been used to elucidate the mechanism of toxicity of NPs, and in the current thesis, a macrophage cell line was used to investigate the cellular interactions of various forms of AgNPs (Chapter 2). From the results of the aforementioned study and those of others discussed in chapter 2, there is need for further development, validation and standardisation of the in vitro methods currently used. Finding comparable and suitable in vitro models that can account for the possible exposure routes (dermal and oral) for soil invertebrates like earthworms for example is still needed for useful extrapolations from in vitro to in vivo situations. Effect assessment of NPs can be enhanced by investigations at several levels of biological organisation as done in the current thesis. Using simple, high throughput in vitro methods, capable of exhibiting relevant mechanistic toxicity endpoints, will certainly advance the assessment of NPs exposures. The coelomocyte model may be a likely option since it has been used in the hazard assessment of NPs $[40,59]$. Validating and standardising the coelomocyte model for NPs toxicity testing could be the next step.

As the concentrations of AgNPs in the environment are predicted to be extremely low, sensitive techniques for identification and quantification are needed. Generally, there are uncertainties surrounding environmental exposure estimates in nanomaterial risk assessments $[152,153]$. To reduce the uncertainties, methods that are developed to characterize AgNPs in environmental or occupational exposure settings could be used to improve exposure models for several nanomaterials. Also, there are indications from literature that juvenile earthworms are more sensitive to NP toxicity [24,97], and incorporating juvenile toxicity testing in the current standard test methods (OECD 222) 
may improve NP effect assessment. Indeed, investigating the impact of NPs over the full life cycle of the earthworm for instance, and under environmentally relevant conditions, will be useful in improving our understanding of the effects of NP exposure [152].

It is essential to recognise that the increasing numbers and forms of NPs entering the market certainly complicate the ERA further, since their fate and behaviour in the environment may likely be as different as their individual physico-chemical properties. But from what is now known in literature, similar toxicity end-points are emerging which may be associated with certain modes of action. An interesting proposition being pursued by a new EU project is considering the possibility that even though manufactured, pristine NPs vary widely in terms of their physical and chemical characteristics, their fate in the environment with potential for toxicity may likely be less varied. It could be that the NPs eventually change, likely producing only fewer intermediate stage products depending on the environmental compartment they are partitioned to. These intermediate products could be the ones that can potentially pose a risk, and identifying them will greatly improve and enhance our ERA strategies. A recent study reported that for ionic and particulate forms of silver, the molecular mechanism of effect in E. fetida were induced by the same pathways even though uptake mechanisms were different [154]. Hopefully, the health and environmental risks of NPs may still be low based on environmental levels earlier predicted [10]. But future developments in the applications and use of NPs as highlighted above may alter the current levels of occurrence and associated risks, necessitating continuous monitoring and evaluation of NPs in the environment. One can never be too prepared for unforeseen potential risks and as the idiomatic expression says, prevention is better than cure. It is also quite interesting to note that after many years, we are still trying to define NPs and elucidate the processes that govern and dominate their kinetics and dynamics, but could it be that NPs do not want to be defined but described?

\section{Conclusion}

Even though AgNPs have been in use for many years as colloids, their fate in and effects on the environment and humans are yet to be fully clarified. The current study showed that under the stated experimental conditions, surface coating (charge) was important in driving the fate and effects of the tested AgNPs. This was clearly demonstrated by the BSA-coated negatively charged AgNPs. NP size on the other hand had only a limited influence, perhaps due to the narrow size ranges of $20-50 \mathrm{~nm}$ used in the current thesis. It was also shown that AgNPs can be taken up by earthworms in their particulate form, although the contribution of the particulate form to the total silver body burden 
may vary considerably, likely depending on the type of NP and the surface coating applied. The conclusion that the physico-chemical properties of NPs do influence their environmental fate and toxicity, is thus supported. It also appears that defining regularities in the way in which NP characteristics drive uptake and toxicity is not straightforward and may vary with the type of NPs studied, and should be evaluated on a case by case basis. Our research supports the use of in vitro models to prioritize further in vivo studies. Studies investigating the fate and effects of NPs in soil organisms are vital for a holistic approach towards a comprehensive and adequate ERA. The studies described in this thesis contribute to this knowledge by improving our understanding of the hazards and risks due to exposure to AgNPs, thus enabling their adequate and comprehensive ERA. 


\section{References}

[1] Kennell D. Nanotechnology: An Industrial Revolution? Monthly Review MRZine. 2009.

[2] Wennersten R, Fidler J, Spitsyna A. in Handbook of Performability Engineering (Ed. Misra KB)2008, pp. 943-52 (Springer London: London).

[3] Wijnhoven SWP, Oomen AG, Sips AJAM, Bourgeois FC, te Dorsthorst GJPM, Kooi MW, et al. Development of an inventory for consumer products containing nanomaterials Final Report RIVM Report 000201006. 2010, 103

[4] Wijnhoven SWP, Peijnenburg WJGM, Herberts CA, Hagens WI, Oomen AG, Heugens EHW, et al. Nanosilver - a review of available data and knowledge gaps in human and environmental risk assessment. Nanotoxicology. 2009, 3(2), 109-38. doi10.1080/17435390902725914

[5] Vance ME, Kuiken T, Vejerano EP, McGinnis SP, Hochella MF, Jr., Rejeski D, et al. Nanotechnology in the real world: Redeveloping the nanomaterial consumer products inventory. Beilstein journal of nanotechnology. 2015, 6, 1769-80. doi10.3762/bjnano.6.181

[6] Foldbjerg R, Jiang X, Miclăuş T, Chen C, Autrup H, Beer C. Silver nanoparticles - wolves in sheep's clothing? Toxicol Res. 2015, 4(3), 563-75. doi10.1039/c4tx00110a

[7] TechNavio IRL. Global Silver Nanoparticles Market 2015-2019. 2015, 60.

[8] Gomes SI, Soares AM, Scott-Fordsmand JJ, Amorim MJ. Mechanisms of response to silver nanoparticles on Enchytraeus albidus (Oligochaeta): survival, reproduction and gene expression profile. J Hazard Mater. 2013, 254-255(0), 336-44. doi10.1016/j.jhazmat.2013.04.005

[9] Gottschalk F, Sonderer T, Scholz RW, Nowack B. Modeled environmental concentrations of engineered nanomaterials ( $\mathrm{TiO}(2), \mathrm{ZnO}, \mathrm{Ag}, \mathrm{CNT}$, Fullerenes) for different regions. Environ Sci Technol. 2009, 43(24), 9216-22. doi10.1021/es9015553

[10] Mueller NC, Nowack B. Exposure modeling of engineered nanoparticles in the environment. Environ Sci Technol. 2008, 42(12), 4447-53. doi10.1021/es7029637

[11] Schlich K, Klawonn T, Terytze K, Hund-Rinke K. Hazard assessment of a silver nanoparticle in soil applied via sewage sludge. Environmental Sciences Europe. 2013, 25(1), 17. doi10.1186/2190-471525-17

[12] Tran QH, Nguyen VQ, Le AT. Silver nanoparticles: synthesis, properties, toxicology, applications and perspectives. Adv Nat Sci-Nanosci. 2013, 4(3), 033001. doi10.1088/2043-6262/4/3/033001

[13] Samberg ME, Orndorff PE, Monteiro-Riviere NA. Antibacterial efficacy of silver nanoparticles of different sizes, surface conditions and synthesis methods. Nanotoxicology. 2011, 5(2), $244-53$. doi10.3109/17435390.2010.525669

[14] Powers CM, Badireddy AR, Ryde IT, Seidler FJ, Slotkin TA. Silver nanoparticles compromise neurodevelopment in PC12 cells: critical contributions of silver ion, particle size, coating, and composition. Environ Health Perspect. 2011, 119(1), 37-44. doi10.1289/ehp.1002337

[15] Aadil KR, Barapatre A, Meena AS, Jha H. Hydrogen peroxide sensing and cytotoxicity activity of Acacia lignin stabilized silver nanoparticles. Int J Biol Macromol. 2016, 82, 39-47. doi10.1016/j.ijbiomac.2015.09.072

[16] Bastús NG, Merkoçi F, Piella J, Puntes V. Synthesis of Highly Monodisperse Citrate-Stabilized Silver Nanoparticles of up to 200 nm: Kinetic Control and Catalytic Properties. Chem Mater. 2014, 26(9), 2836-46. doi10.1021/cm500316k

[17] Deng X, Wang Y, Zhang F, Yin Z, Hu Q, Xiao X, et al. Acidic pH-induced charge-reversal nanoparticles for accelerated endosomal escape and enhanced microRNA modulation in cancer cells. Chem Commun (Camb). 2016, 52(15), 3243-6. doi10.1039/c5cc10396g

[18] Jang I, Song K, Park JH, Kim M, Kim DW, Oh SG. Effect of PVP molecular weight on the formation of Ag nanoparticles on echinoid-like TiO2. Mater Lett. 2013, 96, 214-7. doi10.1016/j.matlet.2013.01.045

[19] McShan D, Ray PC, Yu H. Molecular toxicity mechanism of nanosilver. J Food Drug Anal. 2014, 22(1), 116-27. doi10.1016/j.jfda.2014.01.010

[20] Michota A, Bukowska J. Surface-enhanced Raman scattering (SERS) of 4-mercaptobenzoic acid on silver and gold substrates. J Raman Spectrosc. 2003, 34(1), 21-5. doi10.1002/jrs.928

[21] Zheng J, Zhou Y, Li X, Ji Y, Lu T, Gu R. Surface-Enhanced Raman Scattering of 4-Aminothiophenol in Assemblies of Nanosized Particles and the Macroscopic Surface of Silver. Langmuir. 2003, 19(3), 6326. doi10.1021/la011706p

[22] Rajan K, Roppolo I, Chiappone A, Bocchini S, Perrone D, Chiolerio A. Silver nanoparticle ink technology: state of the art. Nanotechnology, science and applications. 2016, 9, 1-13. doi10.2147/NSA.S68080 
[23] Mironov AV, Vikhoreva GA, Kil'deeva NR, Uspenskii SA. Reasons for unstable viscous properties of chitosan solutions in acetic acid. Polymer Science Series B. 2007, 49(1-2), 15-7. doi10.1134/S1560090407010046

[24] Van Der Ploeg MJ, Handy RD, Heckmann LH, Van Der Hout A, Van Den Brink NW. C60 exposure induced tissue damage and gene expression alterations in the earthworm Lumbricus rubellus. Nanotoxicology. 2013, 7(4), 432-40. doi10.3109/17435390.2012.668569

[25] Izak-Nau E, Huk A, Reidy B, Uggerud H, Vadset M, Eiden S, et al. Impact of storage conditions and storage time on silver nanoparticles' physicochemical properties and implications for their biological effects. Rsc Advances. 2015, 5(102), 84172-85. doi10.1039/c5ra10187e

[26] Hagendorfer H, Kaegi R, Parlinska M, Sinnet B, Ludwig C, Ulrich A. Characterization of silver nanoparticle products using asymmetric flow field flow fractionation with a multidetector approach--a comparison to transmission electron microscopy and batch dynamic light scattering. Anal Chem. 2012, 84(6), 2678-85. doi10.1021/ac202641d

[27] Shannahan JH, Lai X, Ke PC, Podila R, Brown JM, Witzmann FA. Silver nanoparticle protein corona composition in cell culture media. PLoS One. 2013, 8(9), e74001. doi10.1371/journal.pone.0074001

[28] Pavlin M, Bregar V. Stability of nanoparticle suspension in different biologically relevant media. Digest Journal of Nanomaterials and Biostructures. 2012, 7(4), 1389-400.

[29] Lyon DY, Fortner JD, Sayes CM, Colvin VL, Hughe JB. Bacterial cell association and antimicrobial activity of a C60 water suspension. Environ Toxicol Chem. 2005, 24(11), 2757-62. doi10.1897/04-649R.1

[30] Kittler S, Greulich C, Diendorf J, Koller M, Epple M. Toxicity of Silver Nanoparticles Increases during Storage Because of Slow Dissolution under Release of Silver lons. Chem Mater. 2010, 22(16), 4548-54. doi10.1021/cm100023p

[31] Reidy B, Haase A, Luch A, Dawson K, Lynch I. Mechanisms of Silver Nanoparticle Release, Transformation and Toxicity: A Critical Review of Current Knowledge and Recommendations for Future Studies and Applications. Materials. 2013, 6(6), 2295-350. doi10.3390/ma6062295

[32] Sekine R, Brunetti G, Donner E, Khaksar M, Vasilev K, Jamting AK, et al. Speciation and lability of Ag-, $\mathrm{AgCl}$-, and Ag2S-nanoparticles in soil determined by $\mathrm{X}$-ray absorption spectroscopy and diffusive gradients in thin films. Environ Sci Technol. 2015, 49(2), 897-905. doi10.1021/es504229h

[33] Levard C, Reinsch BC, Michel FM, Oumahi C, Lowry GV, Brown GE. Sulfidation processes of PVP-coated silver nanoparticles in aqueous solution: impact on dissolution rate. Environ Sci Technol. 2011, 45(12), 5260-6. doi10.1021/es2007758

[34] Starnes DL, Unrine JM, Starnes CP, Collin BE, Oostveen EK, Ma R, et al. Impact of sulfidation on the bioavailability and toxicity of silver nanoparticles to Caenorhabditis elegans. Environ Pollut. 2015, 196, 239-46. doi10.1016/j.envpol.2014.10.009

[35] Strikwold M, Spenkelink B, Woutersen RA, Rietjens IM, Punt A. Combining in vitro embryotoxicity data with physiologically based kinetic (PBK) modelling to define in vivo dose-response curves for developmental toxicity of phenol in rat and human. Arch Toxicol. 2013, 87(9), 1709-23. doi10.1007/s00204-013-1107-4

[36] Simone UD, Roda E, Signorini C, Coccini T. An integrated in Vitro and in Vivo Testing Approach to Assess Pulmonary Toxicity of Engineered Cadmium-Doped Silica Nanoparticles. American Journal of Nanomaterials. 2015, 3(2), 40-56. doi10.12691/ajn-3-2-1

[37] Braakhuis HM, Kloet SK, Kezic S, Kuper F, Park MV, Bellmann S, et al. Progress and future of in vitro models to study translocation of nanoparticles. Arch Toxicol. 2015, 89(9), 1469-95. doi10.1007/s00204-015-1518-5

[38] Connolly M, Fernandez-Cruz ML, Quesada-Garcia A, Alte L, Segner H, Navas JM. Comparative Cytotoxicity Study of Silver Nanoparticles (AgNPs) in a Variety of Rainbow Trout Cell Lines (RTL-W1, RTH-149, RTG-2) and Primary Hepatocytes. Int J Environ Res Public Health. 2015, 12(5), 5386-405. doi10.3390/ijerph120505386

[39] Kummitha CM, Malamas AS, Lu ZR. Albumin pre-coating enhances intracellular siRNA delivery of multifunctional amphiphile/siRNA nanoparticles. International journal of nanomedicine. 2012, 7, 520514. doi10.2147/IJN.S34288

[40] van der Ploeg MJ, van den Berg JH, Bhattacharjee S, de Haan LH, Ershov DS, Fokkink RG, et al. In vitro nanoparticle toxicity to rat alveolar cells and coelomocytes from the earthworm Lumbricus rubellus. Nanotoxicology. 2014, 8(1), 28-37. doi10.3109/17435390.2012.744857

[41] Dietzel S, Hermann S, Kugel Y, Sellner S, Uhl B, Hirn S, et al. Multiphoton Microscopy of Nonfluorescent Nanoparticles In Vitro and In Vivo. Small. 2016, n/a-n/a. doi10.1002/smll.201503766 
[42] Deepa MK, Suryaprakash TNK, Pawan K. Green synthesized silver nanoparticles. J Chem Pharm Res. 2016, 8(1), 9.

[43] Li L, Sun J, Li X, Zhang Y, Wang Z, Wang C, et al. Controllable synthesis of monodispersed silver nanoparticles as standards for quantitative assessment of their cytotoxicity. Biomaterials. 2012, 33(6), 1714-21. doi10.1016/j.biomaterials.2011.11.030

[44] Park MV, Neigh AM, Vermeulen JP, de la Fonteyne L, Verharen HW, Briede JJ, et al. The effect of particle size on the cytotoxicity, inflammation, developmental toxicity and genotoxicity of silver nanoparticles. Biomaterials. 2011, 32(36), 9810-7. doi10.1016/j.biomaterials.2011.08.085

[45] Liu W, Wu Y, Wang C, Li HC, Wang T, Liao CY, et al. Impact of silver nanoparticles on human cells: effect of particle size. Nanotoxicology. 2010, 4(3), 319-30. doi10.3109/17435390.2010.483745

[46] AshaRani PV, Low Kah Mun G, Hande MP, Valiyaveettil S. Cytotoxicity and genotoxicity of silver nanoparticles in human cells. ACS nano. 2009, 3(2), 279-90. doi10.1021/nn800596w

[47] Lemasters JJ, Nieminen AL, Qian T, Trost LC, Elmore SP, Nishimura Y, et al. The mitochondrial permeability transition in cell death: a common mechanism in necrosis, apoptosis and autophagy. Biochim Biophys Acta. 1998, 1366(1-2), 177-96. doihttp://dx.doi.org/10.1016/S0005-2728(98)00112-1

[48] Aranda A, Sequedo L, Tolosa L, Quintas G, Burello E, Castell JV, et al. Dichloro-dihydro-fluorescein diacetate (DCFH-DA) assay: a quantitative method for oxidative stress assessment of nanoparticletreated cells. Toxicol In Vitro. 2013, 27(2), 954-63. doi10.1016/j.tiv.2013.01.016

[49] Jeong YS, Oh WK, Kim S, Jang J. Cellular uptake, cytotoxicity, and ROS generation with silica/conducting polymer core/shell nanospheres. Biomaterials. 2011, 32(29), 7217-25. doi10.1016/j.biomaterials.2011.06.020

[50] Asharani PV, Lianwu Y, Gong Z, Valiyaveettil S. Comparison of the toxicity of silver, gold and platinum nanoparticles in developing zebrafish embryos. Nanotoxicology. 2011, 5(1), 43-54. doi10.3109/17435390.2010.489207

[51] Foldbjerg R, Dang DA, Autrup H. Cytotoxicity and genotoxicity of silver nanoparticles in the human lung cancer cell line, A549. Arch Toxicol. 2011, 85(7), 743-50. doi10.1007/s00204-010-0545-5

[52] Akopova OV, Kolchynskayia LY, Nosar VY, Smyrnov AN, Malisheva MK, Man'kovskaia YN, et al. The effect of permeability transition pore opening on reactive oxygen species production in rat brain mitochondria. Ukrains'kyi biokhimichnyi zhurnal (1999). 2011, 83(6), 46-55.

[53] Suresh AK, Pelletier DA, Wang W, Morrell-Falvey JL, Gu B, Doktycz MJ. Cytotoxicity induced by engineered silver nanocrystallites is dependent on surface coatings and cell types. Langmuir. 2012, 28(5), 2727-35. doi10.1021/la2042058

[54] Carlson C, Hussain SM, Schrand AM, Braydich-Stolle LK, Hess KL, Jones RL, et al. Unique cellular interaction of silver nanoparticles: size-dependent generation of reactive oxygen species. J Phys Chem B. 2008, 112(43), 13608-19. doi10.1021/jp712087m

[55] Nafee N, Schneider M, Schaefer UF, Lehr CM. Relevance of the colloidal stability of chitosan/PLGA nanoparticles on their cytotoxicity profile. Int J Pharm. 2009, 381(2), 130-9. doi10.1016/j.ijpharm.2009.04.049

[56] Johnston HJ, Hutchison G, Christensen FM, Peters S, Hankin S, Stone V. A review of the in vivo and in vitro toxicity of silver and gold particulates: particle attributes and biological mechanisms responsible for the observed toxicity. Crit Rev Toxicol. 2010, 40(4), 328-46. doi10.3109/10408440903453074

[57] Coutris C, Hertel-Aas T, Lapied E, Joner EJ, Oughton DH. Bioavailability of cobalt and silver nanoparticles to the earthworm Eisenia fetida. Nanotoxicology. 2012, 6(2), $186-95$. doi10.3109/17435390.2011.569094

[58] Unrine JM, Colman BP, Bone AJ, Gondikas AP, Matson CW. Biotic and abiotic interactions in aquatic microcosms determine fate and toxicity of Ag nanoparticles. Part 1. Aggregation and dissolution. Environ Sci Technol. 2012, 46(13), 6915-24. doi10.1021/es204682q

[59] van der Ploeg MJ, Handy RD, Waalewijn-Kool PL, van den Berg JH, Herrera Rivera ZE, Bovenschen J, et al. Effects of silver nanoparticles (NM-300K) on Lumbricus rubellus earthworms and particle characterization in relevant test matrices including soil. Environ Toxicol Chem. 2014, 33(4), 743-52. doi10.1002/etc. 2487

[60] Shoults-Wilson WA, Reinsch BC, Tsyusko OV, Bertsch PM, Lowry GV, Unrine JM. Effect of silver nanoparticle surface coating on bioaccumulation and reproductive toxicity in earthworms (Eisenia fetida). Nanotoxicology. 2011, 5(3), 432-44. doi10.3109/17435390.2010.537382 
[61] Shoults-Wilson WA, Reinsch BC, Tsyusko OV, Bertsch PM, Lowry GV, Unrine JM. Role of Particle Size and Soil Type in Toxicity of Silver Nanoparticles to Earthworms. Soil Sci Soc Am J. 2011, 75(2), 365. doi10.2136/sssaj2010.0127nps

[62] Gray EP, Coleman JG, Bednar AJ, Kennedy AJ, Ranville JF, Higgins CP. Extraction and analysis of silver and gold nanoparticles from biological tissues using single particle inductively coupled plasma mass spectrometry. Environ Sci Technol. 2013, 47(24), 14315-23. doi10.1021/es403558c

[63] Salari Joo H, Kalbassi MR, Yu IJ, Lee JH, Johari SA. Bioaccumulation of silver nanoparticles in rainbow trout (Oncorhynchus mykiss): influence of concentration and salinity. Aquat Toxicol. 2013, 140-141, 398-406. doi10.1016/j.aquatox.2013.07.003

[64] Mount DR, Dawson TD, Burkhard LP. Implications of gut purging for tissue residues determined in bioaccumulation testing of sediment withLumbriculus variegatus. Environ Toxicol Chem. 1999, 18(6), 1244-9. doi10.1002/etc.5620180625

[65] Petersen EJ, Huang Q, Weber WJ. Ecological uptake and depuration of carbon nanotubes by Lumbriculus variegatus. Environ Health Perspect. 2008, 116(4), 496-500. doi10.1289/ehp.10883

[66] Gliga A, Skoglund S, Odnevall Wallinder I, Fadeel B, Karlsson H. Size-dependent cytotoxicity of silver nanoparticles in human lung cells: the role of cellular uptake, agglomeration and Ag release. Part Fibre Toxicol. 2014, 11(1), 11.

[67] Shin SW, Song IH, Um SH. Role of Physicochemical Properties in Nanoparticle Toxicity. Nanomaterials. 2015, 5(3), 1351-65. doi10.3390/nano5031351

[68] Lefebvre DE, Venema K, Gombau L, Valerio LG, Jr., Raju J, Bondy GS, et al. Utility of models of the gastrointestinal tract for assessment of the digestion and absorption of engineered nanomaterials released from food matrices. Nanotoxicology. 2015, 9(4), 523-42. doi10.3109/17435390.2014.948091

[69] Braakhuis HM, Cassee FR, Fokkens PH, de la Fonteyne LJ, Oomen AG, Krystek P, et al. Identification of the appropriate dose metric for pulmonary inflammation of silver nanoparticles in an inhalation toxicity study. Nanotoxicology. 2016, 10(1), 63-73. doi10.3109/17435390.2015.1012184

[70] De Jong WH, Hagens WI, Krystek P, Burger MC, Sips AJ, Geertsma RE. Particle size-dependent organ distribution of gold nanoparticles after intravenous administration. Biomaterials. 2008, 29(12), $1912-$ 9. doi10.1016/j.biomaterials.2007.12.037

[71] Jiang Y, Huo S, Mizuhara T, Das R, Lee YW, Hou S, et al. The Interplay of Size and Surface Functionality on the Cellular Uptake of Sub-10 nm Gold Nanoparticles. ACS nano. 2015, 9(10), 9986-93. doi10.1021/acsnano.5b03521

[72] Ivask A, Kurvet I, Kasemets K, Blinova I, Aruoja V, Suppi S, et al. Size-dependent toxicity of silver nanoparticles to bacteria, yeast, algae, crustaceans and mammalian cells in vitro. PLoS One. 2014, 9(7), e102108. doi10.1371/journal.pone.0102108

[73] Yang X, Gondikas AP, Marinakos SM, Auffan M, Liu J, Hsu-Kim H, et al. Mechanism of silver nanoparticle toxicity is dependent on dissolved silver and surface coating in Caenorhabditis elegans. Environ Sci Technol. 2012, 46(2), 1119-27. doi10.1021/es202417t

[74] Lee JH, Kim YS, Song KS, Ryu HR, Sung JH, Park JD, et al. Biopersistence of silver nanoparticles in tissues from Sprague-Dawley rats. Part Fibre Toxicol. 2013, 10(1), 36. doi10.1186/1743-8977-10-36

[75] Topuz E, van Gestel CA. Toxicokinetics and toxicodynamics of differently coated silver nanoparticles and silver nitrate in Enchytraeus crypticus upon aqueous exposure in an inert sand medium. Environ Toxicol Chem. 2015, 34(12), 2816-23. doi10.1002/etc.3123

[76] Shang L, Nienhaus K, Nienhaus GU. Engineered nanoparticles interacting with cells: size matters. Journal of nanobiotechnology. 2014, 12, 5. doi10.1186/1477-3155-12-5

[77] Canton I, Battaglia G. Endocytosis at the nanoscale. Chem Soc Rev. 2012, 41(7), $2718-39$. doi10.1039/c2cs15309b

[78] von der Kammer F, Ferguson PL, Holden PA, Masion A, Rogers KR, Klaine SJ, et al. Analysis of engineered nanomaterials in complex matrices (environment and biota): general considerations and conceptual case studies. Environ Toxicol Chem. 2012, 31(1), 32-49. doi10.1002/etc.723

[79] Handy RD, Cornelis G, Fernandes T, Tsyusko O, Decho A, Sabo-Attwood T, et al. Ecotoxicity test methods for engineered nanomaterials: practical experiences and recommendations from the bench. Environ Toxicol Chem. 2012, 31(1), 15-31. doi10.1002/etc.706

[80] Handy RD, van den Brink N, Chappell M, Muhling M, Behra R, Dusinska M, et al. Practical considerations for conducting ecotoxicity test methods with manufactured nanomaterials: what have we learnt so far? Ecotoxicology. 2012, 21(4), 933-72. doi10.1007/s10646-012-0862-y 
[81] Poda AR, Bednar AJ, Kennedy AJ, Harmon A, Hull M, Mitrano DM, et al. Characterization of silver nanoparticles using flow-field flow fractionation interfaced to inductively coupled plasma mass spectrometry. J Chromatogr A. 2011, 1218(27), 4219-25. doi10.1016/j.chroma.2010.12.076

[82] Deering CE, Tadjiki S, Assemi S, Miller JD, Yost GS, Veranth JM. A novel method to detect unlabeled inorganic nanoparticles and submicron particles in tissue by sedimentation field-flow fractionation. Part Fibre Toxicol. 2008, 5, 18. doi10.1186/1743-8977-5-18

[83] van der Zande M, Vandebriel RJ, Van Doren E, Kramer E, Herrera Rivera Z, Serrano-Rojero CS, et al. Distribution, elimination, and toxicity of silver nanoparticles and silver ions in rats after 28-day oral exposure. ACS nano. 2012, 6(8), 7427-42. doi10.1021/nn302649p

[84] Campbell P, Ma S, Schmalzried T, Amstutz HC. Tissue digestion for wear debris particle isolation. J Biomed Mater Res. 1994, 28(4), 523-6. doi10.1002/jbm.820280415

[85] Yu C, Penn LD, Hollembaek J, Li W, Cohen LH. Enzymatic tissue digestion as an alternative sample preparation approach for quantitative analysis using liquid chromatography-tandem mass spectrometry. Anal Chem. 2004, 76(6), 1761-7. doi10.1021/ac035077v

[86] Peters RJ, Rivera ZH, van Bemmel G, Marvin HJ, Weigel S, Bouwmeester H. Development and validation of single particle ICP-MS for sizing and quantitative determination of nano-silver in chicken meat. Anal Bioanal Chem. 2014, 406(16), 3875-85. doi10.1007/s00216-013-7571-0

[87] Makama S, Peters R, Undas A, van den Brink NW. A novel method for the quantification, characterisation and speciation of silver nanoparticles in earthworms exposed in soil. Environmental Chemistry. 2015, 12(6), 643. doi10.1071/en15006

[88] Song YJ, Wang M, Zhang XY, Wu JY, Zhang T. Investigation on the role of the molecular weight of polyvinyl pyrrolidone in the shape control of high-yield silver nanospheres and nanowires. Nanoscale research letters. 2014, 9(1), 17. doi10.1186/1556-276X-9-17

[89] Chou KS, Lai YS. Effect of polyvinyl pyrrolidone molecular weights on the formation of nanosized silver colloids. Mater Chem Phys. 2004, 83(1), 82-8. doi10.1016/j.matchemphys.2003.09.026

[90] Vijver MG, van Gestel CAM, van Straalen NM, Lanno RP, Peijnenburg WJGM. Biological Significance of Metals Partitioned to Subcellular Fractions within Earthworms (Aporrectodea Caliginosa). Environ Toxicol Chem. 2006, 25(3), 807. doi10.1897/05-128r.1

[91] Vijver MG, Van Gestel CA, Lanno RP, Van Straalen NM, Peijnenburg WJ. Internal metal sequestration and its ecotoxicological relevance: a review. Environ Sci Technol. 2004, 38(18), 4705-12. doi10.1021/es040354g

[92] Foldbjerg R, Irving ES, Hayashi Y, Sutherland DS, Thorsen K, Autrup H, et al. Global gene expression profiling of human lung epithelial cells after exposure to nanosilver. Toxicol Sci. 2012, 130(1), 145-57. doi10.1093/toxsci/kfs225

[93] Shalini K, Jeyanthi G. Free Radical Scavenging Activity of Metallothioneins from Peripheral Blood Lymphocytes of Gold Jewellery Karigars. International Research Journal of Medical Sciences. 2014, 2(1), 15-20.

[94] Giguere A, Campbell PG, Hare L, Couture P. Sub-cellular partitioning of cadmium, copper, nickel and zinc in indigenous yellow perch (Perca flavescens) sampled along a polymetallic gradient. Aquat Toxicol. 2006, 77(2), 178-89. doi10.1016/j.aquatox.2005.12.001

[95] Tourinho PS, van Gestel CAM, Morgan AJ, Kille P, Svendsen C, Jurkschat K, et al. Toxicokinetics of Ag in the terrestrial isopod Porcellionides pruinosus exposed to Ag NPs and AgNO3 via soil and food. Ecotoxicology. 2016, 25(2), 267-78. doi10.1007/s10646-015-1585-7

[96] Wallace WG, Lee BG, Luoma SN. Subcellular compartmentalization of Cd and Zn in two bivalves. I. Significance of metal-sensitive fractions (MSF) and biologically detoxified metal (BDM). 2003, 249, 183-97.

[97] Schlich K, Klawonn T, Terytze K, Hund-Rinke K. Effects of silver nanoparticles and silver nitrate in the earthworm reproduction test. Environ Toxicol Chem. 2013, 32(1), 181-8. doi10.1002/etc.2030

[98] Heckmann LH, Hovgaard MB, Sutherland DS, Autrup H, Besenbacher F, Scott-Fordsmand JJ. Limit-test toxicity screening of selected inorganic nanoparticles to the earthworm Eisenia fetida. Ecotoxicology. 2011, 20(1), 226-33. doi10.1007/s10646-010-0574-0

[99] Ruttkay-Nedecky B, Nejdl L, Gumulec J, Zitka O, Masarik M, Eckschlager T, et al. The role of metallothionein in oxidative stress. International journal of molecular sciences. 2013, 14(3), 6044-66. doi10.3390/ijms14036044

[100] Coyle P, Philcox JC, Carey LC, Rofe AM. Metallothionein: the multipurpose protein. Cell Mol Life Sci. 2002, 59(4), 627-47. 
[101] Walsh JG, Cullen SP, Sheridan C, Luethi AU, Gerner C, Martin SJ. Executioner caspase-3 and caspase-7 are functionally distinct proteases. Proceedings of the National Academy of Sciences of the United States of America. 2008, 105(35), 12815-9. doi10.1073/pnas.0707715105

[102] Qu T, Huang B, Zhang L, Li L, Xu F, Huang W, et al. Identification and Functional Characterization of Two Executioner Caspases in Crassostrea gigas. PLoS One. 2014, 9(2), e89040. doi10.1371/journal.pone.0089040

[103] Klok C, de Roos AM. Population Level Consequences of Toxicological Influences on Individual Growth and Reproduction inLumbricus rubellus(Lumbricidae, Oligochaeta). Ecotoxicol Environ Saf. 1996, 33(2), 118-27. doihttp://dx.doi.org/10.1006/eesa.1996.0015

[104] Bezakova G, Ruegg MA. New insights into the roles of agrin. Nat Rev Mol Cell Biol. 2003, 4(4), $295-308$. doi10.1038/nrm1074

[105] Hussain SM, Javorina AK, Schrand AM, Duhart HM, Ali SF, Schlager JJ. The interaction of manganese nanoparticles with PC-12 cells induces dopamine depletion. Toxicol Sci. 2006, 92(2), 456-63. doi10.1093/toxsci/kfl020

[106] Husain N, Pellikka M, Hong H, Klimentova T, Choe KM, Clandinin TR, et al. The agrin/perlecan-related protein eyes shut is essential for epithelial lumen formation in the Drosophila retina. Developmental Cell. 2006, 11(4), 483-93. doi10.1016/j.devcel.2006.08.012

[107] Hrus A, Lau G, Hutter H, Schenk S, Ferralli J, Brown-Luedi M, et al. C. elegans Agrin Is Expressed in Pharynx, IL1 Neurons and Distal Tip Cells and Does Not Genetically Interact with Genes Involved in Synaptogenesis or Muscle Function. Plos One. 2007, 2(8). doi10.1371/journal.pone.0000731

[108] Sarrazin S, Lamanna WC, Esko JD. Heparan sulfate proteoglycans. Cold Spring Harb Perspect Biol. 2011, 3(7), a004952. doi10.1101/cshperspect.a004952

[109] Sollner C, Mentele R, Eckerskorn C, Fritz H, Sommerhoff CP. Isolation and characterization of hirustasin, an antistasin-type serine-proteinase inhibitor from the medical leech Hirudo medicinalis. Eur J Biochem. 1994, 219(3), 937-43.

[110] Zhao P, Dong ZM, Duan J, Wang GH, Wang LY, Li YS, et al. Genome-Wide Identification and Immune Response Analysis of Serine Protease Inhibitor Genes in the Silkworm, Bombyx mori. Plos One. 2012, 7(2). doi10.1371/journal.pone.0031168

[111] Christianson HC, Belting M. Heparan sulfate proteoglycan as a cell-surface endocytosis receptor. Matrix Biol. 2014, 35, 51-5. doi10.1016/j.matbio.2013.10.004

[112] Benn T, Cavanagh B, Hristovski K, Posner JD, Westerhoff P. The Release of Nanosilver from Consumer Products Used in the Home. Journal of Environment Quality. 2010, 39(6), 1875. doi10.2134/jeq2009.0363

[113] Geranio L, Heuberger M, Nowack B. The behavior of silver nanotextiles during washing. Environ Sci Technol. 2009, 43(21), 8113-8. doi10.1021/es9018332

[114] Benn TM, Westerhoff P. Nanoparticle silver released into water from commercially available sock fabrics. Environ Sci Technol. 2008, 42(11), 4133-9.

[115] Cuddy MF, Poda AR, Moser RD, Weiss CA, Cairns C, Steevens JA. A weight-of-evidence approach to identify nanomaterials in consumer products: a case study of nanoparticles in commercial sunscreens. J Expo Sci Environ Epidemiol. 2016, 26(1), 26-34. doi10.1038/jes.2015.51

[116] Cavalle JS, Puntes V. Nanoparticles before nanotechnology. nanowikiinfo. 2013, 3.

[117] Whiteley CM, Dalla Valle M, Jones KC, Sweetman AJ. Challenges in assessing release, exposure and fate of silver nanoparticles within the UK environment. Environ Sci Process Impacts. 2013, 15(11), 2050-8. doi10.1039/c3em00226h

[118] Taleb A, Petit C, Pileni MP. Synthesis of Highly Monodisperse Silver Nanoparticles from AOT Reverse Micelles: A Way to 2D and 3D Self-Organization. Chem Mater. 1997, 9(4), 950-9. doi10.1021/cm960513y

[119] Hu Y, Ge J, Lim D, Zhang T, Yin Y. Size-controlled synthesis of highly water-soluble silver nanocrystals. J Solid State Chem. 2008, 181(7), 1524-9. doi10.1016/j.jssc.2008.02.028

[120] Peters RJ, van Bemmel G, Herrera-Rivera Z, Helsper HP, Marvin HJ, Weigel S, et al. Characterization of titanium dioxide nanoparticles in food products: analytical methods to define nanoparticles. J Agric Food Chem. 2014, 62(27), 6285-93. doi10.1021/jf5011885

[121] Peters R, Herrera-Rivera Z, Undas A, van der Lee M, Marvin H, Bouwmeester H, et al. Single particle ICP-MS combined with a data evaluation tool as a routine technique for the analysis of nanoparticles in complex matrices. J Anal At Spectrom. 2015, 30(6), 1274-85. doi10.1039/c4ja00357h 
[122] Montaño MD, Badiei HR, Bazargan S, Ranville JF. Improvements in the detection and characterization of engineered nanoparticles using spICP-MS with microsecond dwell times. Environmental Science: Nano. 2014, 1(4), 338. doi10.1039/c4en00058g

[123] Tuoriniemi J, Cornelis G, Hassellov M. A new peak recognition algorithm for detection of ultra-small nano-particles by single particle ICP-MS using rapid time resolved data acquisition on a sector-field mass spectrometer. Journal of Analytical Atomic Spectrometry. 2015, 30(8), 1723-9. doi10.1039/C5JA00113G

[124] Yu SJ, Yin YG, Liu JF. Silver nanoparticles in the environment. Environ Sci Process Impacts. 2013, 15(1), 78-92. doi10.1039/C2EM30595J

[125] Diez-Ortiz M, Lahive E, Kille P, Powell K, Morgan AJ, Jurkschat K, et al. Uptake routes and toxicokinetics of silver nanoparticles and silver ions in the earthworm Lumbricus rubellus. Environ Toxicol Chem. 2015, 34(10), 2263-70. doi10.1002/etc.3036

[126] van der Ploeg MJC, Baveco JM, van der Hout A, Bakker R, Rietjens IMCM, van den Brink NW. Effects of C60 nanoparticle exposure on earthworms (Lumbricus rubellus) and implications for population dynamics. Environ Pollut. 2011, 159(1), 198-203. doihttp://dx.doi.org/10.1016/j.envpol.2010.09.003

[127] Braydich-Stolle LK, Lucas B, Schrand A, Murdock RC, Lee T, Schlager JJ, et al. Silver nanoparticles disrupt GDNF/Fyn kinase signaling in spermatogonial stem cells. Toxicol Sci. 2010, 116(2), 577-89. doi10.1093/toxsci/kfq148

[128] Lee KJ, Nallathamby PD, Browning LM, Osgood CJ, Xu XH. In vivo imaging of transport and biocompatibility of single silver nanoparticles in early development of zebrafish embryos. ACS nano. 2007, 1(2), 133-43. doi10.1021/nn700048y

[129] Bar-llan O, Albrecht RM, Fako VE, Furgeson DY. Toxicity assessments of multisized gold and silver nanoparticles in zebrafish embryos. Small. 2009, 5(16), 1897-910. doi10.1002/smll.200801716

[130] Kong L, Tang M, Zhang T, Wang D, Hu K, Lu W, et al. Nickel nanoparticles exposure and reproductive toxicity in healthy adult rats. International journal of molecular sciences. 2014, 15(11), 21253-69. doi10.3390/ijms151121253

[131] Shi H, Magaye R, Castranova V, Zhao J. Titanium dioxide nanoparticles: a review of current toxicological data. Part Fibre Toxicol. 2013, 10(1), 1-33. doi10.1186/1743-8977-10-15

[132] Moretti E, Terzuoli G, Renieri T, lacoponi F, Castellini C, Giordano C, et al. In vitro effect of gold and silver nanoparticles on human spermatozoa. Andrologia. 2013, 45(6), 392-6. doi10.1111/and.12028

[133] Choi O, Hu Z. Size dependent and reactive oxygen species related nanosilver toxicity to nitrifying bacteria. Environ Sci Technol. 2008, 42(12), 4583-8. doi10.1021/es703238h

[134] Yen HJ, Hsu SH, Tsai CL. Cytotoxicity and immunological response of gold and silver nanoparticles of different sizes. Small. 2009, 5(13), 1553-61. doi10.1002/smll.200900126

[135] Trickler WJ, Lantz SM, Murdock RC, Schrand AM, Robinson BL, Newport GD, et al. Silver nanoparticle induced blood-brain barrier inflammation and increased permeability in primary rat brain microvessel endothelial cells. Toxico/ Sci. 2010, 118(1), 160-70. doi10.1093/toxsci/kfq244

[136] Yang X, Jiang C, Hsu-Kim H, Badireddy AR, Dykstra M, Wiesner M, et al. Silver nanoparticle behavior, uptake, and toxicity in Caenorhabditis elegans: effects of natural organic matter. Environ Sci Technol. 2014, 48(6), 3486-95. doi10.1021/es404444n

[137] Chappell MA, Miller LF, George AJ, Pettway BA, Price CL, Porter BE, et al. Simultaneous dispersiondissolution behavior of concentrated silver nanoparticle suspensions in the presence of model organic solutes. Chemosphere. 2011, 84(8), 1108-16. doi10.1016/j.chemosphere.2011.04.040

[138] Abdelhalim MAK, M. Mady M, M. Ghannam M. Physical Properties of Different Gold Nanoparticles: Ultraviolet-Visible and Fluorescence Measurements. Journal of Nanomedicine \& Nanotechnology. 2012, 03(03). doi10.4172/2157-7439.1000133

[139] Avalos A, Haza Al, Mateo D, Morales P. Effects of silver and gold nanoparticles of different sizes in human pulmonary fibroblasts. Toxicol Mech Methods. 2015, 25(4), $287-95$. doi10.3109/15376516.2015.1025347

[140] Ayala V, Herrera AP, Latorre-Esteves M, Torres-Lugo M, Rinaldi C. Effect of surface charge on the colloidal stability and in vitro uptake of carboxymethyl dextran-coated iron oxide nanoparticles. Journal of nanoparticle research : an interdisciplinary forum for nanoscale science and technology. 2013, 15(8), 1874. doi10.1007/s11051-013-1874-0

[141] Bondarenko O, Juganson K, Ivask A, Kasemets K, Mortimer M, Kahru A. Toxicity of Ag, CuO and ZnO nanoparticles to selected environmentally relevant test organisms and mammalian cells in vitro: a critical review. Arch Toxicol. 2013, 87(7), 1181-200. doi10.1007/s00204-013-1079-4 
[142] Buesen R, Landsiedel R, Sauer U, Wohlleben W, Groeters S, Strauss V, et al. Effects of SiO2, ZrO2, and BaSO4 nanomaterials with or without surface functionalization upon 28-day oral exposure to rats. Arch Toxicol. 2014, 88(10), 1881-906. doi10.1007/s00204-014-1337-0

[143] Chanana M, Liz-Marzán Luis M. in Nanophotonics 2012, pp. 199.

[144] Clemente Z, Castro VL, Jonsson CM, Fraceto LF. Ecotoxicology of nano-TiO 2-an evaluation of its toxicity to organisms of aquatic ecosystems. International Journal of Environmental Research. 2012, 6(1), 33-50.

[145] Dan M, Wu P, Grulke EA, Graham UM, Unrine JM, Yokel RA. Ceria-engineered nanomaterial distribution in, and clearance from, blood: Size matters. Nanomedicine. 2012, 7(1), 95-110. doi10.2217/nnm.11.103

[146] Lapresta-Fernández A, Salinas-Castillo A, Anderson de la Llana S, Costa-Fernández JM, DomínguezMeister S, Cecchini R, et al. A General Perspective of the Characterization and Quantification of Nanoparticles: Imaging, Spectroscopic, and Separation Techniques. Critical Reviews in Solid State and Materials Sciences. 2014, 39(6), 423-58. doi10.1080/10408436.2014.899890

[147] Mitrano DM, Barber A, Bednar A, Westerhoff P, Higgins CP, Ranville JF. Silver nanoparticle characterization using single particle ICP-MS (SP-ICP-MS) and asymmetrical flow field flow fractionation ICP-MS (AF4-ICP-MS). Journal of Analytical Atomic Spectrometry. 2012, 27(7), 1131. doi10.1039/c2ja30021d

[148] Braun GB, Friman T, Pang HB, Pallaoro A, Hurtado de Mendoza T, Willmore AM, et al. Etchable plasmonic nanoparticle probes to image and quantify cellular internalization. Nat Mater. 2014, 13(9), 904-11. doi10.1038/nmat3982

[149] Yoisungnern T, Choi Y-J, Woong Han J, Kang M-H, Das J, Gurunathan S, et al. Internalization of silver nanoparticles into mouse spermatozoa results in poor fertilization and compromised embryo development. Sci Rep. 2015, 5, 11170. doi10.1038/srep11170

http://www.nature.com/articles/srep11170\#supplementary-information

[150] Singh G, Prakash S. Virulency of novel nanolarvicide from Trichoderma atroviride against Aedes aegypti (Linn.): a CLSM analysis. Environ Sci Pollut Res Int. 2015, 22(16), 12559-65. doi10.1007/s11356-015-4531-6

[151] Tourinho PS, van Gestel CAM, Lofts S, Svendsen C, Soares AMVM, Loureiro S. Metal-based nanoparticles in soil: Fate, behavior, and effects on soil invertebrates. Environ Toxicol Chem. 2012, 31(8), 1679-92. doi10.1002/etc.1880

[152] EPA. EPA document 2012 Nanomaterial Case Study: Nanoscale Silver in Disinfectant Spray. EPA/600/R-10/081F 423. 2012.

[153] Gottschalk F, Sun T, Nowack B. Environmental concentrations of engineered nanomaterials: review of modeling and analytical studies. Environ Pollut. 2013, 181, 287-300. doi10.1016/j.envpol.2013.06.003

[154] Novo M, Lahive E, Diez-Ortiz M, Matzke M, Morgan AJ, Spurgeon DJ, et al. Different routes, same pathways: Molecular mechanisms under silver ion and nanoparticle exposures in the soil sentinel Eisenia fetida. Environ Pollut. 2015, 205, 385-93. doi10.1016/j.envpol.2015.07.010 




\section{Chapter 7}

Summary 


\section{Summary}

Owing to their small sizes, nanoparticles (NPs) exhibit completely different and novel characteristics compared to their bulk counterparts of the same chemical composition. These novel properties include increased reactivity due to large specific surface area, fluorescence and colour changes, increased biological barrier crossings and increased material strengthening combined with light-weight. Virtually all fields of human endeavours are exploiting nanotechnology to combat different challenges. This has led to an increase in the production and potential release of NPs into the environment. The novel properties of these NPs however, mean an enhanced potential for interactions with biological systems that are different from the interactions of known conventional chemicals, thus raising environmental and public health/safety concerns. Available literature has reported NP uptake in different organisms along with associated hazards. Therefore, to safeguard human and environmental health and safety, regulatory measures are necessary. Such measures must be based on sound scientific evidence and be risk-based rather than hazard-based. As such, the need to understand the fate of NPs after environmental release and their potential to pose hazards and risks to the environment is critical for a proper risk assessment and further development of policy strategies on the future regulation of the use of NPs.

Some studies have demonstrated different and sometimes conflicting effects of NP properties on their uptake in different organisms. Given that exposure determines whether hazards will turn into risks, there is a critical need for further systematic evaluation of the physico-chemical properties of engineered or manufactured NPs that influence uptake in terrestrial organisms, and also of how soil properties may affect these processes. The objective of this project was to determine the influence of size and surface coating (charge), two important physico-chemical properties of NPs, on their bioavailability, uptake and toxicity. The red earthworm Lumbricus rubellus, common in most parts of Europe, was used as a model soil organism. Silver nanoparticles (AgNPs) have been identified as one of the most commonly used NPs in many products, and their production is expected to continue to increase. Therefore, we selected AgNPs as our model NPs. For our investigations, we applied an integrated in vitro - in vivo approach, utilising high throughput in vitro methods as well as well-established in vivo toxicity endpoints in the earthworm. A systematic experimental approach was developed for which AgNPs were synthesized in three sizes: 20, 35 and $50 \mathrm{~nm}$. Surface-coating with bovine serum albumin (AgNP_BSA), chitosan (AgNP_Chit), or polyvinylpyrrolidone (AgNP_PVP) resulted in negative, positive and neutral particles respectively.

Firstly, in vitro experiments were conducted in which macrophage cells (RAW 264.7) were exposed to AgNPs at $0-200 \mu \mathrm{g} / \mathrm{mL}$ (nominal concentrations) and uptake 
dynamics, cell viability, as well as induction of tumour necrosis factor (TNF)- $\alpha$ and reactive oxygen species (ROS) were assessed (Chapter 2 ). Generally, the adverse effects of exposure to the tested AgNPs resulted in reduced overall viability of the cells, which was similar for all AgNPs tested. On adenosine triphosphate (ATP) production and specific mechanisms of toxicity (TNF- $\alpha$ and ROS production) however, we observed that the AgNPs differed significantly, with the negatively charged AgNP_BSA being the most toxic. Significant ROS induction was only observed after exposure to the $20 \mathrm{~nm}$ positively charged AgNP_Chit. Effect of size was less prominent than that of surface coating, showing mostly limited differences that were not statistically significant under our experimental conditions.

Live confocal imaging of exposed cells allowed the monitoring of the uptake dynamics and subcellular cytoplasmic accumulation of AgNPs. We observed fast uptake of AgNPs within 2.5 hours which is essential in case of exposure durations of 6 and 24 hours, as applied in our experiments. However, similar uptake did not always result in similar effects. A combination of several factors likely played a role in determining the outcome of exposure to the AgNPs, supporting similar observations made by other investigators. These may include the processes involved in synthesis of the NPs, the presence and type of coating agents resulting in various physico-chemical properties (size, charge, hydrophobicity, etc.). Understanding the dynamics of the interactions among the NPs, exposure media and the model used, each governed by unique properties, requires further evaluation to enhance the current hazard and risk assessment of AgNPs. For instance, in addition to the two important properties of AgNPs tested in the current study, some exposure media-related properties like protein content and $\mathrm{pH}$ should be investigated. Subsequently, exposure to the same NPs can be similarly tested in the same model as was used in Chapter 2.

With the insights obtained from the in vitro assessments, we investigated the effects of size and surface coating (charge) of AgNPs on the bioaccumulation in, and toxicity (survival, growth, cocoon production) to the earthworm L. rubellus. Currently, metal engineered NPs in tissues are generally quantified based on total metal concentrations after acid destruction of samples. Since these methods are destructive, dissolving the metallic NPs, they are limited in providing information on the speciation and the forms of NPs which is essential for characterising the fate of NPs. Also, optical methods like electron microscopy have been used for characterisation of NPs in situ, although quantification of the exposure is hampered using these methods. In the present thesis, we developed a method using a combination of enzymatic tissue processing and single particle inductively coupled plasma-mass spectrometry (sp-ICP-MS) to characterise and quantify AgNPs in tissues of earthworms (Chapter 3). Subcellular fractionation of tissues was applied to investigate potential association of AgNPs with the cellular 
metallothionein (MT) containing fraction of the earthworm tissues. This study provided, to the best of our knowledge, the first estimates of tissue Ag concentrations in both particulate and ionic forms in earthworms exposed in vivo to AgNPs via soil. The results obtained showed fairly low uptake of AgNPs, with earthworms exposed to a commercially obtained PVP-coated AgNPs showing approximately 34\% of their total Ag tissue burden being in particulate form. This indicates that although AgNPs accumulated in tissues of earthworms in their primary form, the dissolution of $\mathrm{Ag}$ in the soil, organism, or both played an important role in determining the ultimate fate of the AgNPs. Although the biological uptake of AgNPs was generally low, the method described in Chapter 3 was still capable of extracting NPs in quantities sufficient for identification, quantification and characterisation. It should be noted however, that the lower size detection threshold for the ICP-MS instrument used for these analyses is approximately $30 \mathrm{~nm}$. Consequently, information on NPs smaller than $30 \mathrm{~nm}$ was not available. With the increasing optimisation of analytical systems that combine sp-ICPMS, or other detection methods with, for example, asymmetric flow field-flow fractionation (AF4) which pre-sort different particle sizes, the potential for application of methods described in this thesis will be even greater.

Having developed a method for extracting Ag from tissues, we exposed earthworms to all nine synthesized AgNPs in a 28-day sub-chronic reproduction toxicity test in soil in Chapter 4. These AgNPs were the same as were used in the in vitro studies. Earthworms were also exposed to $\mathrm{AgNO}_{3}$ at two concentrations below known $\mathrm{EC}_{50} \mathrm{~S}$ to control for ionic effects of Ag. Uptake was observed to be generally highest for the negatively charged AgNP_BSA especially at the lower exposure concentration ranges. Total Ag concentrations in earthworm tissues reached a plateau level of about $80 \mathrm{mg} \mathrm{Ag} / \mathrm{kg}$ dry weight (DW) for exposure concentrations between $15-100 \mathrm{mg} \mathrm{Ag} / \mathrm{kg}$ soil DW. Reproduction was impaired at high nominal soil concentrations of all AgNPs tested, with AgNP_BSA particles being the most toxic. Size had an influence on uptake of the AgNP_PVP, showing both uptake and effect on reproduction of the $20 \mathrm{~nm}$ sized group to be significantly more than those of the 35 and $50 \mathrm{~nm}$ AgNP_PVP. This size effect however, did not hold for AgNP_BSA nor AgNP_Chit. Both AgNP_BSA and AgNP_PVP had negative zeta potentials in the exposure medium (soil extract), making them less likely to interact with the negatively charged clay particles in the soil or with the generally negatively charged organic matter. Hence, AgNPs coated with BSA or similar negatively charged biological molecules may be more available in soil for uptake. Higher uptake from the soil may consequently lead to a higher potential for toxicity in organisms. Interestingly, internal total Ag tissue concentrations measured after 72 hour exposure were better at predicting the effect on reproduction than tissue concentrations after 28 days exposure. It is likely therefore, that reproduction was affected already in the 72 hour exposure window. 
In order to further elucidate the likely mechanisms by which these AgNPs were exerting their effects, we conducted a toxicogenomic study. Although AgNPs have been increasingly investigated in the last few decades, information regarding their effects on gene expression profiles of especially soil organisms is limited. RNA-sequencing (RNAseq) has emerged as a powerful technology that has made it possible to investigate the genes that are being actively expressed by organisms at any given time. Using RNAseq, we investigated the gene expression profiles of the earthworm L. rubellus following exposure to all nine AgNPs in Chapter 5. Samples to be analysed were selected based on reproduction toxicity, which was the most sensitive in vivo toxicity end-point from the 28-day study described in Chapter 4. As was the case with the 28-day exposure (Chapter 4), AgNP_BSA accumulated more in the tissues of earthworms after 72 hours, and alterations in their gene expression profiles reflected this. The highest number of significant differentially expressed genes (DEGs) was encountered in earthworms exposed to the negatively charged AgNP_BSA. Thus, gene expression profiles of earthworms appeared to indicate a role of surface coating (charge) of AgNPs in exerting their toxicity. Interestingly, an effect of size was also shown as the $35 \mathrm{~nm}$ sized AgNPs generally induced more significant DEGs than the 20 or $50 \mathrm{~nm}$ sizes for all tested AgNPs. This may suggest the likelihood of an optimal NP size, essential to induce effects. For the $35 \mathrm{~nm}$ sized group, tissue Ag concentrations appeared to partly explain our observations, since the highest number of significant DEGs were expressed in earthworms that also accumulated $\mathrm{Ag}$ the most. In contrast, ionic $\mathrm{Ag}^{+}\left(\mathrm{AgNO}_{3}\right)$ induced minimal gene expression at both low and high exposure concentrations. The ionic $\mathrm{Ag}^{+}$exposure concentrations used were the same as the ones used in Chapter 4.

When all significant DEGs induced by the nine different AgNPs and their ionic $\mathrm{Ag}^{+}$ controls were compared, only one gene was commonly significantly regulated among all treatments, indicating that there was hardly any functional overlap between responses to the AgNPs with different coatings. This gene was metallothionein, a cysteine-rich peptide known to strongly bind free metal ions for chelation and detoxification, and it was strongly up-regulated in all treatments. The induction of the MT-genes does imply a role of MT as defense mechanisms towards exposure to Ag. However, in Chapter 2, Ag concentrations were not associated with the MT-fraction of earthworm tissues, indicating that although MT-genes were up-regulated, this seemed not to be an important mode of storage and detoxification of the AgNPs. When we selected all DEGs of all NP-treated earthworms as a group and compared them to the group comprising all DEGs from the ionic $\mathrm{Ag}^{+}$treated earthworms, $37 \mathrm{DEGs}$ overlapped. Of these shared genes, 31 were regulated in the same direction by both particulate and ionic $\mathrm{Ag}^{+}$treated earthworms. This would indicate the role of $\mathrm{Ag}^{+}$ions in inducing gene expression effects following AgNP exposure. It should be noted however, that there were also a large number of significant DEGs (969) that were expressed in earthworms exposed to AgNPs 
but not in earthworms exposed to $\mathrm{Ag}^{+}$ions. Therefore, the role of particulate silver was also indicated.

Gene ontology enrichment analysis defined the classes of the expressed genes in order to describe their functions. In our study, we focused on biological processes and molecular functions as these two were the most informative categories. This analysis revealed significantly enriched gene ontology terms relating to several biological processes, including response to $\mathrm{pH} /$ regulation of intracellular $\mathrm{pH}$, proton transport, cell differentiation, microtubule organisation, and MT induction. Indeed, proton transport and response to $\mathrm{pH}$ are clearly supported by the strong up-regulation of some sodium hydrogen exchangers and vacuolar-type ATPases. In vitro exposure of macrophages to AgNPs in Chapter 2 had also led to depletion in ATP levels compared to the control. The fact that reproduction was most affected in vivo (Chapter 4) may partly be associated with energy depletion, in line with in vitro decrease in intracellular ATP levels, as well as the activation of genes relating to proton transport and other biological responses. It is likely that the earthworms' energy balance might have shifted away from reproduction to other (repair) processes, which would explain the significantly reduced number of cocoons laid as observed in the 28-day exposures to AgNPs (Chapter 4). With respect to molecular functions, gene ontology analysis showed that hydrogen ion transmembrane activity was significantly affected, supporting the observation relating to the affected biological processes which revealed earthworms responded to changes in their physiologic $\mathrm{pH}$.

Comparing the three different types of AgNPs revealed only a major overlap of DEGs among the AgNP_BSA and AgNP_Chit (Chapter 5). The annotated genes agrin and antistasin were identified to be strongly activated in response to both NP-types. These proteins are expressed and active in the extracellular matrix and can bind macromolecules. Agrin is essential in postsynaptic specialization at the neuromuscular junction in vertebrates and invertebrates, and also plays a role in T-cell activation. Antistasin is a potent inhibitor of blood coagulation factor $\mathrm{Xa}$ found in leeches, and is implicated in resistance to pathogenic microorganisms and immune defense. The exact roles of these genes in the toxicity of NPs in earthworms is yet unknown, but based on their identified functions in other species, they may be important in neurotoxicity and immunotoxicity. This is in line with our findings in vitro where TNF- $\alpha$ was significantly induced in macrophage cells exposed to AgNP_BSA. Reports on the characterisation of proteoglycans in earthworms are generally lacking, and to the best of our knowledge, this is the first report of the activation of these genes in earthworms following exposure to AgNPs. 
The current study showed that within the range of 20 to $50 \mathrm{~nm}$, effects of the size of AgNPs on toxicokinetics and toxicodynamics of the NPs are limited. However, effects of surface coating were consistent over the different levels of biological integration. Generally, the negatively charged AgNP_BSA accumulated to a higher extent in the earthworms, especially at lower concentrations. The in vitro uptake was fast for all NPs, but also showed the highest uptake of AgNP_BSA. The negatively charged AgNPs were also the most toxic, likely related to their increased uptake. This was evident at all levels: gene expression, cellular, and individual (population dynamic parameters) levels. At the in vitro level, this applied mostly to effects on specific modes of action (TNF- $\alpha$ induction, ROS production). For more general cytotoxic effects, the effects of surface coatings were less evident. Except in cells exposed to AgNP_Chit $20 \mathrm{~nm}$, where there was a slight increase in ROS production, this set of AgNPs under the experimental conditions applied, did not appear to induce the production of ROS. This was supported by the lack of expression of any ROS-related gene in the gene expression profile analyses.

Based on the results from Chapters 2, 3, 4 and 5, it can be concluded that the physicochemical properties of NPs do influence their environmental fate and toxicity. It should be noted however that general predictions on the outcome of exposure to NPs are difficult to make, and NPs should be evaluated on a case by case basis. Our research supports the use of in vitro models to limit and prioritize further in vivo studies. Studies investigating the fate and effects of NPs for soil organisms are vital for a holistic approach towards a comprehensive and adequate environmental risk assessment (ERA). The studies described in this thesis contribute to this knowledge, thereby improving our understanding of the hazards and risks due to exposure to AgNPs, thus enabling their adequate and comprehensive ERA. 



\section{Appendices}

Acknowledgements

About the Author

List of publications, Conferences and proceedings

Overview of completed training activities

SENSE Certificate 



\section{ACKNOWLEDGEMENTS}

The PhD journey was one I looked forward to with great excitement and aspirations and I must say it was quite a trip! I count it a blessed privilege to have had this experience and this was so because of the wonderful individuals who have contributed in several ways to the success of this phase of my life and now I joyfully acknowledge.

My sincere gratitude goes first to my promoter Ivonne and co-promoter Nico under whose guidance I have enjoyed the opportunity of conducting such an interesting research. From our first encounter back in 2008, Ivonne had stood out to me as an embodiment of efficiency, always seeking how to bring out the best in herself and others. I am honoured to have had another opportunity to be supervised by you. Nico is a very interesting mix of several scientists in one: he loves nature and enjoys being in the field; likely the reason why he is a very easy going but hard worker. I enjoyed our regular meetings and academic discussions over the last $4+$ years. It has broadened and sharpened my imagination. It is so easy to work with you because even when things get tough, I can be sure that we can still crack a joke or two. The fact that you were pragmatic and meticulous in your own unique and different ways, made my experience even richer. I will be happy to work with you any time and look forward to future collaborations.

Special thanks to all my other co-authors: Kees, Dick, Tjalf, Riet, Jordi, Victor, Anna, Ruud, Norbert. I really enjoyed working with you and count it a great privilege to belong to such an excellent network.

I will also like to thank the committee members Prof. Dr. H. Rijnaarts, Prof. Dr. A.P. van Wezel, Prof. Dr. Ir. W. J. G. M. Peijnenburg and Dr. J. H. Faber for taking the time to evaluate this thesis. I feel honoured to have been examined by you.

Having lived in the Netherlands for about 7 years cumulatively, I consider it my home and that is because of the many wonderful people that have made Netherlands a memorable experience for me and my family. The Tox family is indeed a very special one. We are so multinational and multidimensional that everyone easily fits in and finds a home. From the very out-going and adventurous ones, to the quiet and more reserved bunch, and everything in between - we got them all! Since I lived a little out of Wageningen (where most of you reside) and also my office not being within Tox, sometimes I miss out on some of our get-togethers. Nevertheless, we do make it up when I get to be around and I have enjoyed each of you individually and as a group in our many outings especially WE-Day and Lab trips. I will miss my past colleagues - Arif, Barae, Jonathan, Agata, Myrthe, Jac, Reiko, Justine, Hequn, Wasma, Merel, Nynke, Ans, Irene, Tinka, Alexandros, Samantha; present colleagues - Rung, Rozaini, Aziza, Ignacio (Nacho), Abdul, Amer, Artem, Ashraf, Mebrahton, Lenny, Marcia, Myrto, Diego, Lu, Jia, Georgia, Mengying, Marije, Ans, Bert (coenthusiast of choral music), Hans (my buddy), Sebas, Karsten, Jochem, Laura, Lidy, Letty, Hans Bouwmeester. Thanks to all of you for being great colleagues and friends. I will remember you.

At Alterra, where I was domiciled for the last 4+ years, the story is the same. I will like to say a big thank you to my awesome colleagues especially the Animal Ecology Team. It was really a delight working with you and I will remember how you all (most of you: Ruud, Wim, Jan, Dorine, Huug, Dennis, Ivo, Marielle) got to join me in terminating some of my experiments. You made an otherwise very long and laborious work fun and a delight. Special mention needs be made of Wim my neighbour with whom I have enjoyed many discussions and long working hours as we go 
collecting earthworms, traversed Atlas and Lumen many times processing samples. Jan is the go-to man when I need to find equipment or order for materials and I am grateful to you for all the efforts to ensure my orders arrive in time. Leona and Maritha (also Irene and Lidy of Tox Dept.) have been wonderful with sorting out administrative matters and I say thank you. Many thanks also to my other colleagues: Jaap Bloem and Jaap Nelemans, Willeke, An, and Tamas from the Atlas building where I go to process my samples. You are greatly appreciated.

To my paranymphs Ariadna and Marta, and also to Valerie I am honoured you accepted to stand by my side today as you have done always. You have been dear friends and I will remember my sporadic Spanish and French lessons from Ariadna (Gracias); working with soil and earthworms with Marta, and the joy on Valerie's face when she sings il va me prendre, il va m'arranger, il va me positioner (French). Merci beaucoup! I wish you success with your PhDs.

The Amazing Grace Parish (AGP family) of the RCCG Holland Mission has been a very important and integral part of my academic pilgrimage and the entire pages of this book would be insufficient for me to adequately express my profound gratitude to each of you. I love and hold you dear in my heart and can only say, "may you be richly blessed in all you do". Keep working while it is day, for when the night comes no one can work. Special thanks to Hans and Marike and the entire van Binsbergen family, and to all our neighbours and friends in Zetten and other parts of the Netherlands for their love and friendship.

Special thanks go to my friend and brother Jacob Onoja as well as his wife Awazi. We have been through many paths together and we can always look back and be grateful we got each other. Thank you Jacob for joyfully and promptly painting the picture I used for the cover of my thesis. Olalekan, Olushina, Ozias; you have been part of this journey and have remained a great support to the end. I am blessed to have you as friends and brothers. To all my other friends who have supported me in various ways, I say thank you very much.

To my dear wife and Princess Maureen, and our wonderful kids Tlkahyel and Pitsahyel who directly bore the stress of a PhD daddy without much complaint, I say I am the most favoured of all men to have you. I love you dearly. I will like to also acknowledge my family and relations especially my dad and mum whose hearts are so big no wonder they have many children. You both taught us how to truly live and we are eternally grateful. My brothers and sisters together with your families - you are the best! The rest of my family members, I love you all. I missed many of the marriages, the births and naming ceremonies; I missed in sharing in our griefs when some of our dear ones passed on including my father-in-law; the anxiety when the scourge of terrorism came nearer than ever to our doorstep as our youngest sister went missing for about 3 days. Nevertheless, I was with you in thoughts and prayers through it all. Now, I look forward to being reunited with you all again.

Finally, I am eternally grateful to my Lord Jesus Christ who gave me strength and has been my anchor and my stay many times when the journey got tough and rough.

As I move on to the tropical nation of Nigeria where one of the happiest and friendliest people live; where the sun is always high, the stars bright and sparkly and where we usually don't like to say "goodbye", I say to you kūr sūkar-zu (Kilba; meaning: see you later). I take along with me these beautiful memories and more, knowing we shall meet again sometime somewhere somehow! 


\section{About the Author}

Sunday Makama was born on June 8th, 1975 in Jimeta-Yola, Nigeria. He completed his basic primary education at Capital School, Yola in 1987 and proceeded to Federal Government College (FGC) Port-Harcourt, Rivers State, Nigeria for his Junior Secondary School (JSS) education. Sunday moved back to the middle-belt region of Nigeria and had his Senior Secondary School (SSS) education at FGC, Wukari, Taraba State where he obtained his Senior School Certificate of Education (SSCE). Sunday attended the Ahmadu Bello University (ABU), Zaria where he obtained a Doctor of Veterinary Medicine (DVM) degree. He was posted to Benue State on a one year compulsory National Youth Service Corps (NYSC) program where he served as the Veterinarian on the Special Program for Food Security (SPFS). During this assignment, he led several educational and awareness projects focusing on biosecured animal production practices and public health significance of zoonotic diseases. Sunday worked with an agro-allied company as a Company Sales and Technical Representative for the Northern region of Nigeria for about three years before taking up a scientific research position in 2007 at the National Veterinary Research Institute, NVRI, Vom where he currently works as a Principal Veterinary Research Officer in Toxicology. Sunday's interest in public (food) and environmental health and safety brought him to Wageningen University first in 2007 to do a Master's program in Food Safety which he completed in 2009. During his Master's program, Sunday had the privilege of working both in the Netherlands Food Safety Institute (RIKILT) as well as the Netherlands Institute for Public Health and Environment (RIVM) for his MSc thesis and internship research projects, respectively. In 2012, Sunday returned again to Wageningen University for his PhD at the Division of Toxicology. His research described in this thesis was on nano(eco)toxicology and was conducted in collaboration with Alterra, the Dutch research institute for the green environment. Sunday enrolled in the post-graduate education program as a toxicologist-in-training during his PhD to become a Registered Toxicologist post-graduation. 


\section{List of publications}

\section{Peer reviewed articles}

S. Makama, Peters R., Undas A., van den Brink N. W. A novel method for the quantification, characterisation and speciation of silver nanoparticles in earthworms exposed in soil. Environmental Chemistry. 2015, 12(6), 643-651. doi:10.1071/EN15006

S. Makama, Peters R., Undas A., van den Brink N. W. Properties of silver nanoparticles influencing their toxicity to the earthworm Lumbricus rubellus following exposure in soil. Environmental Pollution. 2016, xx, xxx-xxx. doi:10.1016/j.envpol.2016.08.016 In Press

S. Makama, Kloet, S. K., Piella, J., van den Berg, J. H. J., de Ruijter, N. C. A., Puntes, V. F., Rietjens, I. M. C. M., van den Brink, N. W. Cellular interactions of silver nanoparticles with systematic variation in size and surface coating with macrophage RAW 264.7 cells. Submitted

S. Makama, Roelofs, D., de Boer, T. E., Vooijs, R., van Gestel, C. A. M., van den Brink, N. $W$. Transcriptome analysis reveals the importance of surface coating in driving effects of silver nanoparticles on the earthworm Lumbricus rubellus. Submitted

S. K. Kloet, Makama, S., van den Berg, J. H. J., Wu, G., Saviolakis, G., Vogt, H., Manolesou, K., van den Brink, N. W., Rietjens, I. M. C. M., Louisse, J. Effects of nanoparticle formulations of metal (oxide) type food additives and related nanoparticles on cell viability, TNF-alpha production and mitochondrial parameters in RAW264.7 macrophages. Submitted

\section{Conference presentations}

\section{Platform oral presentations}

- $\quad$ Physicochemical properties of AgNP influencing bioaccumulation and toxicity in Lumbricus rubellus. SETAC Europe 25 $5^{\text {th }}$ Annual Meeting, 3-7 may 2015, Barcelona, Spain

- Toxicity of silver nanoparticles to soil organisms: an integrated in vitro-in vivo approach. SETAC Europe $26^{\text {th }}$ Annual Meeting, 22-26 May 2016, Nantes, France

\section{Poster presentations}

- $\quad$ SETAC Europe 24 ${ }^{\text {th }}$ Annual Meeting, 11-15 May 2014, Basel, Switzerland

- NanoCity Conference, 27 - 28 October, 2014, Utrecht, Netherlands

- QualityNano Conference, 15 - 17 July, 2015, Crete, Greece (2 posters)

- NanoCity 5 - 6 October, 2015, Amersfoort, Netherlands (2 posters) 


\section{SENSE Certificate}

\section{SENSE}

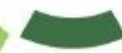

Netherlands Research School for the

Socio-Economic and Natural Sciences of the Environment

\section{I P L O M A}

For specialised PhD training

The Netherlands Research School for the Socio-Economic and Natural Sciences of the Environment (SENSE) declares that

\section{Sunday Linus Makama}

born on 8 June 1975 in Jimeta-Yola, Nigeria

has successfully fulfilled all requirements of the

Educational Programme of SENSE.

Wageningen, 15 September 2016

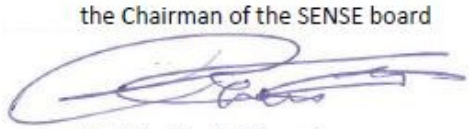

Prof. dr. Huub Rijnaarts the SENSE Director of Education

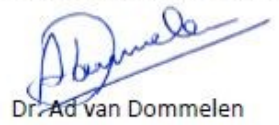

The SENSE Research School has been accredited by the Royal Netherlands Academy of Arts and Sciences (KNAW) 


\section{Overview of completed Training Activities}

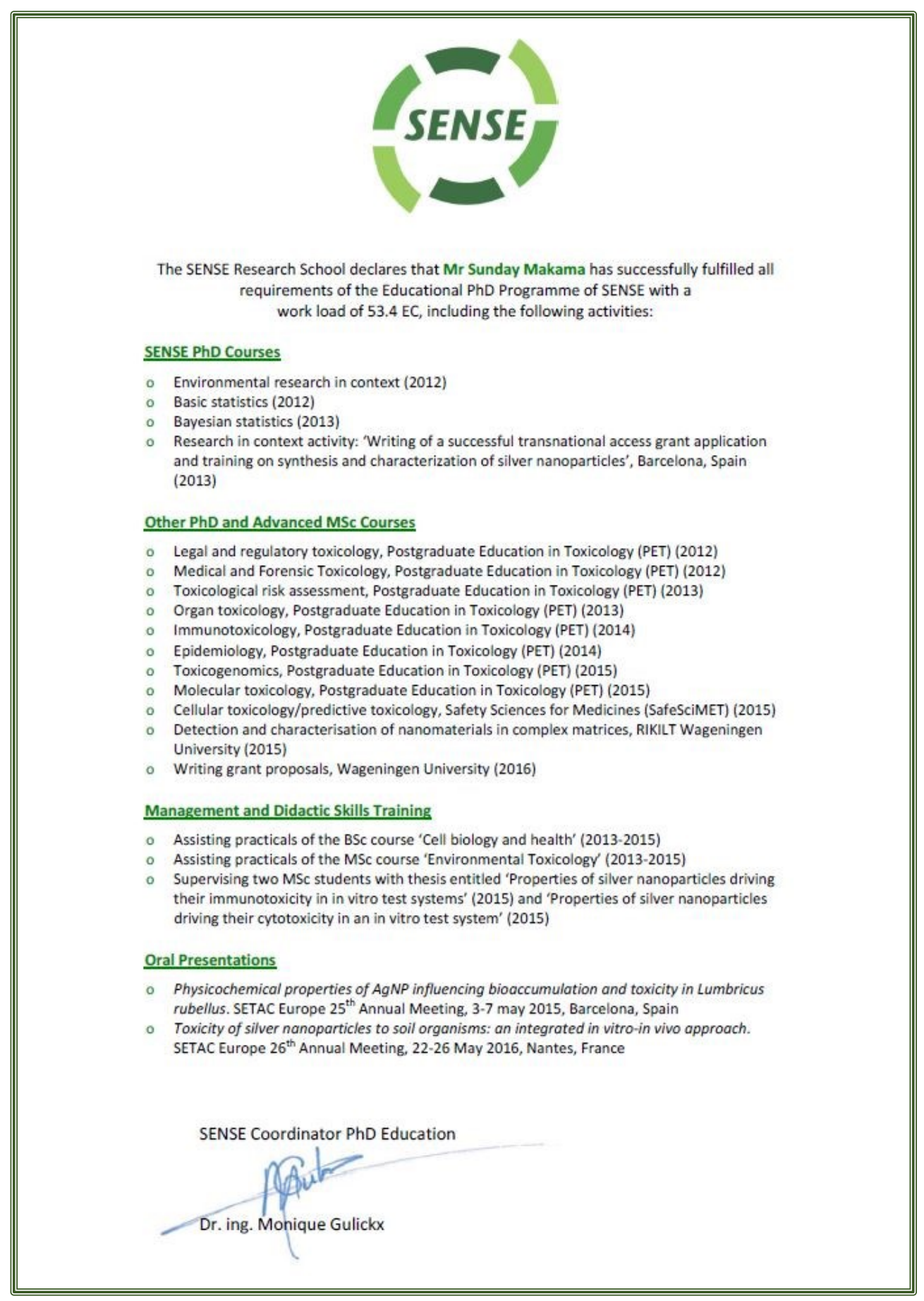


Notes 
The research described in this thesis was financially supported by: NanoNextNL, a microand nano-technology consortium of the Government of The Netherlands and 130 partners; Managing Risks of Nanoparticles, MARINA (EU-FP7, contract CP-FP 263215); the Strategic Research Funds - Novel technologies provided by the Ministry of Economic Affairs of The Netherlands.

Financial support from Wageningen University for the printing of this thesis is gratefully acknowledged.

Cover design by Jacob Onoja \& Sunday Makama

Layout by Sunday Makama and Gilderprint

Printed by Gildeprint Drukkerijen, Enschede NL II gilderprint.nl 